\title{
Chapter 5 \\ Reflection on Disruptions: Managing the City in Need, Saving the City in Need
}

We will neglect our cities to our peril, for in neglecting them we neglect the nation.

-John F. Kennedy.

\subsection{The Anatomy of the City in Disruptive Times}

At the time when mostly negative news flow between countries, the reactions of national-level and city-level governments should reflect on their full preparedness and responsive management. This book has covered these aspects in Chaps. 3 and 4. We know by now how cities are affected, how they need to be prepared, and in which ways they have to react to disruptive disease outbreak events. At the city level, changes are progressive, sudden transformations are inevitable, and impacts are tangible. In reality, the city's anatomy changes as it has to deal with new pressures, adversities, and disruptions. In the many examples of scholarly work on the anatomy of the city, focused mostly on how cities operate and function (Ascher 2007; Lamorgese and Petrella 2016; Renner 2018), there are a few that look into aspects of smartness (Al-Nasrawi et al. 2017; Bibri 2019; Desjardins 2019), creative examples (Cohendet et al. 2010), context-specific explorations (Shultz 1968; Quirk 2013; Tillett 2018), etc. Some may look into specific factors of historical analysis (Stone and Zimansky 1992), data-driven approaches (Bibri 2019), mobility analysis (Gallotti and Barthelemy 2015; Jauregui-Fung et al. 2019), transportation and planning (Goldwyn 2018), or even economic crisis (Baumol 1967). But none has looked into the anatomy of the city due to transformations, and most importantly the ones that are sudden, disruptive, and possibly temporary. The changes occur during the period of outbreak progression are impactful on the city and its communities. There are many factors that indicate and trigger substantial changes in the overall anatomy of the city during an outbreak. Hence, it is important for us to demonstrate some of those changes and how they become disruptions for the city and its management. 
So far, we have covered a wide range of viewpoints and approaches to urban resilience thinking. We have also explored how urban resilience plays an important part in better preparedness against outbreak events. We argued this could happen through urban resilience enhancement, which should be systematic and progressive. Later, we looked into specifics of urban resilience measures from the perspective of strategic planning and action plan. These arguments then led to further elaboration on city management issues during all phases of the outbreak progression (see Chaps. 3 and 4). These issues were looked at from the multiplicity of responsiveness, reflectiveness, and integrated thinking. In this chapter, these arguments are illustrated through the narrative of a city example. This is done in a twofold: in the first half, through experience and how the impacts are developed, measured, and perceived; and in the second half, through a reflection on what occurs and what are the reactions. In the first section covering the 'experience', disruption factors are discussed from five perspectives of society, safety and monitory, adaptability and resilience, economy and governance. These are then followed by highlighting the realities in the second section on the matters of 'reflection', capturing and covering key factors under four resilience dimensions (from Chap. 3), namely operational, institutional, services, and supplies (Cheshmehzangi 2020a). In this chapter, we only cover selective matters that are relevant to the central theme of the book. Hence, they mainly represent an example of an outbreak and its disruptions. In sum, this chapter serves as a case study/example chapter, which is narrated through perceptions, reactions, and reflections.

\subsection{An Experience: Narrative of a City Example}

On 23rd of January 2020, one day before the official celebration of the Chinese New Year, the source location of COVID-19 disease was under full lockdown. This was the populated City of Wuhan, the capital of Hubei Province in Central China (officially estimated more than 11 million people for the City of Wuhan, and approximately 60 million for the province). Weeks after the start of the outbreak, the number of cases was soaring rapidly. The new transmission cases were increasing beyond the boundaries of Wuhan. It only took a few days that a disease outbreak turned into a major epidemic outbreak event. Several weeks later, it was eventually declared a pandemic event. On 30th of January 2020, the International Health Regulations Emergency Committee of the World Health Organisation, declared the outbreak a "public health emergency of international concern" (CDC 2020a). Within one month after the start of Wuhan's lockdown, there were similar measures in not only other cities or towns of the same province, but also across the country. These measures were then replicated by other countries, too. By then, some of the major industrial provinces of the country were under restricted lockdown. While China was facing the epidemic through heightened control and monitory of many cities and provinces during its busiest period, the disease was already globally widespread. On the verge of a major pandemic outbreak, by end of February 2020, there were records of infected 
cases in all continents (with an exception of Antarctica). Under the likely threat of further spread, the situation worsened from the 20th of February onwards. By then, the global attention shifted from a one-country problem to a large-scale global health emergency. The economic impacts became global, rippling on every single sector. The biggest hit on oil production with China's reduced demand (i.e. estimated at $20 \%$ reduction in the first weeks of the event) was of the earliest news about the economic impacts of the disease. From an economic perspective, the situation turned into a global economic crisis. Soon later, the hit was on all sectors, affecting production, trade, marketing, transportation, supply chains, construction, medical, and all other industries. Somehow, the world was no longer just aware, it awakened!

As per records, the early signs of the disease cases were detected in the last days of December 2019. Assuming that it could get contained in that early phase of uncertainties, early containment could simply not happen. Conversely, the first sign of the novel coronavirus was detected earlier, and was acknowledged on the 10th of December, at least two or three weeks before it was an evident case of a novel disease. The official statement by the Chinese government to the World Health Organisation (WHO) confirmed the first diagnosed case was on the 8th of December 2019. Some unpublished data report traces of the disease as early as the 17th of November 2019. Nevertheless, without confirmed cases of human-to-human transmission and owing to a lack of knowledge about this novel disease, the official announcement of the outbreak happened later in January 2020. The source was then identified from a seafood merchant in the Hua'nan market of Wuhan, which was later closed as a result of this incident. But unfortunately, the transmission was inevitable, and community spread was already rapidly growing, from one case to another, and possibly from one location to another, too. By the 9th of January 2020, there were signs of the cluster of cases in Wuhan (WHO, an online source, 9 January 2020). The control was still not successful and containment could not happen. In the midst of uncertainties, the leaders of the epidemic response officially announced the outbreak on the 20th of January 2020. By then, the spread was partly out of hand. This made Wuhan become the original epicenter of this novel disease. Three days later, the city was under full lockdown. In some way, we can argue the disease outbreak happened at the wrong time and in the wrong place. It occurred just before the largest annual mobility of people (i.e. during the Chinese New Year) across the globe, and right in the most central node of the country, where the City of Wuhan is located. The City of Wuhan is the 42 nd most populated city in the world, a firsttier city and one of the main populated urban hubs, which is well-connected to all other populated parts of the country. The city holds a large population of migrant workers and professionals, who had to travel back to be with their families and friends during the New Year celebrations. The city is a major transportation hub, extensively connected by railways and air travel to many major cities at nationwide, regional, and global levels. In particular, the city is a major economic hub connected to multiple regions and countries in East and Southeast Asia. There are direct cross-continental flights in and out of the city and on a regular basis. Thus, the inescapable mobility of the city and the province were unknowingly fuelling up the situation. 
By the end of January 2020, it was clear that all Chinese provinces had confirmed cases, and the number of infected cases was already growing outside mainland China, in the region, and in many further locations like Australia, Europe, and North America. Soon after, the disease reached another parts of mainland Europe, North Africa, and the Middle East. The pattern of spread continued to reach more regions, countries, and locations, while also creating several emerging hotspots in different parts of the world. Those new hotspots caused further spread first in their immediate contexts and later exported the disease to other (further) locations. The whole pattern of spread represents an example of how fast a disease can spread through air travel and other modes of transportation; i.e. from one community to another, from one city to another, and so on. The speed of spread was extraordinarily fast, and in some cases occurred so sudden that some countries/cities did not have a chance to be well prepared in advance. The hit was clearly global. While mortality rate remained relatively low (in comparison to previous diseases of the same category), the severity of the disease and the growing numbers of person-to-person transmissions (or community transmission) remained a major worry for many people and governments. The disruptions became global, and many cities and communities struggled to cope and react to rapidly changing situations. There was little time to prepare and the struggle was clearly visible in unstructured announcements of governments in multiple regions.

The virus was initially phrased as a novel coronavirus before it was officially named severe acute respiratory syndrome coronavirus 2 (SARS-CoV-2) on the 12th of February 2020. The delay for such official naming was primarily caused by scientific studies on the virus, which should have collected enough data in order to identify and categorise it in the right way. At the same time, the disease associated with the virus was then renamed COVID-19. Also, this novel disease was officially recorded as the one never tracked in human cases before. While there remain many speculations about the actual source of the disease, to date it remains unclear how it actually developed and how it was transmitted to the first index case (i.e. human). At first, the precautionary guidelines were basic, mostly based on similar experiences of previous diseases or outbreaks (e.g. SARS-CoV and MERS-CoV). It took a while till the society recognised the seriousness of the situation, and by then uncertainties turned into anxiety. This was no longer the anxiety of China, but also became global distress. By the early days of March 2020, the disease already reached some unexpected places in four unreachable locations, like in Brazil, Iceland, New Zealand, and South Africa; hence, posing a larger threat to global health. Later, it reached more unexpected places, such as Greenland, Suriname, Madagascar, Papua New Guinea, etc.

It was as early as the 28th of January that we started to notice the gradual control measures of lockdown in some other cities outside China's Hubei Province. The steps were taken cautiously and gradually, but within just less than a week, many cities were under full control measures of cordon sanitaire and lockdown. The unprecedented public health measures affected millions of people, changed patterns of mobility, and had significant impacts on society. The City of Ningbo, a major port located in Zhejiang Province, in East China was one of these city examples. The unprecedented lockdown measures brought in significant control and monitory to all operations, to 
all mobility, and across all sectors. By the 7th of February 2020, the online food delivery systems were also affected. The society experienced many uncertainties, not knowing how long the situation would last. The city's reaction was essential and immediate support was necessary. The situation was no longer just a matter of pandemic outbreak; it was a major test for the city, and other cities and communities, to enhance their resilience and to manage the outbreak's impacts in the face of new adversities. With the gradual lockdown, the city had to increase its measures for safety, control, and monitory. With depopulated scenes in every part of the city apart from healthcare centers and hospitals, the society experienced a sudden shock; something the society was not used to before, something which will be remembered as a lifetime experience. A ghost-town effect was the highlight of many local and foreign media, something that was later on recognised as a collective approach by many stakeholders who played their part in speeding up the process of containment and reducing the possibility of community transmissions. The same scenes that were later seen and experienced in other countries, too. The city became a platform for innovation, where resilience enhancement was no longer a case of experimentation but merely implementation and success. With high risks of failure, the city had to reflect on the outbreak progression and face the adversities through new and temporary regulations, extended guidelines, enhanced monitory, new legislation, and community support. Lessons learned from this particular instance are invaluable and strategies that we can build upon are certainly important for managing the city in need, and ultimately saving the city in need.

\subsubsection{The Experience of Disruptive Time}

Disruptions are perceptible across the city as they hit every single sector. Through this, the city struggles to accommodate its daily operations. The overall operationalisation of the city and its urban systems are affected significantly through a sudden shock caused by a particular emergency. It is not yet recognised as a disaster situation unless it is not managed well. As identified by Ritchie et al. (2008) there can be certain aspects affecting the response. And if the response is affected by any means, then the whole process of containment is affected, too. Hence, the experience and impacts of the outbreak follow this major matter. As their findings indicate (ibid) the limited response is under influence of multiple factors, such as lack of preparedness which is common, speed of spread, and speed and severity of media coverage (particularly international media). The need for communication strategies is also highlighted as one of the effective methods to overcome issues of response, and help to overcome some of the disruptions.

In general, what we experience is not a common scenario. Society goes through a high level of uncertainties, with which it is hard to re-adjust day to day routines and the lifestyle that provides us comfort and security. The situation hits the vulnerable and low-income groups the most, with the highest impact on the urban poor often 
reside in crowded communities of impoverished infrastructures and unhealthy living environments. The risks can also increase drastically with the lack of hygiene or limited, and sometimes ineffective, precautionary measures. More than everything, the impacts on social infrastructure and socio-economic values of the city are of major concern to all stakeholders and communities. Businesses face decline and possible closure (even if temporary), and the society can only cope with all these adversities for a limited time. Hence, having resilience planning in place is ever essential. This impacts not only the governance and management of the city, but everything else that makes up the cityness of the city.

\section{Society}

It is noteworthy to observe how society perceives change and adapts to it in a process. The continuous flow of negative and false news impacts how society's perception of the disease can change at any time. Anything that gives a false alarm can be harmful and anything that reduces the society's awareness is even more so. Besides medical support and dealing with the treatment of the disease, a larger requirement is to maintain the mental stability of society. As disruptions impact people's daily lives, it is essential to be adaptive and positive. In order to cope with the transformative conditions of the outbreak, people should enhance their resilience both individually and collectively. The latter is vital to societal well-being as it helps to reunite the society against shared adversity.

In the race to finding the cure, often through the development of a novel vaccine, there seems to be more curiosity from the general public than the scientists' community. People get attracted to floating news and information that could reduce their anxiety, which is a natural self-calming effect needed in such events. Yet, collective measures are much more effective. For instance, society could play a major part in various ways, such as through voluntary support, engagement in community support, security enhancement, training, and education, etc. Only with a resilient mindset, one can overcome the negativities of the outbreak. But the ones affected directly from the disease would suffer the most. Hence, it is likely that maintaining continuous support to them, their pressures could be eased to some extent. Moreover, society's compliance with precautionary measures is highly important. It is only through a collective approach that the society can maintain large-scale self-isolation, and reduce the chances of community spread.

In our careful observations, we noticed the difference between urban and rural communities of the municipality. While we may wrongly assume rural communities are more vulnerable, they are in fact more resilient and self-sufficient, which are the exact characteristics of rural life. The slow pace of rural life remains unchanged (with the only impact on their tourism industry), while the city changes from a busy socioeconomic hub into a static environment with limited operations. In other observations, we noticed the vulnerability of people who cannot adapt to sudden change as they may assume disruptions may last long. They may struggle to cope well, but healthier communications from the right sources could support them. Other examples are boredom, anxiety, and regular panic attacks that may affect the mental stability of society the most. We noticed examples of people enhancing their communities even through contactless activities, and provided care and support to those in need. 
Approaches that include sharing correct knowledge and experiences could help to relax those individually-perceived adversities.

\section{BOX 5.1 Notice for Preventing 2019 Novel Coronavirus from Spreading (A dual language document was released by Ningbo Science and Technology Bureau)}

Recently, many areas have been affected by the 2019 Novel Coronavirus (2019$\mathrm{nCoV}$ ) pneumonia. The Chinese government has taken a series of rigorous measures to fully contain the spread of the epidemic (later became pandemic on 11 March 2020). Thus, we propose the following proposals to all foreigners and their employers in Ningbo:

\section{Everyday preventive actions}

Novel Coronavirus (2019-nCov) is a coronavirus, which is identified as the cause of the respiratory disease outbreak in Wuhan, China, and can be transmitted from person to person. Please follow these instructions to protect yourself:

(1) Restrict activities outside your home and avoid group activities such as parties. If you have to go out, you must wear a face mask correctly;

(2) Open windows and ensure good ventilation at home, wash hands frequently and disinfect regularly;

(3) Avoid close contact with anyone who has fever and/or cough;

(4) The consumption of raw or undercooked animal products should be avoided;

(5) Monitor body temperature of yourself and family members.

\section{What should you do if you feel unwell?}

(1) Contact your employers or friends in China and tell them about your status;

(2) According to your condition, visit medical institutions nearby in time, and try to avoid taking subway, bus and other means of public transportation;

(3) Tell doctors about your recent travels and living history especially in relation to epidemic-stricken areas, as well as the people in contact after the onset of the disease, and cooperate with doctors to carry out relevant investigations.

\section{Keep yourself reachable via phone or email}

Please keep the communication channels such as telephone or email unblocked during the epidemic/pandemic. The employer shall pay attention to the physical health and schedules of foreign employees. It is suggested that foreign employees who are not in Ningbo during the holidays may postpone their return. 


\section{About the extension of work permit service window}

According to the arrangement of superior departments, the service time of the work permit service window for foreigners originally scheduled to open on January 31 may be postponed. After confirmation, we will give a further notice. For the applicants affected by this change, please contact desk receptionist to file for expedited service if necessary. We will arrange a green channel for urgent processing and coordinate with relevant departments.

\section{Ningbo epidemic prevention and control contact number}

Explanation Note: The document includes details of 10 Centers for Disease Control and Prevision, covering all urban and non-urban districts under the municipality of Ningbo (including: Ningbo (main central), Yuyao, Cixi, Xingshan, Fenghua, Ninghai, Yinzhou, Zhenhai, Jianbei, Haishu, and Beilun).

\section{Appointed hospitals for 2019-nCoV treatment}

Explanation Note: The document includes name and location of 15 medical institutions/hospitals whom accept patients for treatment, including five in the city centre area (Ningbo No. 1 Hospital, Ningbo No. 2 Hospital (or Hwa Mei Hospital, University of Chinese Academy of Sciences), Ningbo Medical Center Lihuili Hospital, The affiliated Hospital of Medical School of Ningbo University, and Ningbo Woman and Children's Hospital); as well as 10 other hospitals at district levels, including: Ningbo No. 9 Hospital (Jiangbei District), Ningbo Zhenhai District People's Hospital (Zhenhai), Ningbo Beilun District People's Hospital (Beilun), Ningbo Yinzhou District People's Hospital (Yinzhou), Ningbo Fenghua District people's Hospital (Fenghua), Yuyao People's Hospital (Yuyao), Cixi People Hospital (Cixi), Ninghai No.1 Hospital (Ninghai), Xiangshan No. 1 People's Hospital (Xiangshan).

Source Extracted from: http://kjj.ningbo.gov.cn/art/2020/1/29/art_9940_4 045698.html. Originally Developed from WHO's Novel Coronavirus (2019$\mathrm{nCoV}$ ) advice for the public (original source available from: https://www. who.int/emergencies/diseases/novel-coronavirus-2019/advice-for-public). Adapted from Ningbo Science and Technology Bureau (2020). 


\section{BOX 5.2 "A Letter to All Foreign Friends in Ningbo" (This English document is released by Ningbo Foreign Affairs Office)}

On the occasion of Chinese Spring Festival, we extend our sincere greetings and best wishes to you all. In response to the outbreak of pneumonia caused by the novel coronavirus (2019-nCoV), Zhejiang Provincial Government has activated Level I public health emergency response since 23rd January. Attaching paramount importance to the situation, CPC Ningbo Committee and Ningbo Municipal People's Government have taken high-level prevention and control measures to curb the spread of the virus. For the health of you and your friends, you are kindly requested to follow the requirements of the law of the PRC on the prevention and control of infectious diseases and other relevant laws and regulations, and respond to the calls of the central and local governments by cooperating in the following practices:

I. Follow official updates and do not trust false and unverified information: Please follow "nbfb0574" (the official Wechat account run by Ningbo Municipal People's Government) and other official media outlets for the most recent updates. Check out the list of designated hospitals in Ningbo, and guides for prevention and treatment. If you have any questions, please call 24-hour hotline 87680042. Avoid believing and spreading false or unverified information.

II. Keep distance from infectious sources: Please follow the official release of epidemic/pandemic information and avoid visiting epidemic areas or contacting anyone with cold or flu-like symptoms. Avoid close contact with wild animals or birds; eggs and meat must be thoroughly cooked before consumption. Avoid crowded places, parties and group activities. Correctly wear a mask (preferably a surgical mask) if you have to go out.

III. Keep personal hygiene: Keep good hygiene by washing your hands often with soap or alcohol-based sanitizer. Cover a cough or sneeze with a tissue or your flexed elbow. No spitting. Dispose of used masks appropriately. Maintain proper ventilation and keep rooms clean.

IV. Join in our mass prevention and control efforts: If you have travelled to the infected areas recently, or have contacted anyone who is from the epidemic areas, please immediately report to the community where you reside, cooperate with community or medical staff if they inquire about your condition, and stay at home under medical observation for 14 days.

V. Ask for hospital treatment immediately: If you have a fever over $37.3^{\circ} \mathrm{C}$, cough, fatigue or breathing difficulty, please wear surgical mask, avoid contacting anybody and immediately go to the designed hospitals for treatment. Please do not forget to tell the doctor your travel record.

Dear foreign friends, you have contributed to the economic and social development of Ningbo City. Ningbo is our home and we need to stay unified in solidarity to protect and defend our city in the time of difficulties. 
Foreign Affairs Office, Ningbo Municipal People's Government, 30th January, 2020.

Note A later updates of the letter was also provided on $28 \mathrm{Feb} 2020$ - Extracted from original source http://english.ningbo.gov.cn/art/2020/2/1/art_931_104 1824.html.

\section{BOX 5.3 Updated version: "A Letter to Foreign Nationals from Ningbo Government" (This English document is released by Ningbo Foreign Affairs Office)}

Welcome (back) to Ningbo. In response to the outbreak of the COVID-19 epidemic (later pandemic on 11 March 2020), under the leadership of the Central Government of China, Ningbo Municipal People's Government has put the life and health of its people first and taken prompt action in a science-based and coordinated way. We have implemented the most comprehensive, rigorous and thorough measures of prevention and control, which have produced notable results. We have managed to maintain economic and social stability throughout the city, and currently businesses are re-opening and people returning to their normal life. However, we still face severe pressure from the epidemic as its cuts through borders and spread further afield. Whether you are living, working or travelling in Ningbo, we believe it is important to remind you of the following.

I. Cooperate in health checks for epidemic prevention and control. On occasions (or in places) required by the government, please understand and cooperate with field staff in carrying out health checks. As arriving at your destination, please abide by the prevention and control measures implemented by Ningbo Municipal People's Government. If you come from countries or regions with large number of infected cases, or have contacted anyone who is from the epidemic areas, please immediately report to the community (hotel) where you reside, and try the best to selfquarantine at home for 14 days before engaging in other activities so as to stern possibilities of transmission.

II. Step up self-protection. Wear face masks and wash hands as often as needed. Maintain proper ventilation and keep a clean living and working environment. Avoid crowded places, parties or group activities. Have safe and healthy food. Stay optimistic and have proper exercise to improve your immune system.

III. Ask for medical help immediately. If you have a fever, cough, fatigue, breathing difficulty or other symptoms, please wear a mask and stay calm. Report promptly to your host or community (hotel), local health 
or immigration agencies, and go to the designated hospitals for treatment as advised.

IV. Follow official updates and do not trust false and unverified information. Please follow "http://weibo.com/nbfb" (the official Weibo account run by Ningbo Municipal People's Government) and other official media outlets for the most recent updates. Check out the list of designated hospitals in Ningbo, and guides for prevention and treatment. If you have any questions, please call 24-hour hotline 87680042. Avoid believing and spreading false or unverified information. You can also get into contact with Foreign Affairs office of Ningbo Municipal Government or further assistant.

Epidemic prevention and control needs the understanding, support, cooperation and participation of citizens as well as foreign nationals in Ningbo. Ningbo Municipal People's Government attaches great importance to the health and safety of foreign nationals in Ningbo. We have full determination, confidence and capability to win the battle against epidemic, and contribute to the international public health. Service Hotline of Ningbo Municipal Foreign Affairs Office: 89186517,13805861661

Foreign Affairs Office, Ningbo Municipal People's Government, 28th February, 2020.

Extracted from third party source https://www.nottingham.edu.cn/en/Cam pus-Portal/News/Article.aspx ?id=9e26c727-9fdf-413b-b3e7-1f38f275815d\& language $=$ en-GB.

In addition, four main areas of guidelines developed by the World Health Organization (WHO) (2020), specifically titled: "Coronavirus disease (COVID-19) advice for public", include precautionary measures, education of right and wrong information, safety measures of health workforces and preparation plans for work environments. Their four main areas are named 'when and how to use masks', 'myth-busters', 'advice for health workers', 'getting workplace ready'. Each area includes a set of guidelines, explained through text and several downloadable files in the form of posters. For instance, the myth-busters area is one of the most extended areas that include a range of factors and graphical posters. Those informative and educational posters include a range of facts regarding the disease, its transmission, and many issues that are identified as myths in particular contexts. Examples of these myths or wrong perceptions include: transmission of the disease through mosquito bites, methods of killing the virus, updates on the vaccine development (also include any misinformation or misconception), information on specific food consumption (especially those that are advised in different cultures), etc. It is important to note that as our knowledge of the disease develops, these posters and information also get upgraded. They are made available for the general public as well as for companies/enterprises to display them. The main intention is to raise awareness and educate the majority; a task that requires a lot of reinforcement and collective support. 


\section{Safety and Monitory}

It is simply not adequate enough to merely depend on the placement of safety and monitory measures. More important than their placement, they should be regulated and the society also needs to comply with them. This sense of responsibility should be widespread and must be practiced throughout the communities. This is for the benefit of individuals, the wider community and those who are responsible for the delivery and implementation of those measures. Examples of these are collective reduction of unnecessary mobility, increased remote working, increased contactless activities, and full compliance with advisory and/or regulated measures. In addition, the safety measures must be taken seriously and any official updates should be followed accordingly. In a situation that management should be strengthened through its role of control, the city may require monitory of multiple aspects, such as entries and exits to public places and communities (or mobility record), temperature checks (or other health checks depending on the nature of the disease and its symptoms), regular checks on communities, more security, closure of multiple entries to public places, careful monitory of food safety, monitory of safe productions, monitory of business operations, regular monitory of product pricing, etc. With such a diversity of measures, community involvement is a necessity, ensuring that all aspects of safety and monitory are applied and conducted appropriately.

Furthermore, the implementation of robust management, and the presence of those managerial bodies, are certainly effective to increase the city's monitory and control measures. In our observations, we noticed examples of control on any sort of gathering, minimising human contact as much as possible. The extended limitations on the use of public places involve the presence of high security and even the relevant managerial teams who are responsible to regulate the order of uses and activities of places. In Ningbo, apart from high-security teams all over the main public places, there was a strong presence of other control measures at the community level. In addition to these, a new mobile application was developed to monitor people's health conditions and their mobility. This data-based and data-driven approach, regarded as 'Ningbo Health Code', was the only possible way to enter public places of different types. This mobile application was based on multiple colour codes reflecting on the health conditions of the individuals, and it was required for entry to any public and private premises (including housing compounds). The main intention was to enhance safety and monitory measures through the available technological and digital means. It was an instrument to do multiple things: detect, monitor, and record. Altogether, it was only through the multiplicity of effective measures that the city managed to speed up its containment process. 


\section{BOX 5.4 The Application Procedure for "Ningbo Health Code" (This English document was released by Ningbo government)}

This code system registration is designed for people who are currently in Ningbo, and those who are coming to Ningbo. The simple guide (below) to obtaining your code should be followed once you arrive back in Ningbo, or in China if you return from overseas.

\section{What is the "Health Code"?}

The Ningbo Municipal Government released a code management system for people in and entering Ningbo. It is a self-report system that asks user to update their health information in the app. And it will be checked in transport hubs like metro and train station. It has color of "Green, Yellow and Red".

The "Red Code" including confirmed cases, suspected cases, asymptomatic infections, people in close contacts with confirmed cases, people under medical observation and quarantine, people who came to Ningbo from the hardesthit areas of the epidemic, or have been to these areas and people from other specific areas. In principle, the "Red code" people who want to enter Ningbo will be advised to go back or delay their return. People with "Red code" who have already arrived in Ningbo will be required to have 14 days of centralized quarantine or strict home quarantine for medical observation.

The "Yellow Code" mainly include those people with fever, shortness of breath and respiratory symptoms, those who have close contact with patients with fever or respiratory symptoms, those who have close contact with confirmed cases or have confirmed cases in the same building where they live or live temporarily, and people from high-risk counties (cities, districts) within and outside the province. People with "Yellow code" will be subject to 7 days of home quarantine or centralized quarantine for medical observation according to the provisions.

The "Green Code" are identified as people other than "Red code" and "Yellow code". According to the decision from the Ningbo Leading Group for Epidemic Prevention and Control, people who have "Green code" are allowed to pass throughout the city after their temperature is taken. Checkpoints at all levels of the city shall not be allowed to refuse non-local license plates, nonlocal census register to entry Ningbo or entry into the village and residential areas. Employment and schooling of those people shall not be restricted and they have the freedom to rent houses.

\section{How to apply for "Ningbo Health Code"?}

- Step 1: open Alipay app* and then click "City Service";

- Step 2: make sure the city is "Ningbo" and then choose "Ningbo Health Code";

- Step 3: fill in the boxes. 


\section{How to use "Ningbo Health Code"?}

In all the checkpoints that need to use "Health code", you can open Alipay, click on the "Pocket", "Credentials", and then click to check the "Health code" on the next page, the system will automatically display the user's exclusive "Health code" (red, yellow or green). According to Ningbo's epidemic control rules, users should take the initiative to show the code to staff to pass throughout the city (Ningbo Government Official Page 2020).

*Note Alipay is a popular multi-functional mobile app, mainly used for payment.

(Adapted from main online source which was released and disseminated on official and social media platforms: https://mp.weixin.qq.com/s/tMk5tfXIX yxf_uaFObSwuQ).

\section{Adaptability and Resilience}

In line with safety and monitory measures, it is also important to implement adaptive and resilience measures. During the disruptive time, we cannot anticipate for business-as-usual practices or common daily routines. As it was expressed before, there are many cases of temporary closure, unavailability and limited operation of services, non-operational events and activities, redundant units/businesses/uses, and limited physical access. Hence, the city and its communities need to face the disruptions by increasing the adaptability in all sectors in the first instance. As previously discussed, this also provides a chance for innovation, where we can make better use of our technologies, information-based and data-based platforms, online facilities (or previously regarded as virtual amenities), digital platforms, etc. Through adaptability, we should not only remain adaptive but should also become creative in finding replacements or alternative methods for our daily operations. Now that we live in the age of digital technologies, this should no longer be a major challenge. With the availability of many digital networks, communication instruments, and advanced tools, we are able to develop smart-resilient opportunities (Cheshmehzangi 2017); a hybrid approach that is adaptive and integrative in the practices of adaptive planning and resilience enhancement.

The lockdown meant a major change of lifestyle for many people and its impact became widespread. Many companies and businesses continued with their online operations, education became virtual, and e-commerce was ever popular. The contactless city managed to keep some of its primary operations via digital and online platforms. This approach helped to ease some of the pressures, which helped to provide necessary services and supplies. In a positive turn, the ICTs supported secondary sectors that could not even partially operate. In addition, through the practices of resilience, the city had to go through some new practices. At the community level, adaptive measures were limited, which meant little chance for flexibility of practices and measures. For individuals and individual households, however, there were 
more chances to manoeuvre around the imposed adaptive measures. This became an opportunity for team-building exercises, extra care and support, efficient lifestyle, and replaced daily activities. Through these resilience measures, entertainment was redefined and people found a chance to learn new skills. In reality, the situation can either strengthen or worsen the methods of cooperation and integrative thinking. This fact depends on how we could effectively and efficiently manage to respond to the issues of adaptability, how we can strengthen the resilience, and how we can ultimately manage to cope with the disruptions.

In our observations, we noticed a tangible difference between people who are more individual than social (i.e. introvert vs extrovert people). This difference changes the way they could adapt to the changing situations of the outbreak. In both categories (individual and social groups), people choose their replacement activities differently. On one hand, people with individual mindsets tend to be more resilient, as they are used to pseudo-isolation situations or are generally less needy of social activities. On the other hand, socially active people (or people of the social personality type) may struggle to adapt themselves to less social activities and changes that affected their daily routine(s). The replacement activities could be healthier examples of fitness activities (both indoor and outdoor when possible), jogging, cycling, etc. Hence, adaptive thinking to minimise social contacts is not an easy task. But a variety of alternative activities should be planned to replace some of our everyday life's common activities. This requires good management of time and activities.

\section{Economy}

Apart from health impacts, one of the primary concerns is usually associated with the economic impacts of the outbreak. As far as they could get, there are traces of economic impacts in every sector. With small and medium-sized enterprises/businesses getting the biggest hit, the situation puts many secondary businesses and amenities/services in decline. At multiple levels of local, national, and international, we see many examples of economic losses; and in most cases, the situation is narrated as an economic crisis. While outbreak events may be somehow considered beneficial to environmental factors, they pose a significant threat to socioeconomic values and particularly the economy of the city (and beyond). In the first two weeks of the COVID-19 outbreak, the reduction in China's fossil fuel consumption was equivalent to the whole oil consumption of Italy and the United Kingdom combined. This was not only due to lower fuel demand for transportation, but for other sectors too. An example of which is the construction sector, with nearly all its operations on halt. For a country with the highest number of construction projects and large scale development, the impact was perceptible on cities of various sizes. It took approximately six weeks for the construction sector to restart its operations at a much smaller scale, marking three weeks of delay after the Chinese New Year holidays. The economic impacts also include effects on the free movement of workforces such as labour forces. With the situation of lockdown, such movement was highly restricted at first and could only retain its regular flow from the early stages of the recovery phase. 
Moreover, disruptions on the economy could create a range of imbalances in society, one of which is issues related to human resources. Hence, there are probable chances for increases in unemployment, business closure, redundancies, and special unpaid leave. With a lack of relevant legislation, society may not be able to cope with such added adversities of financial nature. A larger example of such imbalance is related to the tourism industry as well as the large scale and wide range of trade and marketing that are part of it. Undoubtedly, the tourism industry is affected significantly not only during the outbreak event but also during the post-recovery phase (and afterward). The stabilisation of the tourism industry for highly infected cities or regions may take a much longer time, months or even years after the outbreak. Hence, post-recovery management of the tourism industry, trades, and marketing is essential for the city's economic reclamation.

In our observations, we witnessed the depopulation effect in the main economic hubs of the city, both business and retail/commercial typologies. Known that the city cannot continue for long with such disruptive impacts on its economic activities, all industries have to safeguard the safety of their workforces and working environments. In all those weeks of many empty buildings, those affected industries have to develop their adaptive planning (Alterman 1988) and strategies. Depending on their main operations, we noticed different control and monitory measures across all sectors. For instance, primary services were mostly back to full operation after almost six to seven weeks, while secondary services were only partially operational by then. The city's step into economic revitalisation is crucial, but it simply is more important to do so in the safest possible way and a gradual process. The impacts are yet to be holistically assessed, and the full economic recovery is far ahead.

\section{Governance}

The main part of how the outbreak could be successfully managed comes under the role and duties of governance. It is clear that everyday governance cannot cope with such a transformative-but disruptive-period. Hence, it is urgently required to make governance as resilient as the city's management and provision factors. On the spur of the moment, decision making becomes more sensitive and processes adhere to new strategies. Governance should respond to multiple factors (see Chap. 4), such as the need for primary social services in the city as a main example of governance. The enforcement of new policies should be regulated and widespread, allowing little flexibility in control and monitory of the outbreak progression. Subsequently, the feasibility of practical implementation must be carefully assessed, inclusively developed, and formally announced. Hence, it is vital to equip governance of any level with the right instruments or tools for channelisation of all procedures in the formal process. The informality of responsiveness could harm governance, as it creates an unstructured approach to dealing with the situation, and it might also reduce the level of societal awareness or care. Therefore, the city governance ought to develop a group of stakeholders (Benson et al. 2016; Deng and Cheshmehzangi 2018; Hellsten et al. 2019), decision-making instruments (Ambat et al. 2019; Cheshmehzangi 2020a), adaptive measures (Monge et al. 2020; Shears and Garavan 2020), and formal procedures. Similarly, the informality of any of these factors would have adverse impacts on the control and containment plans. The society's full awareness of precautionary measures and guidelines is essential, and so is their engagement and involvement in strategic planning processes. 
Furthermore, the need for adequate legislation and adjustment of institutional constellations (Cheshmehzangi and Dawodu 2018; Kang 2019) is evident in the process of decision making. The city governance should enhance crosscommunication between: multiple actors of the city management teams, the society and various stakeholders, and with the authorities of different levels (i.e. both higher than the municipal level, and smaller levels under the municipality, such as districts, neighbourhoods, townships, etc.). Altogether, governance could provide added values beyond the position of the government. Hence, collaborative governance should merge into a network of key stakeholders, an all-inclusive approach that can assess the outbreak progress, verify the priorities, and make the right and reflective readjustments. This is not necessarily a top-down approach, but it should be driven and fully managed through the right top-down channels.

In our observations, we noticed regular changes; some more sudden than the others, and some in the form of updates. Eventually, the word 'Progress' meant a different thing in different contexts/countries/regions-one may just progress as the mean of improvement, and one may face the progression of the outbreak through increasing transmission and upsurge of the number of cases. To achieve the former, robust governance appeared to be essential and effective. This was evident through the role of governance in many Chinese cities, as also appraised by Bruce Aylward, head of the WHO-China Joint Mission on COVID-19, "China is doing an unprecedented job in battling an unknown disease with rigor and innovation" (reported by Zhao and Ma 2020). In other observations, two achievements of robust governance in China are appraisable, one is the formality of procedures, and the other is early control measures on transportation and mobility at multiple levels. Through formal procedures, the governance of the outbreak was effective, which helped to raised people's awareness and regulated collective compliance with precautionary measures. And through early control measures, the community transmissions were controlled, detected, and reduced in numbers.

\section{BOX 5.5 "The provincial epidemic prevention and control supervision group visits Ningbo for supervision and inspection" (This English document is released by Ningbo Municipal Economic and Information Technology Bureau-Dated 13 February 2020)}

In the afternoon of 11 February 2020, the provincial epidemic prevention and control supervision group visited Ningbo for supervision and inspection of the work on prevention and control of the COVID-19. Zhang Shifang, Director of the Ningbo Municipal Economic and Information Technology Bureau, made a report to the supervision group on the current support of materials for epidemic prevention and control, the difficulties in current material supply and demand, and the plan for the next step in Ningbo.

The supervision group fully affirmed the work that Ningbo has done and appreciated quick material support for epidemic prevention and control in Ningbo. Meanwhile, in view of the current difficulties in emergency materials 
supply, early return to work, labour recruitment, and transportation congestion and so on, four pieces of suggestion for the next step were put forward.

Firstly, strengthen examination and approval of enterprises' return to work.

It is suggested that we further understand the status-quo of enterprises, strengthen the work of providing "3 Services" for enterprises, and prevent any return to work without government approval.

Secondly, improve classified ability of rapid screening, such as nucleic acid detection.

It is suggested that we make full use of technology for nucleic acid detection and scientifically set the time for people under medical observation or home quarantine under the premise of ensuring safety.

Thirdly, provide guidance for enterprises to earnestly implement all requirements on epidemic prevention.

It is suggested that enterprises establish and improve daily cleaning, disinfection, ventilation and body temperature monitoring.

Fourthly, strengthen implementation of policies.

It is suggested that we strengthen publicity among and guidance for enterprises on policies, telling enterprises what to do and how, that we strengthen supervision and checking to make sure that relevant polices are complied with during the period of epidemic prevention and control.

Extracted from original source: http://www.nbec.gov.cn/art/2020/2/13/art_ 1907_4048855.html.

BOX 5.6 "Notice of "Twelve Regulations" for Epidemic Prevention and Control of Pneumonia Infection by the New Coronavirus in Ningbo" (This Chinese document is released by Office of the Leading Group of Epidemic Prevention and Control of Pneumonia Infection by the New Coronavirus, Ningbo-Dated 4 February 2020)

On February 4th, Ningbo's Leading Group of Epidemic Prevention and Control announced twelve newly enacted rules, known as the "Twelve Regulations", to further contain the epidemic and asks all citizens in Ningbo to abide by the rules. The translation of the announcement is below. 
The battle against the pneumonia epidemic caused by 2019-nCov (later pandemic on 11 March 2020) now enters a key stage. In order to win this fight and to ensure the safety and health of our people, we've enacted twelve specific containment measures known as the "Twelve Regulations", based on previously issued requirements for epidemic prevention and control. The "Twelve Regulations" are as follows:

1. Anyone from outside Ningbo city, who either returns or visits the city, should report to the company/organization where they work, or the village/community residence quarter where they live, at the earliest possible opportunity.

2. All villages/community residence quarters should have their access controlled. People residing in a village (community residence quarter) are not allowed to go outside without a designated certificate or submitting to a temperature check. External visitors and vehicles are not allowed to enter. If without a designated property management unit, a community should control its own access. Any special circumstances should be recorded by property management staff.

3. It is strictly forbidden for a citizen to enter public places without wearing a mask. Each household (except those quarantined at home for medical observation) can send one family member out to purchase necessities every two days while others should stay at home unless they need epidemic prevention or control, need to see a doctor or have a work emergency.

4. It is strictly forbidden for people to gather or to visit friends and relatives. Anyone entering a farmers' market or a supermarket should wear a mask and submit to a temperature check. All areas for congregation within a village or community residence quarter should be closed down. Courier and mail services should be conducted in a non-contact manner.

5. Those quarantined at home for medical observation are strictly forbidden to leave their residence.

6. All centrally controlled air conditioning systems at companies/organizations or public places should be shut down. All elevators and other confined spaces should be disinfected on a daily basis.

7. Public places not related to people's livelihood should be closed down. Farmers' markets, supermarkets, pharmacies and other places should operate with reasonable arrangement of business hours, regular disinfection and all personnel should take temperature checks and wear masks.

8. Weddings should be suspended. Funerals should be simplified and recorded at the administrative departments of villages (community residence quarters), with the cadres managing the whole process 
9. Residents with a fever or cough should report to their villages (community residence quarters) at the earliest possible opportunity, and go to a designated fever clinic. It is strictly forbidden to conceal or fail to report any underlying health issues. Pharmacies should implement real-name registration for sales of fever or cough medicines and report these to the local health department at the first opportunity.

10. Landlords should carry out primary management responsibilities and not sign new leases with persons from areas with high infection rates. Tenants from areas with high infection rates should be instructed not to return to Ningbo in the near future.

11. It is strictly forbidden for companies/organizations to start or resume work before 9th February unless previously approved.

12. All citizens should abide by national, provincial and municipal regulations on epidemic prevention and control. It is strictly forbidden to spread rumors or misreport the epidemic situation. Violation of regulations shall be severely and promptly punished in accordance with the law.

The regulations shall be enforced immediately. The prohibitive measures above are effective until further notice according to the situation of epidemic prevention and control.

Leading Group of Epidemic Prevention and Control of Pneumonia Infection by the New Coronavirus, Ningbo

4 February, 2020.

Extracted from third party source: https://www.nottingham.edu.cn/en/Cam pus-Portal/News/Article.aspx?id=0a341fd2-a4c6-4d91-97a0-5cdd9deaa 06c\&language $=$ en $-\mathrm{GB}$.

Translated by the University of Nottingham Ningbo China, University working group team.

\subsection{The Realities of the Experience}

This section demonstrates a city example by representing some of the realities of the COVID-19 outbreak and their impacts on a real case. These are recorded to showcase the realities of the experience in the City of Ningbo, East China. The city was under a full lockdown situation for several weeks and the impacts were widespread. The city went from the status of emergency to low risk on 3rd of March 2020, with 157 infected cases at its peak. The rapid transformations were remarkable and the city managed to respond effectively. Hence, this pictorial section is an unpretentious 
reflection on the realities of the outbreak, including factors of high consideration, details of control and monitory approaches, measures of various kinds that were in place, and ultimately the ways the society managed to cope with such disruptive time (Figs. 5.1 to 5.103).

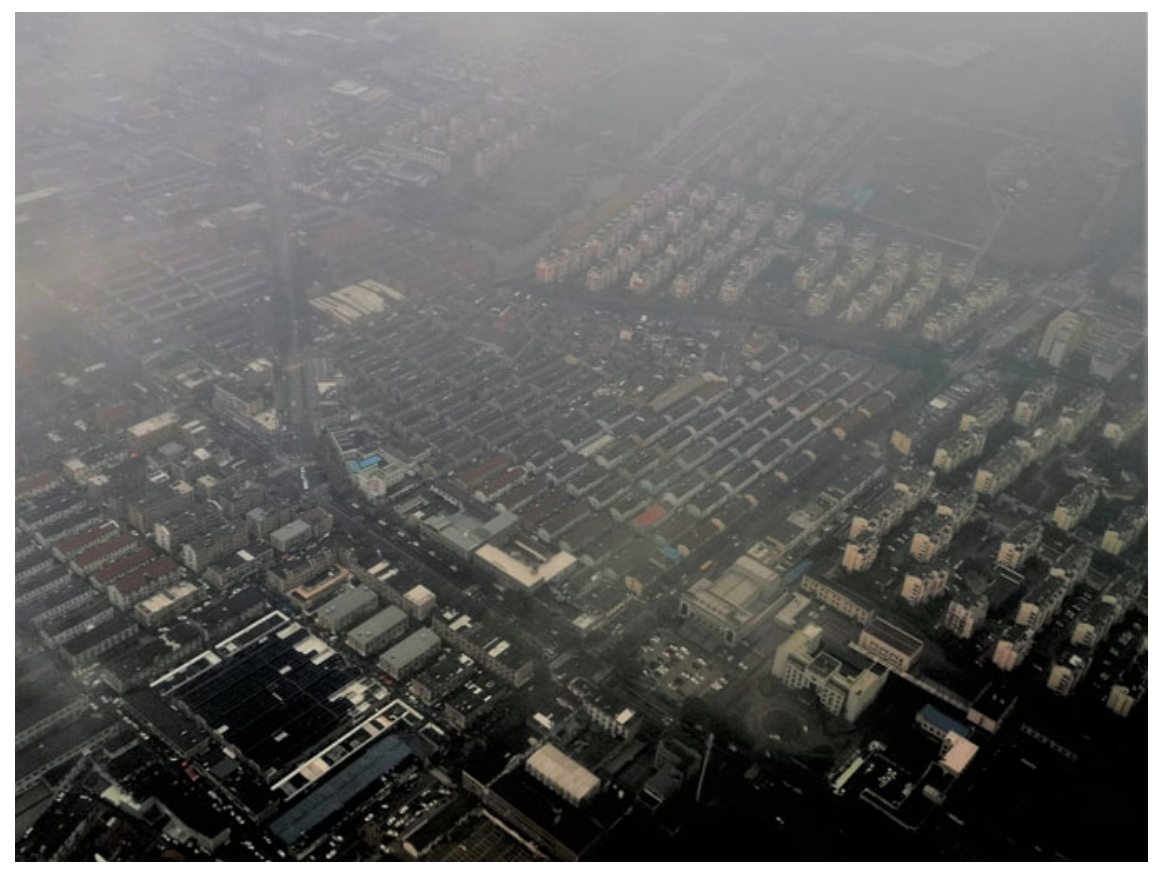

Fig. 5.1 The aerial view of Ningbo's southern areas (mostly with a combined urban layout of low to mid-rise housing and industrial areas), just one day after the lockdown of the original epicenter of the COVID-19 disease outbreak. At this time, the City Ningbo is still fully operational and people are preparing for the Chinese New Year celebrations. In the midst of early uncertainties, there are some growing concerns about disease transmission. People are more cautious with less outdoor activities and less mobility. The new conversation was to assess what is discussed in social media and the official media. Many discussions were around issues of the SARS outbreak and its experience several years ago. By this time, the majority wore facial masks, the news was developing fast, and there were temperature checkpoints in the main transportation hubs of the city. On 24th of January 2020, the city was under the shadow of its very own lockdown. Source Ali Cheshmehzangi 


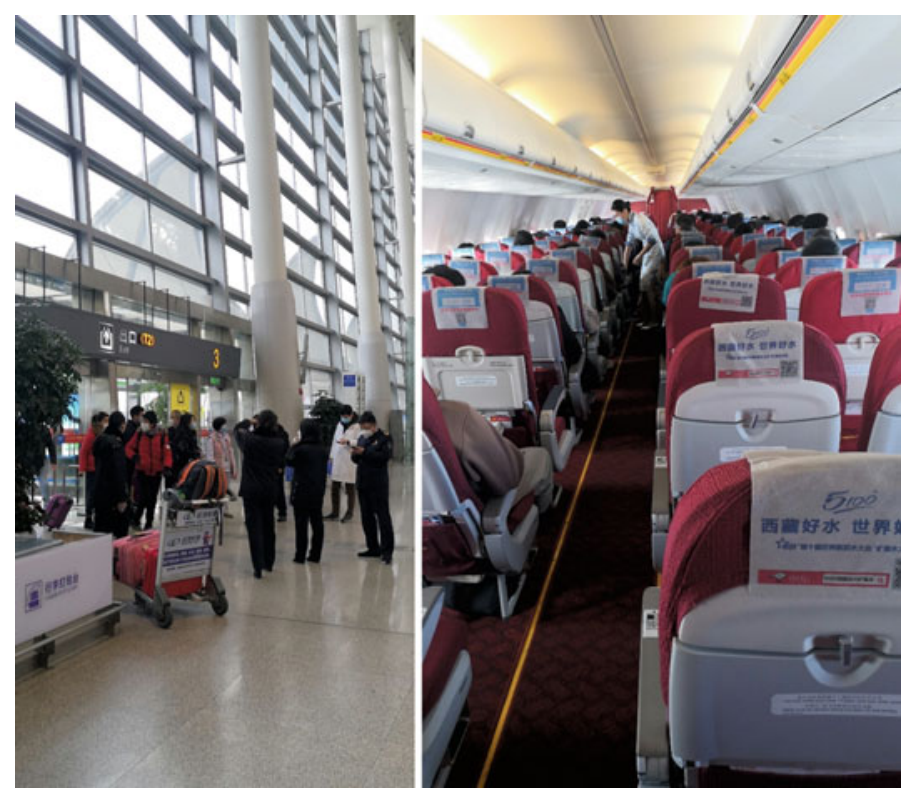

Fig. 5.2 As early as the 24th of January 2020, intensified health checks, high-level security, and empty flights were amongst the early expected scenes, reminding many people about the measures implemented during the SARS outbreak in 2002-2003. With many uncertainties and lack of knowledge about the disease, the immediate actions were to identify suspected cases travelling between cities, provinces, and countries. At this time, there was no sign of 'social distancing' or any of the later measures that became global. Only a few symptoms of the disease were identified and anyone with a temperature over $37.3{ }^{\circ} \mathrm{C}$ was not allowed to travel out of cities. While recapturing or remembering some of those earlier experiences, and not knowing the severity of the disease, most people started to use facial masks in the public. This was also recommended to all flight attendants, pilots, security workers, etc. Everything was moving fast and measures were just adding up one after another. Reactions were fast and there was no sign of inactions under the circumstances. Soon after, streets were empty not because of the Chinese New Year arrival but because of the fear of the unknown and hidden enemy. By then, the media coverage was continuous at the national level, and there were many reports of the outbreak progress in Wuhan and other cities across the country. I took a photo of a pilot wearing a facial mask, and told a few others this must be serious! Source Ali Cheshmehzangi 


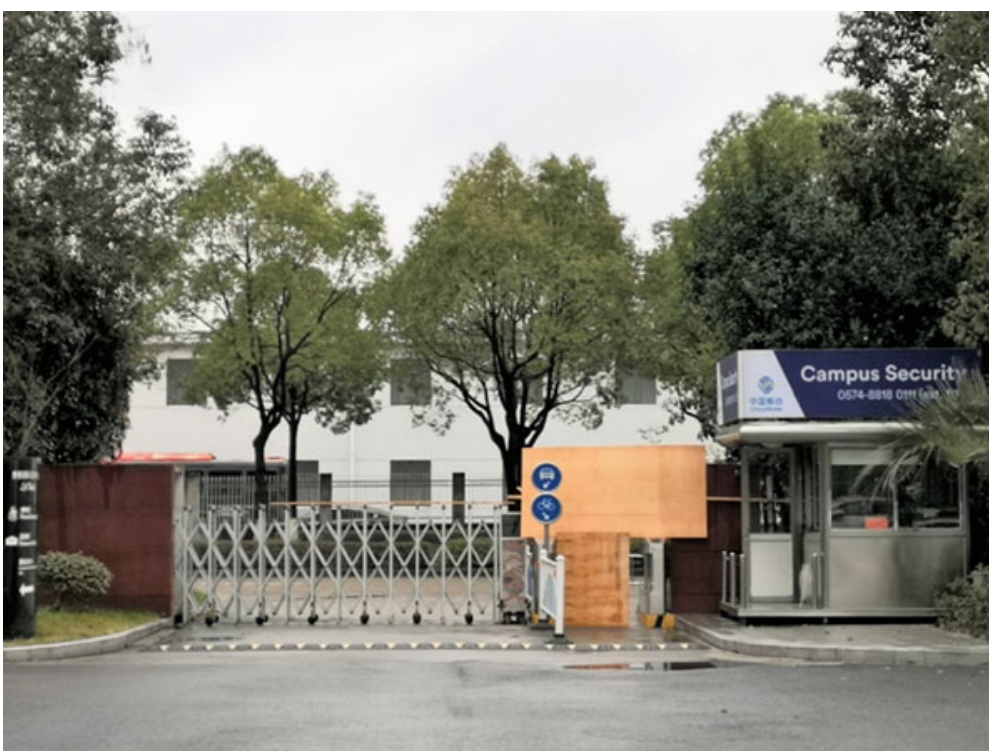

Fig. 5.3 The early closure of secondary gates/entrances of compounds from the 29th of January 2020, applied to residential compounds, educational compounds, and some public amenities. The temporary closure as shown in the image is basic but all residents complied with this temporary measure to ensure the security of their compound/working area/campus is maintained. Hence collective compliance is vital at any scale and in such disruptive event. Source Ali Cheshmehzangi

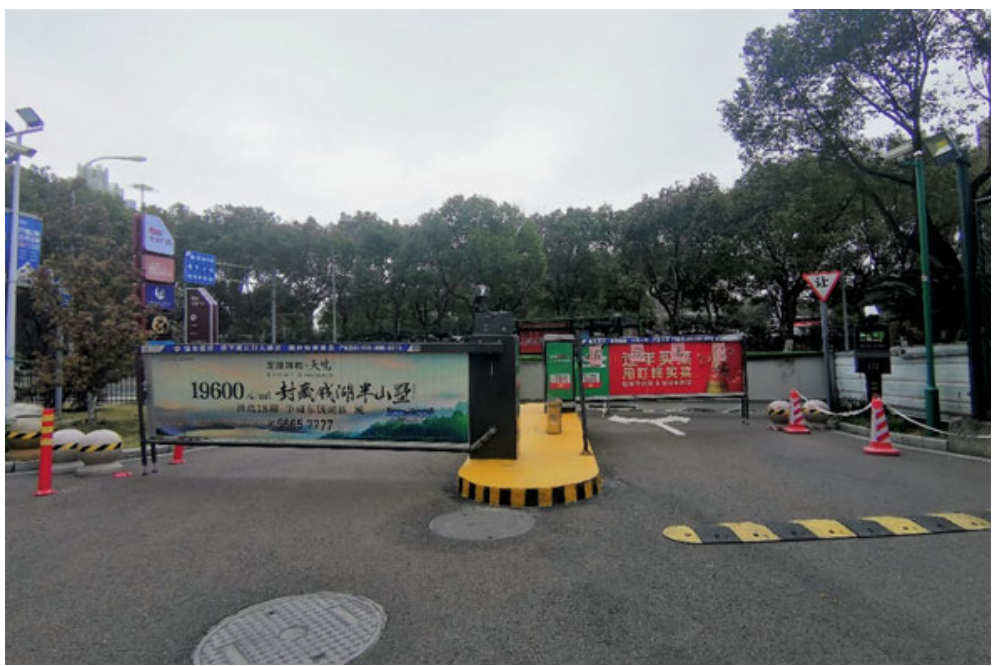

Fig. 5.4 The closure strategy soon applied to mixed use development of retail and businesses, and limiting access points. Source Ali Cheshmehzangi 


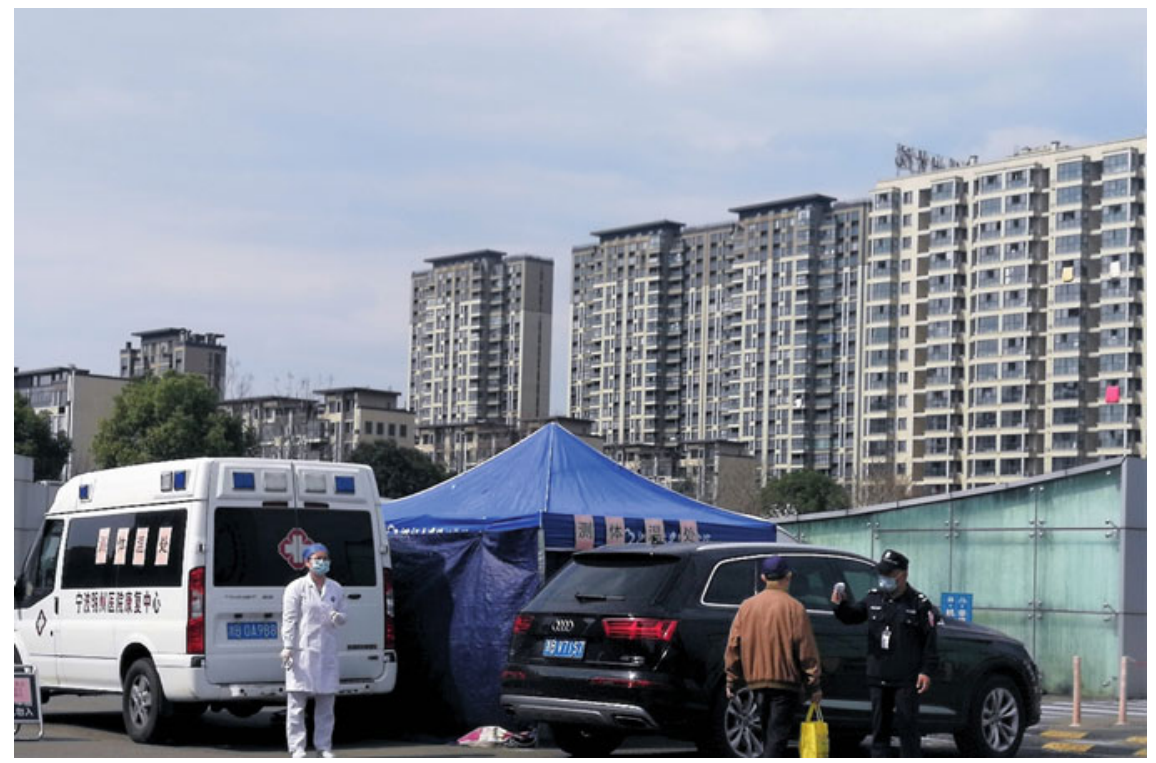

Fig. 5.5 Early presence of three main services, namely security/safety, medical, and emergency, next to each other in front of main healthcare centers and hospitals to monitor entries and to provide immediate response. Source Ali Cheshmehzangi

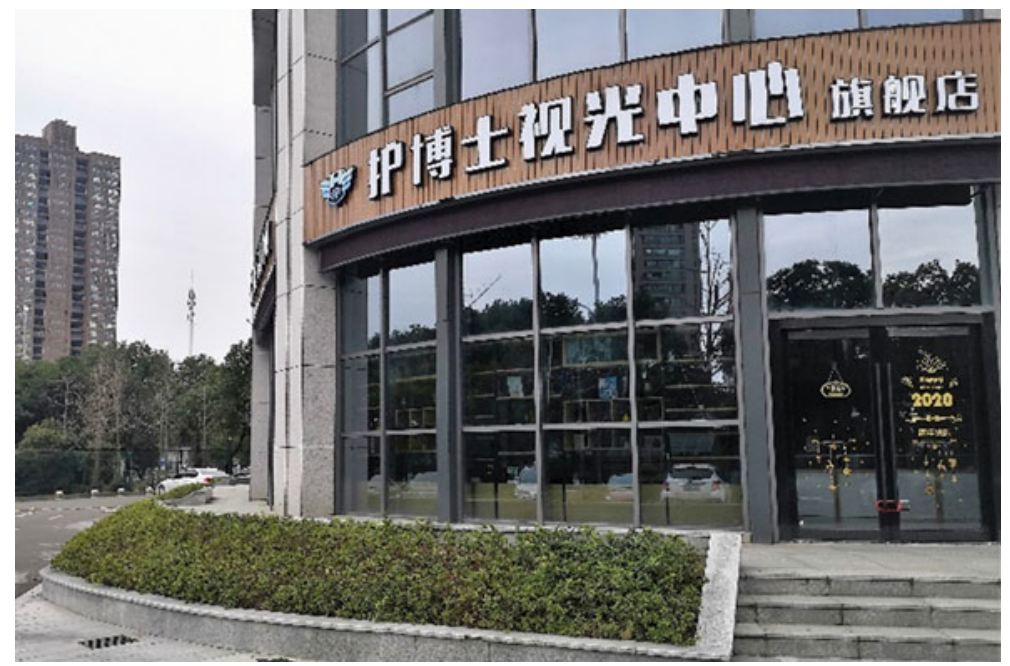

Fig. 5.6 The gradual closure of secondary amenities, such as restaurants, cafés, pubs, bars, etc. to reduce the chance of gathering that pose higher risk of community transmission. Source Ali Cheshmehzangi 


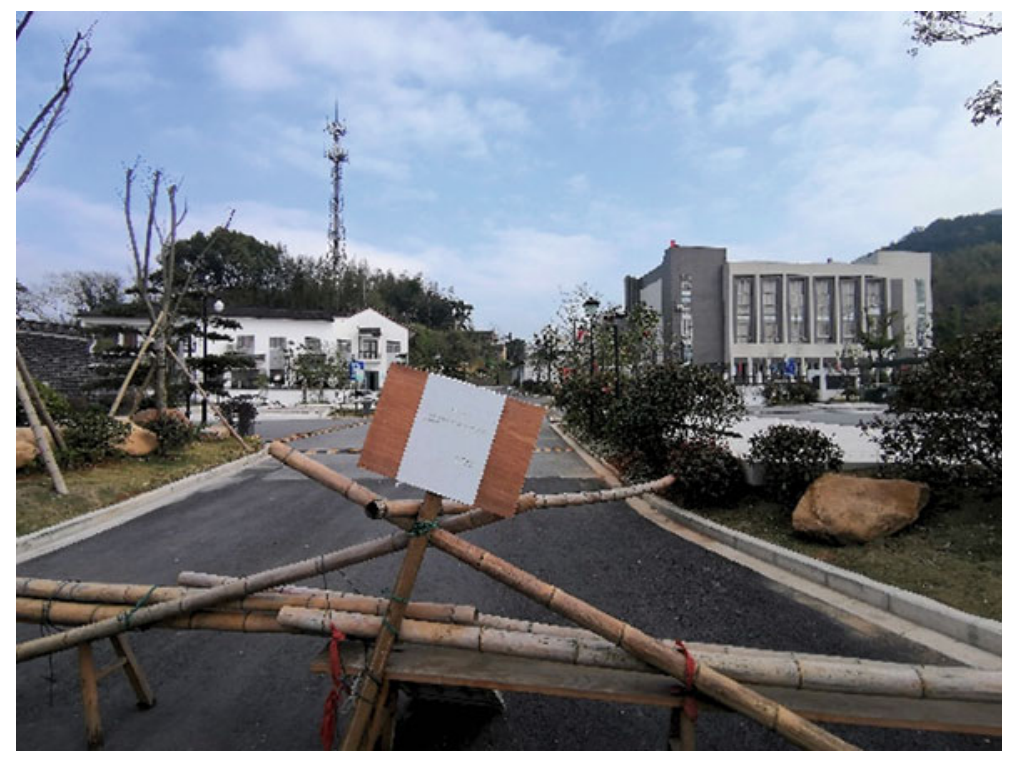

Fig. 5.7 The closure of public buildings and religious buildings, effective from 30th of January 2020. Source Ali Cheshmehzangi

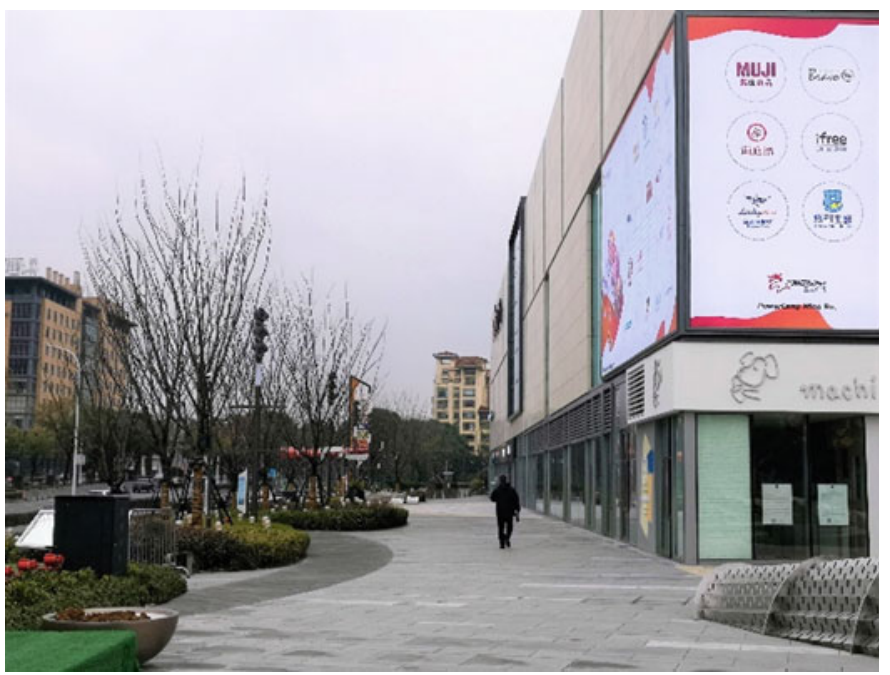

Fig. 5.8 The early closure of larger and clustered retail areas, such as shopping centers/malls with only limited operations of their supermarkets, which were remained accessible with more control and monitory measures. Source Ali Cheshmehzangi 


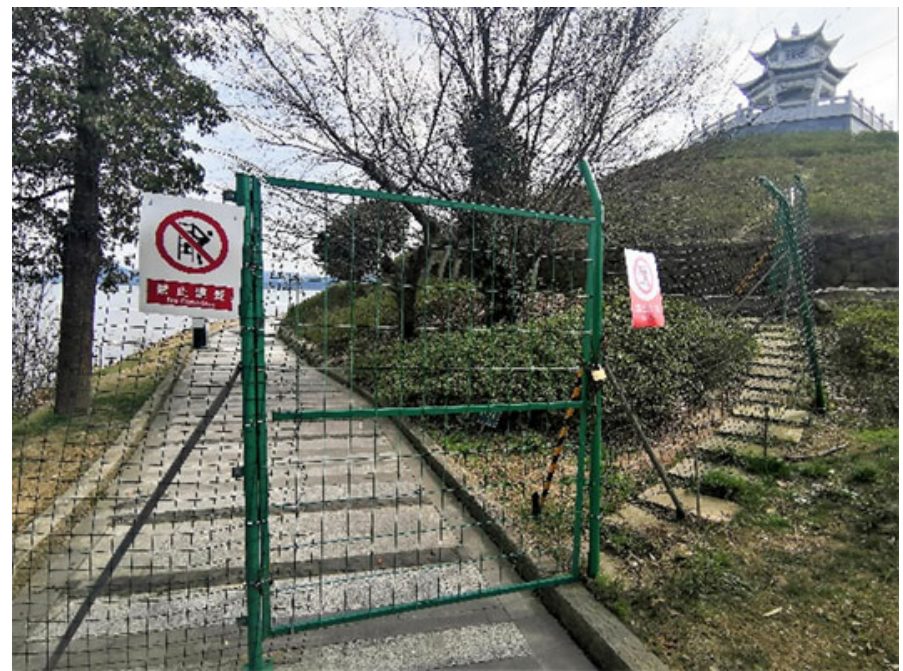

Fig. 5.9 The closure of underused public places with less visibility for control and monitory. Source Ali Cheshmehzangi

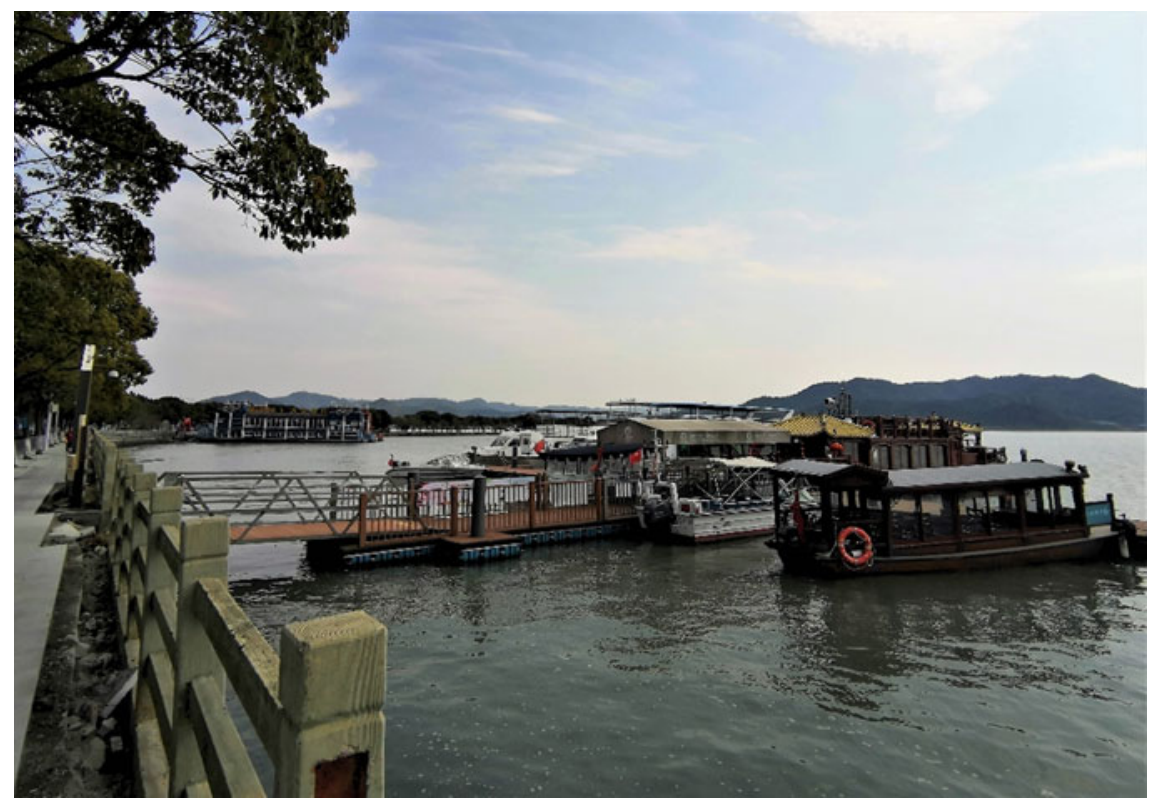

Fig. 5.10 The early closure of leisure and entertainment facilities or places that attract larger group of people or often clustered activities. Source Ali Cheshmehzangi 


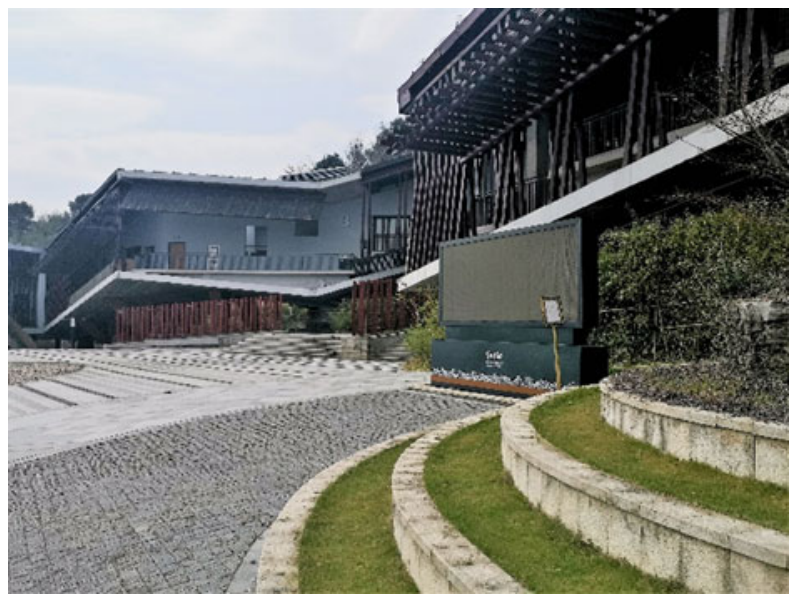

Fig. 5.11 The closure of secondary amenities for a longer period, the example of Ningbo Calligraphy and Painting Academy. Source Ali Cheshmehzangi

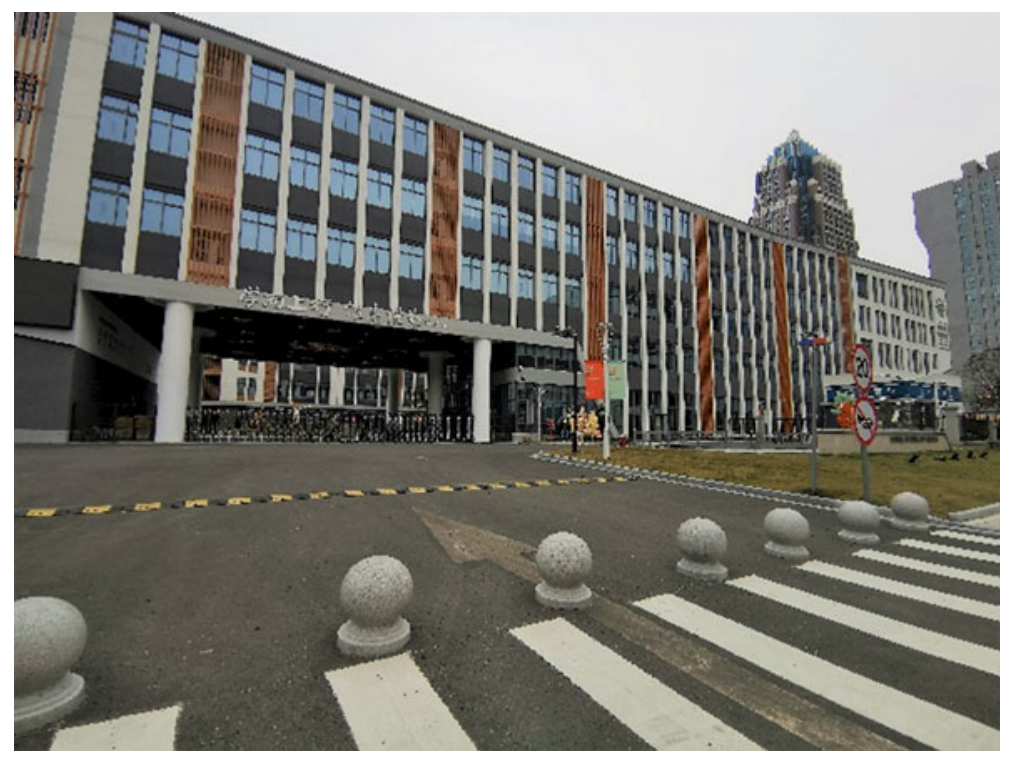

Fig. 5.12 The closure of educational buildings for a longer period, the example of primary school in Yinzhou District. Source Ali Cheshmehzangi 


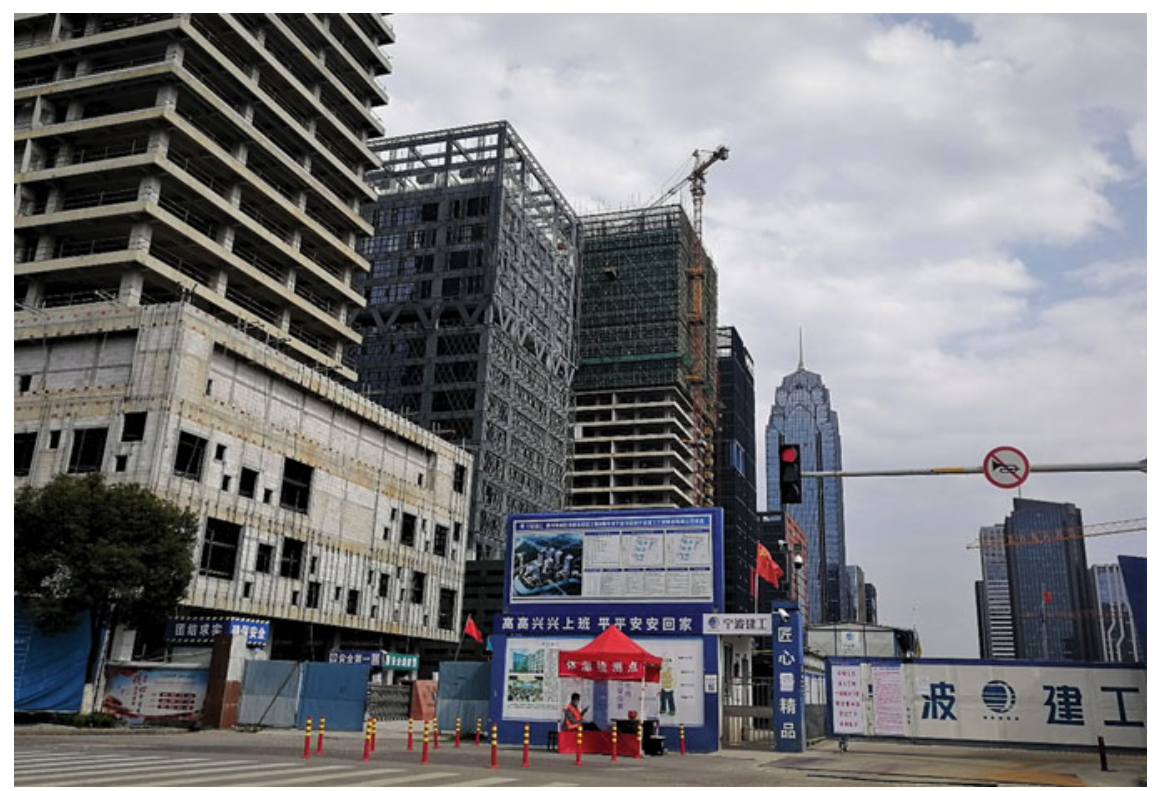

Fig. 5.13 The extended closure of all construction sites, regulated for any non-compliance activities, particularly that construction sector was affected significantly. Source Ali Cheshmehzangi

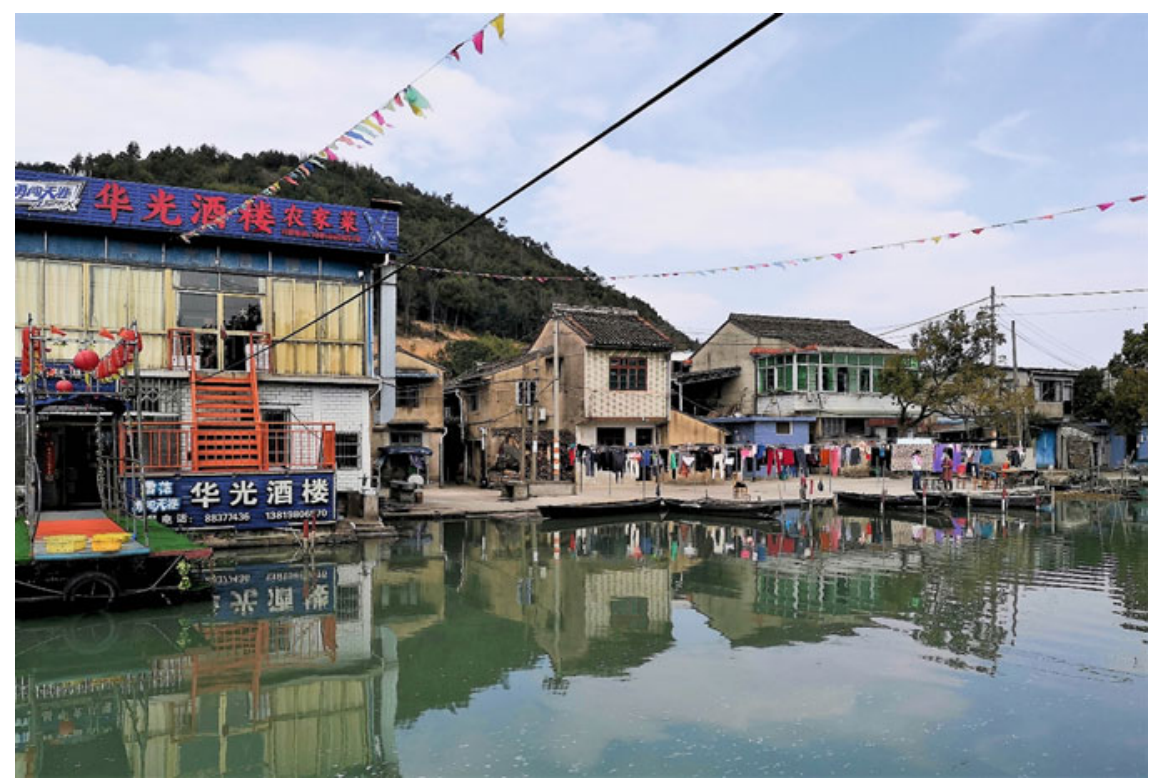

Fig. 5.14 The persistence of the slow(er) pace rural life with tangible impact on their tourism industry. Source Ali Cheshmehzangi 


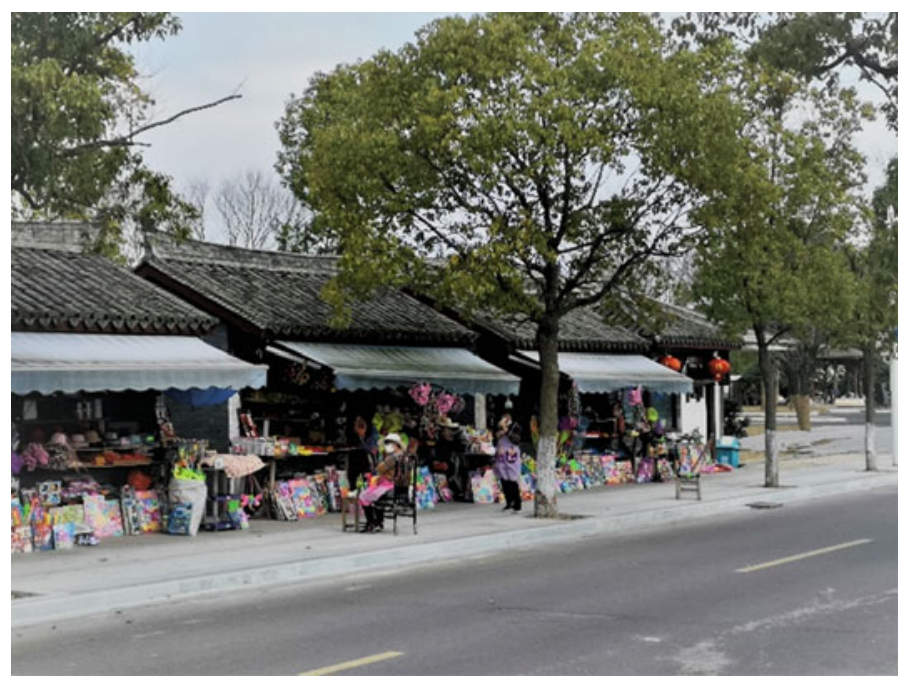

Fig. 5.15 Minimised tourism industry in rural and outskirt areas. Source Ali Cheshmehzangi

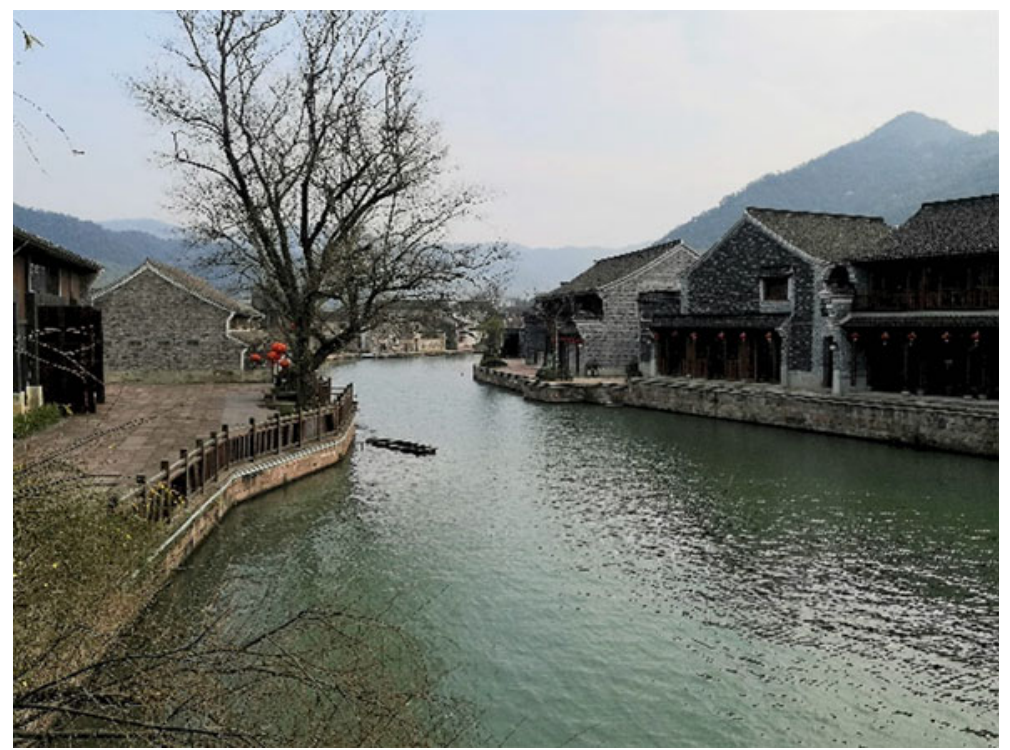

Fig. 5.16 Nearly empty touristic villages in outskirts. Source Ali Cheshmehzangi 


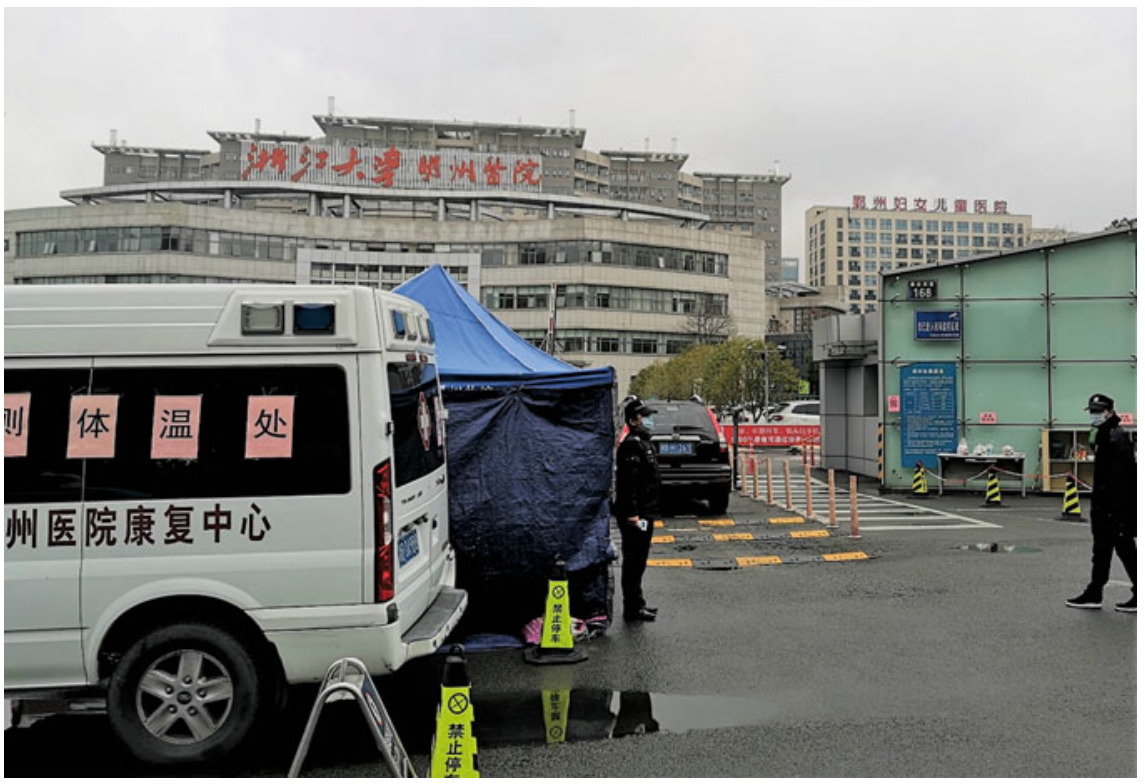

Fig. 5.17 Higher level of control and monitory measures for secondary hospitals during the transmission and transition phases, bearing in mind that only selective hospitals (15 in total) could accept infected patients across the city and its outer districts. Source Ali Cheshmehzangi

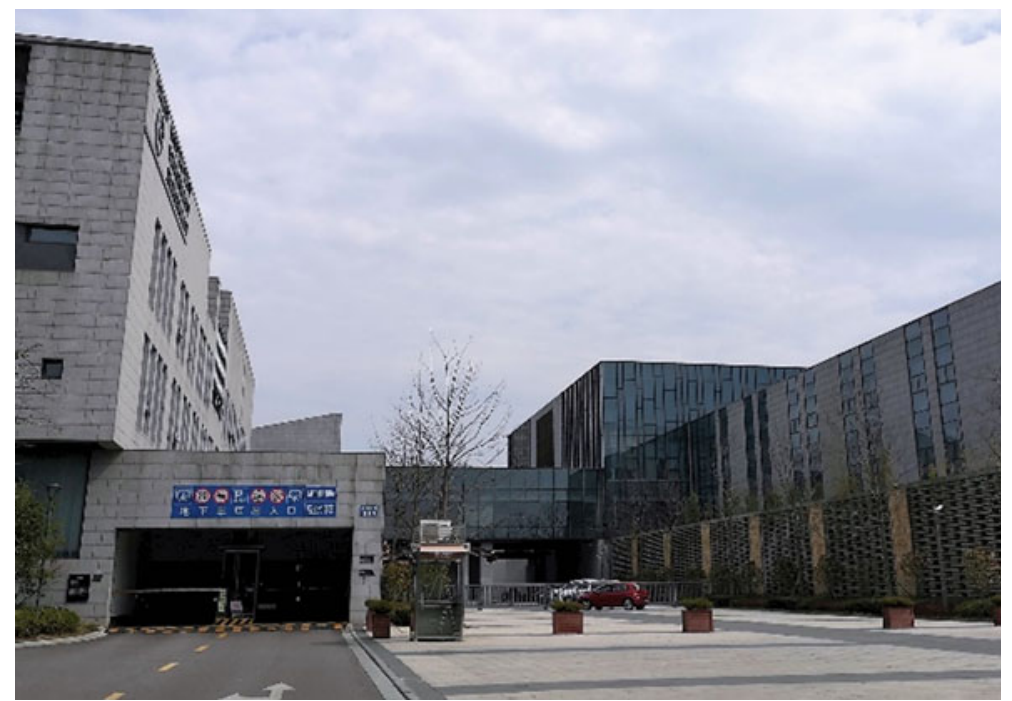

Fig. 5.18 Limited operations of secondary social services, such as the local tax office. Source Ali Cheshmehzangi 


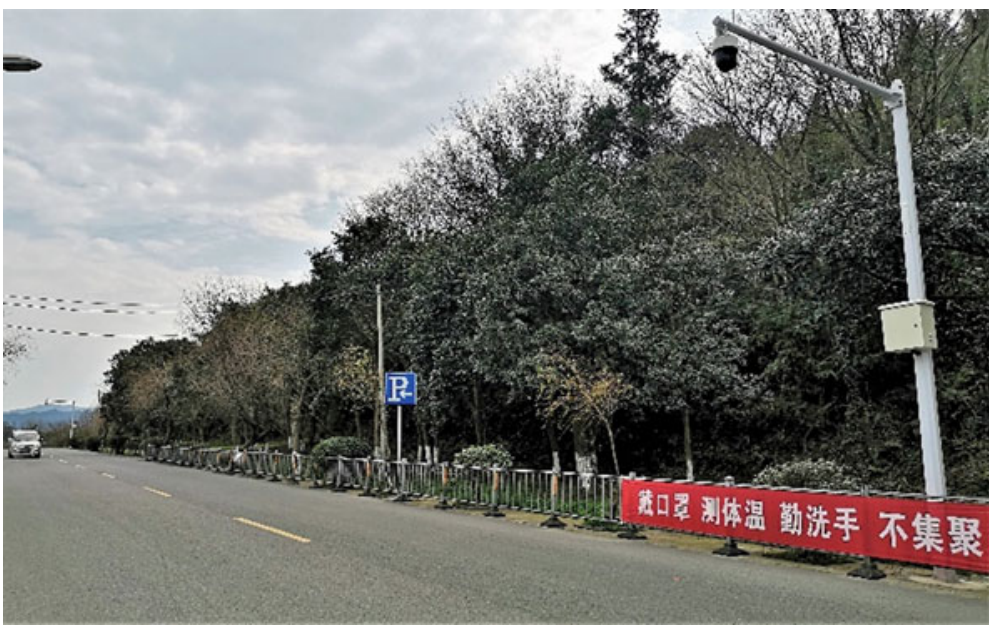

Fig. 5.19 The city authorities placed slogans with the main highlights of precautionary measures. In this example there are four protective reminders: "put on the mask, check your temperature, wash your hands regularly, and no gathering". Source Ali Cheshmehzangi

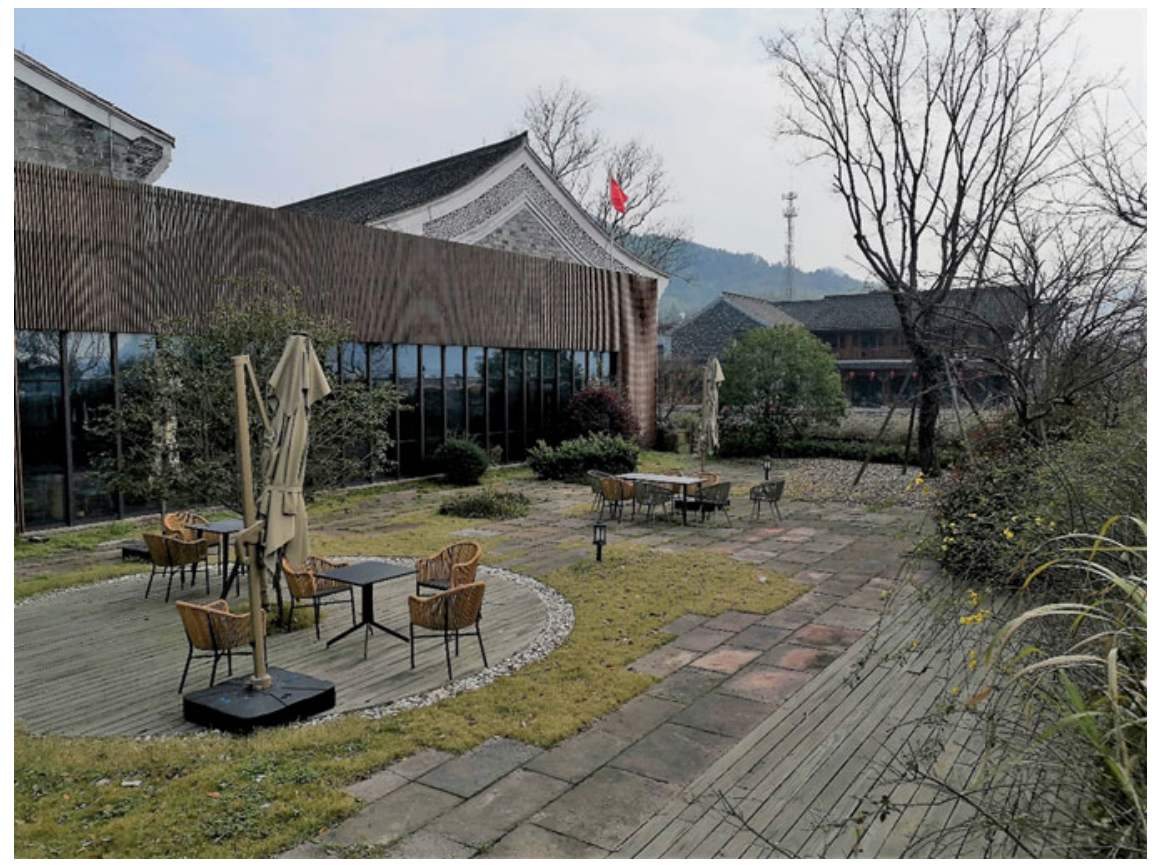

Fig. 5.20 Empty and closed public places and secondary amenities across the city and its rural districts with a large impact on people's lifestyle. Source Ali Cheshmehzangi 


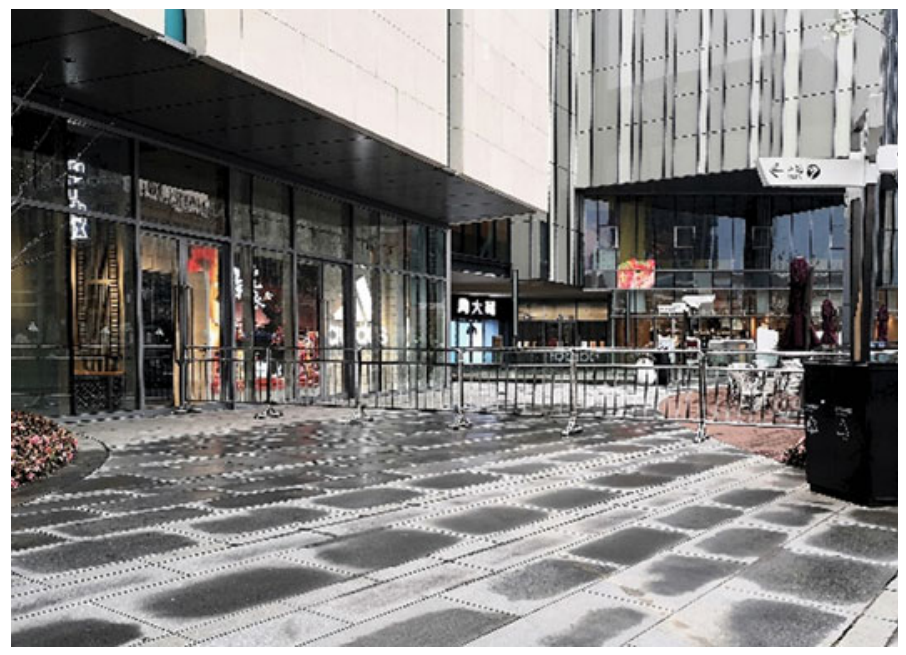

Fig. 5.21 The closure of multiple access points to open public spaces in order to limit and centralise control and monitory of checkpoints. Source Ali Cheshmehzangi

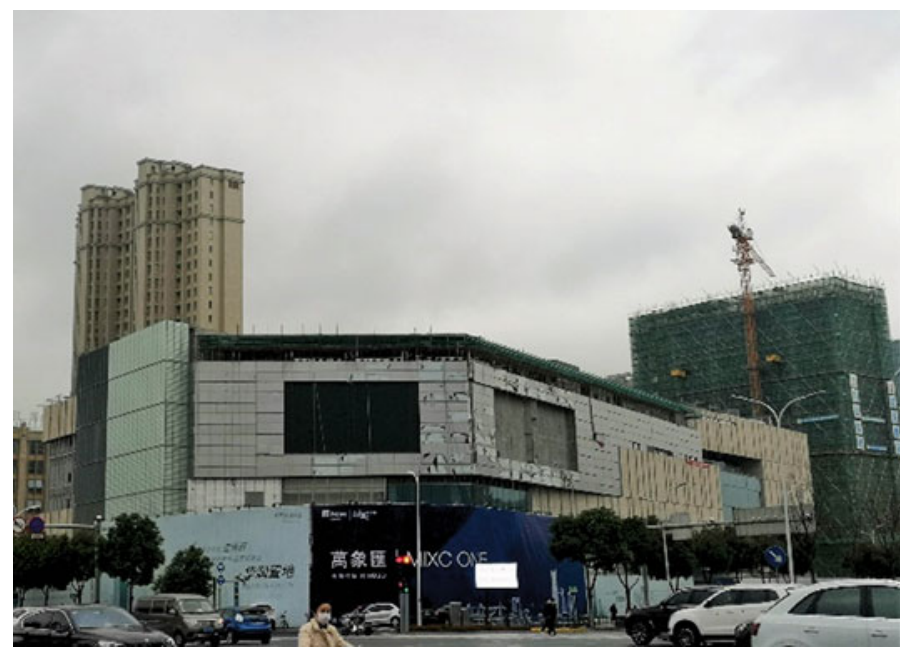

Fig. 5.22 The city's many constriction sites were on halt for an extended period due to multiple facts, partly associated to limited resources and workforces or the need for larger mobility of workforces from other parts of the province and other provinces. Source Ali Cheshmehzangi 


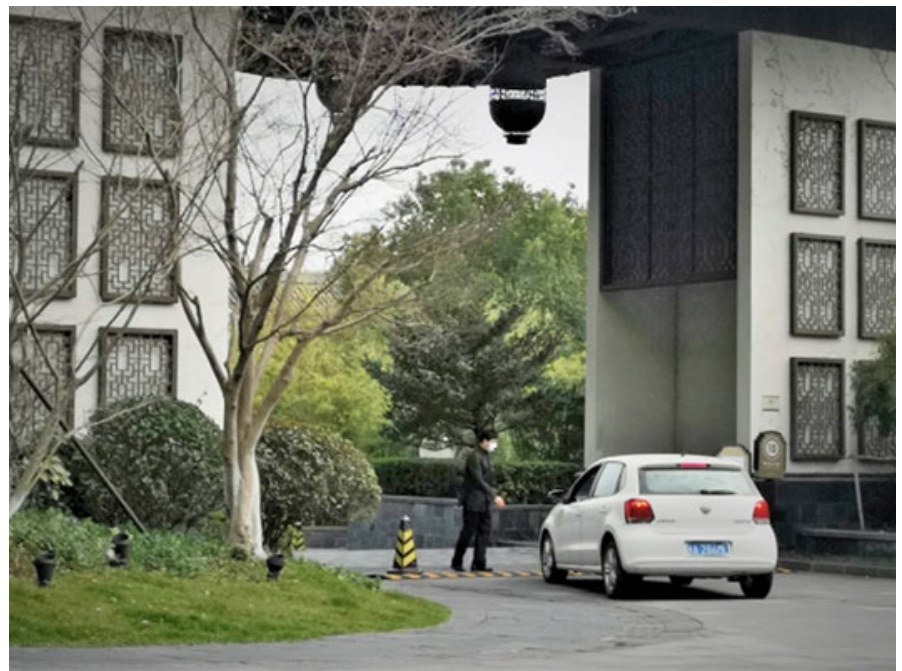

Fig. 5.23 Regular checks and control were implemented for hotels and resorts, ensuring the early detection of cases coming from others provinces or countries/regions. This was a time when hotel businesses are not doing well due to limited travel and significant impact on tourism. Source Ali Cheshmehzangi

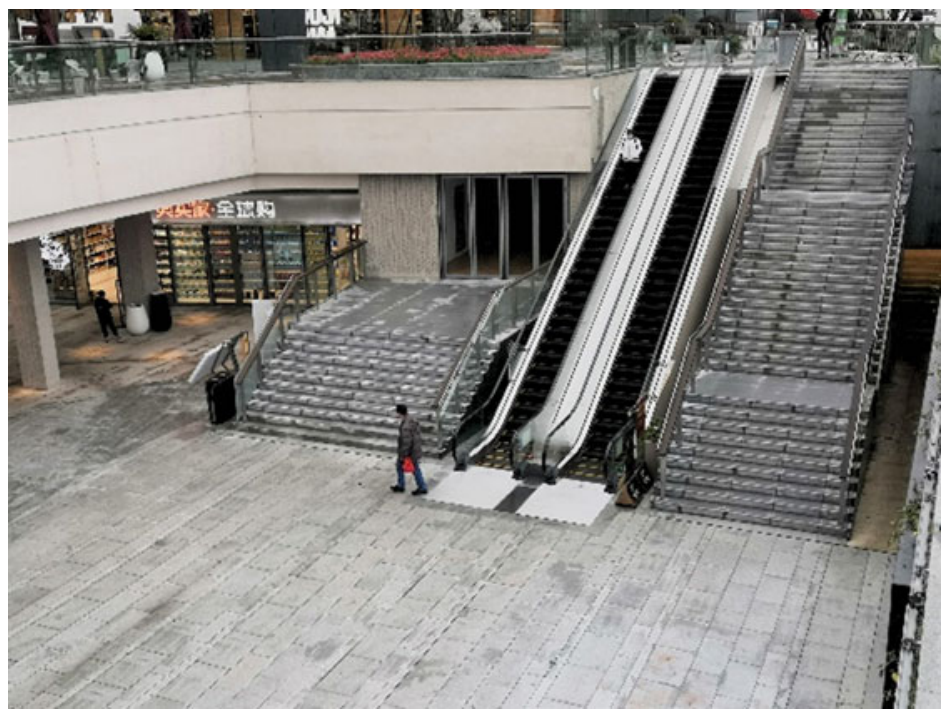

Fig. 5.24 Regular disinfection procedures of main public places, public buildings, and public facilities, which was changed from a daily routine at first to several times a day. Source Ali Cheshmehzangi 


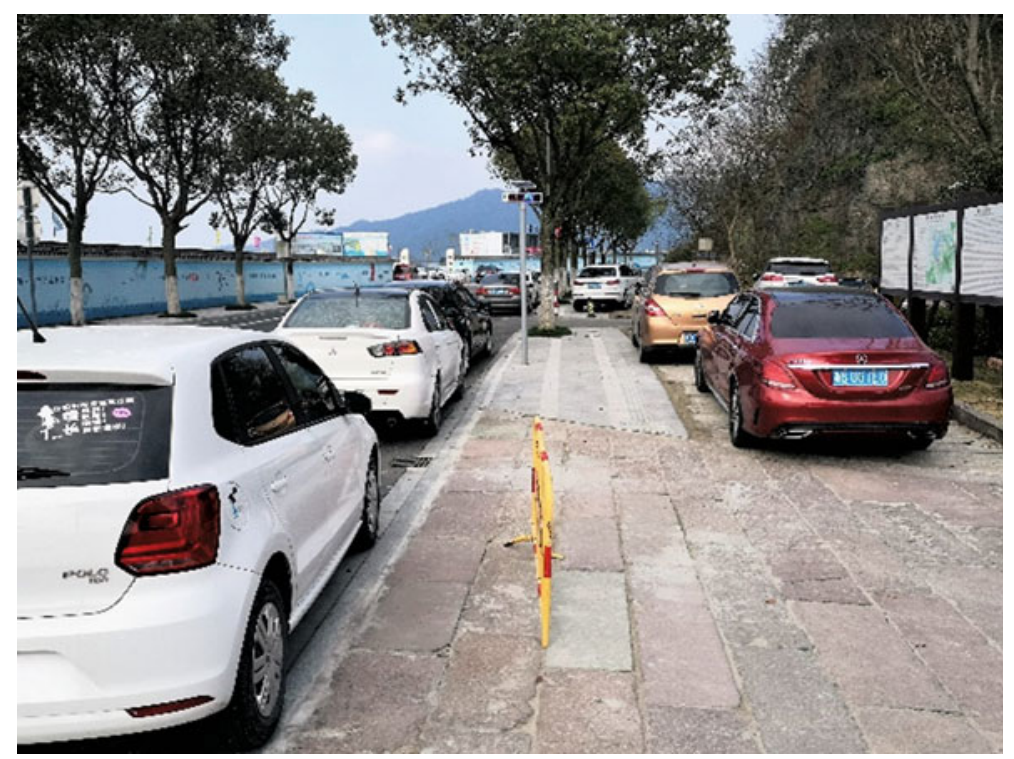

Fig. 5.25 Societal disorders, regardless of their magnitude and impacts, became more visible throughout the transition and recovery phases. Approximately five minutes after the photo was taken, the police was on site to charge the cars. Source Ali Cheshmehzangi

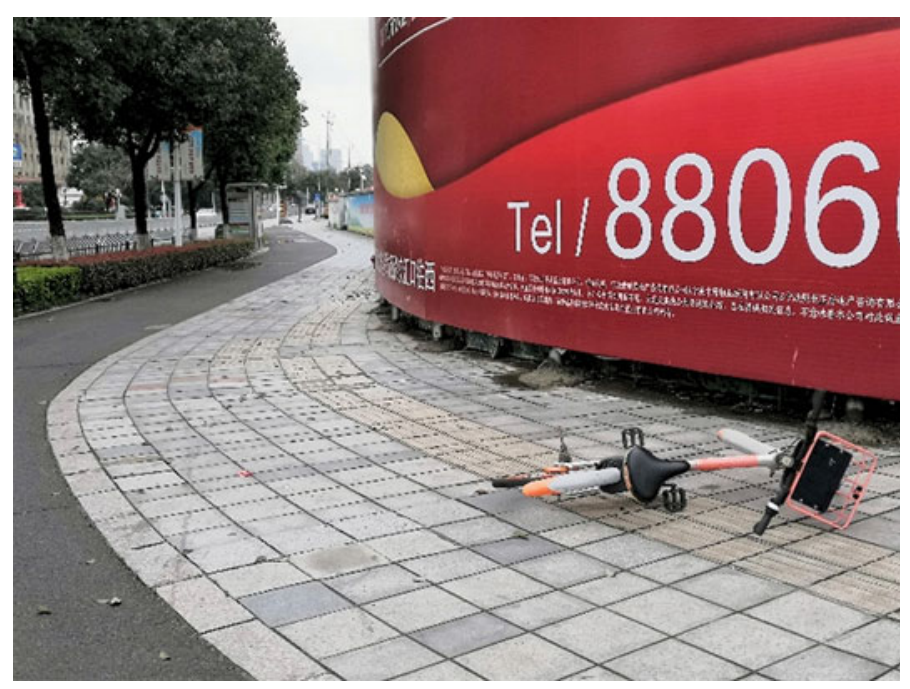

Fig. 5.26 Another simple but unnecessary disorder that requires a particular a unit to get involved. That unit is perhaps non-operational, partial in their regular operations, or lack human resources. Source Ali Cheshmehzangi 


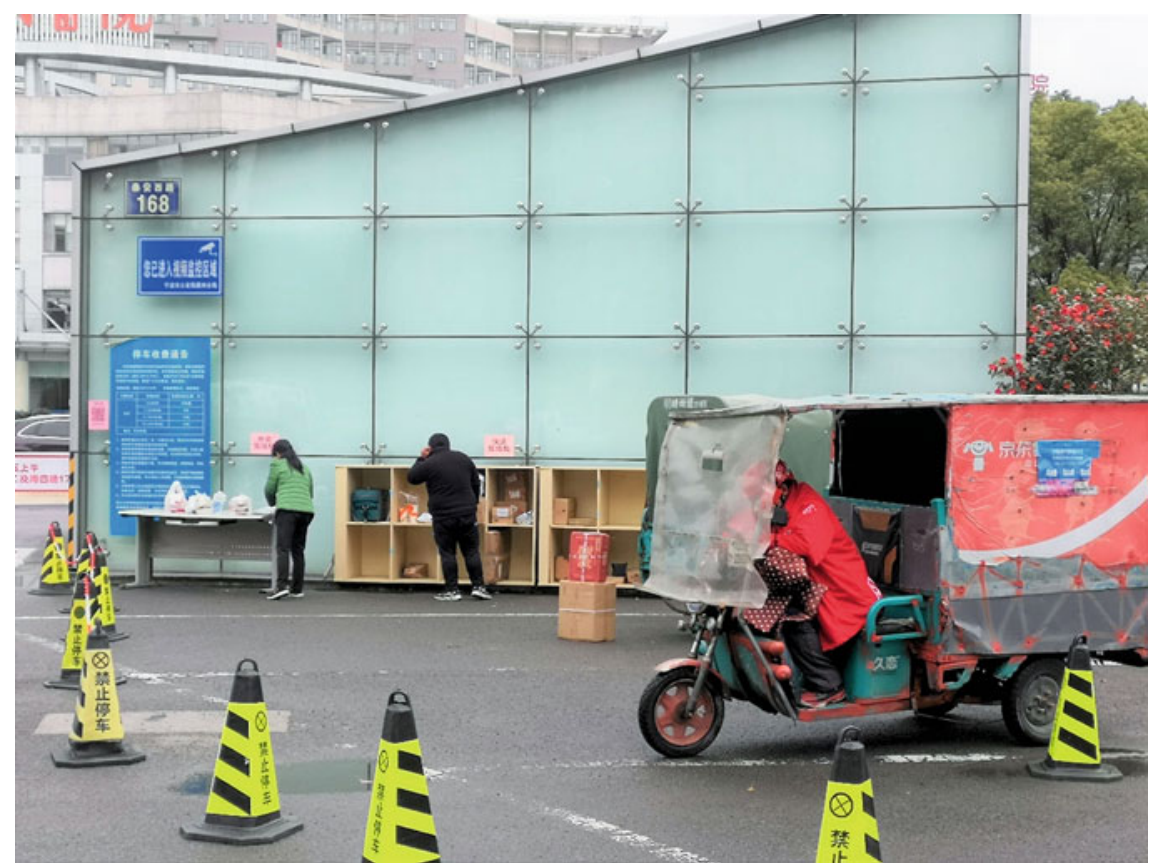

Fig. 5.27 Designated food delivery and goods collection point beside the main entrance of one of the hospitals to help with contactless operations to maintain essential provisions to vulnerable and affected groups of the society. Source Ali Cheshmehzangi

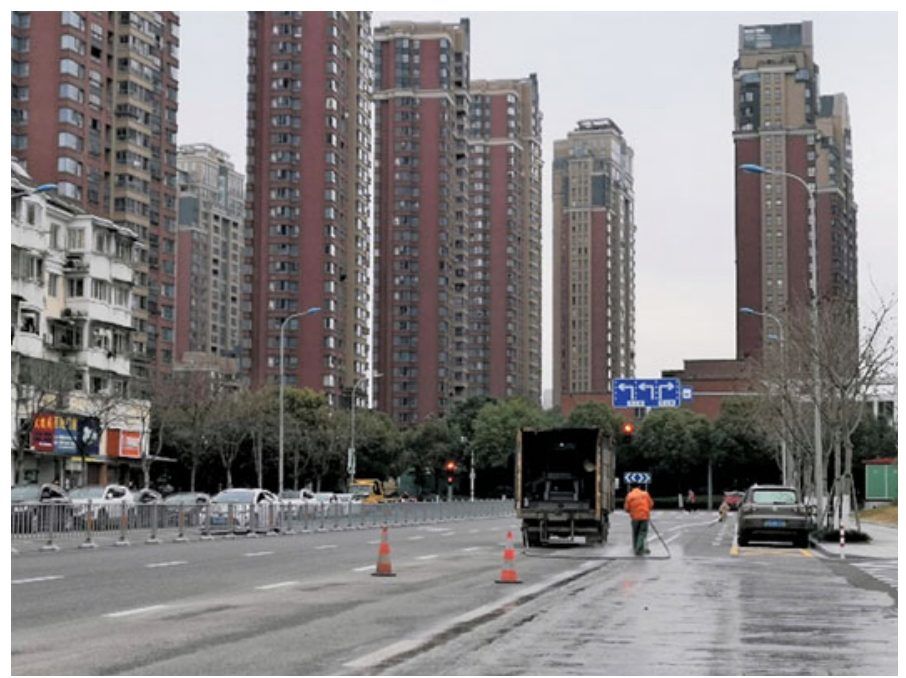

Fig. 5.28 Mobile amenities only operate for those primary maintenance needs and operations, which were effectively regulated by relevant units. Source Ali Cheshmehzangi 


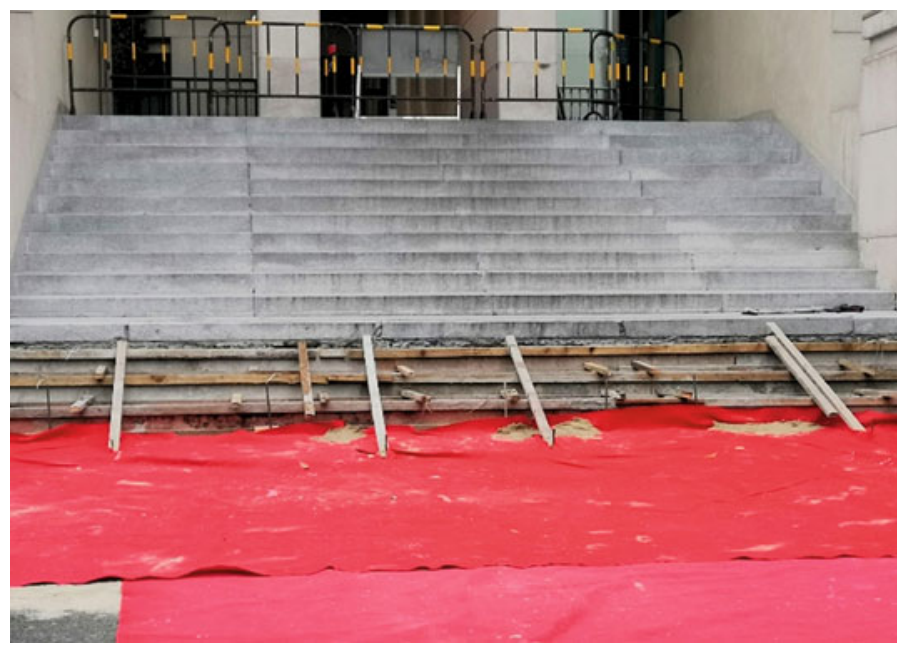

Fig. 5.29 With limited resources and high risks of community transmission, construction works were limited to emergency and necessary construction jobs which could were mainly small scaled and required limited resources. Source Ali Cheshmehzangi

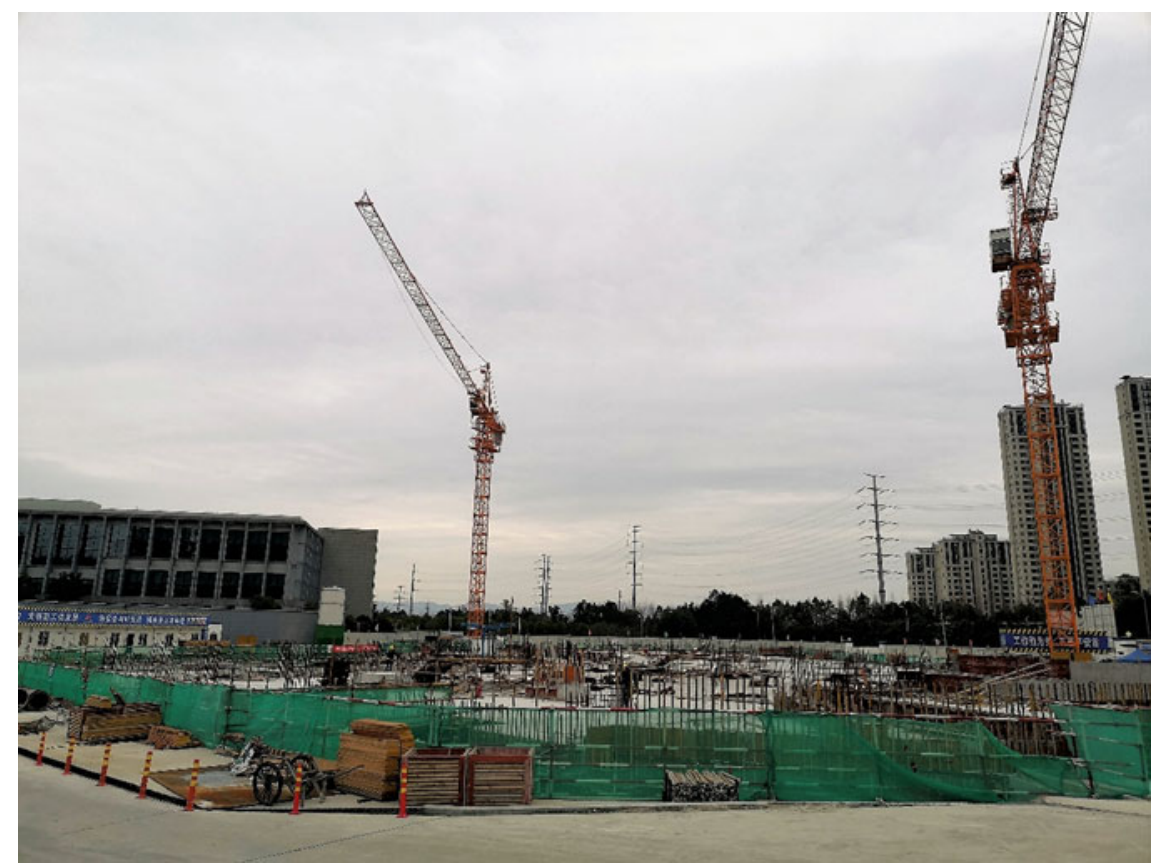

Fig. 5.30 With almost three weeks of delay, the construction work started with gradual and limited operations. Somehow, the construction noise brought life back to the city. Source Ali Cheshmehzangi 


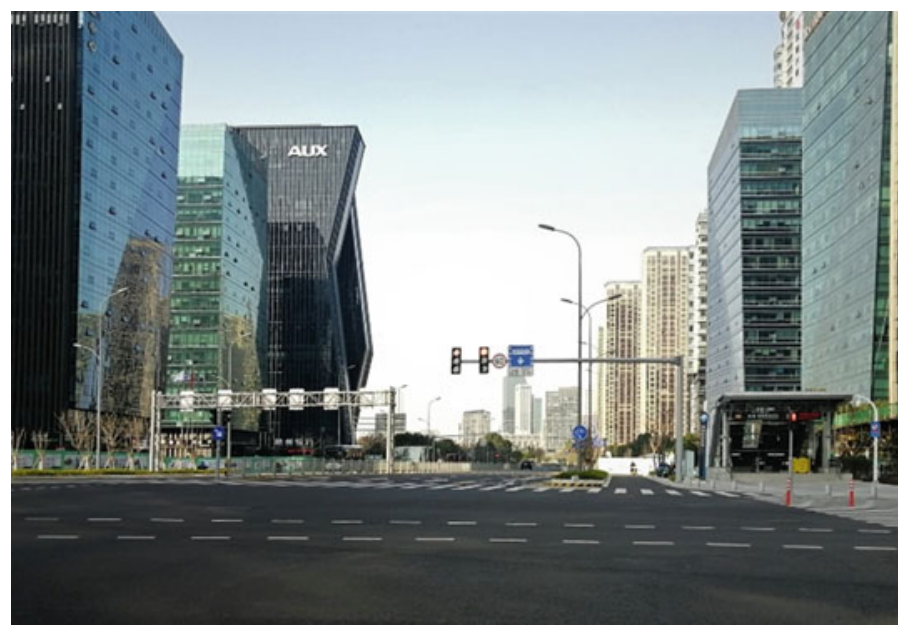

Fig. 5.31 Tangible decline in daily activities of one of the three Central Business Districts (CBD) of the city during the lockdown period and towards the end of transmission phase. Source Ali Cheshmehzangi

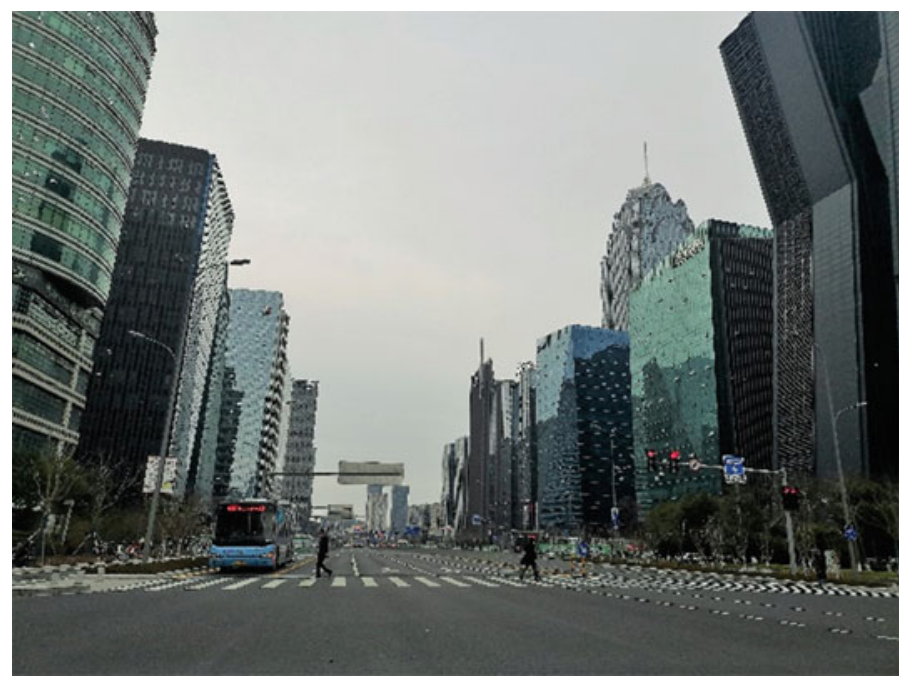

Fig. 5.32 Gradual operation of CBD area inclusive of financial sector and middle sized businesses immediately after the lockdown period and towards the end of transition phase. Source Ali Cheshmehzangi 


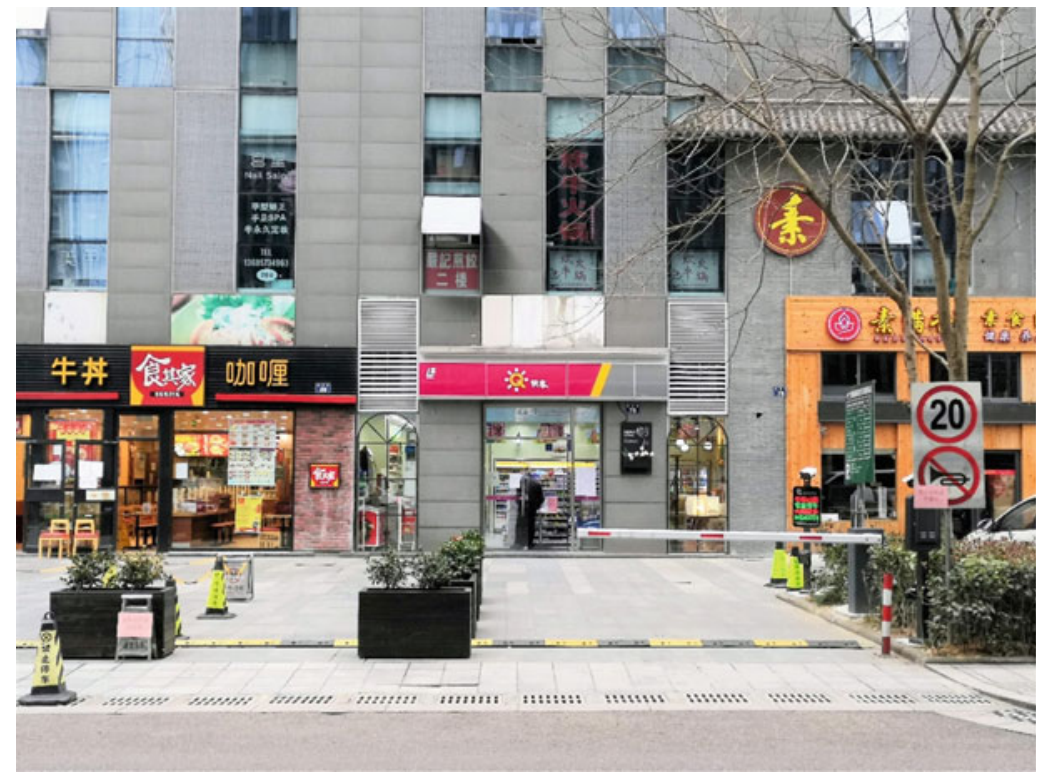

Fig. 5.33 Gradual operation of retail and public services with limited hours of operations, limited workforces, and high safety measures. Source Ali Cheshmehzangi

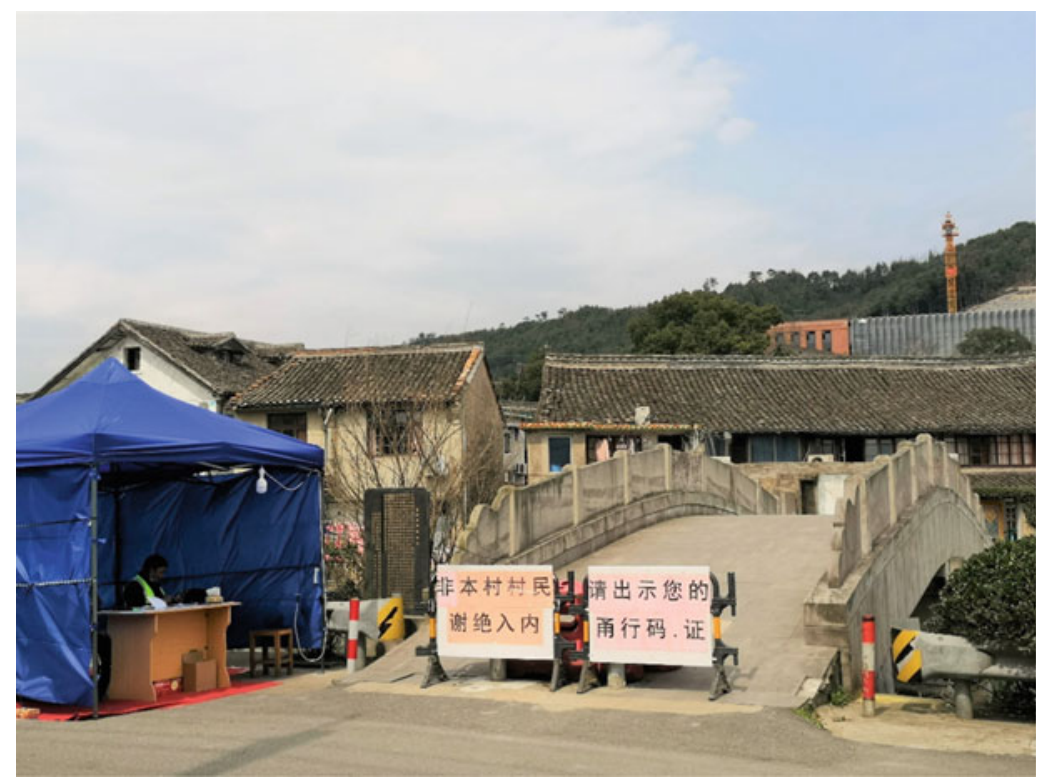

Fig. 5.34 An example of checkpoint at the main entry node to rural areas, with restriction on non-local entry to specified areas. The set-up includes signage, a visible tent, disinfection products, record of documents, and community volunteers. Source Ali Cheshmehzangi 


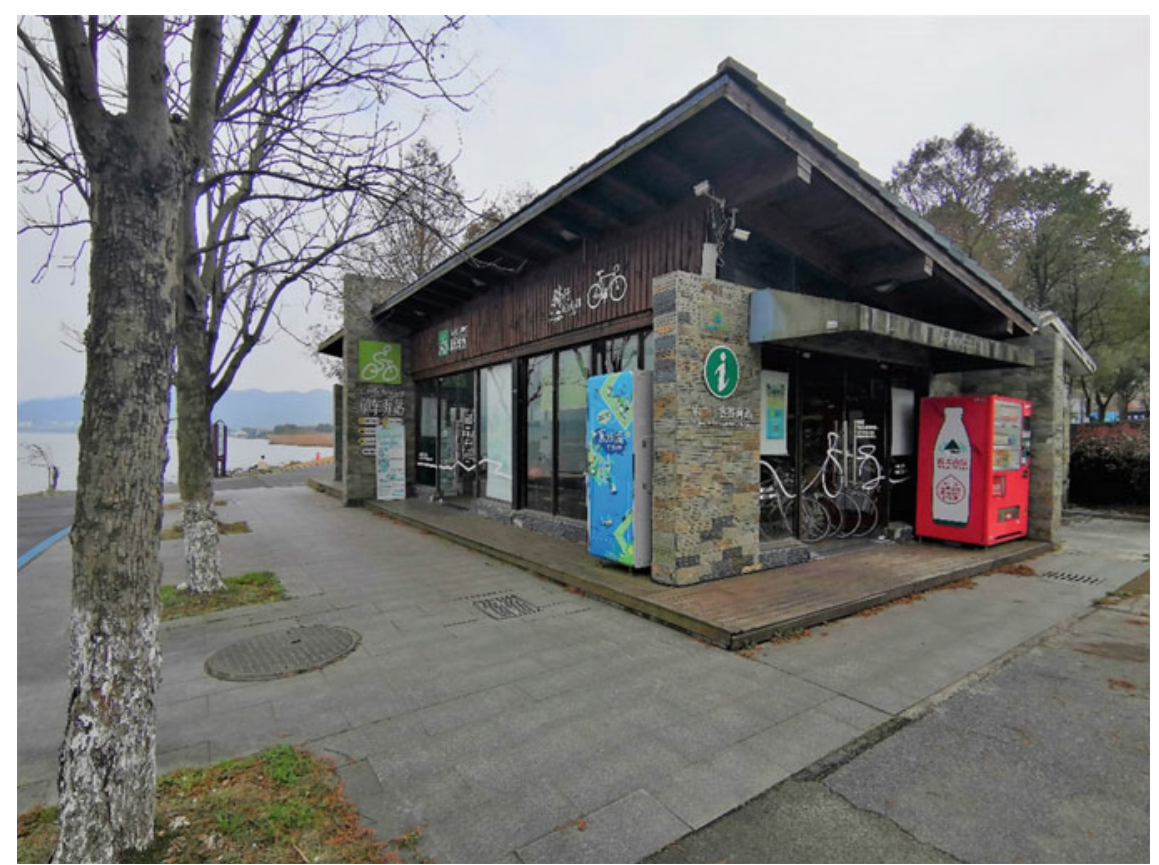

Fig. 5.35 Temporary but longer closure of shared bike hire facilities, which are normally with little control measures and high risks of person-to-person/community transmission. Source Ali Cheshmehzangi

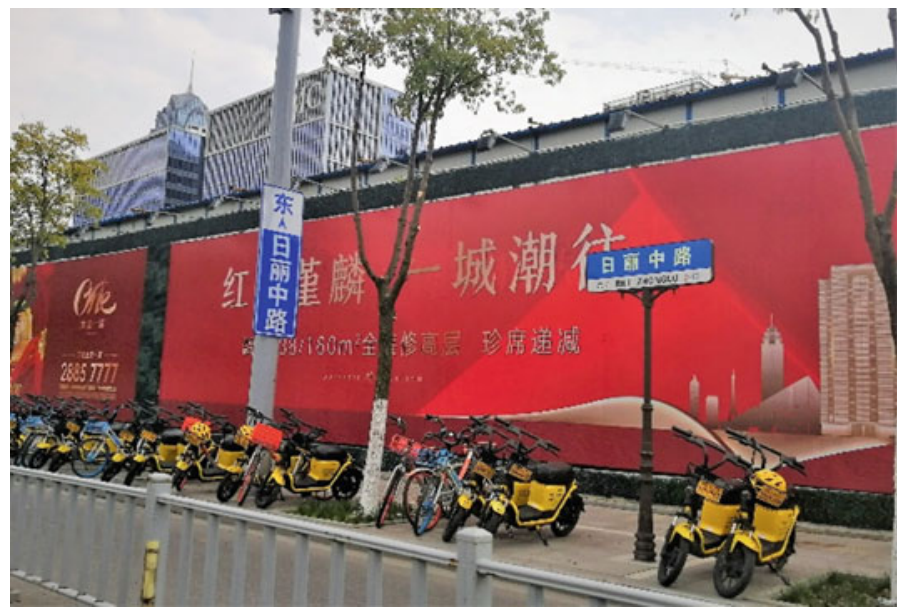

Fig. 5.36 Ningbo faced a decline in the use of shared facilities. In fact, shared bikes and similar shared facilities may have less control or even add burden to disinfection teams. Hence, it is suggested to temporarily close or limit their operations in order to have a better monitory in place. Source Ali Cheshmehzangi 


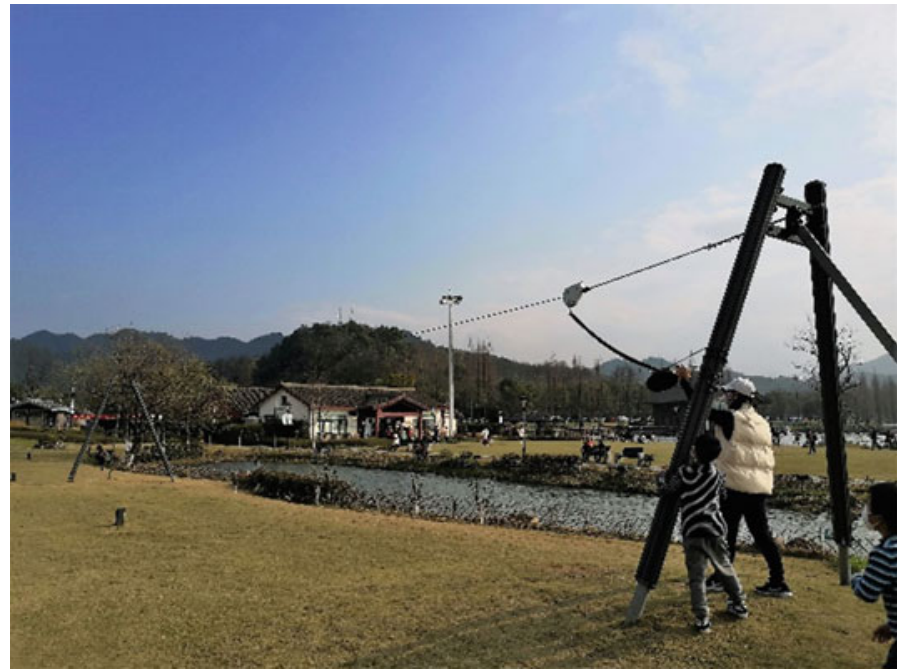

Fig. 5.37 Temporary closure of playground facilities is essential and they should be regularly disinfected alongside with all public facilities. Source Ali Cheshmehzangi

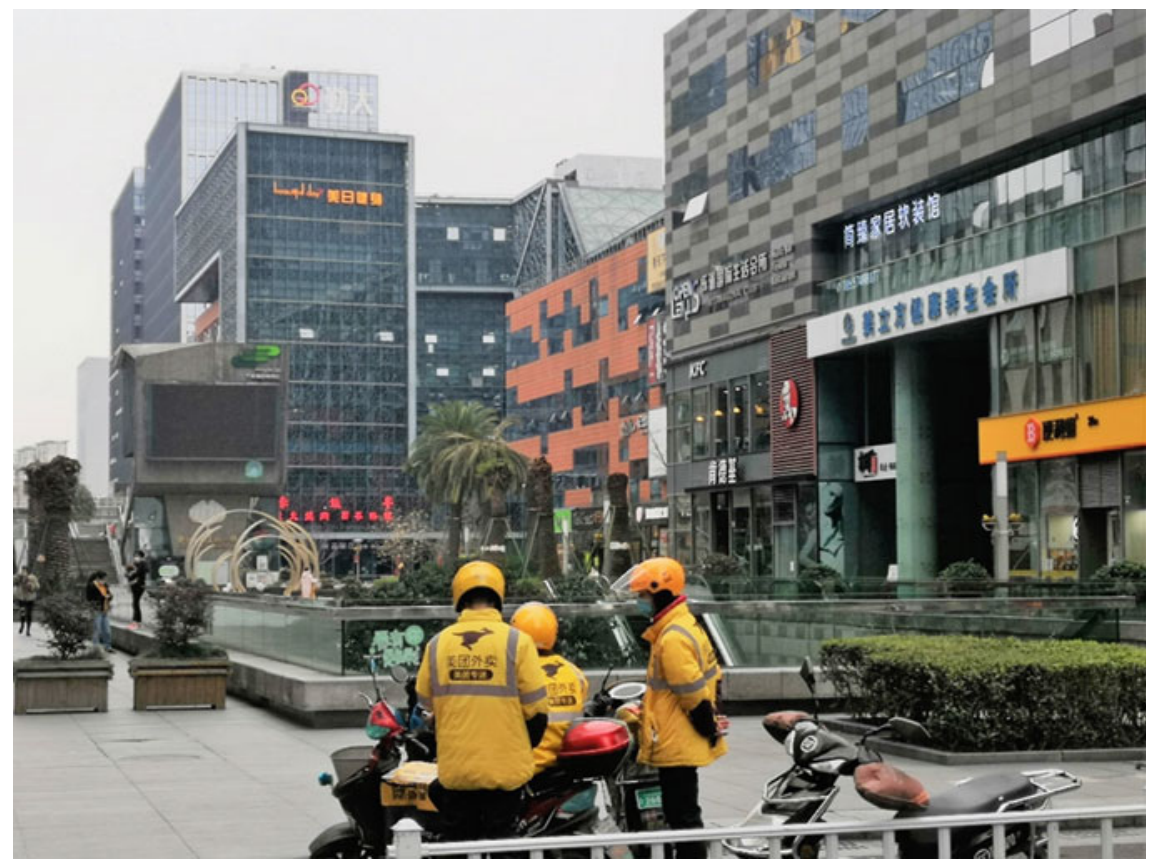

Fig. 5.38 A group of delivery workers stay in a designated zone nearby clustered retail and restaurant areas. Source Ali Cheshmehzangi 


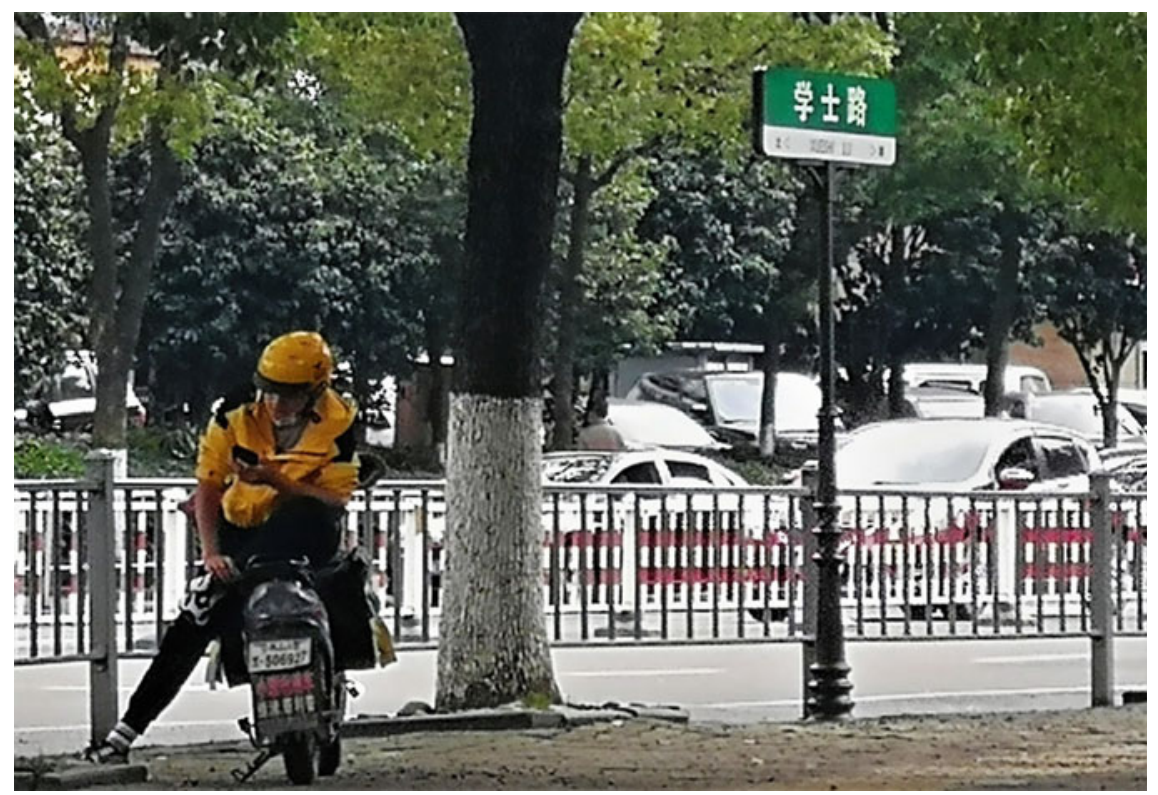

Fig. 5.39 High level of safety measures are essential for delivery workers as they may be in contact with more people during the day. In here, a delivery person is waiting for his next delivery job adjacent to a secondary retail area. Source Ali Cheshmehzangi

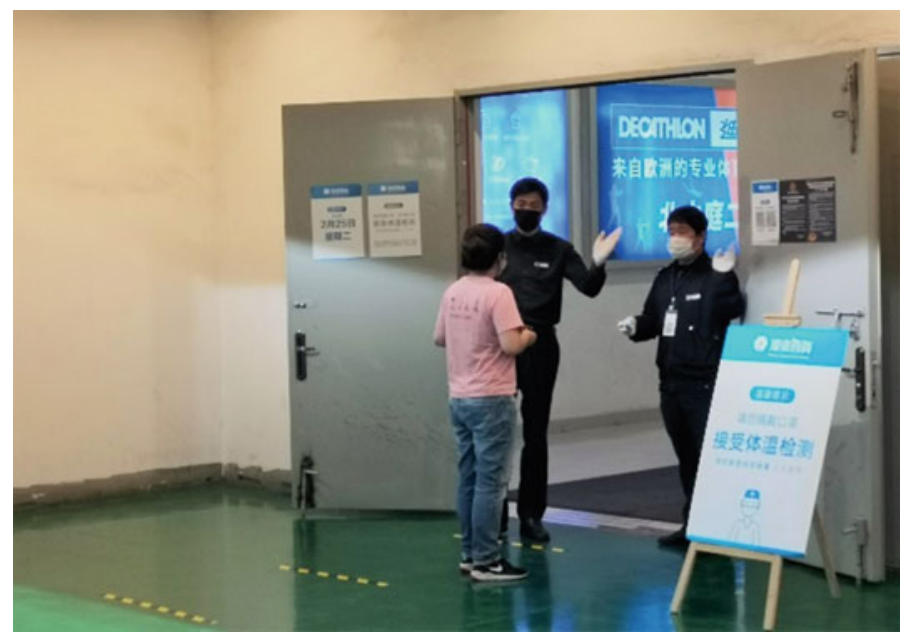

Fig. 5.40 The use of 'Ningbo Health Code' becomes compulsory and it takes $24 \mathrm{~h}$ to get confirmation after registration. In this instance, the entry to shopping center/mall was not granted and the security members are instructing the person with required procedures. Source Ali Cheshmehzangi 


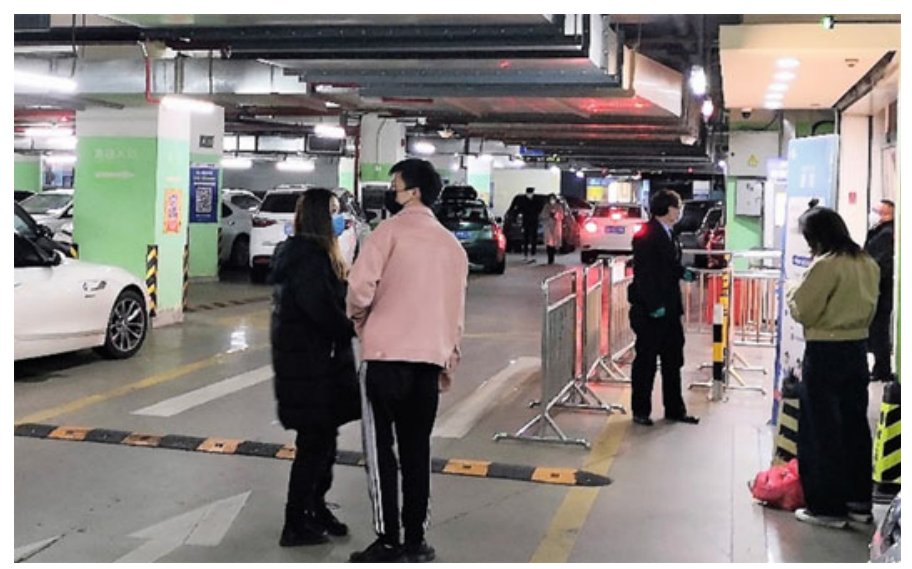

Fig. 5.41 Designated entry zone with multiple checks (health code and temperature) in underground parking of a shopping center/mall. Source Ali Cheshmehzangi

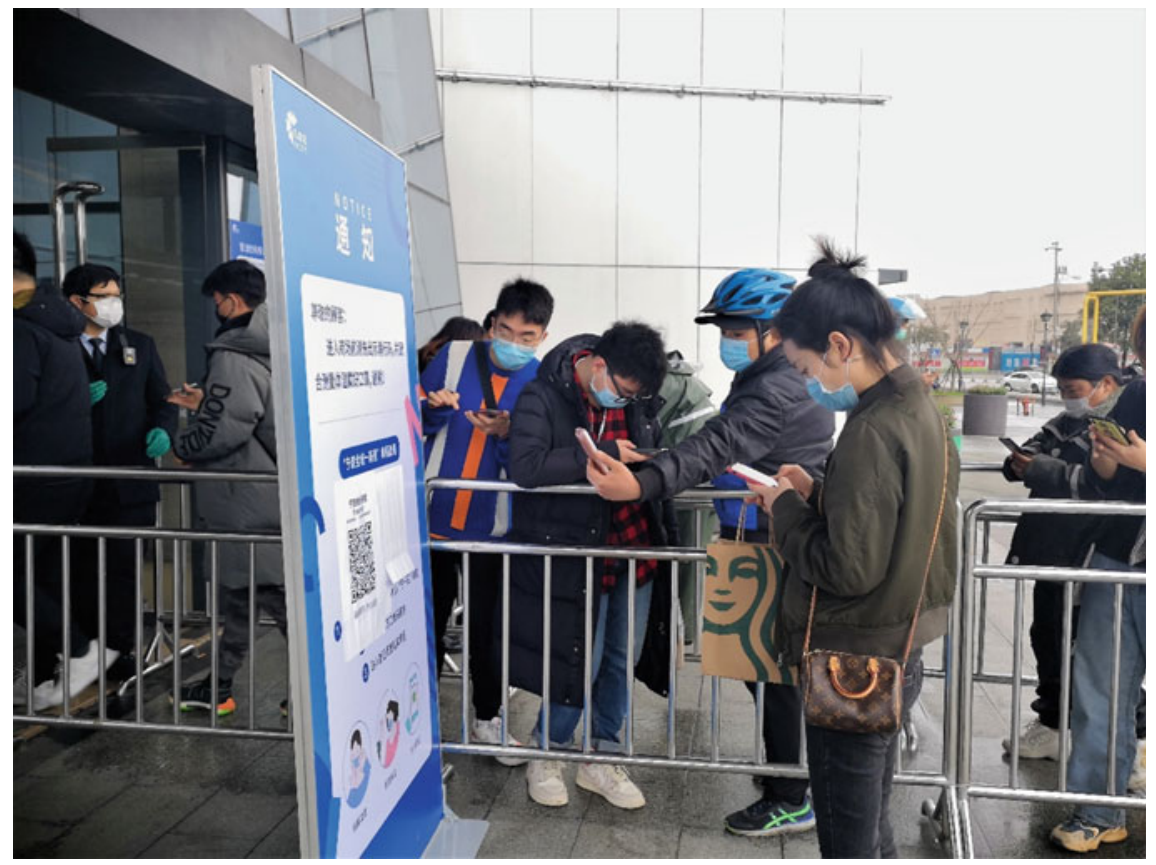

Fig. 5.42 A board providing instruction for 'Ningbo Health Code' at the entry of a shopping center/mall towards the end of transition phase. Source Ali Cheshmehzangi 


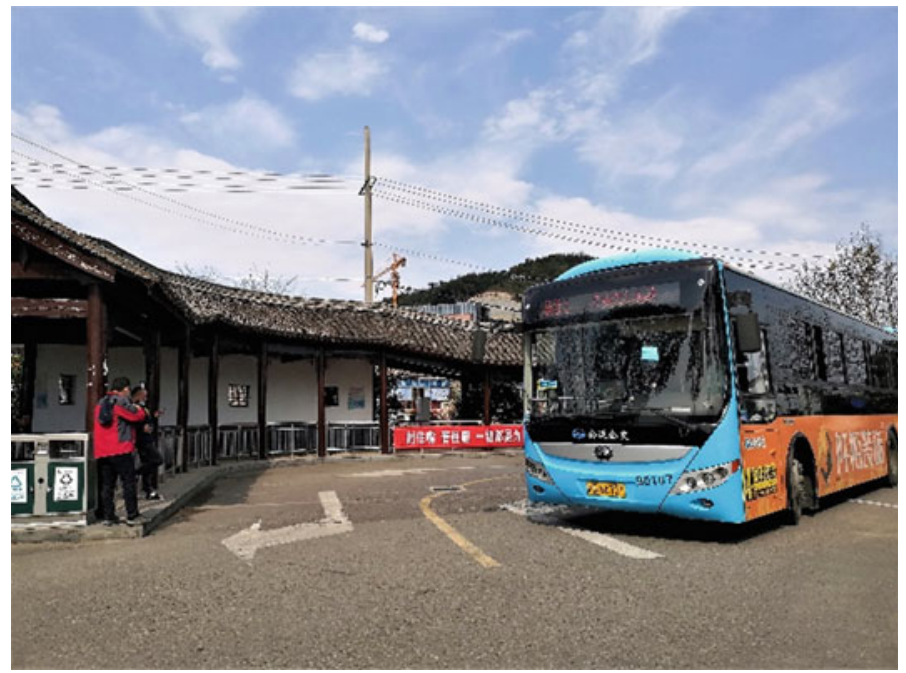

Fig. 5.43 After a temporary half in operations, bust services became less frequent and often without any passengers. But they remained in operations for inter-city connection and reaching the rural/outer districts of the city. Source Ali Cheshmehzangi

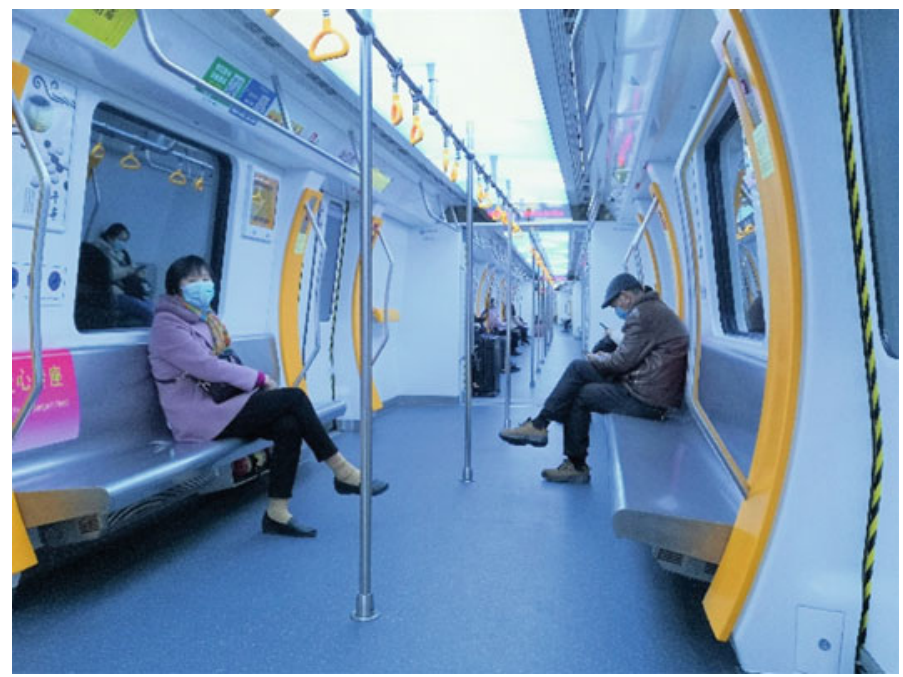

Fig. 5.44 Metro/underground operations were back to normal after several weeks and people had to keep their distance inside the cabins. Source Ali Cheshmehzangi 


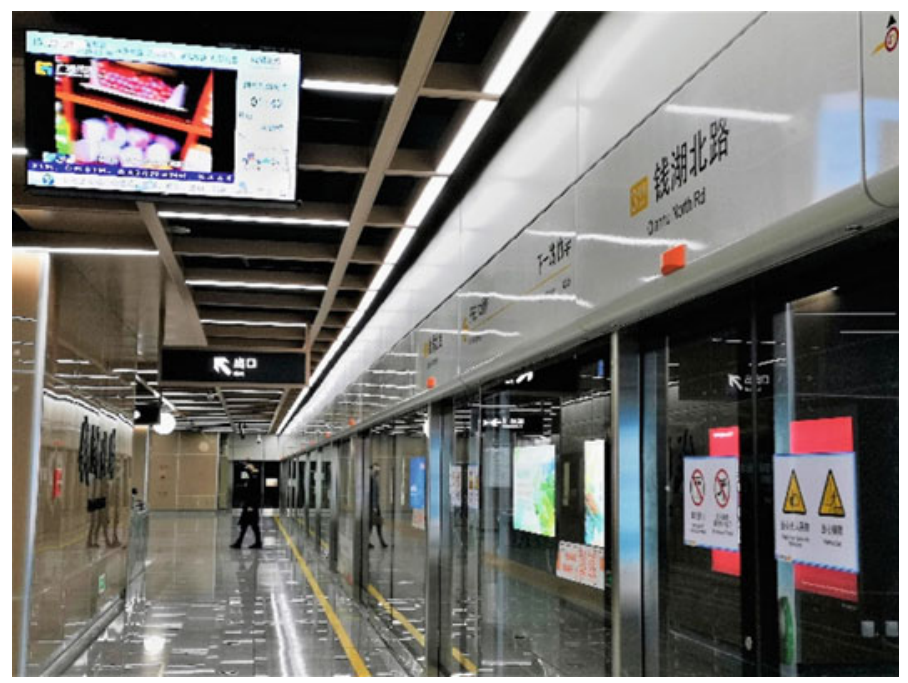

Fig. 5.45 High level presence of security and monitory checks are added value to maintain safety of the public services. Source Ali Cheshmehzangi

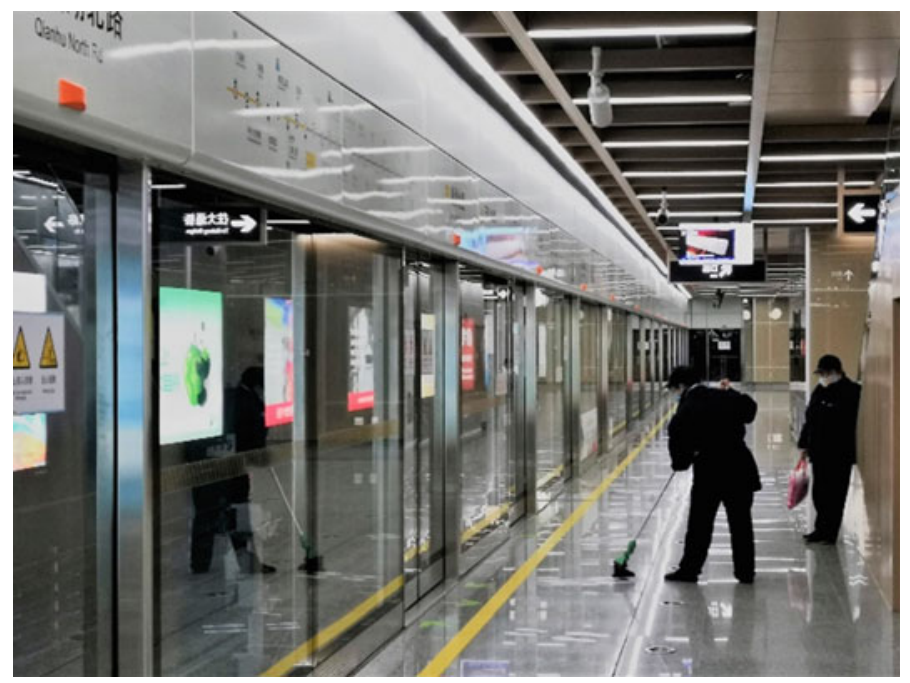

Fig. 5.46 Regular cleaning and disinfection procedures play a big part in maintaining hygiene and safety of high risk transportation hubs. Source Ali Cheshmehzangi 


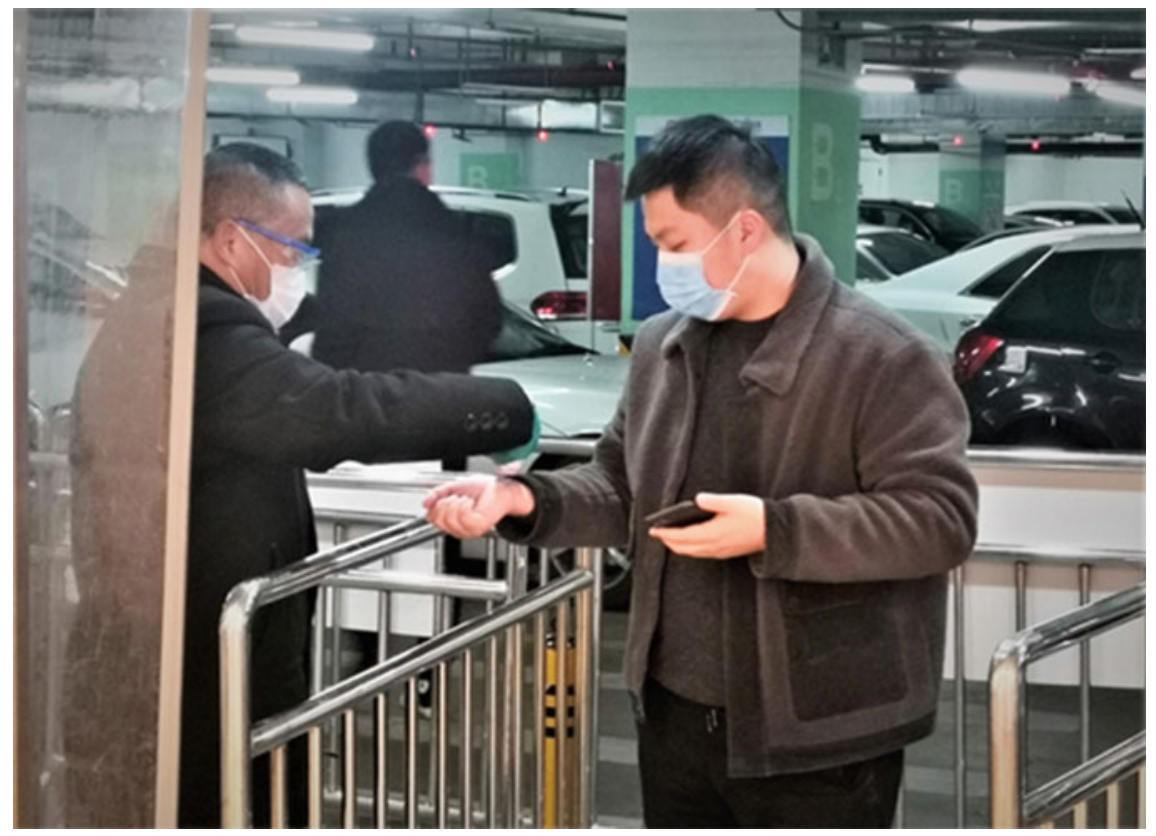

Fig. 5.47 Temperature check alongside the confirmation of 'Ningbo Health Code' are compulsory for all people entering public buildings. Source Ali Cheshmehzangi

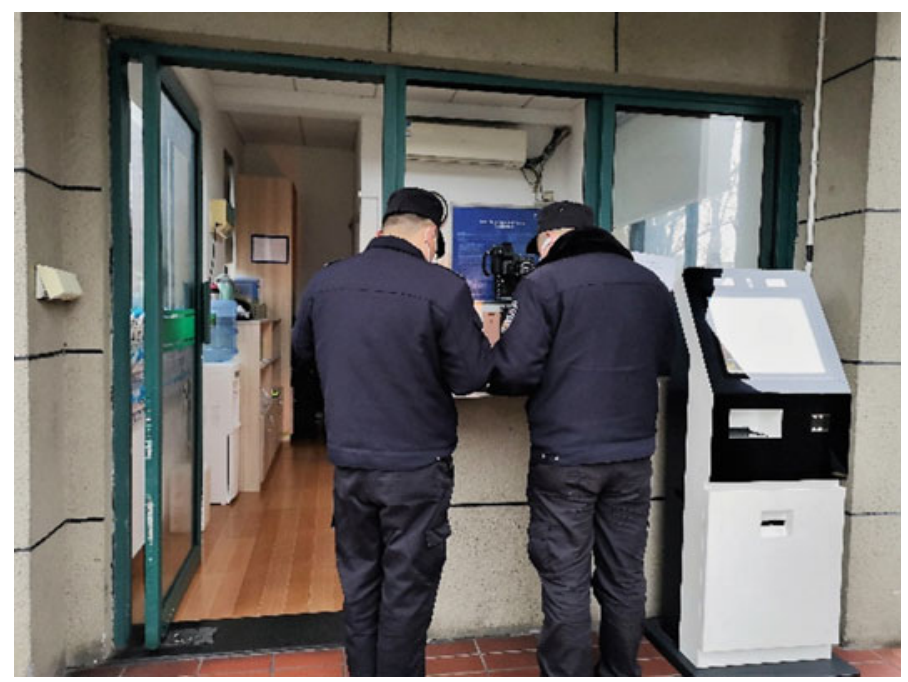

Fig. 5.48 The university campus imposed high level checks, and only allow entries for internal members who reside on campus and those internal and external members whom hold their daily permits with pre-approval at three managerial levels. Source Ali Cheshmehzangi 


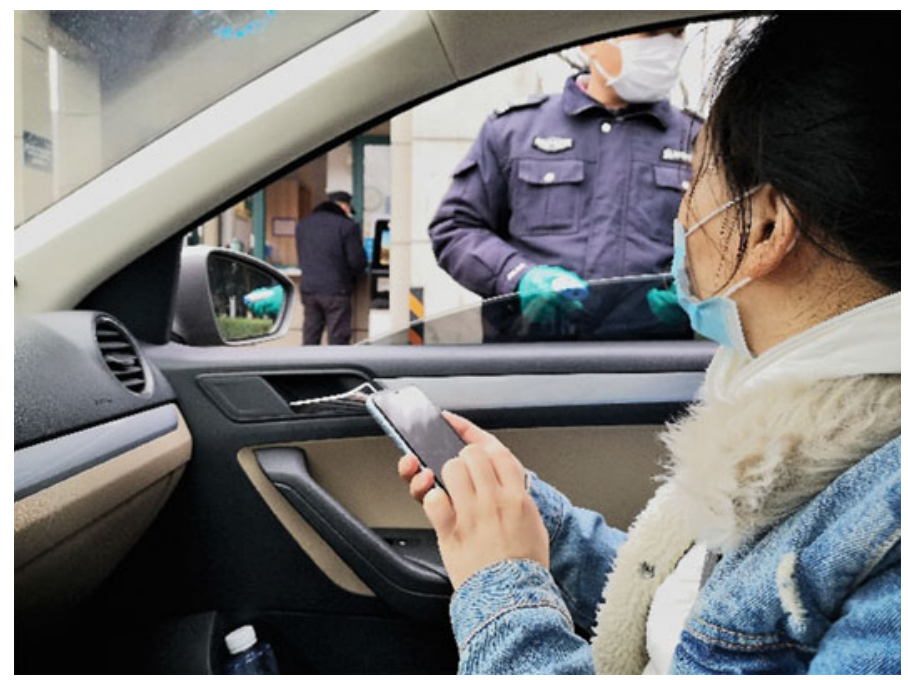

Fig. 5.49 The equipped security members check records (with relevant paper works) and measures temperature before allowing anyone to their premises. Source Ali Cheshmehzangi

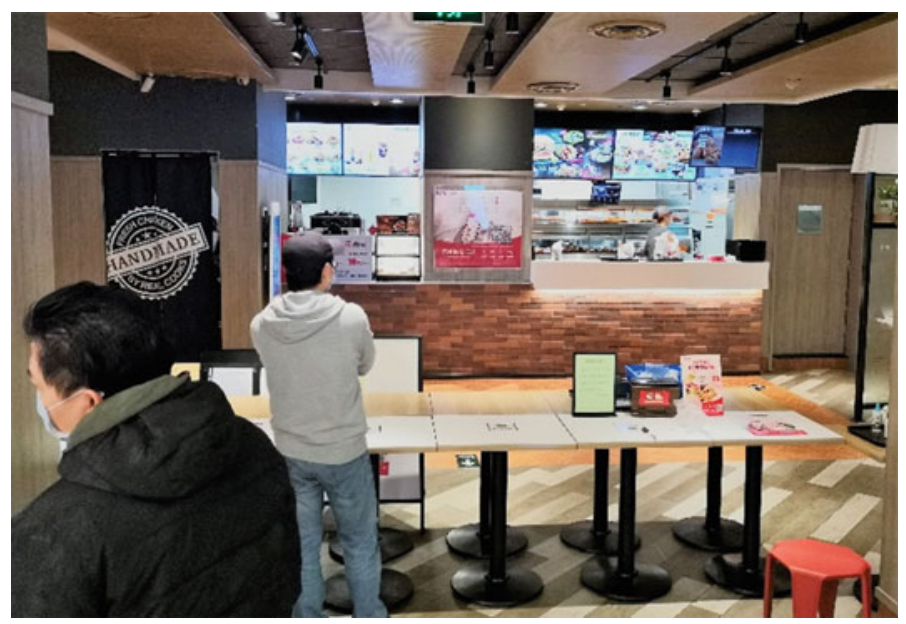

Fig. 5.50 Fast food services only operate for delivery and pick-up purchases and temporary closed their entrances to public. Source Ali Cheshmehzangi 


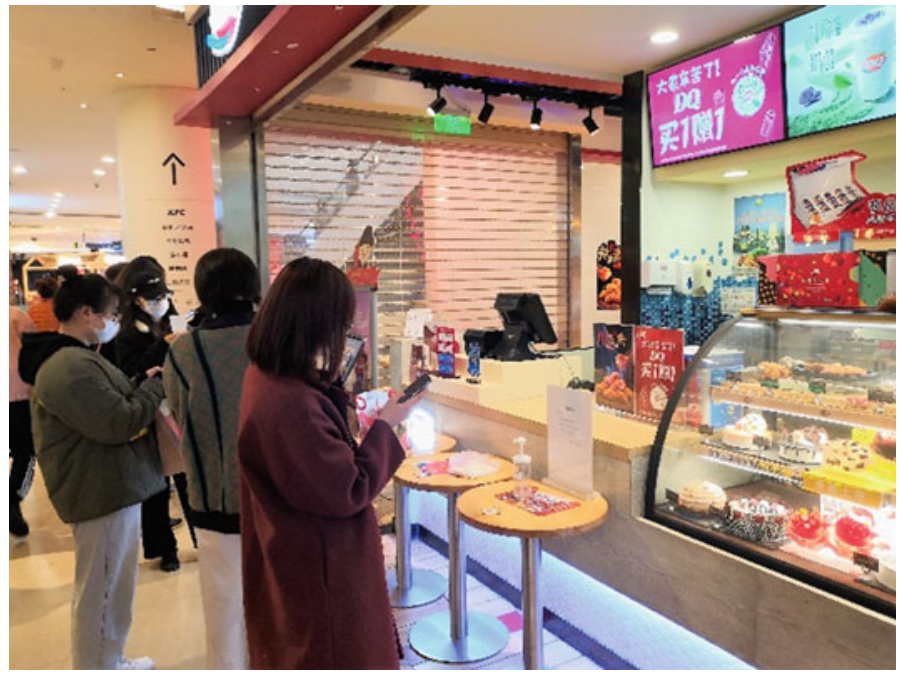

Fig. 5.51 Other retail services/amenities started limited operations after 3-4 weeks of no operations, and only operated with contactless services. Source Ali Cheshmehzangi

Fig. 5.52 Customerworkplace interactions were minimised through various ways, and online platforms were flooded with purchases and delivery requests. The retail units allocate designated space for either pick-up or delivery of their goods/products/food. Source Ali Cheshmehzangi

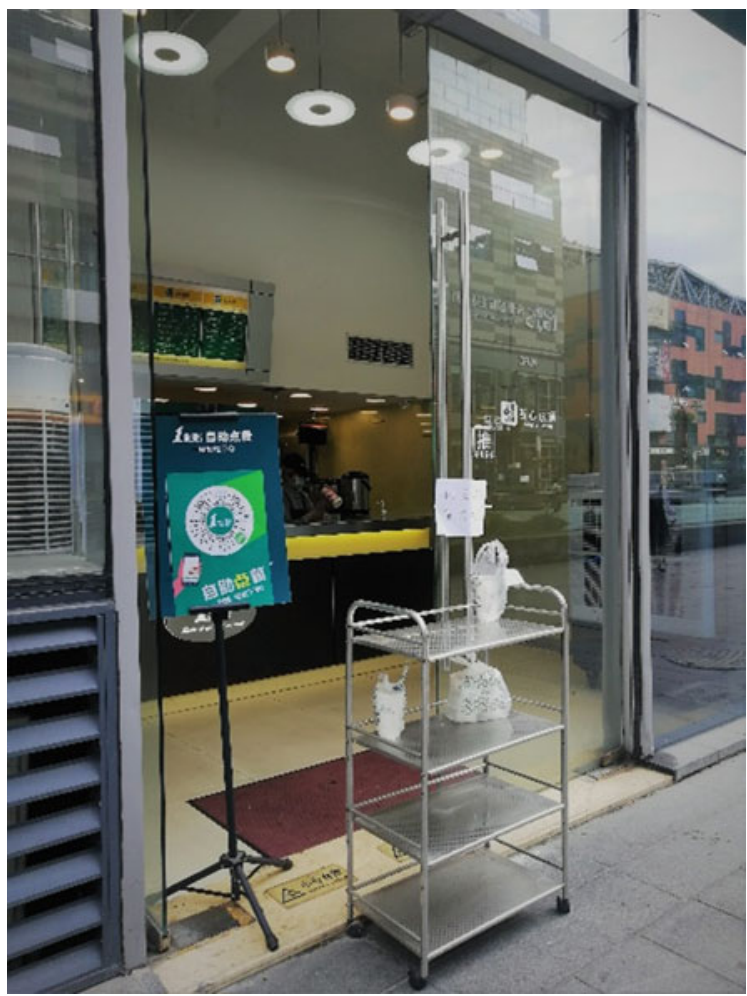




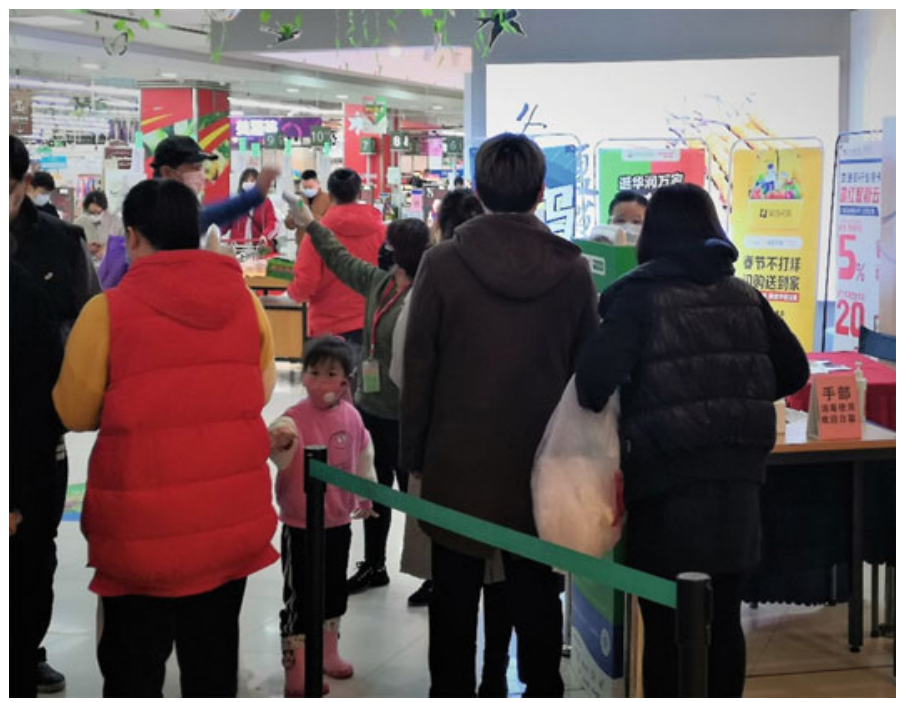

Fig. 5.53 Double checks imposed for populated supermarkets, to maintain safety and to avoid becoming hotspots for the community transmissions. Source Ali Cheshmehzangi

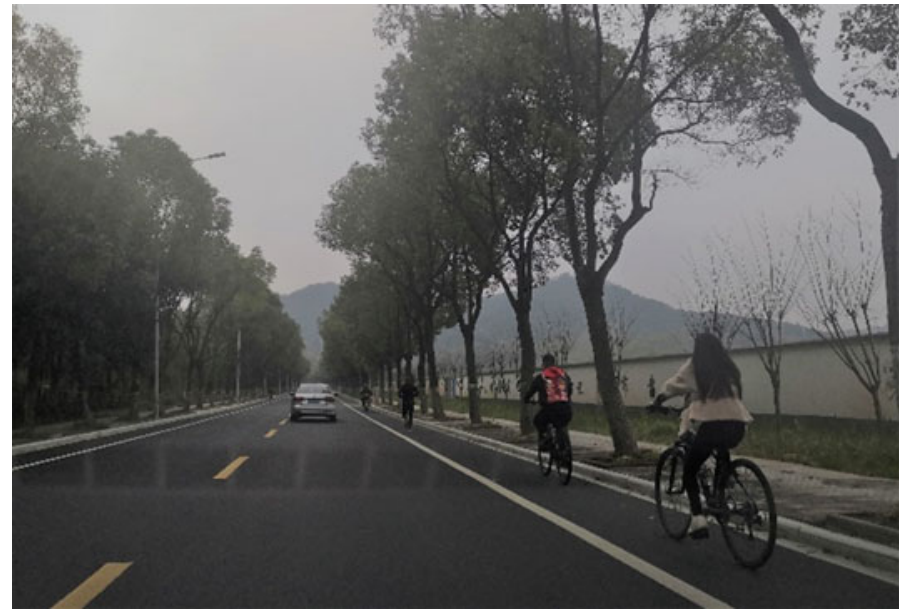

Fig. 5.54 People should keep their individual healthy activities such as jogging and cycling in unpopulated areas, while indoor fitness activities are also very effective. Source Ali Cheshmehzangi 


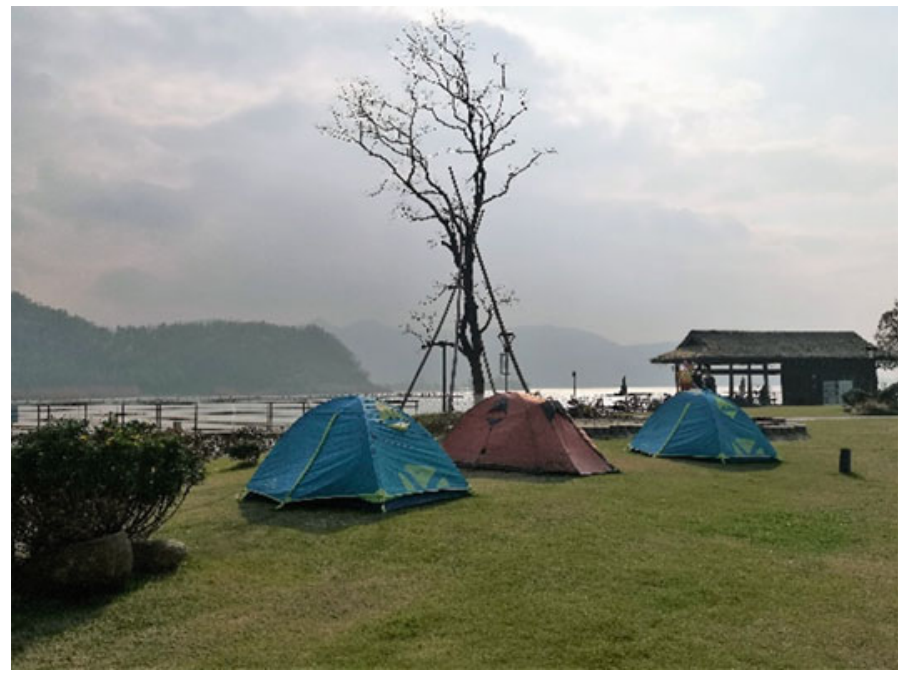

Fig. 5.55 Limited camping is an easy way to spend hours with new activities which should be arranged in dispersed layout. In this instance, high safety and monitory checks were reinforced during the recovery phase. Source Ali Cheshmehzangi

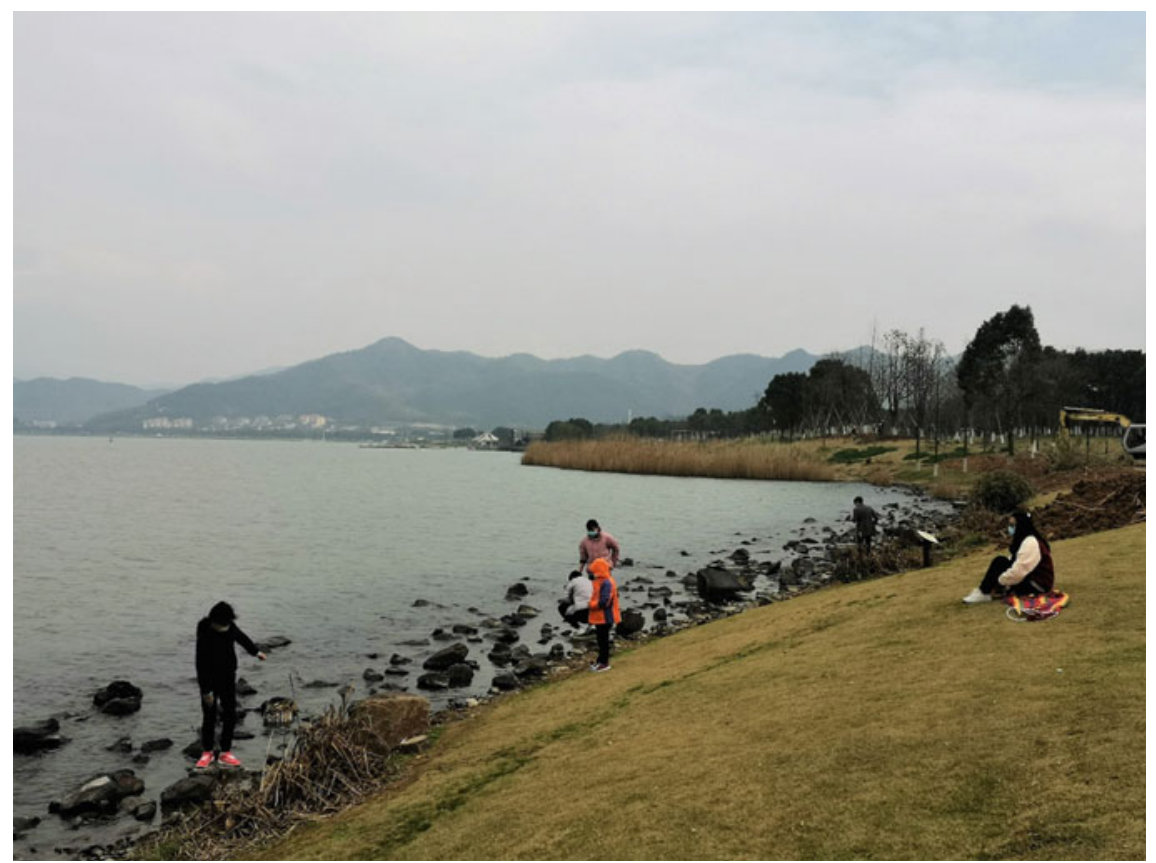

Fig. 5.56 Gradual and dispersed family picnic activities can maintain the health and happiness of children in particular. This is recorded towards the end of the recovery phase. Source Ali Cheshmehzangi 


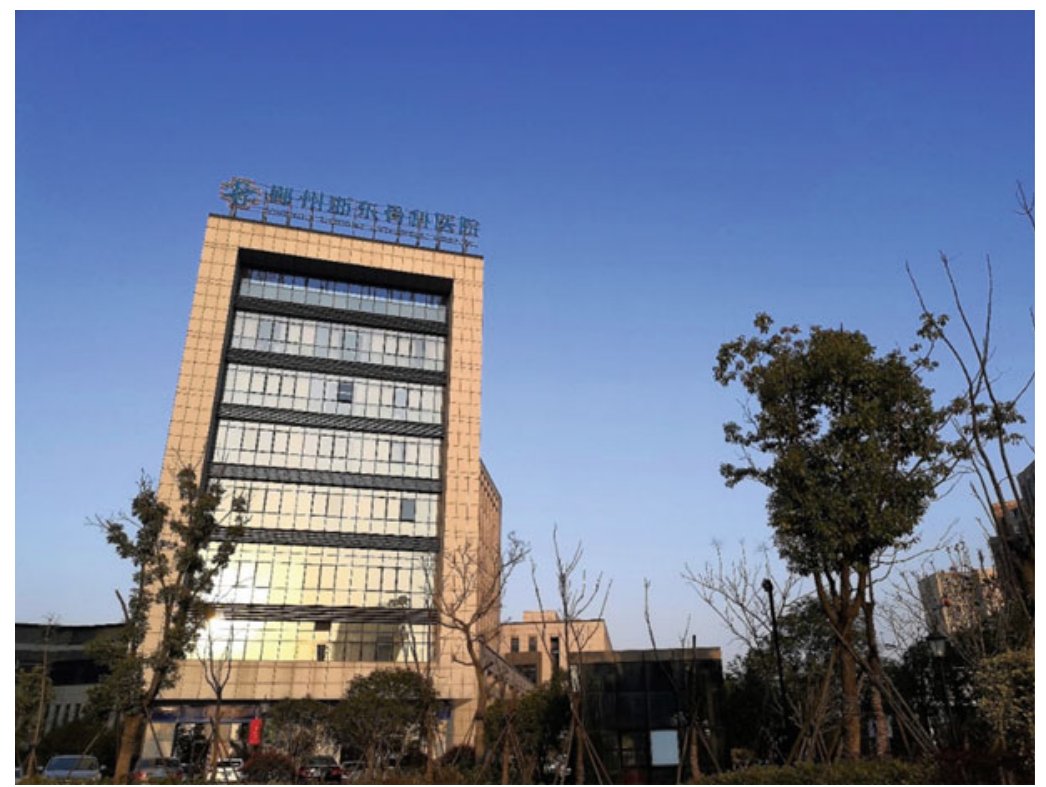

Fig. 5.57 A major benefit of specialised hospitals is decentralisation of health system operations, which could provide safe services to special and non-infectious issues. This is an example of Orthopaedic Hospital in Ningbo. Source Ali Cheshmehzangi

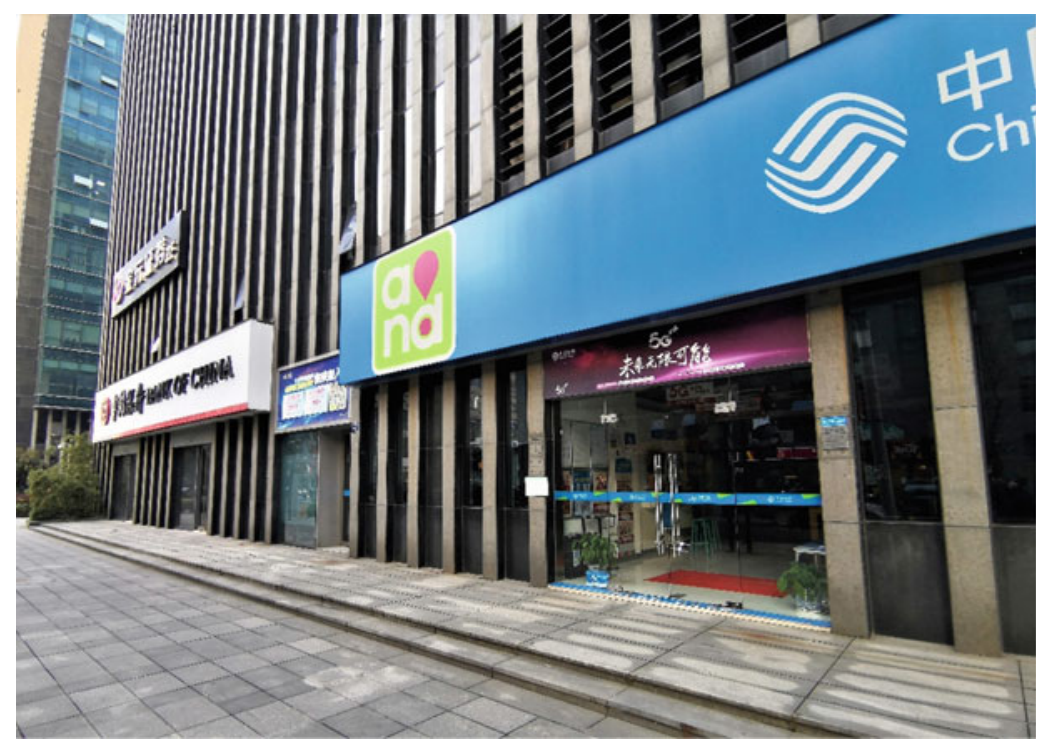

Fig. 5.58 Throughout the outbreak response plan, the operation of secondary amenities were either forbidden or limited. Source Ali Cheshmehzangi 


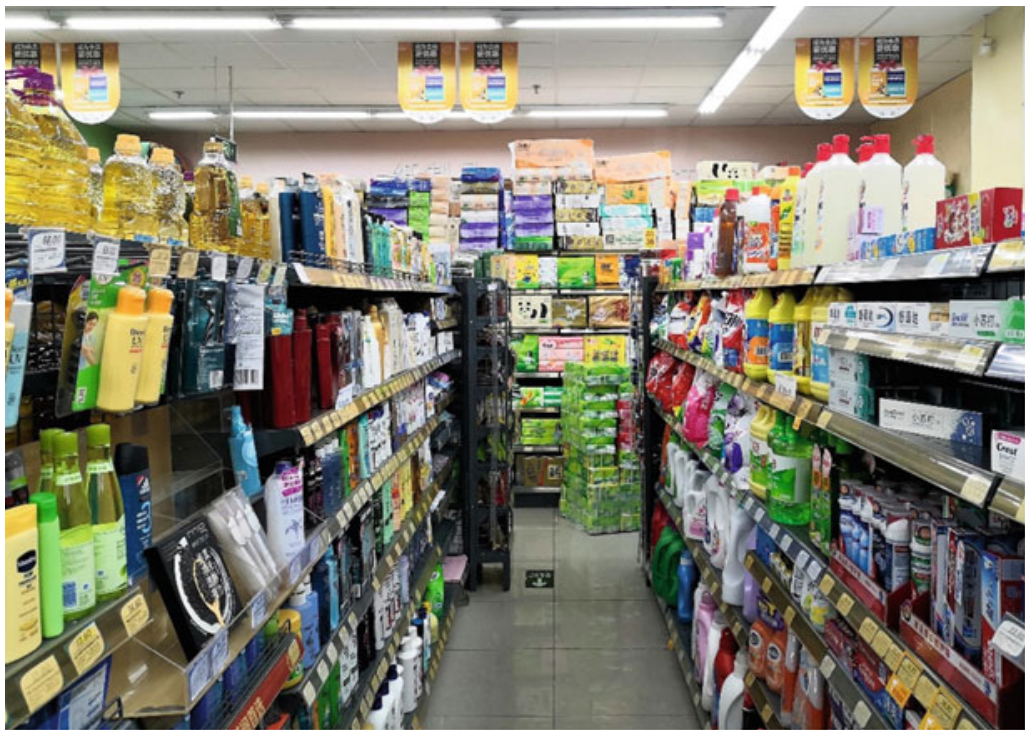

Fig. 5.59 Provision of primary products in local supermarkets. People should sustain a greater sense of social responsibility and avoid panic buying. People should remain considerate to their communities, while the provision of essential/primary products should be maintained throughout the outbreak progression. In Ningbo, some shortages of primary products were experienced for one to two weeks during the transmission phase. Source Ali Cheshmehzangi

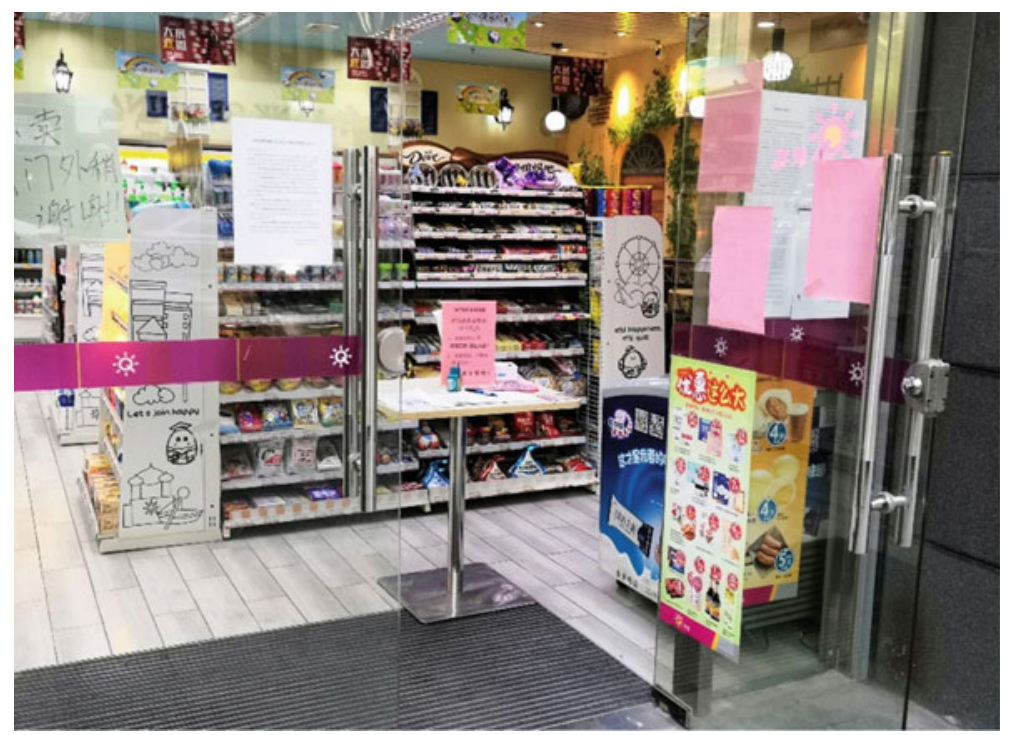

Fig. 5.60 In the recovery phase, the city's primary operations were under the influence of rapidly intensifying global situations. Local supermarkets continued with high level of safety measures, as well as control and monitory of customers. This was essential to avoid reversing the containment at the city level. Source Ali Cheshmehzangi 


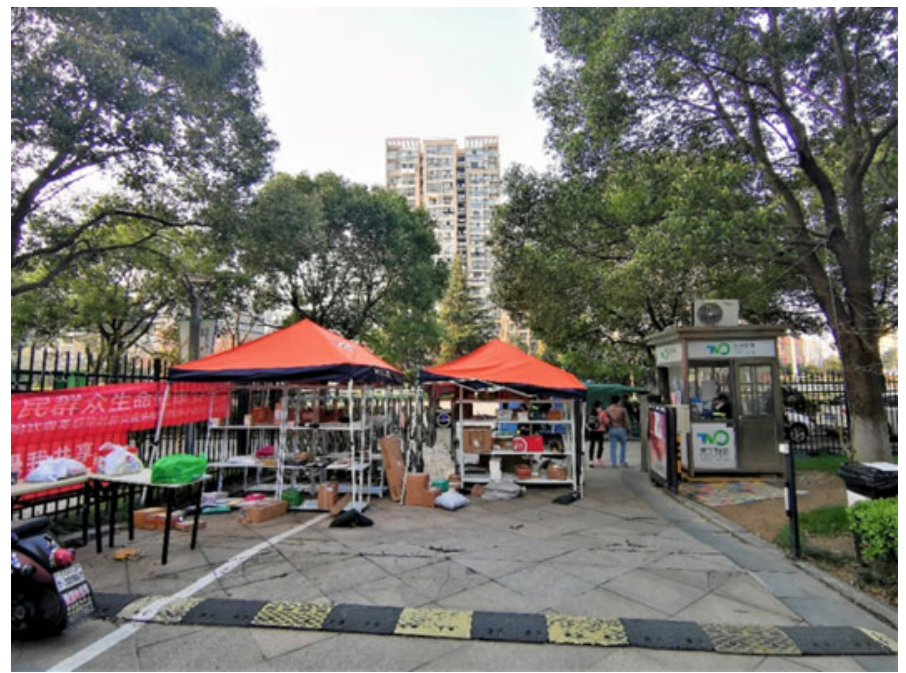

Fig. 5.61 In the recovery phase, residential compounds preserved their security checks. In here, we see multiple aspects, from left to right: red banners for general guidelines, temporary tables for food collection, temporary goods collection point at micro-level, security checks (inclusive of temperature check), one secured access point to the compound, and rubbish bin next to the entrance for the disposal of any masks, gloves, etc. Source Ali Cheshmehzangi

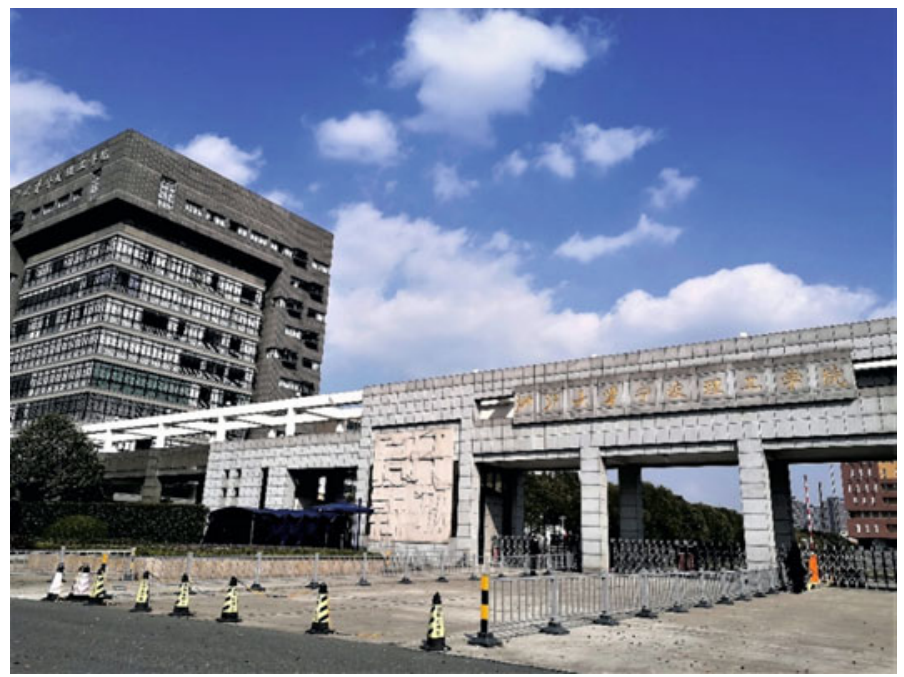

Fig. 5.62 The gradual opening of larger scale institutes or businesses under full control and monitory were amongst the later signs of recovery phase. The actual date of reopening was postponed to a much later date. The reopening was subject to much-enhanced health checks, new prevention and control measures, new installations, and in-advance rehearsal procedures before the approval could be granted at multiple stages. Source Ali Cheshmehzangi 


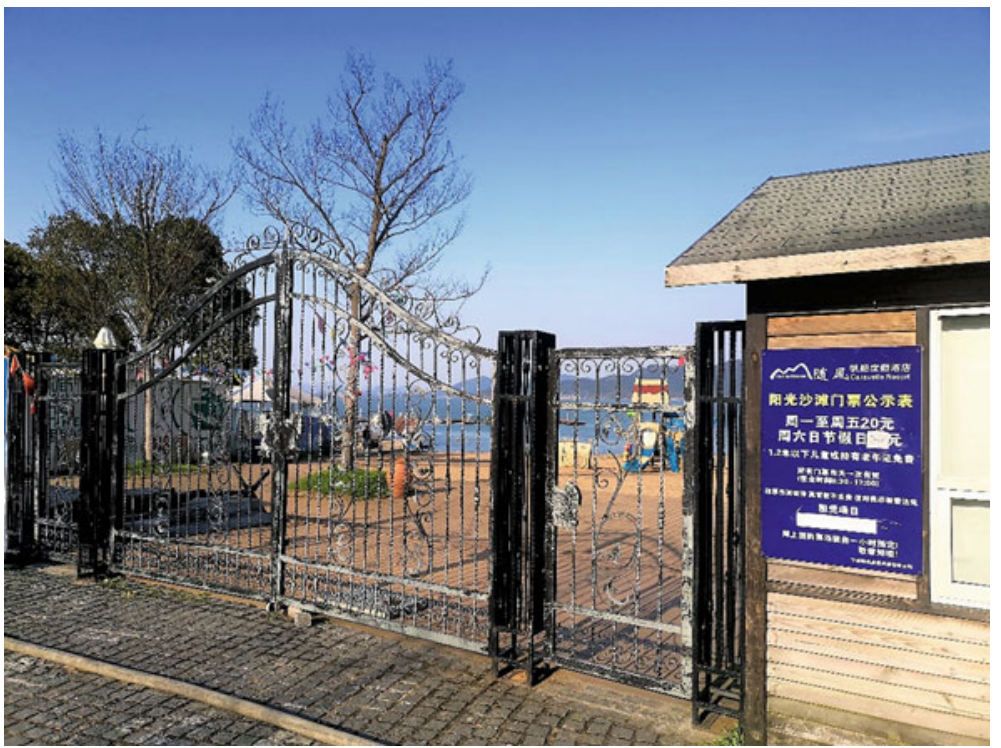

Fig. 5.63 In the recovery phase, closure of unnecessary public places were still in place, allowing for continuous practice of social distancing in populous areas or with high level of multiple functionalities. Source Ali Cheshmehzangi

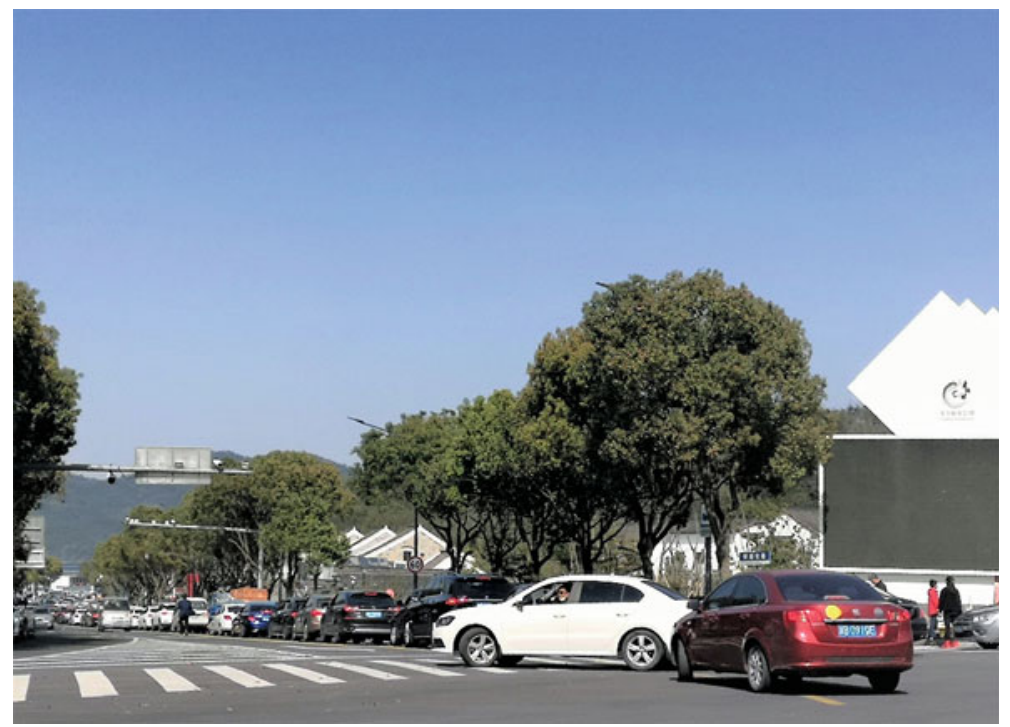

Fig. 5.64 Early days of recovery phase meant return of popular local destinations for social activities, which then created road blockages and heavy traffic. Source Ali Cheshmehzangi 


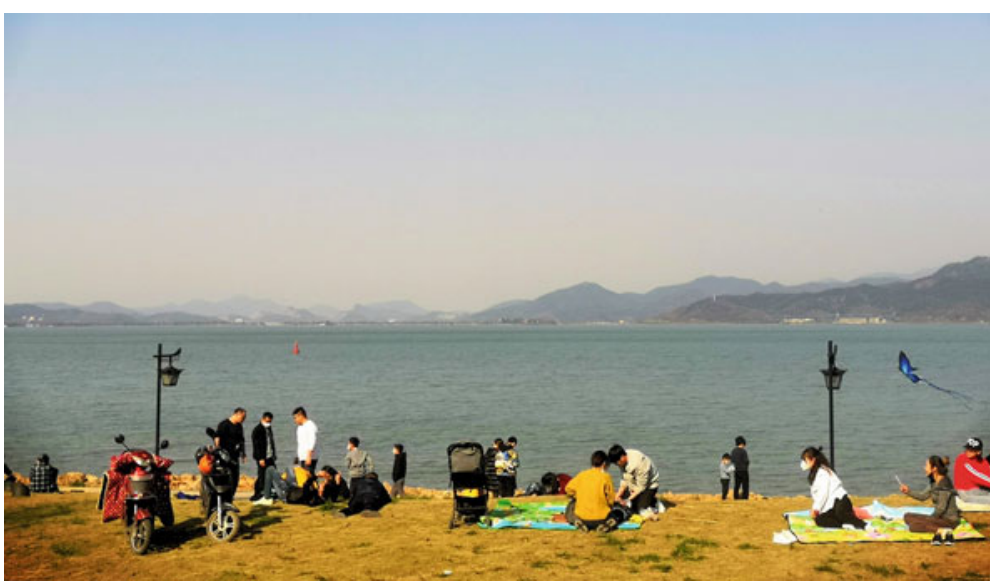

Fig. 5.65 Amid all monitory measures, large gathering was still disallowed and leisure activities were monitored by safety and security workforces. Source Ali Cheshmehzangi
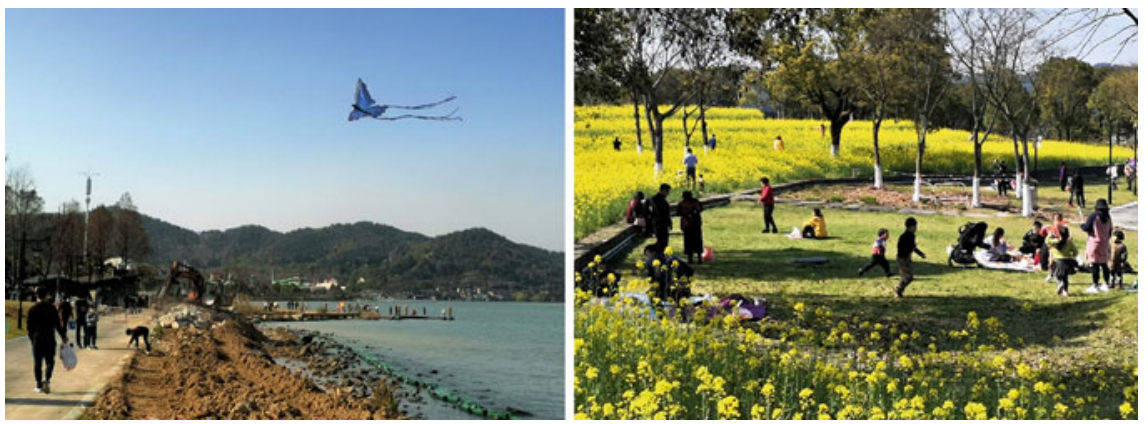

Fig. 5.66 A new beginning for a city and its resident coming out of lockdown and reaching outbreak containment meant continuous caution, reviving the social life, and signs of positive progress. It became viral to say 'life goes on', which were meant to help the overall mental stability despite all adversities and disruptions. It was clear that many people were affected and more people became vulnerable during the outbreak. But under the shadow of the global emergency, people sensed a sign of hope to enjoy the outdoors more than any other time. With kites flying in blue skies, it simply felt like freedom. Source Ali Cheshmehzangi 

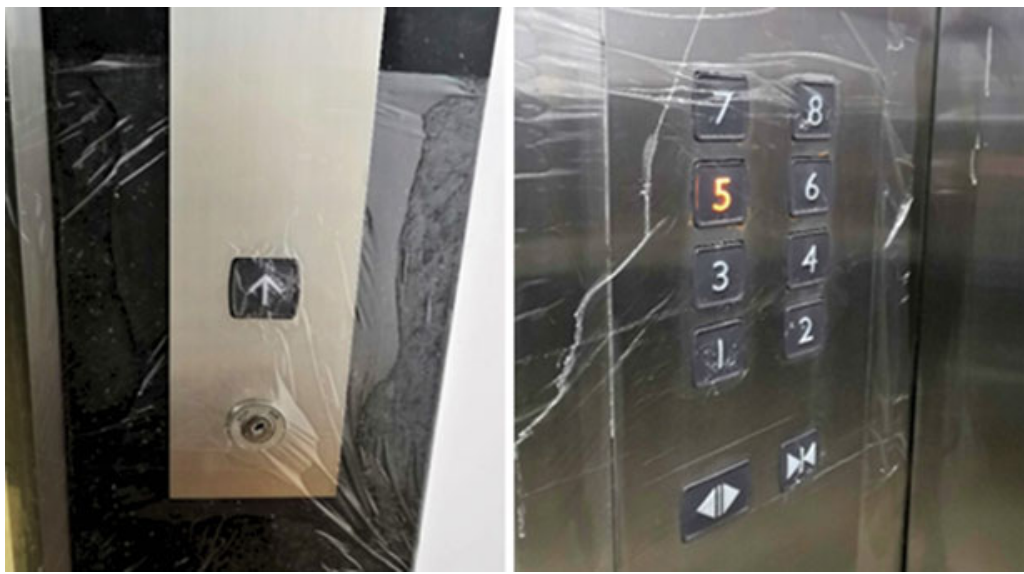

Fig. 5.67 While considering protection measures, it is more than just the generalities but also details of certain aspects that require further attention. For instance, here we see examples of adhesive plastic wrap covering the area where we touch the most on a regular basis. They are disinfected regularly and are replaceable easily. Doing this is a simple measure but also effective not to damage the buttons due to regular disinfection procedures. Source Ali Cheshmehzangi

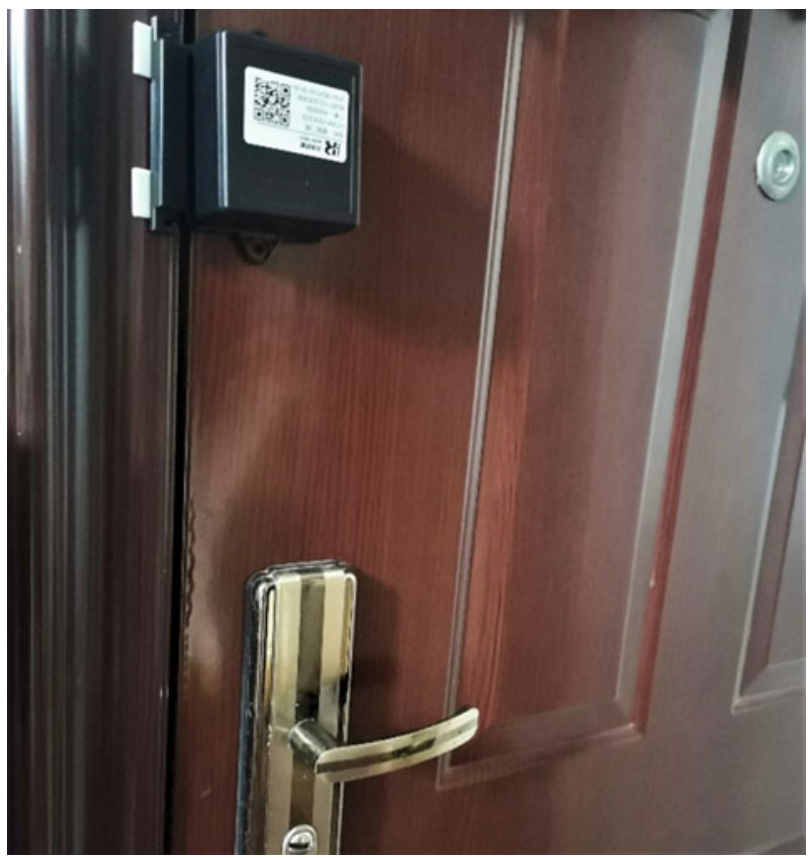

Fig. 5.68 Temporary electronic lock is placed on the residences' doors of people returning to China in the recovery phase. Source Ali Cheshmehzangi 


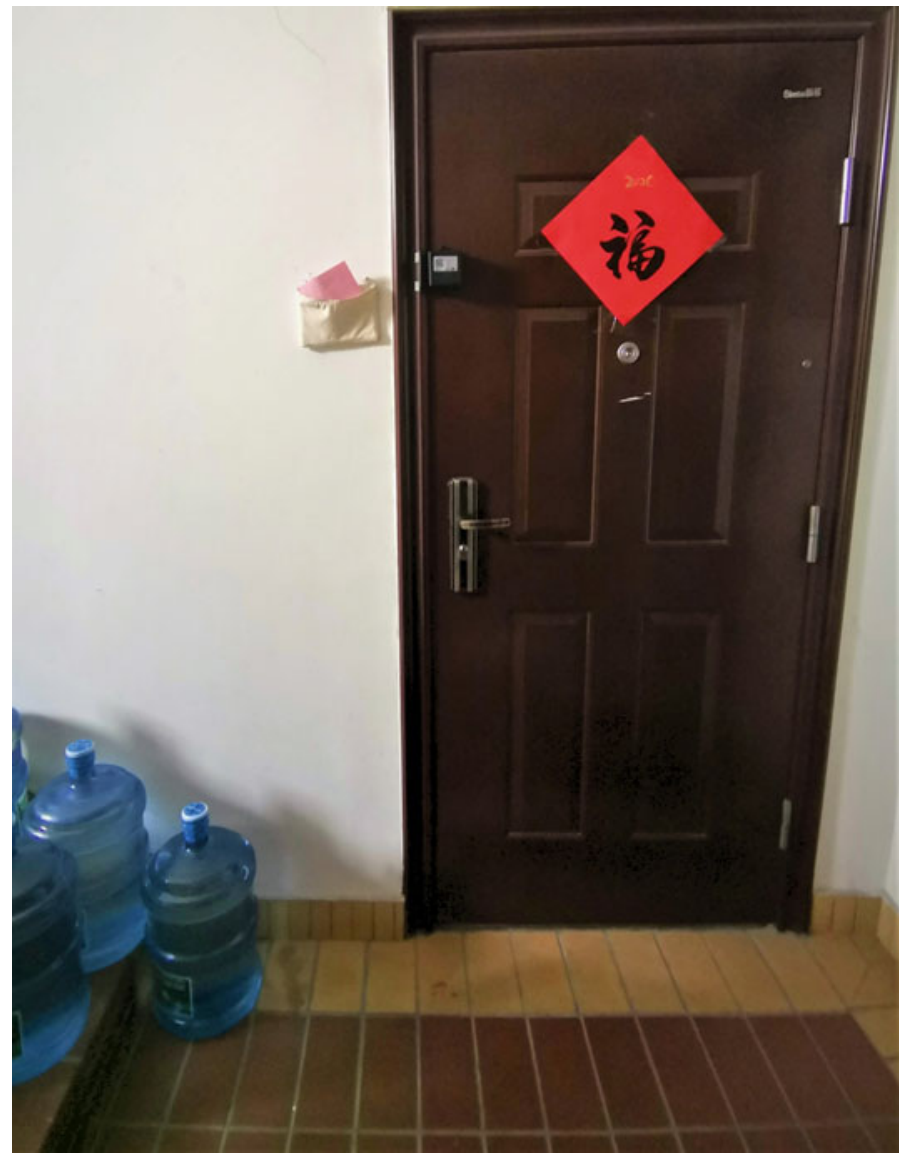

Fig. 5.69 The officials put a temporary electronic lock on the doors of those in quarantine in their homes. The officials or allocated personnel provide and deliver the essentials such as water and food (three time a day). Also, there are three times medical checks per day for the allocated quarantine period during the recovery phase. All these measures highlight three main factors: measures to avoid reversing the outbreak progression, attention to details, and strong institutional arrangement through good governance. Source Ali Cheshmehzangi 


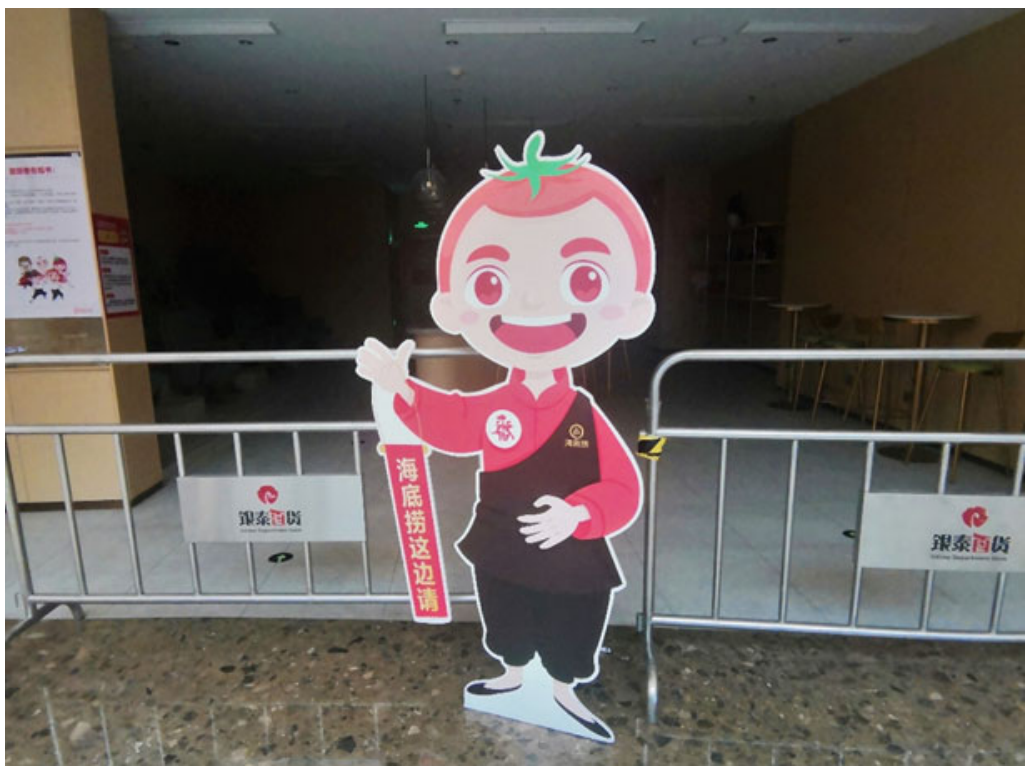

Fig. 5.70 Upon the reopening of secondary amenities, such as restaurants, the waiting areas and procedures to dine inside the restaurants had to change. In some cases, you could only dine inside through pre-booking system with allocated time and place to sit. Source Ali Cheshmehzangi

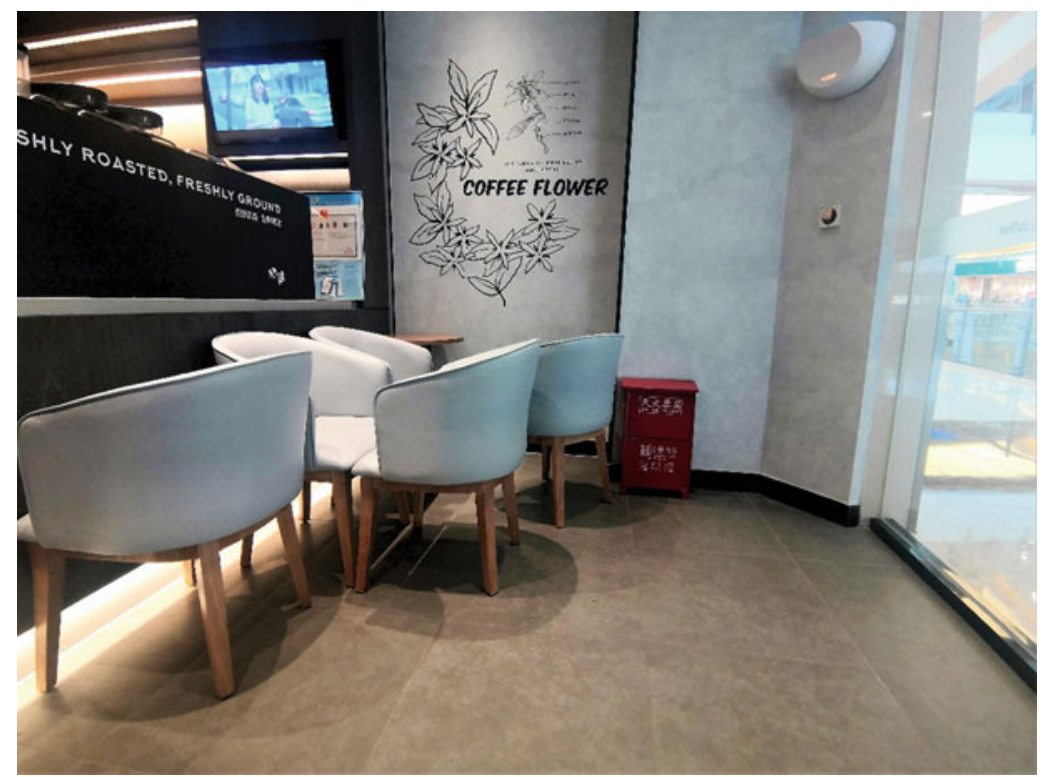

Fig. 5.71 Similar to restaurants, most cafés/tea shops/coffee shops opened in a gradual pace and limited or closed their sitting-in facilities. Source Ali Cheshmehzangi 


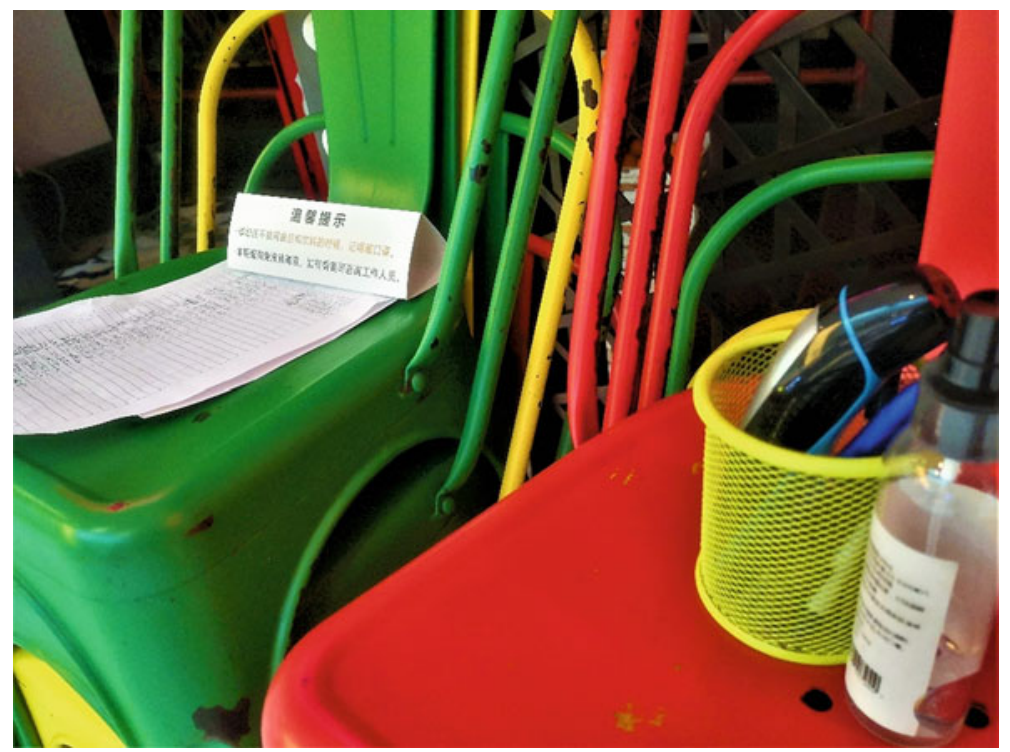

Fig. 5.72 In the recovery phase, some restaurants still delayed the restart of their operations or they were working on limited hours. Those that restarted their operations, closed their waiting areas, had a list to check and record details and temperature of whoever dined inside, and provided disinfection products for all users. Source Ali Cheshmehzangi
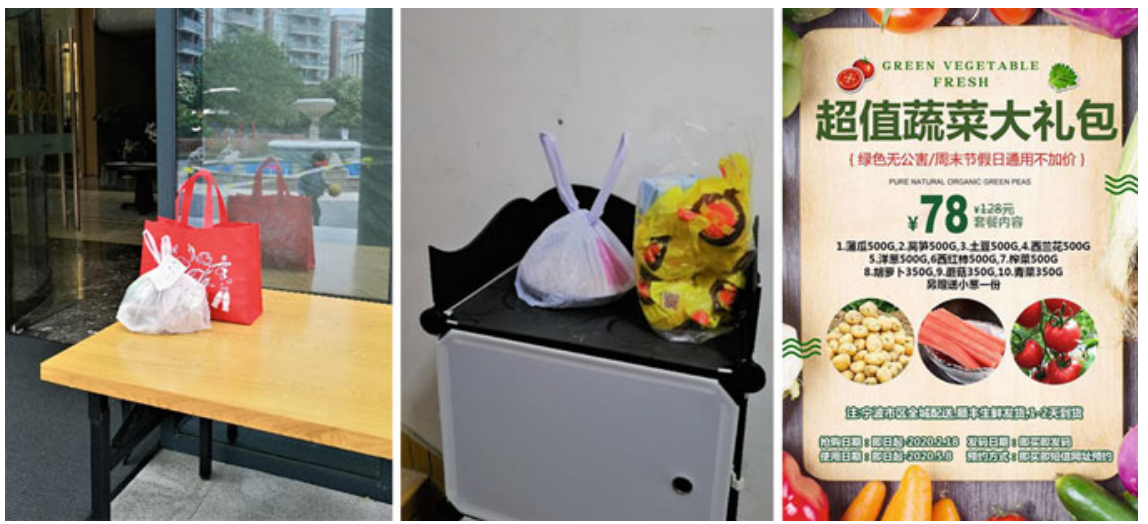

Fig. 5.73 This event was an opportunity to promote contactless food delivery in various modesfrom leaving them in designated areas or at front of gates/properties ( $a$ and $b$ ), to online delivery of packages of essential food supply. Source Ali Cheshmehzangi 


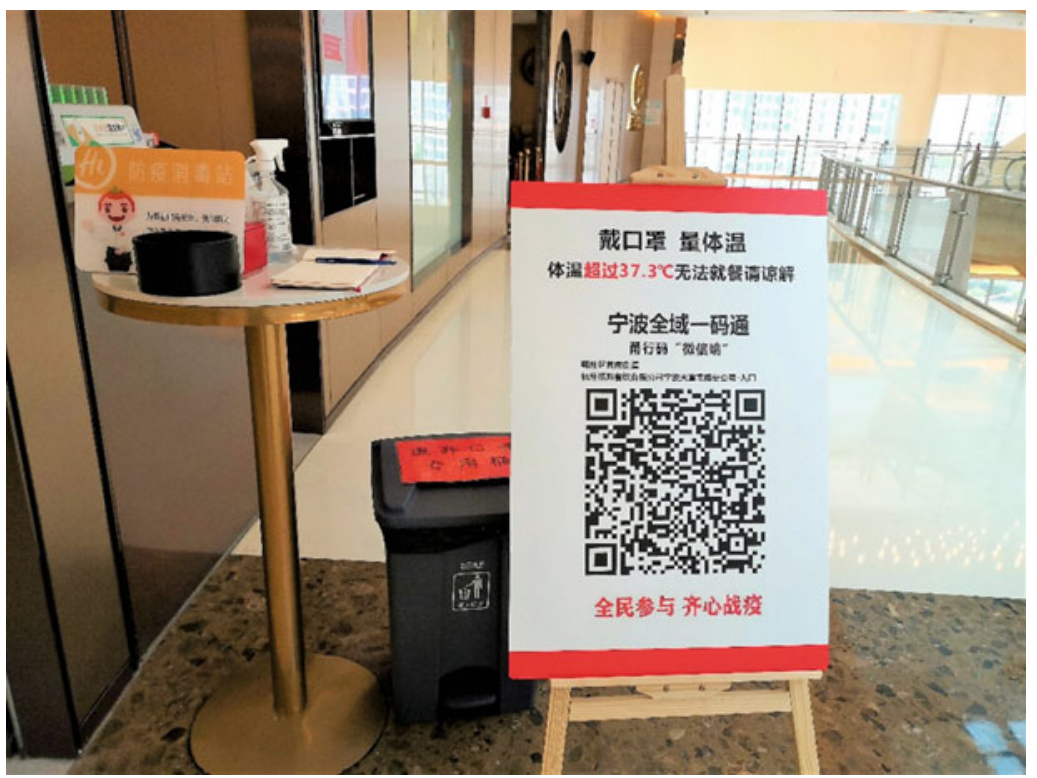

Fig. 5.74 Apart from the approved green health code, permission to enter all public premises was dependant on temperature checks and records. In China, this was set at $37.3^{\circ} \mathrm{C}$, while in some other countries this was slightly higher. Source Ali Cheshmehzangi

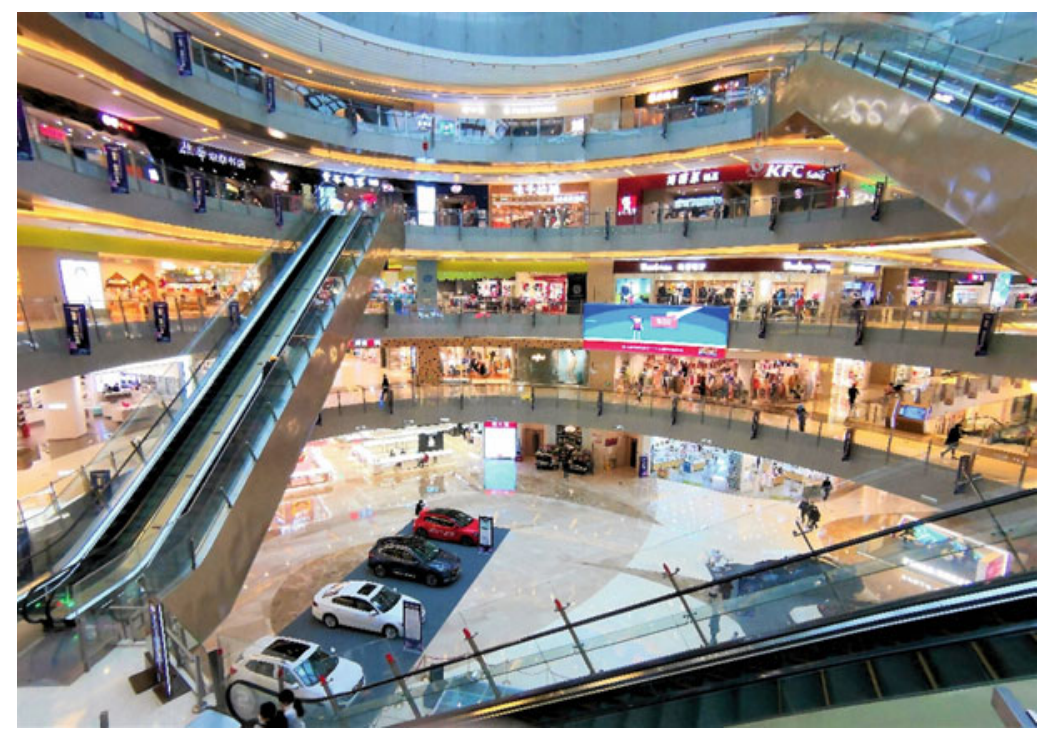

Fig. 5.75 Scenes of empty shopping malls became global. In Ningbo, many places remained depopulated or closed during the recovery phase. Many secondary services/amenities remained closed in light of business losses and lack of customers. Source Ali Cheshmehzangi 


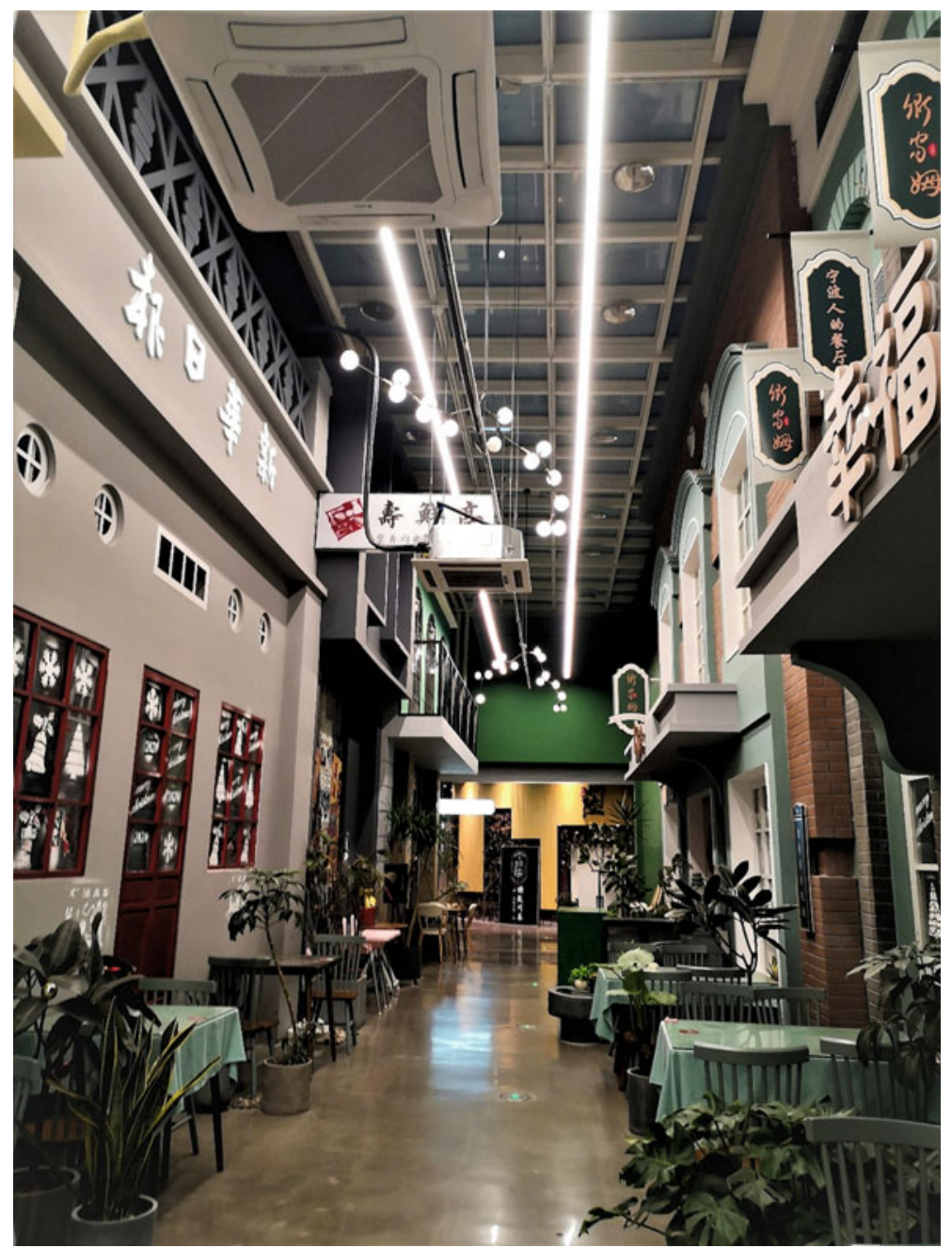

Fig. 5.76 All centrally-controlled air conditioning systems remained non-operational throughout the outbreak. The unpopular and/or smaller shops and restaurants remained closed even during the recovery phase. Their closure was based on several factors, including lack of customers, lack of workforces, and significant business losses. Smaller businesses simply struggle to cope with their economic loss. The permanent closure of such businesses is expected globally as they are expected to be more vulnerable. Source Ali Cheshmehzangi 

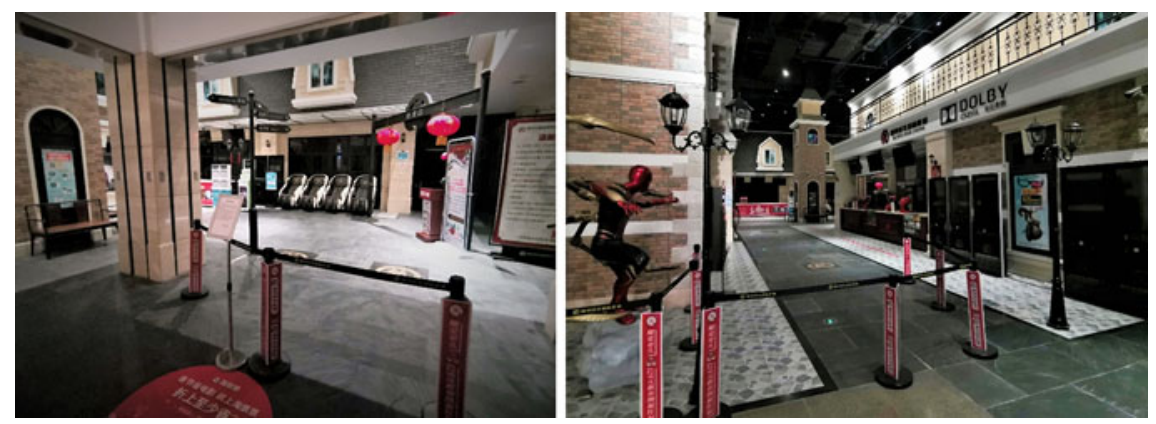

Fig. 5.77 Despite earlier signs of re-opening public entertainment amenities, the national-level decision decided to continue with cinema closures for a longer period. This decision was based on the worries of any reversing trends in the containment process. Source Ali Cheshmehzangi
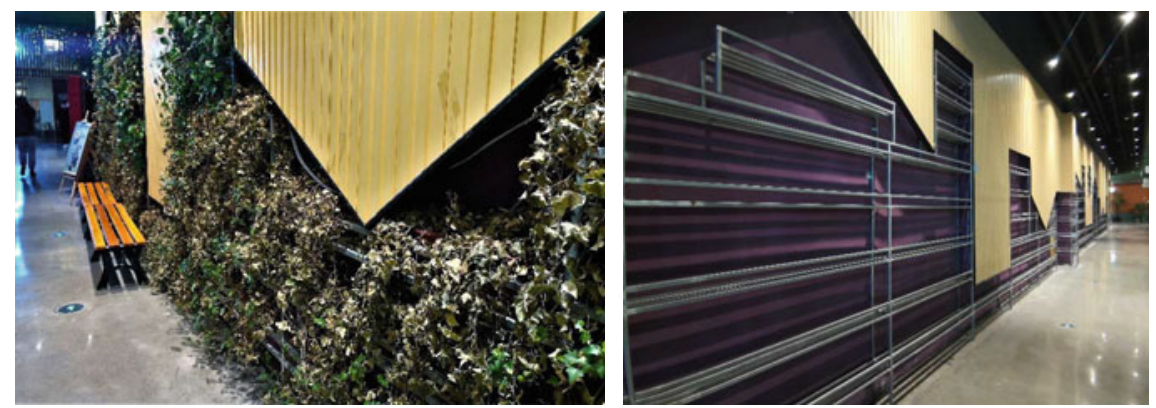

Fig. 5.78 Maintenance of those declining or closed businesses became the added burden to those responsibilities for their management. Here, we see the change from dead plants to empty scenes of the frontages of retail units and restaurants in a shopping mall. Source Ali Cheshmehzangi 

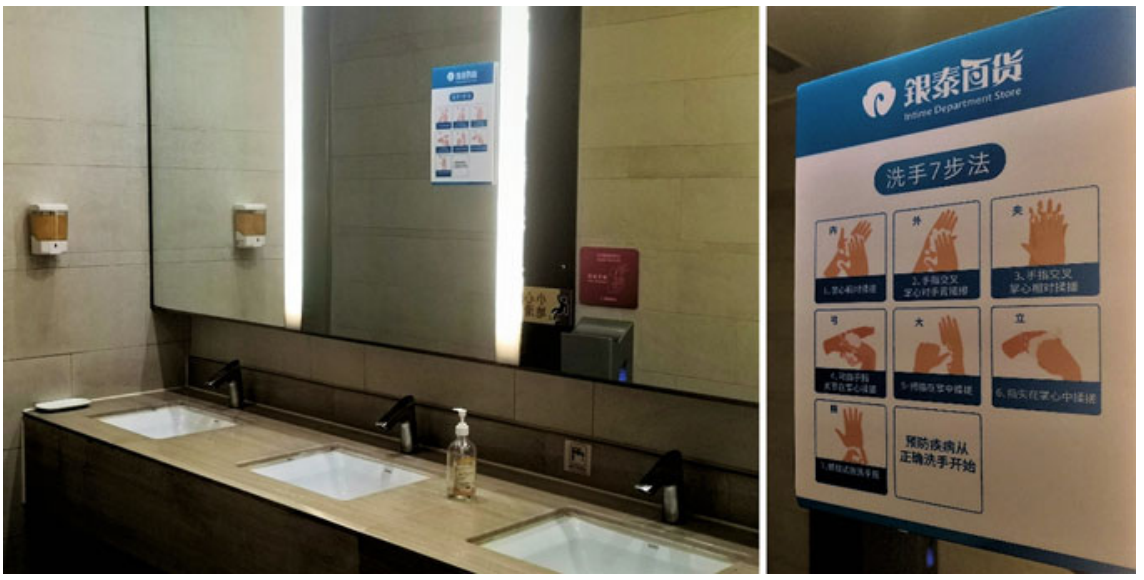

Fig. 5.79 As a secondary amenity, public toilets have to be remain closed during the outbreak progression. Once reopened, it is ideal to have contactless hand cleaning and hand drying methods. Also relevant information on hand washing procedures should be provided visibly to ensure everyone can comply with main precautionary measures. Source Ali Cheshmehzangi

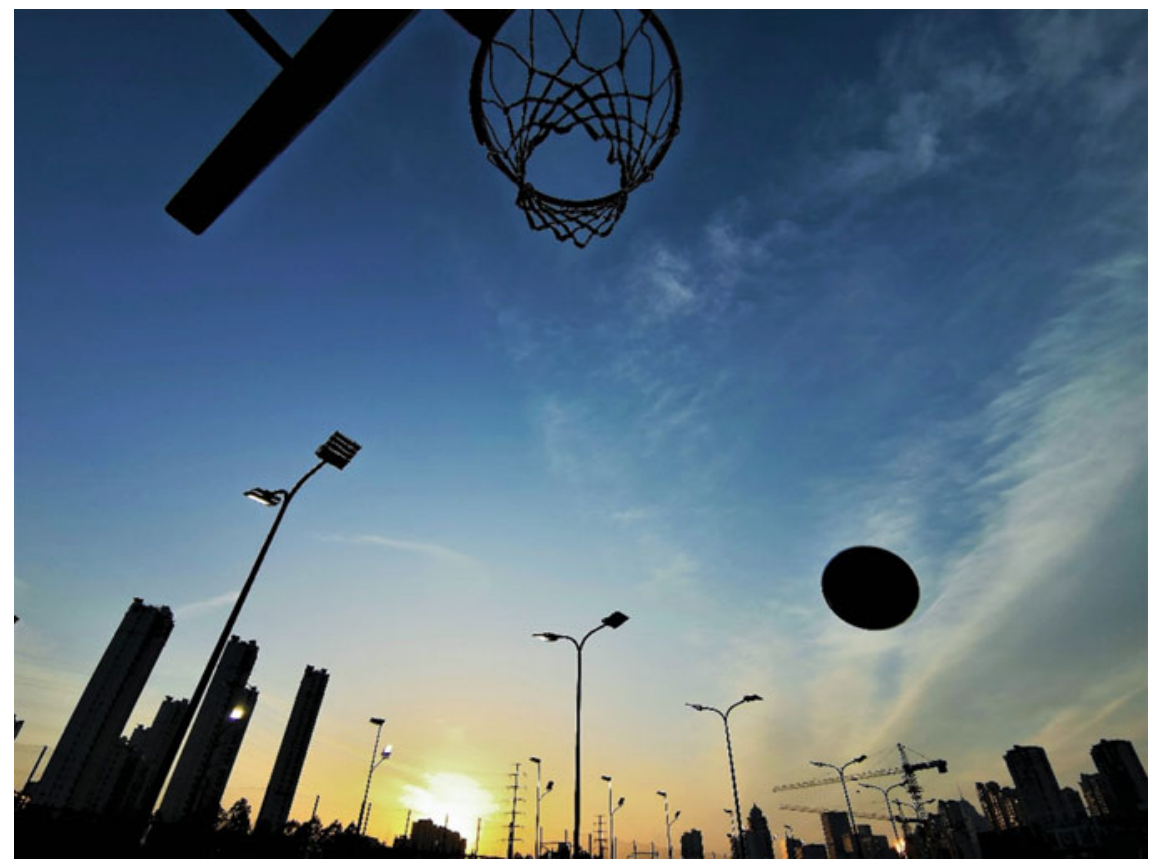

Fig. 5.80 Regular fitness activities are essential. If possible, it is important to use outdoor spaces and parks for various activities such as walking, jogging, and playing sports. It is important to only do such activities when possible. These should be done either individually or in smaller groups to avoid any cluster activities of such kind. It is also important to maintain dispersed activities in large public areas, open spaces, and parks. Source Ali Cheshmehzangi 


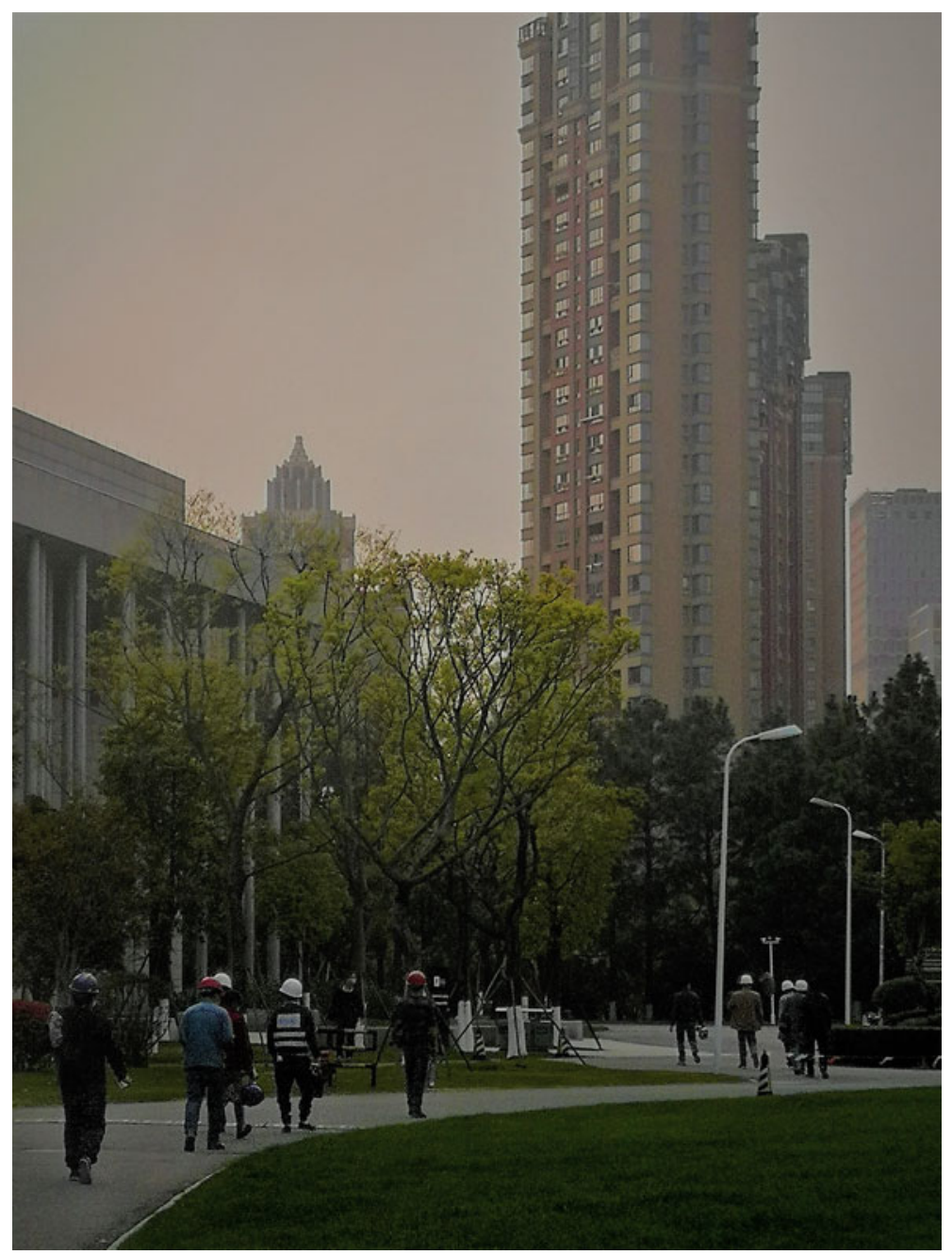

Fig. 5.81 In the recovery phase, construction workers are allowed in and dismissed in certain designated times. They are only allowed in and out in smaller groups of less than 10 people at a time, and in intervals with careful monitory and supervision in multiple nodes throughout the whole process. Source Ali Cheshmehzangi 


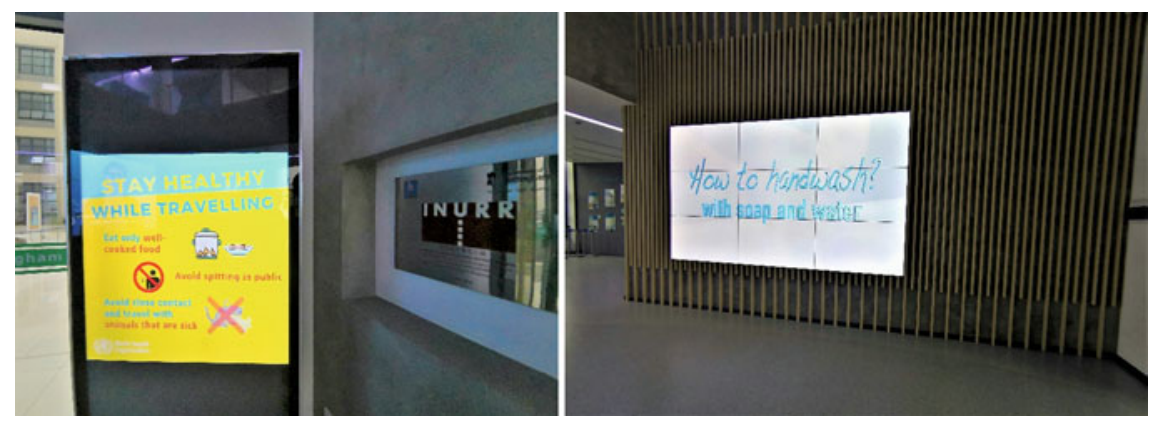

Fig. 5.82 Utilising all display boards to showcase procedures, guidelines, and information about the disease and raising awareness to overcome the issues. These boards are placed in transit and access nodes, such as lobbies, public areas and are visible to users and passer-bys. Here are examples of display boards at the university campus. Source Ali Cheshmehzangi

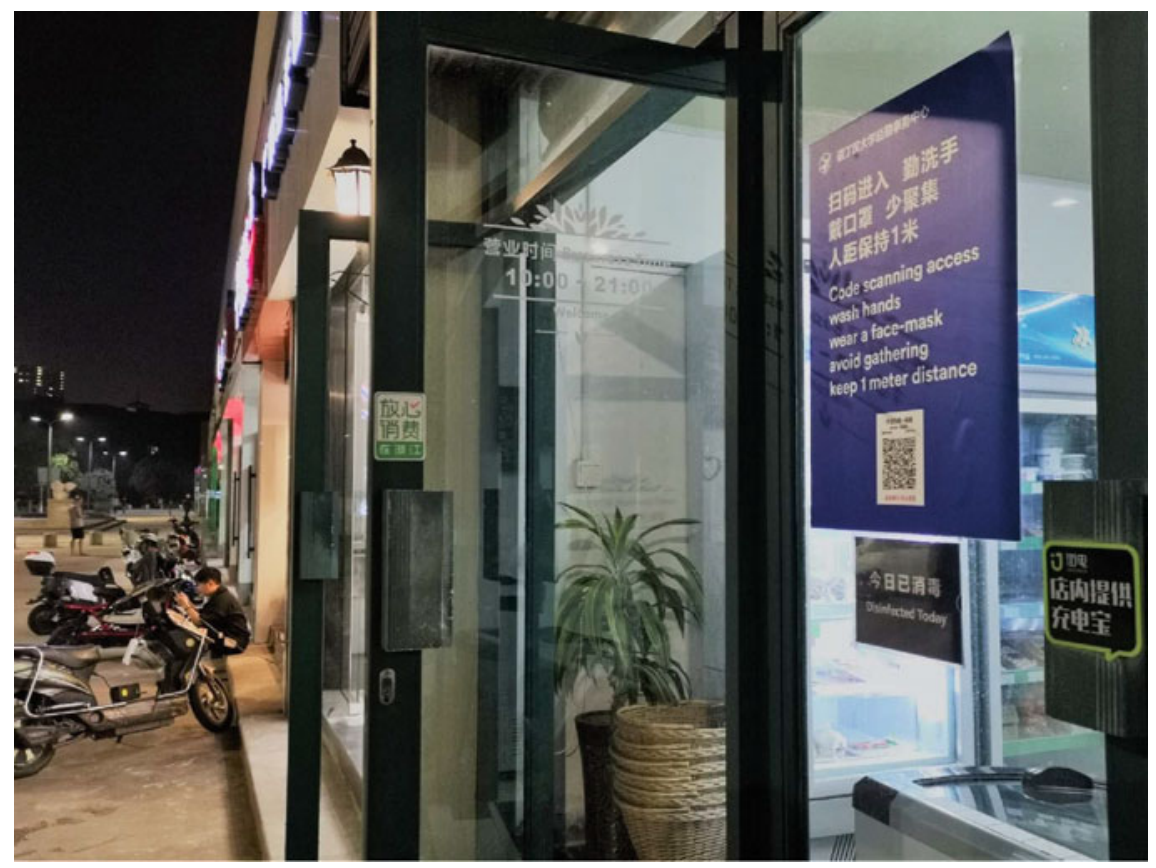

Fig. 5.83 The newly added signs on shops and public buildings/premises included new information such as the emphasis on "code scanning access", as well as reminders of the primary prevention and safety measures, such as "wash hands", "wear a facial mask", "avoid gathering", and "keep 1-meter distance". The information for disinfection procedures was also indicated and displayed to assure the users/public of their cleaner environments. Such measures, if they last for a longer time, would have a positive impact on the hygiene improvement of the general public as well as public buildings, retail units, restaurants, markets, etc. Source Ali Cheshmehzangi 


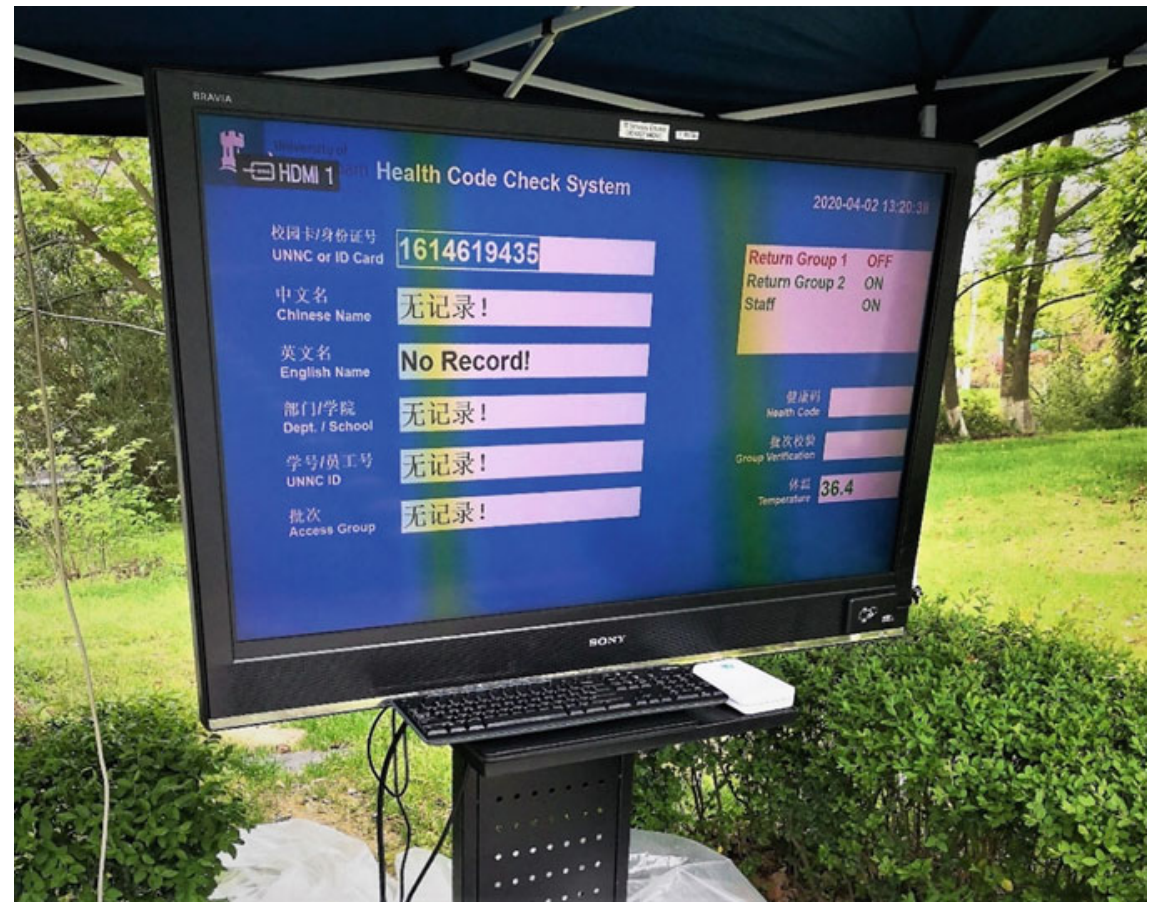

Fig. 5.84 A new access control management system is installed at the main gate of the university campus at the start of the post-recovery phase. Source Ali Cheshmehzangi
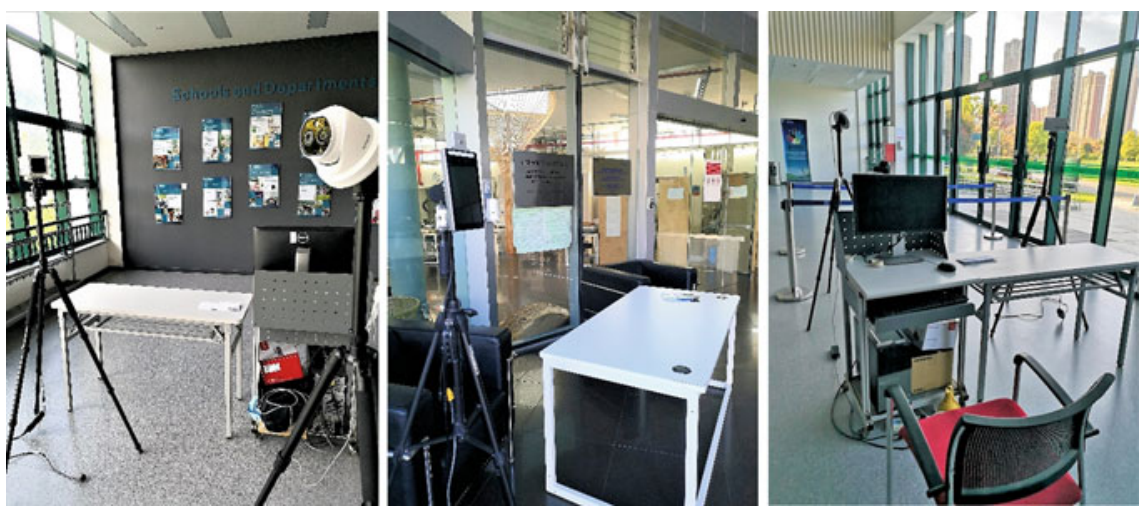

Fig. 5.85 Placement of new gadgets for temperature checks and recording of entries and exits to teaching areas/buildings. Source Ali Cheshmehzangi 


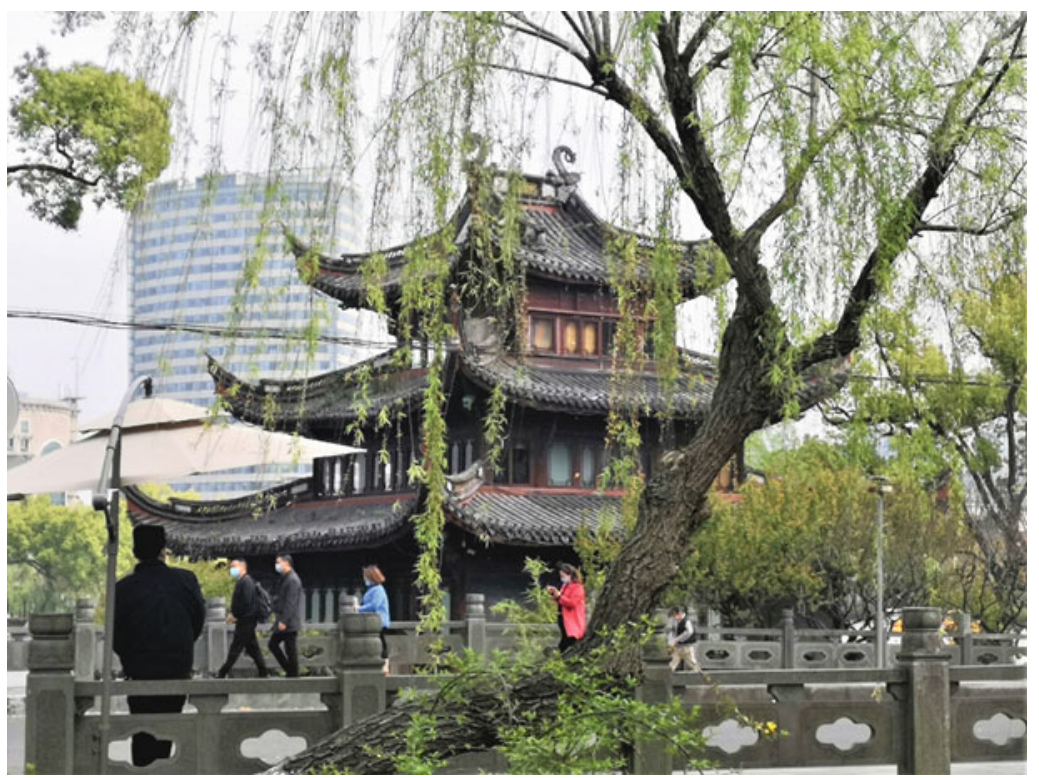

Fig. 5.86 Allocation of security at the entry of main public places at the city level is not an easy task to manage the populated flows in and out of communities and popular public areas. Source Ali Cheshmehzangi

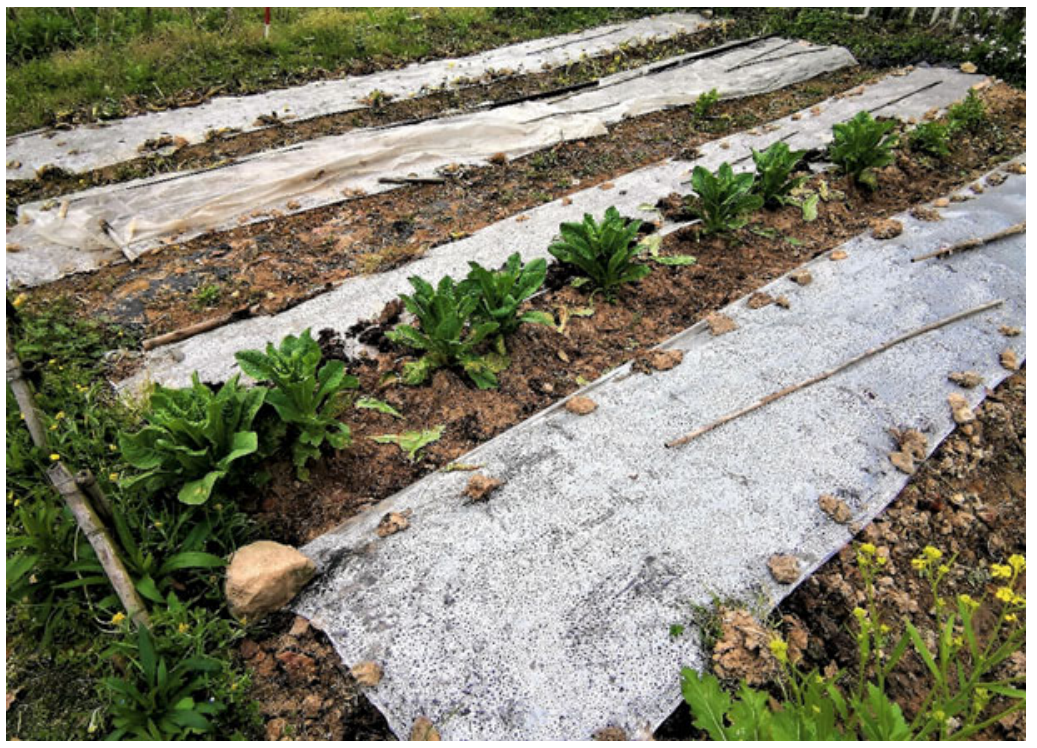

Fig. 5.87 If possible, micro-scale farming would be helpful to reduce the pressure on the local food supply chain. Source Ali Cheshmehzangi 


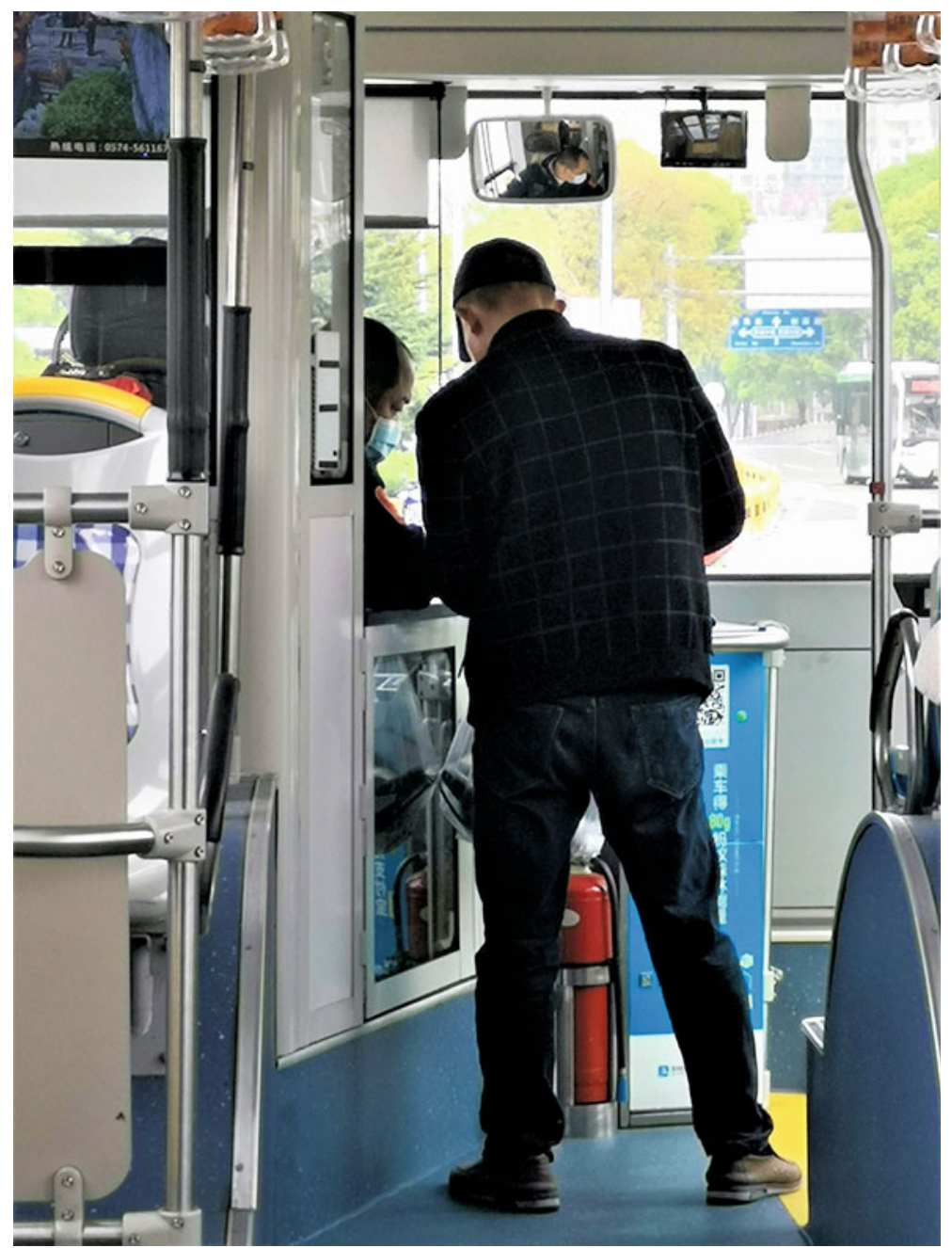

Fig. 5.88 The use of public buses is subject to health check measures. The person without a facial mask was given one by the driver. Source Ali Cheshmehzangi 

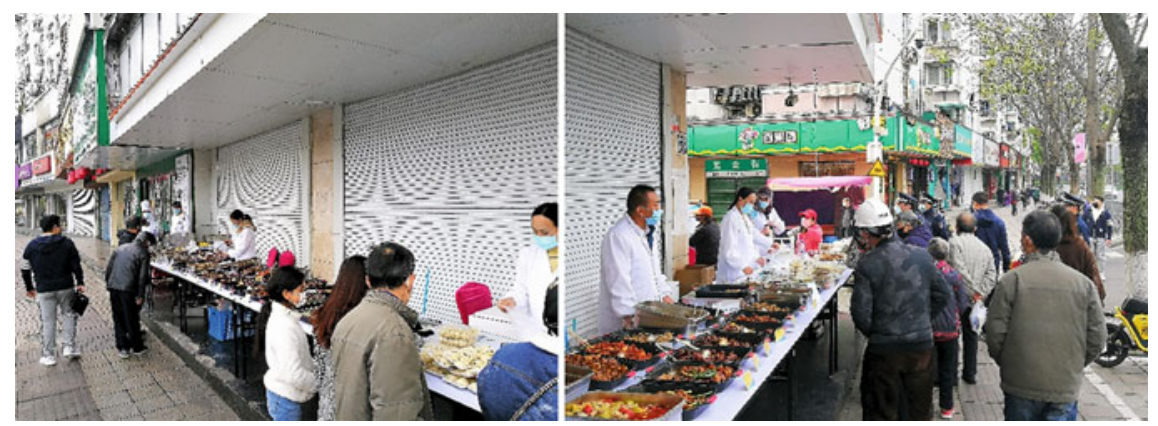

Fig. 5.89 Some restaurants may choose to alter their mode of serving, but these should be coordinated with relevant authorities in advance. This method requires health checks, hygiene checks, and food safety checks. Source Ali Cheshmehzangi

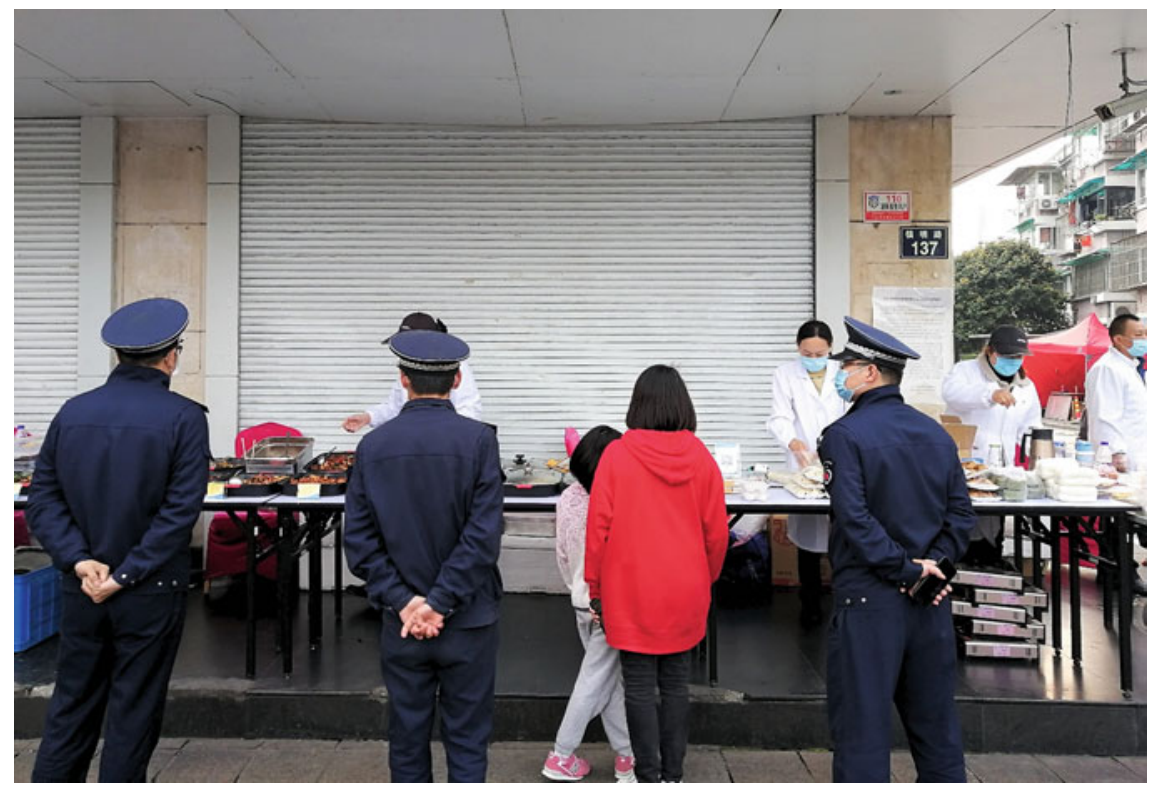

Fig. 5.90 In this incident, the security forces had to interfere and stop the operation of this noncoordinated street food sale. A total number of eight security members were called to the place to stop the operations with immediate effect. Source Ali Cheshmehzangi 


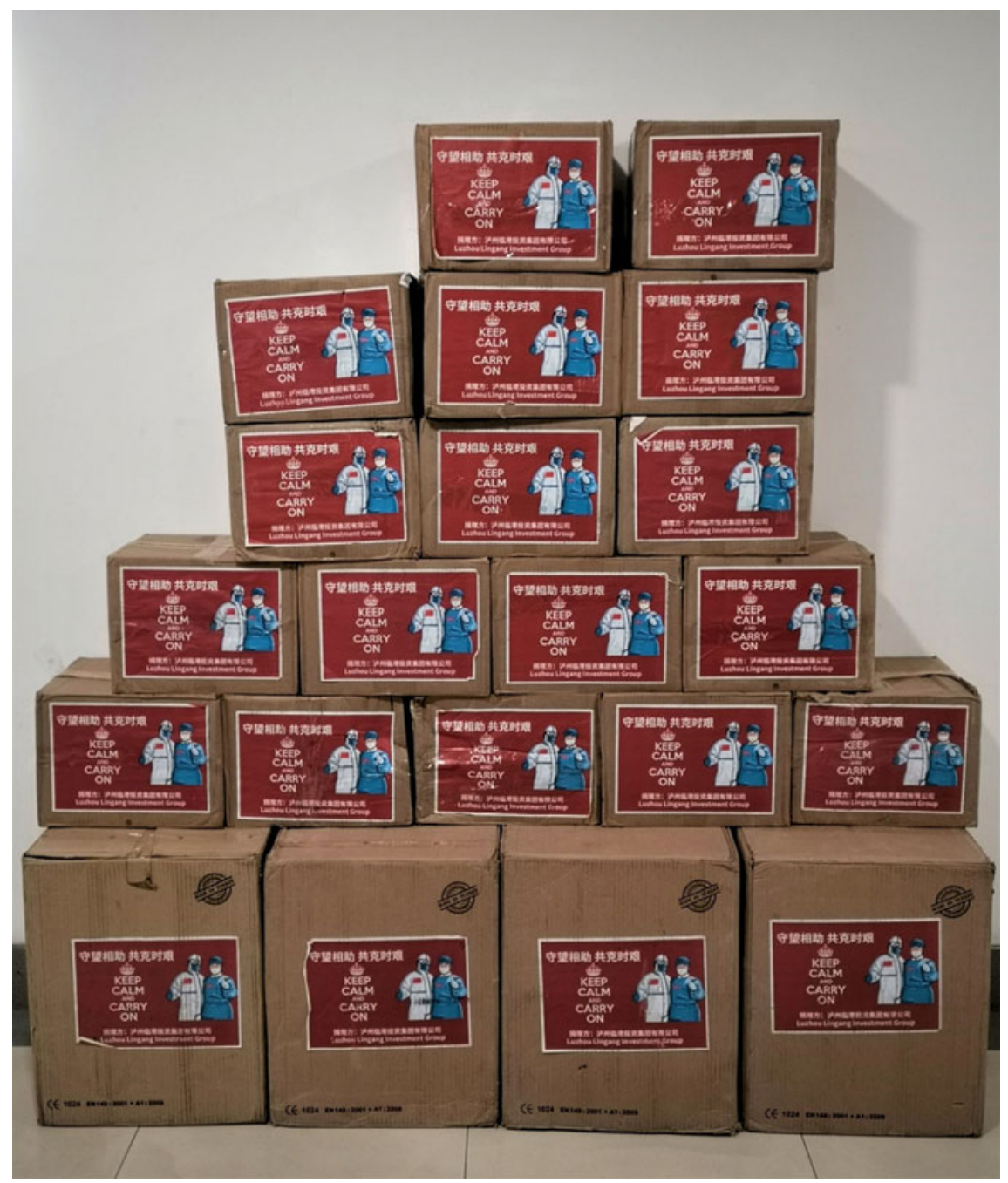

Fig. 5.91 At the time, the communities were confident of the recovery stage the flow of help and support changed its direction. Many enterprises/companies/communities started to send medical supplies, sanitisation products, and medicine. Here, we see $61 \mathrm{~kg}$ of medical products ready to dispatch to the UK (from Ningbo) with the wording "Keep Calm and Carry On" taken on 23 March 2020. Source Ali Cheshmehzangi 

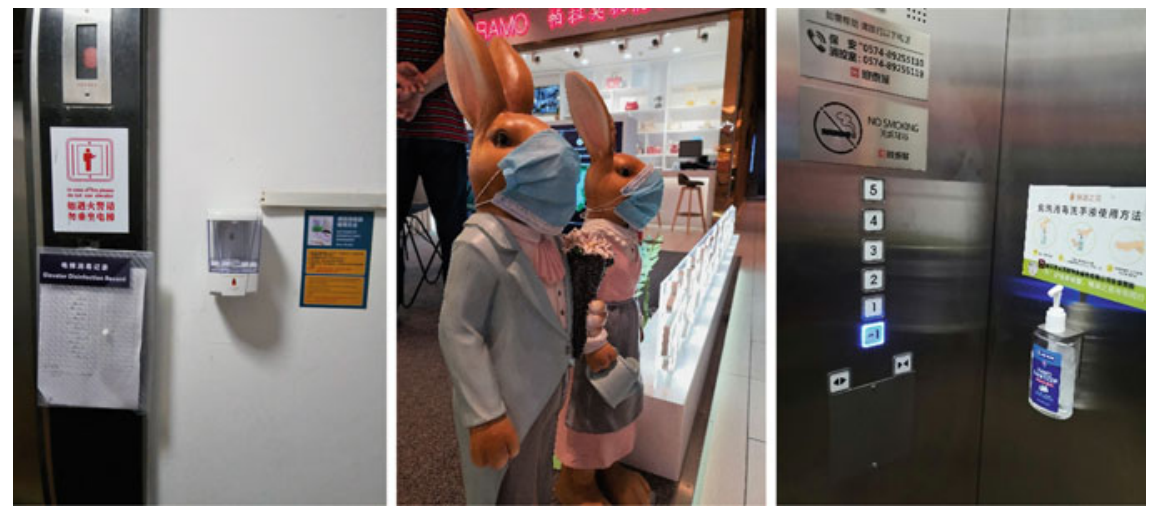

Fig. 5.92 The new additions to our main public areas aimed to promote hygiene improvement, especially that the education of such matter require time and a lot of public engagement. The new information displays and taking into consideration the essential procedures were amongst the many changes. If people do not forget fast, as they normally do, such measures could help to improve our personal and public hygiene. But, it is very likely people would forget recklessly once this pandemic is over. Source Ali Cheshmehzangi

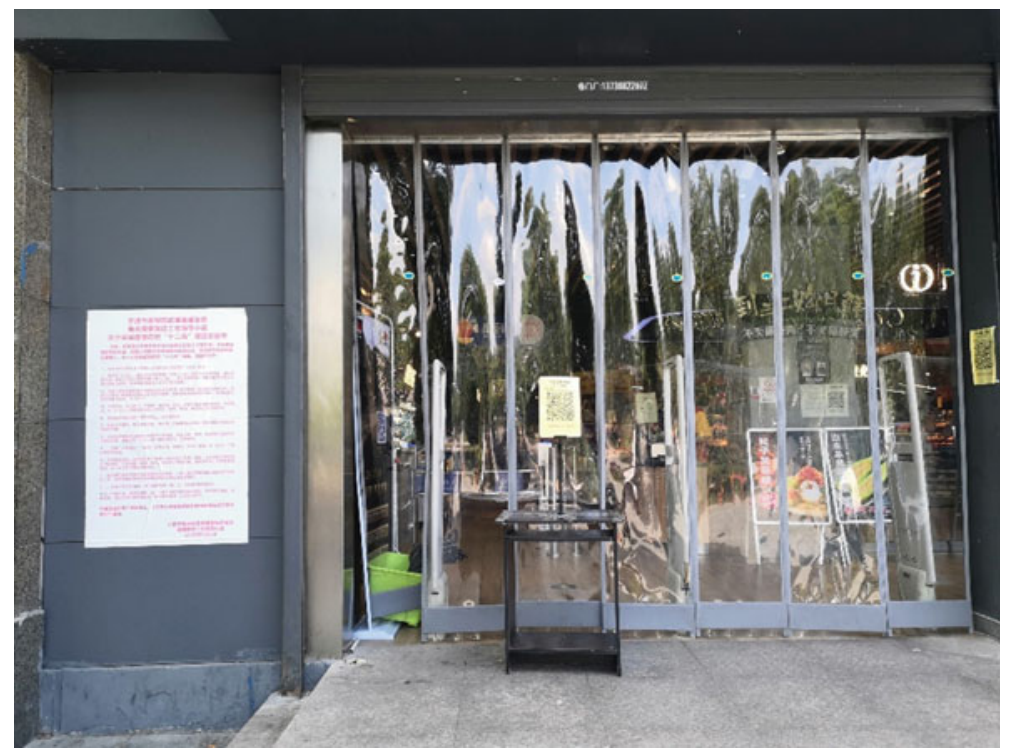

Fig. 5.93 One example of extended safety measures at the front of a community supermarket during the post-recovery phase, with the continuing requirements of check and register at the entry point. Source Ali Cheshmehzangi 


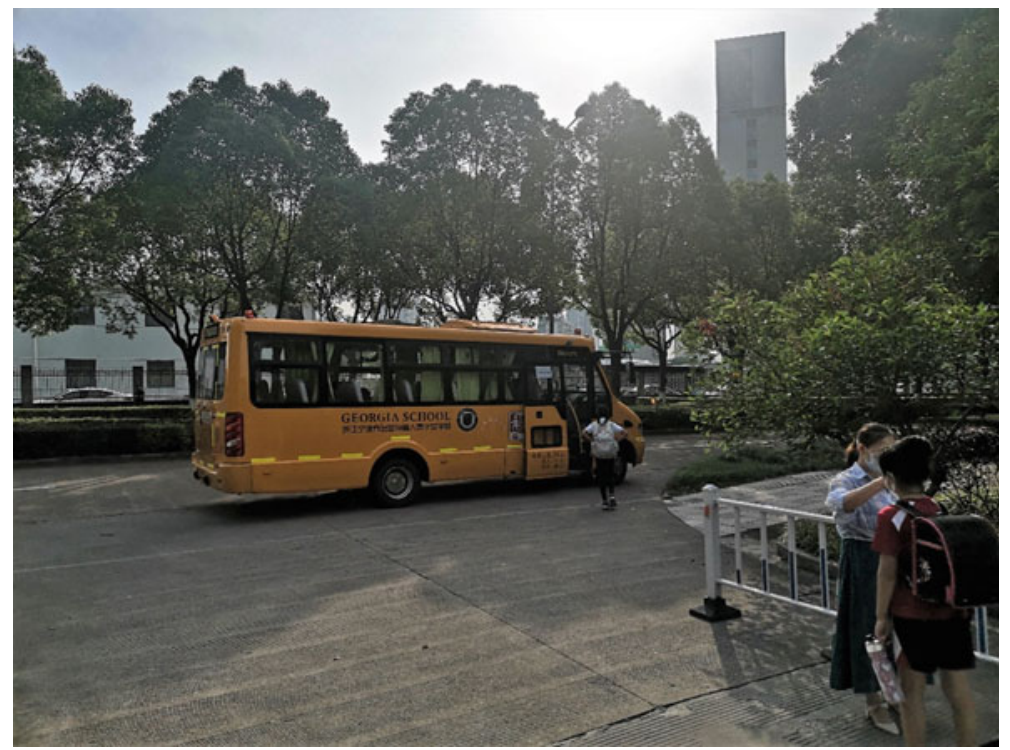

Fig. 5.94 After the gradual opening of schools, the students' temperature and health code were checked and registered before going to school and upon arrival at the school premises. Source Ali Cheshmehzangi

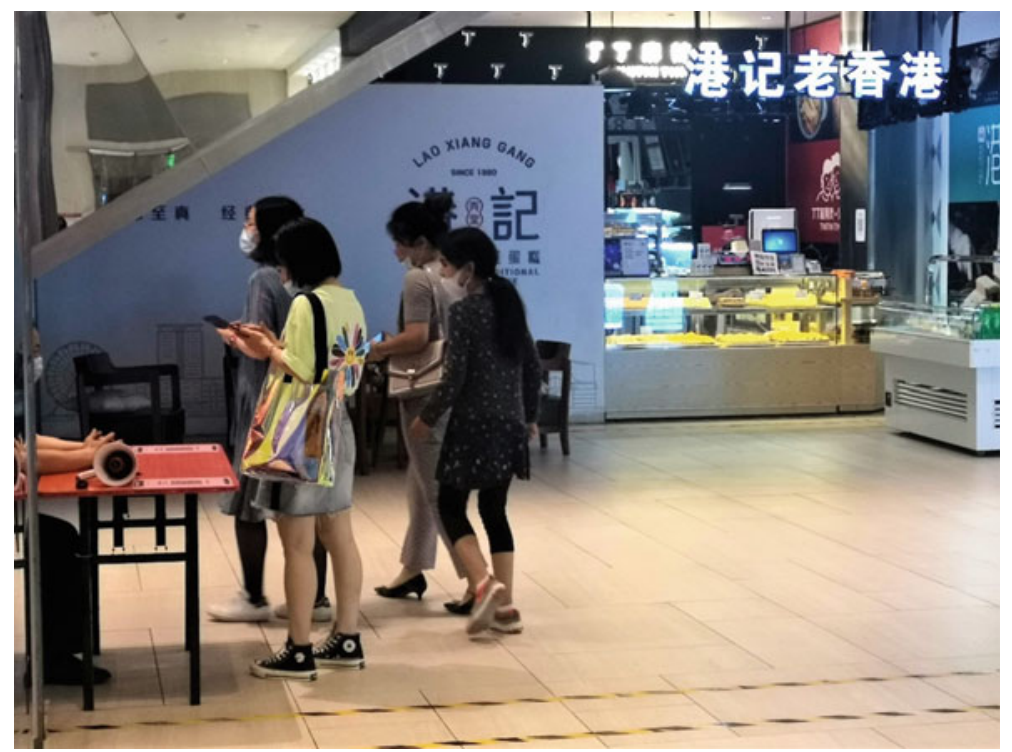

Fig. 5.95 Continued safety checks were remained in place during the post-recovery phase to ensure all risks are detected, assessed, and managed — and through prevention and safety procedures. Source Ali Cheshmehzangi 


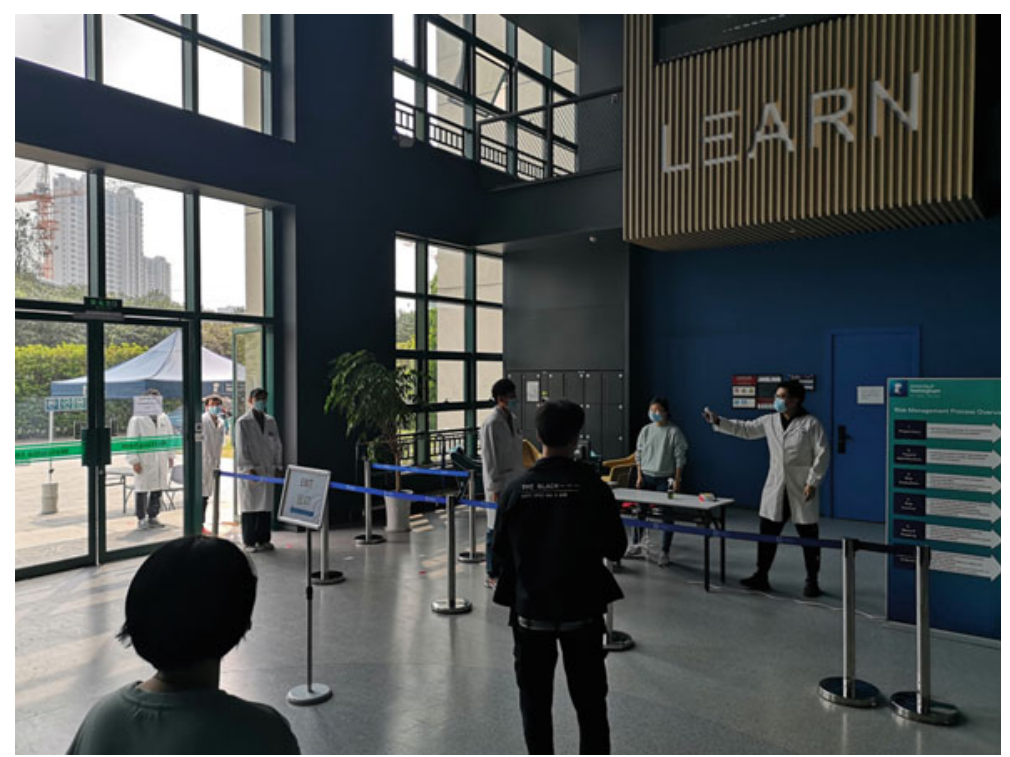

Fig. 5.96 Rehearsal sessions were conducted prior to opening of the education sector, including safety check procedures for all staff and students. This was then followed by several guidelines, including emergency response for fever and suspected COVID-19 case. Source Ali Cheshmehzangi

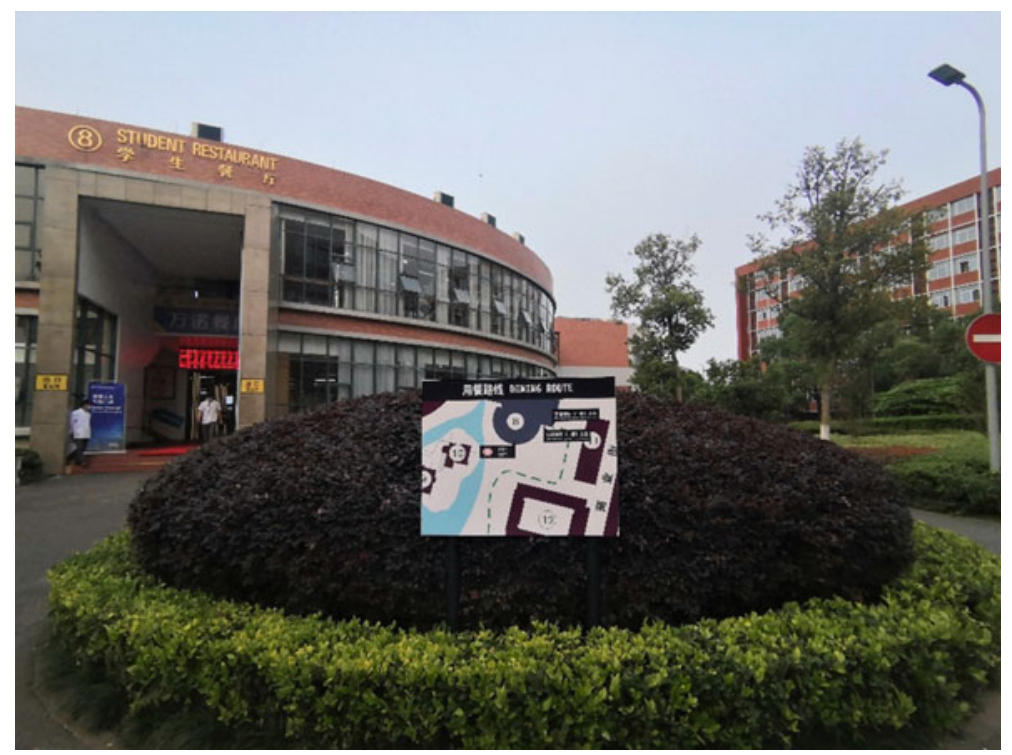

Fig. 5.97 Creating one-way path systems were amongst some of those early spatial arrangements (Cheshmehzangi 2020c) to have a better monitory of public places and populated areas. Source Ali Cheshmehzangi 


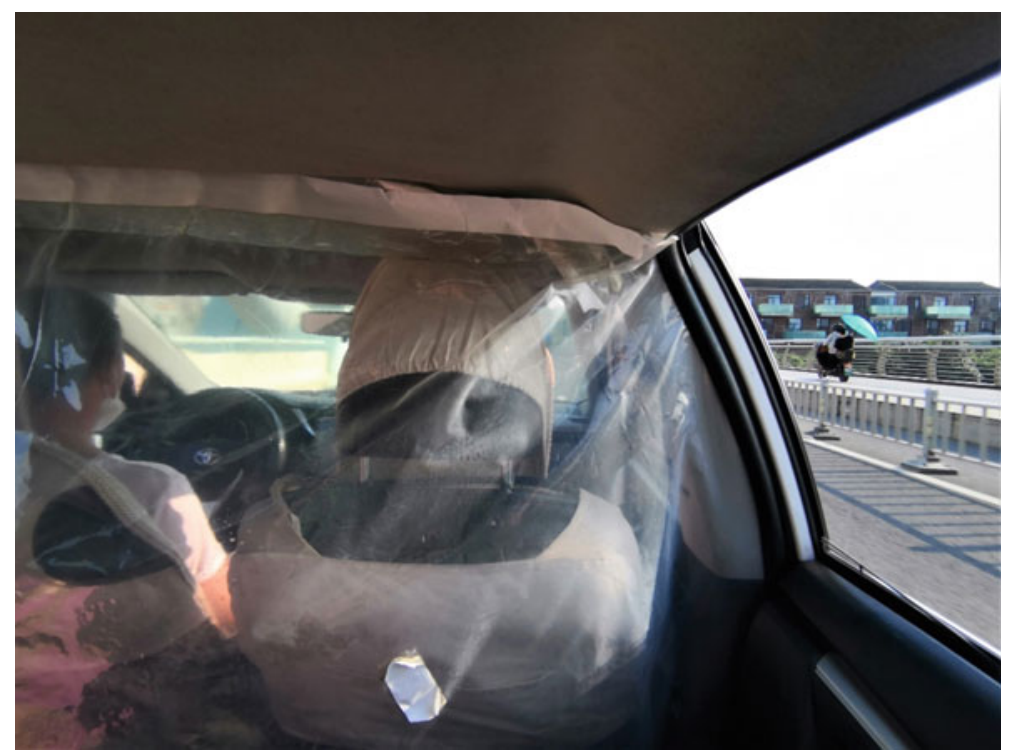

Fig. 5.98 Some measures were put in place by people at the individual level. Here, we see a plastic curtain that is placed by the taxi driver to separate himself from the clients. Also, cash payments were minimal and were not advised even at the post-recovery phase. Source Ali Cheshmehzangi
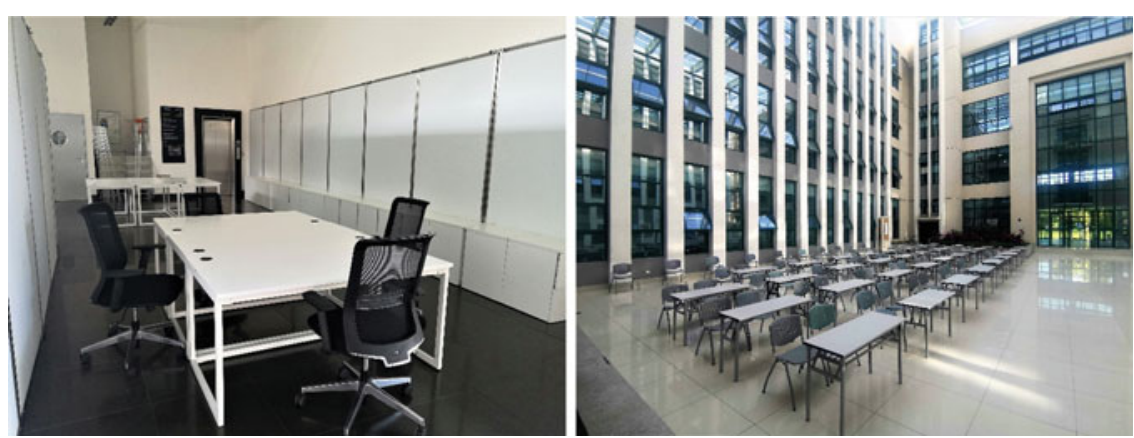

Fig. 5.99 Adaptive measures for spatial arrangements (Cheshmehzangi, 2020c) were effective in making new temporary working spaces, separated units, and new designated areas to avoid gathering. Source Ali Cheshmehzangi 


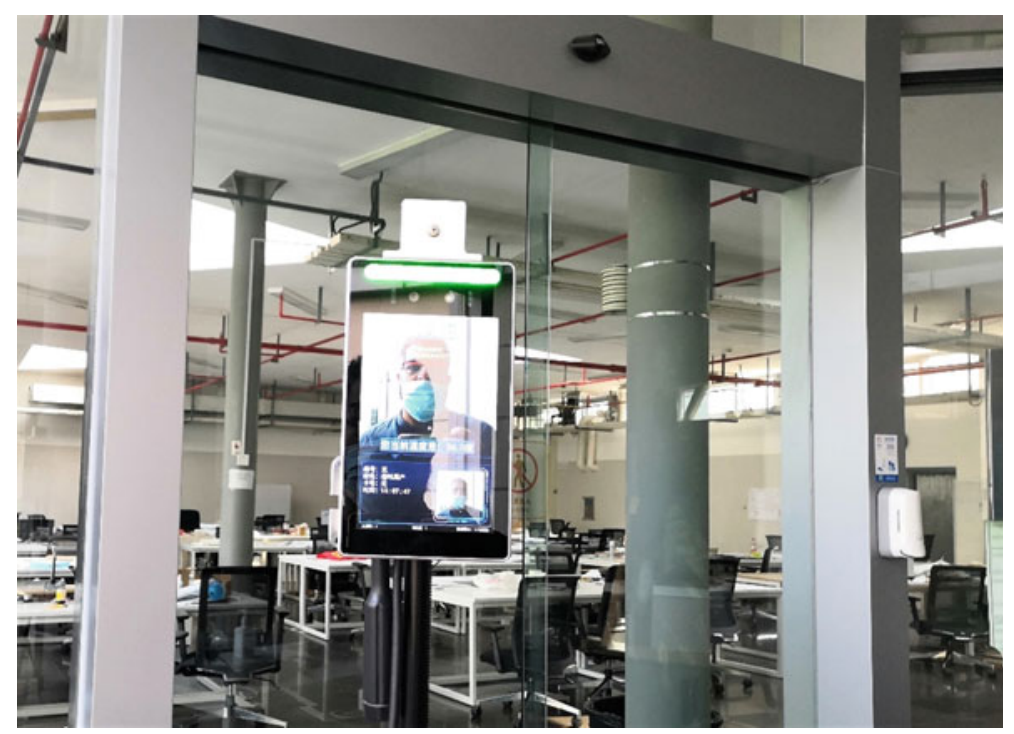

Fig. 5.100 This pandemic has created a unique opportunity to speed up the use of facial rendition devices, and some may cost us our privacy in the near future. Source Ali Cheshmehzangi

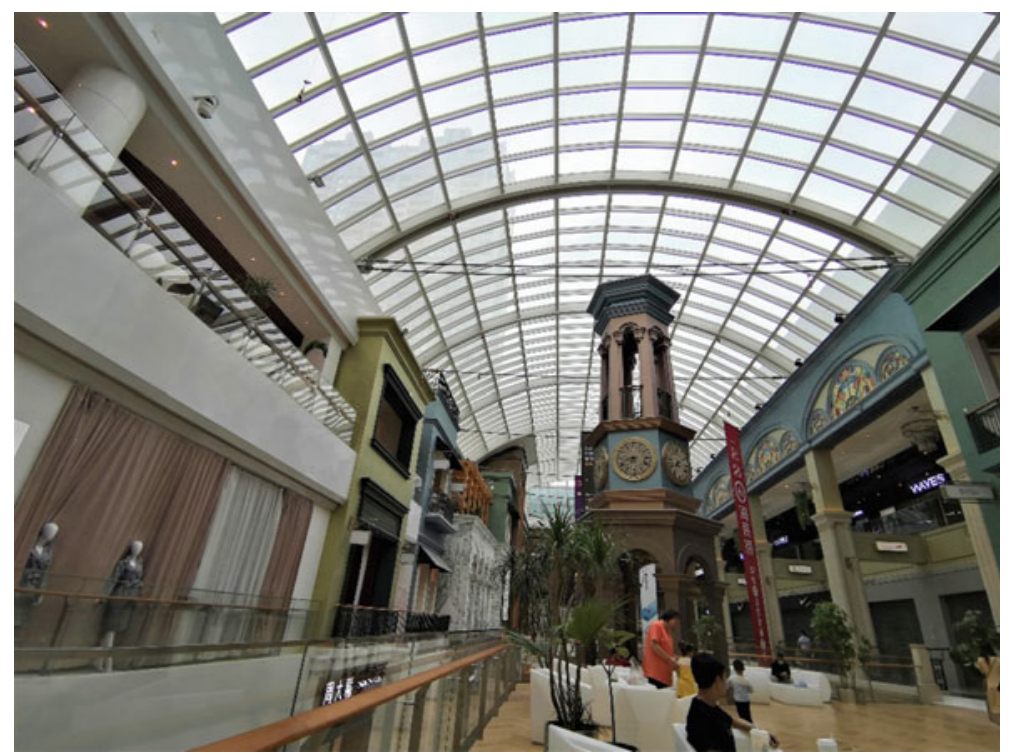

Fig. 5.101 The major impact was seen in the sector that did not or could not offer online services. Also, this affected those populated areas and secondary public facilities, particularly in city areas. Source Ali Cheshmehzangi 


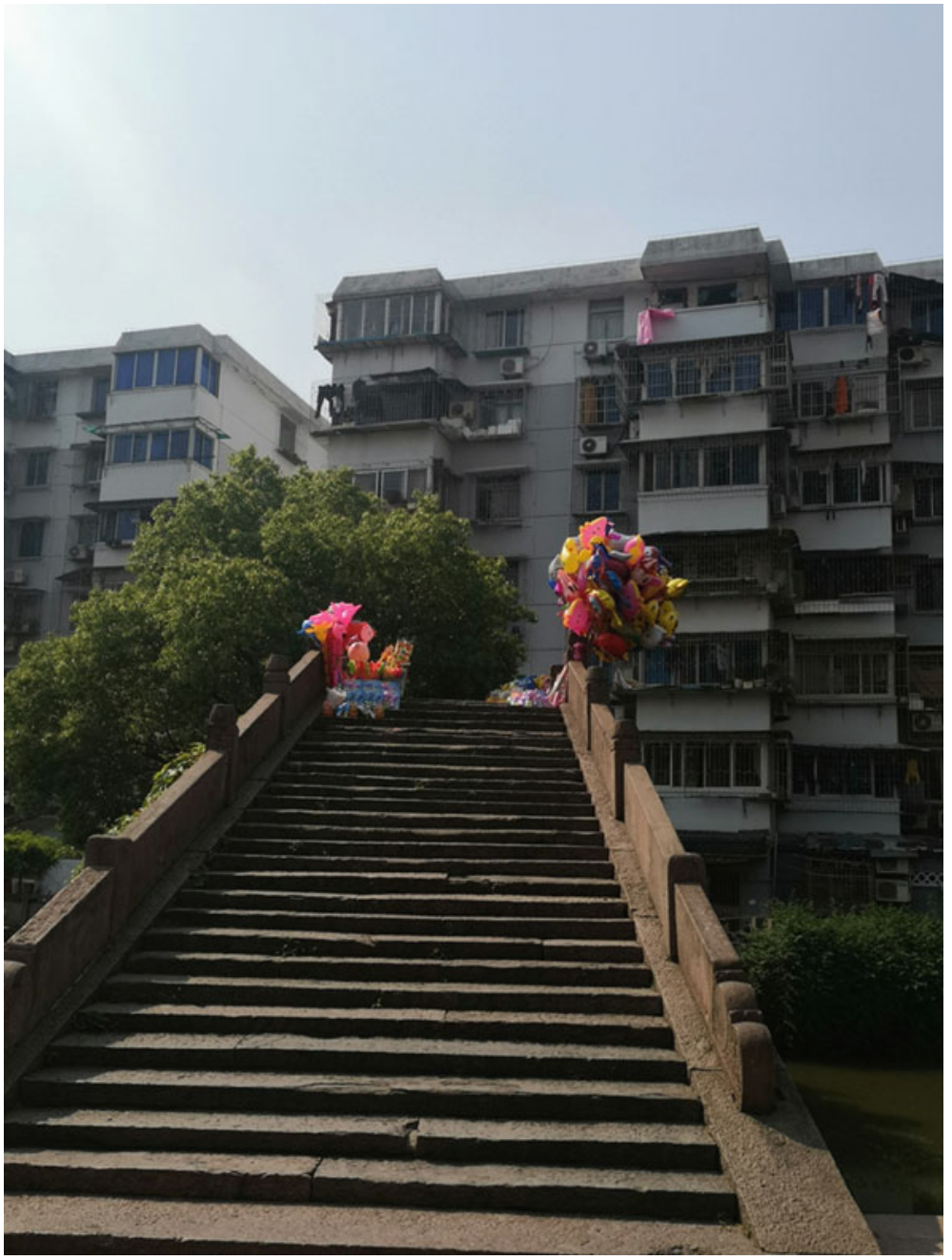

Fig. 5.102 One of the tangible impacts is the increasing poverty widespread amongst the lower social classes, particularly those that rely on their daily incomes or hourly pas jobs. Here, we see the impact on street-sellers with a significant decrease in their daily customers. In most cases, there is little financial support or legislation available to help those most vulnerable groups of society. Source Ali Cheshmehzangi 


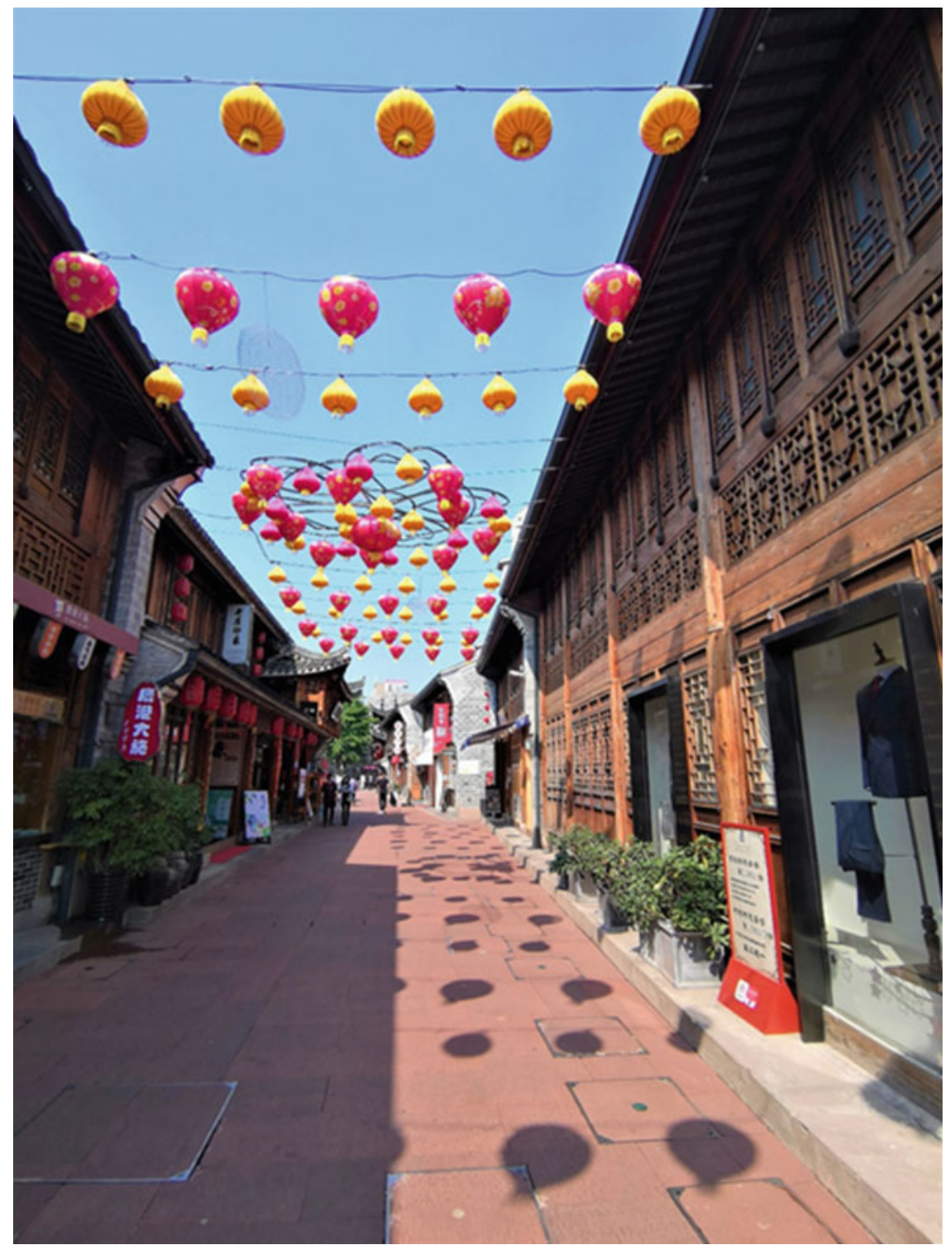

Fig. 5.103 The tourism industry and all industries associated with it are likely to struggle to recover in a short period. Here, we see an example of empty places in one of the most populated areas in the City of Ningbo. Despite the good weather conditions, most people avoid populated areas, especially in the city areas. The situation for the outer-city leisure areas is a different story as most people assume the green areas are safer than the urban areas. The same situation was seen in other countries where, after the lockdown, people avoided populated urban areas/destinations. Source Ali Cheshmehzangi 


\subsection{A Reflection: What Normally Occurs? and How the City Reacts?}

Coinciding partly with the Chinese New Year holiday period, the situation was at first commonly perceived as an extended holiday. The prolonged phase of response and containment changes general perceptions. The seriousness of the situation was evident from the earlier days of the outbreak as most people reflected on their previous experiences of such events (i.e. mainly the outbreak situation of SARS in 20022003). By the time the administrative response was in place, this emergency situation already instigated major shockwaves across all sectors. In fact, it permitted very little time for considerable reactions as circumstances were unceasingly changing and uncertainties were unrestrained. The international media coverage was expectedlybut unfortunately-not very accommodating and nor they were any close to realities that could help the society. Time became scarcer and made decision making processes more subtle. In order to maintain a sensible society, it was simply vital to have the right reactions against what actually occurs on the ground. Governance includes both society and government (Fig. 5.104). Hence, public relations became ever important and how the city could or should react was of major concern to many. In the following four sub-sections, we provide an overview of those reactions that happened in the city in the recent event of the disruptive disease outbreak.

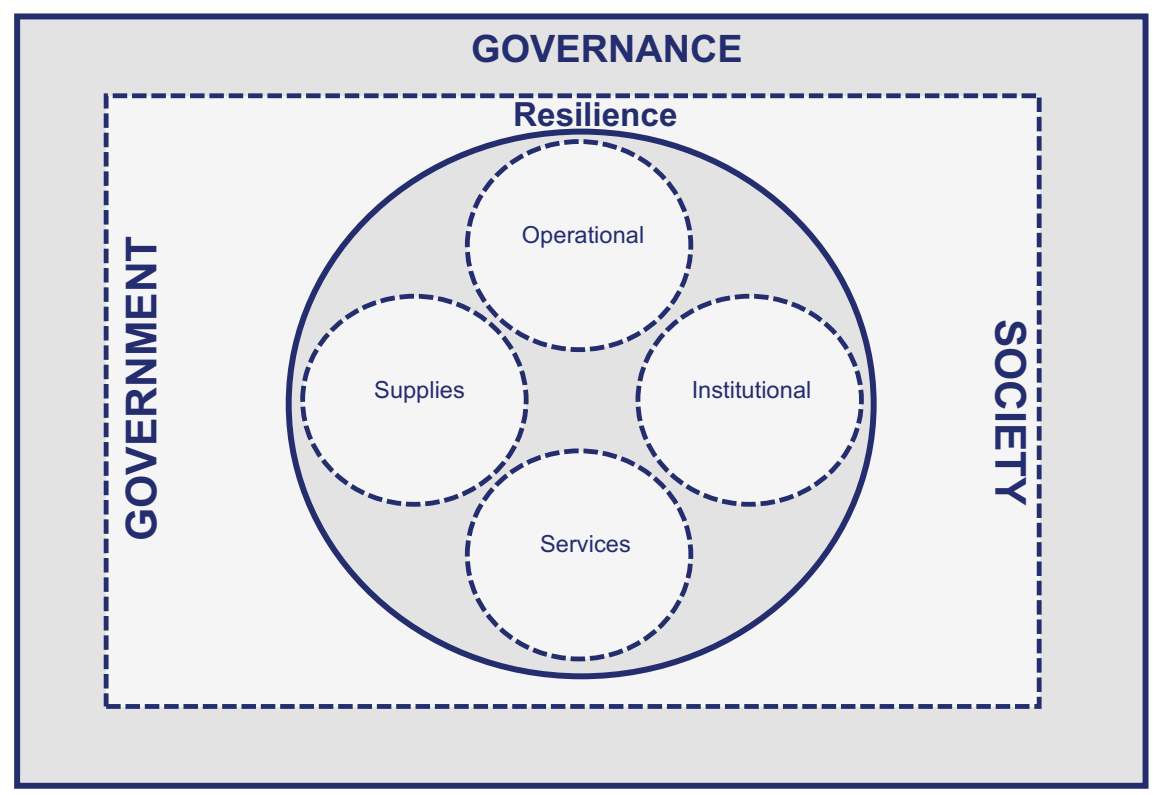

Fig. 5.104 Summary of reflections from resilience dimensions to society and government enhancement and the ultimate governance. Source The Author's own 


\subsubsection{Operational}

The city simply assessed what needs to operate and when they should go into partial or full operation. An all-inclusive assessment is always a difficult task, and in this situation, it had to be procedural and with adequate planning. With immediate responses, the city had to adapt and localise the key national guidelines for quarantine and selfisolation measures. These happened in the peak of the transmission phase, first from the gradual lockdown of communities, and soon later to the nearly-full lockdown of the city. Main reflective arrangements, such as temporary closure of highways, railways, and other main modes of transportation (with restricted air travel) between provinces, were effective not only to control community transmission but also to control import and export of the disease. In this regard, we can highlight the effectiveness of city boundaries and monitory checks in the main parts of the city. Some examples are prohibited entries of non-locals to rural communities of the city as well as vulnerable groups (such as elderly care facilities), temporary isolation of residential compounds with higher risks, and limitations for mobility per household. The latter was officially announced to permit only one family member to go out of their household every two days, which was only put in place during the peak time of the transmission phase. These restricted measures were strengthened also by the control of distinct gated community layout in Chinese cities, which are generally planned with large compounds/urban blocks (Cheshmehzangi 2018). This particular planning layout helped to have a better monitory over entry and exit to residential and commercial areas, which ultimately helped to enhance the city's safety and security (ibid). On another effective measure, we can refer to the already established contactless payment methods via smart mobile phones, which was crucial to reduce transactions with unclean (and possibly contaminated) coin, banknotes, and cards. However, phones themselves must be kept clean and properly disinfected on a regular basis.

The city also limited operations of sectors that often rely on populated workforces, populated operations, and activities that encouraged a higher level of physical contact. The closure of populated offices, construction sites, public buildings, financial buildings, entertainment activities, restaurants, and cafés was of the first steps in the transmission phase. Related to such limitations, the government guidelines forbade the use of centrally controlled air conditioning systems/units (i.e. to reduce air ventilation between different enclosed rooms/areas), and restricted the use of shared facilities, such as open office spaces. An example was to put a restriction on larger businesses and public premises, and only provide entry permits to their employees on a daily basis. This was implemented in educational areas (such as colleges, universities, and institutes), where daily permits were only issued after the approval from multiple managerial levels (e.g. immediate line manager, human resources, and the central management office). Furthermore, the management of services, and in particular healthcare services, were of the highest priority. Through resource management, the city responded to the needs of infected healthcare units and facilities, to ensure the situation is controlled through the highest security and safety measures. 


\subsubsection{Institutional}

The maintenance of healthcare services and facilities, as a major institutional support to outbreak control, was certainly a major urgency for the city. This developed as the main approach to keep healthcare centers/facilities as the primary safe hubs of the city. At a relatively lower risk compared to other cities, the temporary closure of small-scaled clinics and health care units was imposed to overcome any deficiencies. This strategic move was implemented due to a lack of safety measures and workforces in small-scaled healthcare units across the city, which was also decided as a reflection on recorded cases in infected community-level clinics. It was also recognised as a preventive approach against further community spread from sources that are less likely to be regularly and efficiently monitored. Hence, communitylevel measures were only limited to some other aspects. Also, the resourcefulness of all main healthcare units/services should have been carefully managed as part of this major institutional support. A larger stepping stone towards enhanced control measures was the compulsory use of the newly developed and immediately implemented 'Ningbo Health Code', which was mandatory for all people who had to access public places or use any of the public services. This information-based and data-driven approach was developed in the first stages of the transition phase, and soon became a city-wide instrument. It then enabled the city to have a better overview of patterns and possible situations that required immediate attention. This perhaps resembles an example of large scale surveillance, but is proven to be effective in the time of need.

Of the major concerns on institutional arrangements, we can refer to the role of media coverage and the adverse issues it may have on society. Hence, the media was regulated with the right information, updates, relevant training, and announcement of precautionary measures. The local media immediately turned into a knowledgeshare platform between the professionals/experts and the general public, allowing for the right flow of information, which should be accessible, supportive, and positive. A large scale propagation of information also has significant impacts on sociobehaviour patterns, as the impacts can only be in place if the majority would comply with those regulated measures.

Moreover, in parallel to national-level updates on the outbreak progression, the local media took their position firmly in providing transparent and regular updates. Hence, the media was formalised with continuous updates and information. From the early stages of the transition phase, the media coverage also included positive broadcasting of success and updates on progression, which were meant to be reassuring measures to the general public and all relevant stakeholders.

Considering the large scale economic impacts of outbreak events, the reactions to economic management are the ones that we expect to be developed in a longer process, but including some immediate and short-term action plans. These are the actions that may require higher-level legislation, such as issuing tax exemption solutions, sick pay support, business loss insurance, recovery contingencies, adjustments in bank and mortgage interests, provision of low-interest loans, etc. As part of the 
immediate action plan, the step-by-step process for the closure and reopening of businesses was taken into consideration. This can be recognised as part of the early strategic plans for economic assessment and its management. Later on, this process was followed by some flexibility measures through adaptive planning approaches, allowing for alternative operations, a re-adjusted schedule of operations, and gradual support. These approaches then led to gradual normalisation steps, which certainly come with longer plans for economic revitalisation.

\subsubsection{Services}

As broad as they sound, urban services are extremely important for the necessary provisions of the city. With multiple sectors of services, there come also multiple demands/needs, different rearrangements, and different responses. To start with, the safety of transportation services was more of a priority than their regular operations. The early restrictions were crucial to reduce the chance of community transmission, which also restricted people's mobility with a high level of control. This specific measure only lasted for several days, but was effective in a long time. It then led to gradual operations of transportation services with extended safety and security measures. As mentioned earlier, measures such as the early restrictions on residential compounds, and restricting access points to only one or two entry and exit nodes, represent a great starting point to reduce the city-wide mobility. These measures helped to minimise unnecessary travel within the city, between different districts, and in and out of the municipality, which also provided a breathing space for other services to operate more smoothly. The same approach of restricted measures was later adapted for communal and open places, reducing the number of access points with higher monitory levels. Later on, this was also adapted for the reopening of main shopping malls/centers and markets, which were closed in the early days or early phases of outbreak progression. Hence, for the safety and security services, the whole situation became a chance to reinforce their workforces and to identify the less apparent deficiencies of their regular services. In return, the safety and security services had a chance to increase their preparedness and support other services of the city, particularly medical units, emergency medical services, and micro-level security of compounds and public services. To further support these services, the city's plan for the utilisation of military forces were to boost the provision of public services, and those that are important for the control and monitory of the outbreak.

In addition, the maintenance of social services could only be temporarily affected, hence the city had to develop contingency plans across all primary services/sectors. This also became a good opportunity to increase their support at the community level, particularly the ones that seem more vulnerable than the others. In doing so, social services of public means (or public services) had to be prioritised and not get overlooked in multiple phases of the outbreak progression. Of major achievements of the city is the quick establishment of voluntary workforces, some representing 
their communities and some supporting their local public services. This was beneficial from a threefold, which: a) increased the number of people operated on the ground as safety and security volunteers, b) addressed the community-level issues, needs, and/or emergencies; and c) facilitated the opportunity to employ those temporary redundant workforces, whom could then help their immediate communities. The other achievement, which is often hard to control but is very essential, was the careful monitory of price control and hoarding activities, specifically related to primary products, food, medical supplies, etc. In doing so, the city maintained healthy private-public partnerships and developed a robust monitory plan to overcome such difficulties. The involvement of the private sector and the general public in the form of community representatives were effective tools to help with the overall maintenance of the primary social services.

\subsubsection{Supplies}

The city relies very much on the supplies of various types. For example, food supply (intentionally distinguished based on the explanations of Chap. 3) should reflect on several factors of safety, production, availability, and distribution. Hence, the city structure like Ningbo, which includes both urban and rural areas, is advantageous to maintaining food production and delivery-i.e. in a form of the enhanced domestic food supply chain. This was carefully monitored as part of restricted access in and out of rural communities, to ensure the rural communities, especially with high food production, are kept safe and secure throughout the outbreak progression. At the same time, while the city started closing the shopping malls/centers across all districts, the operation of primary supplies such as supermarkets remained uninterrupted. This particular decision maintained the opportunity for the continuous availability of food supply and accessibility of the general public to those main amenities. Some food shortages were only experienced for a very short period, and less than two weeks. This mainly occurs as necessary readjustments are needed for the food supply chain. Moreover, different methods of food delivery and food shopping delivery were introduced and maintained throughout. The only perceptible impact was the eventual reduction in a variety of online retail companies. An example was the main supplier named DingDong, which had a temporary closure of their operations for about three weeks. Once they returned into full operations, they sent reassuring messages to their users regarding their high level of food stocks and the availability of primary products. The city also encouraged contactless online shopping by keeping the local food delivery operational. Through public-private partnerships on primary operations, they also provided mechanisms for safe delivery of necessary fresh products, which were affordable and were then delivered in only two to three days after the submission of online requests (see Fig. 5.73).

Based on our categorisation of amenities supply, the operation of primary amenities — even if partial—were kept as the priority for the provision of the city's services 
and supplies. This meant unnoticeable disruptions in the provision of those amenities, with an exception on goods collection points and maintenance units. These two primary amenities were mostly affected due to limited human resources, which were gradually resolved once the higher level restrictions were lifted. Both the secondary and mobile amenities were the ones affected the most. Yet, the city was able to maintain partial operations of selective and more necessary secondary services such as postal services, fuel services, and bank services, even though there were inevitable delays in their operations (particularly in the first few weeks that was also affected by the Chinese New Year holiday). Some secondary amenities also provided more opportunities for online and telephone-based services, supporting those supplies that could maintain their operations through alternative methods.

Of major concern to the general public was the smooth operations of education. Hence, the local authorities worked closely with the educational services of all levels, ensuring that they are safe at first, and they can operate through alternative methods. Therefore, with only one or two weeks of delay, most of the city's education was delivered through online teaching. With the use of relevant digital technologies and available software, the education was able to start operations with some minor disruptions. This was mostly developed and implemented in the form of self-learning, experiential teaching, and subject-based virtual teaching, and with the extensive use of online educational materials. Therefore, the outbreak was also recognised as an opportunity to empower virtual amenities and utilise them in the time of need. This was something, which was tested before but was never implemented at this scale and pace.

\subsection{Capturing the Realities: The Reactions to Disruptive Time}

This section captures the realities by highlighting some of the reactions at multiple levels, in China and other countries/locales. In doing so, the intention is to cover the realities of the impacts and how they were perceived, addressed, and developed. The highs and lows of such an outbreak event was simply a matter beyond just the city or the country. It only took a few weeks until it became a global health emergency. The realities are fascinating from the various perspectives of politicians, governments, policymakers, economists, scientists, academics, health organisations, businesses, and the general public. This disruptive event truly represented many examples of international relations, strategic planning, decision making, responsive methods, political determinations, public policy, predictions, preventions, community resilience enhancement, etc. From the many examples, only a handful of reactions are selected, which are specifically most relevant to our discussions here. All these perspectives from multiple stakeholders are recorded in this particular section, to reflect appropriately on the reactions to this recent (and partly unprecedented) disruptive time (Boxes 5.7 to 5.27). 
BOX 5.7 "Coronavirus disease (COVID-19) advice for the public" (This extended public guideline was developed by the World Health Organization (WHO), providing: (i) Basic protective measures (with instructive videos), (ii) Protection measures for people whom are in or recently visited infected areas, (iii) Graphical guide for individual protection, (iv) Graphical guide to cope with stress, (v) Graphical guide for food safety, (vi) Graphical guide for shopping and working in wet markets in relevant contexts, and (vii) an Extended graphical guide for travellers)

Under (i)

"Basic protective measures against the new coronavirus"

This was provided in a list, explanatory guide, and educational videos to inform the general public of the basic protective measures. Key factors were highlighted, explaining not only the measures but the reasons for why they are important in this particular event. These factors include:

- Wash your hands frequently;

- Maintain social distancing;

- Avoid touching eyes, nose, and mouth;

- Practice respiratory hygiene;

- If you have fever, cough, and difficulty breathing, seek medical care early;

- Stay informed and follow advice given by your healthcare provider.

Under (ii)

"Protection measures for persons who are in or have recently visited (past 14 days) areas where COVID-19 is spreading”

- Follow the guidance outlined above;

- Stay at home if you begin to feel unwell, even with mild symptoms such as headache and slight runny nose, until you recover. Why? Avoiding contact with others and visits to medical facilities will allow these facilities to operate more effectively and help protect you and others from possible COVID-19 and other viruses;

- If you develop fever, cough and difficulty breathing, seek medical advice promptly as this may be due to a respiratory infection or other serious condition. Call in advance and tell your provider of any recent travel or contact with travellers. Why? Calling in advance will allow your health care provider to quickly direct you to the right health facility. This will also help to prevent possible spread of COVID-19 and other viruses.

Under (iii)

"Protect yourself and others from getting sick" 
This is provided in four pictorial documents, which are just summarised in their categories in here:

- Wash your hands;

- Protect yourself and others from getting sick;

- Protect others from getting sick (1);

- Protect others from getting sick (2).

\section{Under (iv)}

\section{"How to cope with stress during 2019-nCoV outbreak"}

This is provided in two very detailed pictorial documents, which are just summarised in their categories in here:

- Coping with stress during the 2019-nCoV outbreak

(Including a set of six guidelines on emotional matters, healthy lifestyle, guide for health support, getting the facts, limiting worries, and development of new skills);

- Helping children cope with stress during the 2019-nCoV outbreak

(Including a set of five guidelines on children reactions, children care, guideline for support in case of separation incidents, keeping regular routines, and providing them with facts).

\section{Under (v)}

\section{"Practice food safety"}

This is provided in three pictorial documents, which cover guidelines for dealing with food (raw meat and cooked food), hygiene matters, nonconsumption guide for sick animals, and meat preparation.

\section{Under (vi)}

\section{"Shopping/Working in wet markets in China and Southeast Asia"}

This is provided in three detailed pictorial documents, which cover guidelines for a variety of factors covering guidelines on washing hands, avoid contacts with animals, safety measures during and after visiting such places, and a detailed guideline for disinfection measures and practices.

\section{Under (vii)}

\section{"Stay healthy while travelling"}

This is provided in five detailed pictorial documents, which cover guidelines for a variety of factors such as, (1) non-travel guides in case of having any symptoms, (2) certain safety measures during travelling; (3) guide for dealing with precautionary measures and medical products, (4) guide for development 
of symptoms while travelling; and (5) General guide for things that should be avoided while traveling.

Original source https://www.who.int/emergencies/diseases/novel-corona virus-2019/advice-for-public.

\section{BOX 5.8 "Safety measures for local online transportation systems"}

By following all protocols and new regulations, all businesses and enterprises had to provide a reflective guide and report, to maintain the safety of both their employees and customers. $\mathrm{DiDi}$, as the most popular online transportation system in China, provided a range of reassuring guide as part of their reaction to the outbreak. The below examples are mobile phone adverts from DiDi Company.

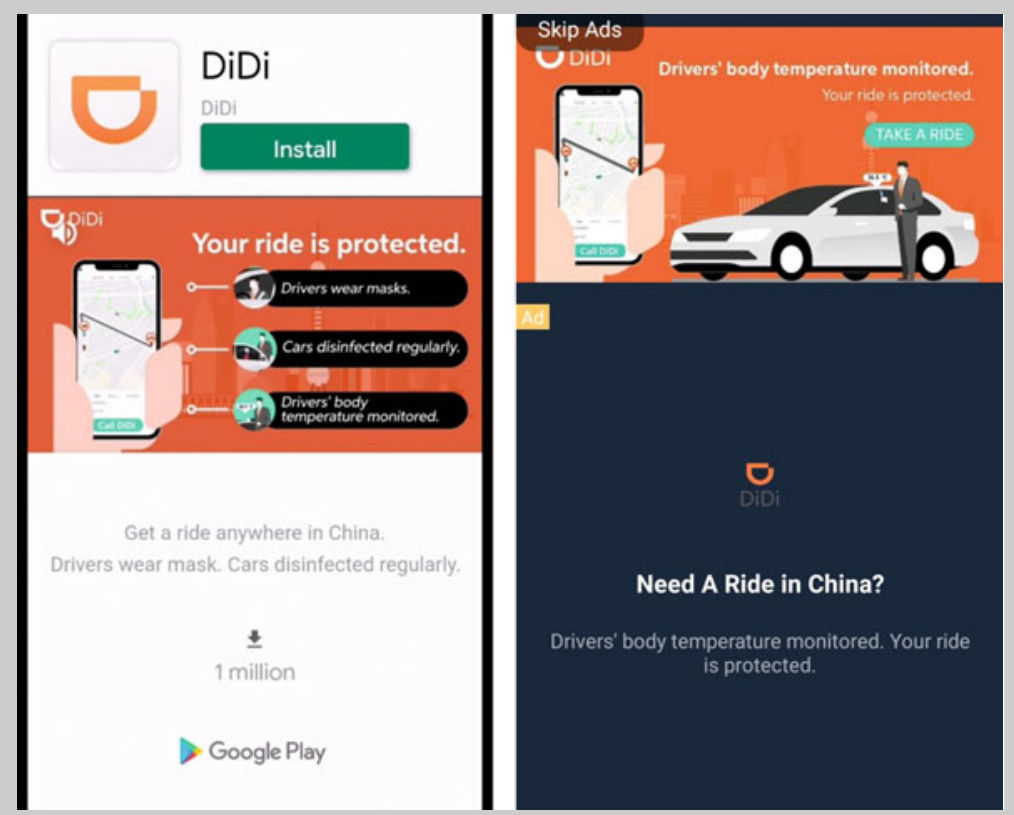

In such particular events, all companies have to be extra cautious as any reported infected cases in their premises/facilities or through their services/operations could cause adverse impacts on the sustainability of their operations. This may also cause longer economic impacts on their businesses. They also have to be cautious in case of any potential malicious acts from unpleasant customers or their rancorous competitors/rivals. It is important that 
in all cases, businesses keep transparency in their operations and must keep their workforces as safe as possible. The wellbeing of their employees should remain a priority. They also have to be as transparent as they can in order to release information on infected cases and provide their reflective response to those incidents. This approach helps them tremendously to tackle any false information/news from unofficial media and social media. Hence, risk assessment is generally high for businesses and enterprises.

\section{BOX 5.9 "Issues of price control and stock checks on primary products"}

The outbreak causes disruptions on primary products, especially those that are identified as useful products against the disease spread, such as disinfection products (shown below), medical supplies (such as masks), medicine, and fresh produce. There are inevitable impacts on unavailability and shortages of such products, lower stocks, higher prices, and counterfeit productions. Some of these may be caused by people's panic buying, hoarding of specific goods, and uncontrolled measures. Hence, high-level regulations and their immediate reinforcement can help to avoid or minimise such impacts. There are also cases of rapid fluctuation in food prices, some lowering due to high stocks and some increasing due to high demand. For instance, in China pork prices were soared by $116 \%$ in less than a month, while chicken meat was at its lowest due to piling up stocks in particular parts of the country. But eventually, the February records indicated a $5.4 \%$ spike in China's consumer price index (CPI), in comparison to last year's figures. Therefore, the imbalance in supply and demand requires immediate attention.

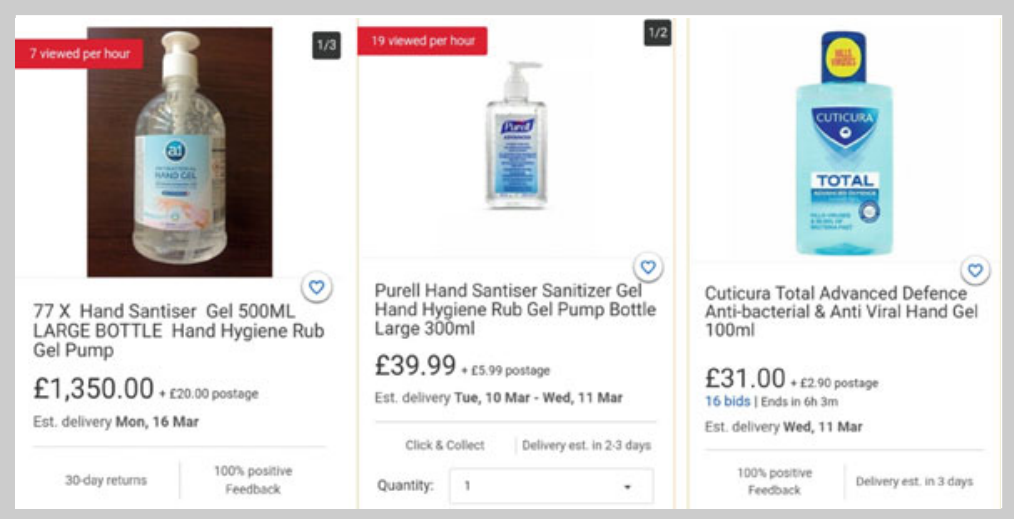


Elsewhere, shortages and rapid increase in prices were even worse. In the UK, for instance, hand sanitisers were sold 25-40 times of the original price (shown above). To overcome some of the issues, the governments responded by reinforcing their law and ensuring they are followed by all involved stakeholders, such as:

In accordance with law and principles, the government will sternly deal with acts that interfere with quarantine efforts, illegal hoarding of medical goods and acts that spark uneasiness through massive rallies.-Quoted from South Korea's Prime Minister, Chung Sye-Kyun, on 22 February 2020

Shortages in essential food and household items could also become a serious concern for the government. After the early rounds of the supermarket rationing act in the UK (in early March 2020), the government had to step into meet with the main supermarkets of the country and discuss their responses. This meeting was arranged on the 9th of March 2020. This also was to ensure the supply chain and delivery of essential goods are well-maintained.

With temporary shortages in the first two weeks, China's Ministry of Commerce (MoC) had to step into boost food production and operations, on 6 February 2020. A response to increasing demand should be met and those who illegally increase the prices would be fined.

\section{BOX 5.10 "Society's Response and Coping with the outbreak disruptions"}

People's reactions are generally dependant on the level of seriousness taken by their governments; i.e. one reflecting precisely on the other. The media coverage is usually a big player, and society reacts to any disseminated news and information. Regardless of their false or correct information, the media coverage is effective as they can feed into the outbreak progression in various ways.

Generally, people's perception of the outbreak changes quite drastically during the whole event. It also differs from culture to culture, as we witnessed through the examples of how the same outbreak was handled differently in various parts of the world. In China, the society went through the cancellation of the New Year celebrations in a bid to contain the outbreak. Amid all uncertainties, people took the issues less seriously at first, but there were signs of growing anxiety. The immediate comparisons to the 2002-03 SARS outbreak were widespread and the lockdown of Hubei Provinces was a major turning point in people's perception of the disease. The local media coverage of the hospital construction site started from 24 January 2020, then intensified the seriousness of the outbreak. State-owned news outlet Changjiang Daily highlighted: "The project will solve the shortages of existing medical resources 
and would be built fast and not cost much". By the day after, 12 provinces in China had growing numbers, which was then doubled by the 26th of January 2020. With more than 50 cases outside mainland China by 28 January 2020 , we witnessed diverse responses at the global level. On the last day of January 2020, Zhejiang province (where Ningbo is located) became the first province outside the epicenter with more than 500 confirmed cases. By then comparisons with previous cases, such as the H1N1 outbreak in 2009, were mostly to reduce the initial shocks. By then, there were growing concerns in various parts of the world. But it was only by the end of February 2020, when the situation was worsened with fewer more countries labelled "high-risk countries", and the spread took a much faster pace outside the boundaries of China.

\section{But how serious is the outbreak?}

We witnessed general global neglect on the seriousness of the outbreak. The persisting dismissive attitude from meme-making and jokes about the disease was not necessarily aimed to ease the anxiety, but they were simply adding to the informality of the situation. In general, such an approach gave a false perception of the seriousness of the situation. This impacted the general public as they often only comply with general requirements when the situation is worsened and in extreme conditions. This is unfortunate, but we have witnessed many examples of such incidents on social media, particularly in the areas where the number of cases was gradually mounting. This can be considered perhaps as a natural reaction of self-comfort, but we have to also understand the possible adverse impacts of being dismissive on something that is quite serious, disruptive, and impactful. It is a good reminder that positive thinking is different from dismissive thinking. Amongst these though, there were some comments that had dual tones, such as: the question "why the disease outbreak became so intense in South Korea?" And the response was, "because South Korea didn't learn from North Korea".

On the other side of society and from those at top of the pyramid, the issues were not any better. Some thought just because they are above the law, they would not get infected or pass the disease. This reflects on the amount of care some of those individuals may have for the general public. Unfortunately, we have seen dismissive responses from those that people are devoted to the most, from famous figures, social media influencers, sportsmen, royal family members, politicians, etc. Undoubtedly, such ignorant behaviour has a pervasive ripple effect on society.

Started with spreading the video and images of 'bat soup' in social media, the society's response was relatively dismissive at first. It took society some time to realise the complexity of the situation and have a more serious understanding of the consequences of the outbreak. As the outbreak started in different locations at different times, and its severity was also different, the responses were quite 
different, too. In general, however, the seriousness of the situation and how it is handled by the society is dependent on how it is driven or handled by the government or the authorities. As proven, if handled less seriously through the power of governance, then it is likely it is also followed less seriously by the general public. This was evidenced through the issues associated with gatherings, people's mobility/movement, people not following precautionary measures, people not following the procedures, and even in some cases ended as breaking the lockdown rules imposed by local governments. In some countries, the local governments also imposed fines against those who acted against the lockdown measures. For instance, there were more fines and restrictions related to issues of hoarding (in the form of stock piling up), unofficial increased prices, and unapproved opening of businesses. Moreover, there were common societal issues with mobility matters as many methods of movement control order were not taken seriously. In some cases, these involved the military or defence forces for the better control of the situation. Other examples include the restrictions or measures imposed for certain procedures to control the transmission and even delay or reduce the impacts. In some countries, we realised the use of medical masks were only practiced by certain groups of people. Also, there were official announcements in those countries to only use such products in case of having any related symptoms. This was somehow perceived as an immediate action against racism or hatred incidences that were growing rapidly.

More focused on general health concerns, the immediate economic impacts were also of major concern to the majority. This, in particular, turned into much bigger adversity for the vulnerable groups of poor and low-income people. The struggle of such vulnerable groups reflected on the knowns and unknowns of the society, the deficiencies of social services, and the ineffectiveness of governmental actions.

For the first time perhaps, the general public noted how a simple act of 'washing hands' is done wrongly on a large scale. Then, there were many educational guidelines from both official and social media to cover such assumingly simple matters. Moreover, the later natural reactions to survival, such as panic buying, were amongst those that represent our greedy nature. On this matter, the way how people reacted and how some responded were noteworthy. The situation made us aware of how vulnerable our societies have become. One anonymous response stated: "vultures emptied my local supermarket of all meat, frozen food, tins, bread, pasta, milk, toilet roll and even washing tablets. But they left all the high-end pricey stuff. Bless them. It's hard to root for mankind sometimes". Another response was on issues of greediness, which argued that "hopefully when the greed runs out, the rest of us can go and do a normal shop without this aggravation. Sadly, only when the stock piling has filled theirfridges, freezers, garages, garden sheds, and the lofts". Also blended with some blames against the political system, there were disappointing feelings against how people are not considerate against the vulnerable groups and 
elderly: "be sensible, take care and look out for the vulnerable". Moreover, they were unprecedented scenes of fights and arguments in supermarkets around the globe, which was then reminded us the famous statement by Margaret Thatcher (quote from 1987) that says, "There is no such thing as society: there are individual men and women, and there are families". There were also some valid comparisons of these generations with those who fought for their countries, who saved lives, and were remembered to be more sympathetic to each other.

Under the growing global concerns and wide-range disruptions, society's inactions were also seen as a major challenge. The ripple effect from informal approaches of the government to lack of compliances by the general public was seen as a major matter that showed the level of collective thinking in our contemporary societies. There were growing worries against certain technologies, some treatment measures, and many examples of anxiety in society. The elderly assumed the disease was an attempt to get rid of their generation, while the youngsters were still in denial about the impacts of the disease on their assumed-stronger immunities. There is no wonder why some countries starting to blame the others as early as they could, and later asked for unrealistic compensations.

With the many hypothetical arguments, non-evidenced knowledge shares, biased discourses, blame games, and deteriorating power relations, there were no surprises that we witnessed random responses from the society, too. We see the growing impacts of such informal approaches on how society perceives the realities and then copes with the adversities. The impacts of such thinking always become widespread and affect society the most. Moreover, in this new chapter in our contemporary age, a novel disease made so much impact on our everyday life and is expected to make more changes in the years to come. Although this event enabled us to realise more about the realities, it is expected the society forgets faster than the normalisation of our operations.

While some countries started to invest in their healthcare systems and strengthen their resilience measures/plans, other countries were threatening to cut their budgets to global health organisations. While some were progressing faster through the development of medical sciences and adaptation of new technologies, some were stuck with their divine narrative. While some countries were accepting patients from their neighbouring countries, some were developing fear and anxiety against the idea of 'contaminated' foreign nationals. While we witnessed much act of love and care, many opportunists went against the flow of humanity and chose to go with the economic values and benefits. While there were growing inequalities in every corner, we had concerns about who were the real heroes of society.

During this event, the need for global governance was ever important, for cross-countries and sub-regional measures to help enhance our unity rather than towards individualism and fragmented decision-making procedures. And also for national guidelines to help regional/provincial strategies to become 
stronger for the support of better implementation in the network of cities, the city and its environments, and the network of communities. While the larger scaler strategies are not realistic, they should be passed on to smaller scales that are more feasible for better implementation and more effective results. In countries where health checks and quarantine (not lockdown) measures were in place most rigidly, those people under quarantine were under full monitory and regular checks.

With 14 days of strict quarantine measures, those people had to undergo a significant number of health cases before they could be provided with a "notice on the removal of medical quarantine observation". Hence, more than quarantine itself, it was the observation measures that were important throughout the process. One of these letters indicated: "Everyone is the first person responsible for their own health. These actions are surely in favour of the health of yourselves, family members, and the public to taking good personal hygiene and living habits, as well as to further improving the awareness and health accomplishment for the epidemic prevention and treatment. It also helps the prevention and control of the novel coronavirus pneumonia epidemic. May we work together to overcome it" (extracted from the notice provided by the Chinese Prevention and Control Teams). This example, along with many others, shows the seriousness of this event, as well as the collective measures that are needed to overcome the issues.

\section{BOX 5.11 "Political and International Responses"}

Here are extracts from a famous British sitcom TV series from 1986 to 1988, "Yes, Prime Minister" (a sequel from the earlier "Yes Minister"), written by Antony Jay and Jonathan Lynn, in its episode on "A Victory for Democracy" (1986), which suggest how the standard foreign office response may be in a time of crisis. This is the communication between two main characters of this episode, Sir Richard Wharton (A), and Sir Humphrey Appleby (B):

(A): In Stage one we say nothing is going to happen. (B): Stage two, we say something may be about to happen, but we should do nothing about it. (A): In stage three, we say that maybe we should do something about it, but there's nothing we *can* do. (B): Stage four, we say maybe there was something we could have done, but it's too late now.

All of a sudden, the above communication was viral on social media.

It is indeed unfortunate to see public health become political. Nevertheless, the outbreak event with its broad international angle, adds to the complexity of politics around public health. The mental wars of one country against another 
(or one group against another) play a big part in the political issues of international relations. The fact that at first COVID-19 was globally symbolised as 'Wuhan Disease', 'Wuhan Coronavirus', or 'Wuhan Virus' showed how onesided this mental war could be in one of the most difficult times of the country. In the early days of the outbreak, China was under international criticism, but was later appraised as its efforts turned into eventual success. At first, China's lockdown approach was condemned by the global powers as it was deemed to have issues against its effectivity from various perspectives. A few weeks later, the approach was not appraised but was branded as a role model for those high-risk countries. Soon after, several countries implemented the same measures. It was on 10 March 2020 that Italy, as the whole country, was under full lockdown.

The US-China relations are a good example of political relations in this particular event. The United States was the first country to impose bans for entries from China, and their government representative referred to the situation as an opportunity for the US economy. The outbreak also exacerbated the already heightening trade wars between the two countries. The situation was escalated so rapidly that the two countries' presidents had to hold their first outbreak-related phone meeting on 7 February 2020. The concluding points of their meeting were on better communication, better coordination, and joint efforts towards the containment of the disease. The meeting then helped to partly ease the already escalated situation. But the political stances may not be overlooked so easily.

Countries that lack preparedness also suffer at the time of response. The delayed announcements or action plans could only worsen the situation. For example, the UK's slow pace in preparation was distressing as the government's 4-stage battle plan seemed to lack adequate resilience thinking. Politically, it is correct that any country should do its best to reduce the negative impacts. But it is utterly unacceptable to utilise this as an approach to reduce awareness and then dwindle the societal preparedness. Moreover, those countries with no reports of infected cases, if not genuine, face three scenarios: (1) they may not know if they have cases for whatever reason, (2) they do not want to know as they may seem to be unprepared, or (3) they do not want others to know for continuity of their international trade, tourism, etc. In the latter instance, the game played on is to make a bigger problem as small as possible. Also as per records, the poorer nations and conflict zones either claimed they had no cases or they simply delayed announcing it as their economies could not cope with disruptions. 


\section{BOX 5.12 "Government Responses"}

Government responses are generally different depending on the level of risk, the needs, and the preparedness they may have to deal with the outbreak. Some of these were strong and reassuring, while the other came with delays and more uncertainties. Some call for solidarity while the others are passively observing the progress. In all cases, the provision of guidelines is essential to be a completely top-down approach. Any informality of responsiveness would have negative impacts on how the plans are taken forward or delivered at later stages. The (national) guidelines come in various forms and represent an array of responses. The Chinese president first announced, "I have, at all times, monitored the spread of the epidemic and the progress in prevention and control work, and continue to give oral orders and instructions". This reflects on the provision of national guidelines to those lower governmental levels for the implementation plan. This led to lockdown strategies. After his first visit to Wuhan during the outbreak on 10 March 2020, the Chinese President acknowledged, "The situation of coronavirus prevention in Hubei and Wuhan has shown positive changes and achieved phased results, initially realizing goals to stabilize and turn around the situation". This was a clear message to reflect on successful progress.

With growing criticism on the general public, the Italian Prime Minister requested people to follow the public health emergency that was imposed on 21 February 2020. He urged people that "The Future depends on us and everyone must do their part". Soon after, on 10 March 2020, the whole country was under full lockdown. Meanwhile, the UK government suggested a 4-stage plan (as shown below) in early March 2020, announced by the UK Prime Minister: "The plan has four strands. Containing the virus, delaying its spread, researching its origins and cure, and finally mitigating the impact should the virus become more widespread. That is, contain, delay, research, mitigate". The research stage was later described as a continuous and prolonged stage.

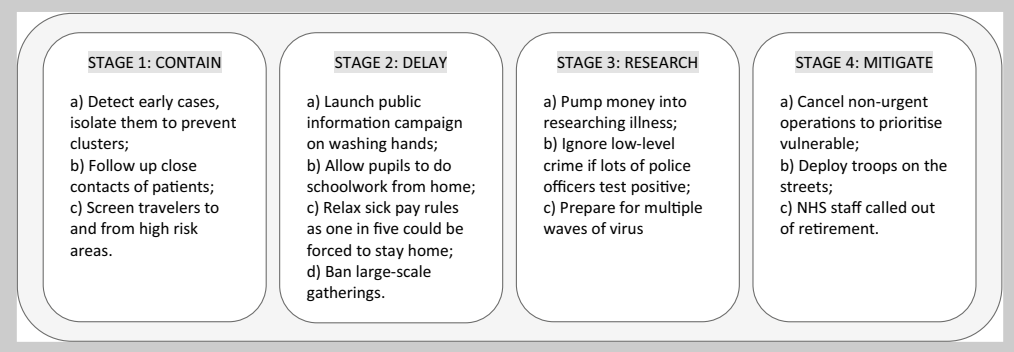

There were examples of responses that reflected on dismissive thinking against the handling of the situation. For instance, as the Grand Princess cruise liner was stuck in limbo off the Californian coast with 21 confirmed infected 
cases on board (at the time), the US president responded "I like the numbers being where they are. I don't need to have the numbers double because of one ship that wasn't our fault". Perhaps this was an inconsiderate reflection on the earlier situation experienced by Japan. This issue also came at the time the stock market had its biggest hit since the 2008 economic crisis and oil prices had the highest drop in value in a day since 1991. This was 9 March 2020, when the US president informally announced: "So last year 37,000 Americans died from the common flue. It averages between 27,000 and 70,000 per year. Nothing is shut down, life \& economy go on. At this moment there are 546 confirmed cases of coronavirus, with 22 deaths. Think about that!'.

\section{BOX 5.13 "Health System Responses"}

According to the Network for Public Health Law (2020, online source), the health system response includes a wide variety of actors and requires to be developed as part of policy development procedures. These actors include: "public health agencies, health care workers, emergency managers, and policymakers are grappling with core legal preparedness and response efforts, particularly related to emergency powers".

Also shown here is an explanation of legal and policy decisions during emergencies:

Public health officials may face many critical legal and policy decisions during public health emergencies, including:

- Inter-jurisdictional legal coordination of federal, tribal, state and local actors in real-time emergencies under changing legal norms;

- The ability to issue isolation or quarantine orders, or other social distancing methods, to control public health threats;

- Whether to close or dismiss schools, or other public assemblies, temporarily or for prolonged periods to prevent the spread of communicable diseases;

- The authority to mandate vaccinations for minors or autonomous adults, including health care workers;

- Licensing, credentialing and privileging out-of-state health practitioners;

- Inter-jurisdictional management of scarce resources including personnel, vaccines, shelter and sustenance.

- Omnipresent concerns over liability of public health practitioners during emergencies

From travel advisory plans as shown in (a) the representation of government action plan (example from Japan), (b) health system responses are vital to the management of the outbreak (example from Australia). The health system responses should be widespread (example from the UK) as shown in (c), or 
location-based and immediate to any arising matters (example from the US) as shown in (d).

(a) Under the measures of "Coronavirus (COVID-19) Advisory information" the Government of Japan (2020) proposed measures for travel, safety tips, information for main official resources, information on 24/3 medical needs (multilingual support), insurance, news, and temporary closures of places of interest/attractions. A detailed health advisory is helpful to provide necessary and right information to the general public. It is important these are regularly updated and everyone has the right to access the resources.

Source https://www.japan.travel/en/coronavirus/.

(b) Alongside many health advisory guidelines, the Department of Health under the Australian Government released action plan information in the forms of "government response to the outbreak" (2020a) and "emergency response plan" (2020b), both accessible by the general public. In the former action plan, the information includes:

"what we aim to do", "who managed the response", "our response plan (also the latter source)", "what we are doing now", and "what you can do".

This is an informative source that covers issues related to overall aims, economic management plans, health matters, reviews and responses, guides, approaches and steps. In the latter source (2020b), the plan is aimed to "guide the response of Government health agencies", "make sure the actions are well coordinated" and "outline four main stages of the responseinitial action, targeted action, stand-down, preparedness". This document is intended for the general public, and includes an overview of the national approach, and the government's operational plan.

Source for 2020a: https://www.health.gov.au/news/health-alerts/novel-cor onavirus-2019-ncov-health-alert/government-response-to-the-covid-19outbreak.

Source for 2020b: https://www.health.gov.au/resources/publications/aus tralian-health-sector-emergency-response-plan-for-novel-coronavirus-cov id-19.

(c) The UK's National Health Service (NHS) is the country's main publicly funded healthcare system. At first, they contacted people in early February via text message notifications:

If you have recently returned from mainland China, or have been in contact with some who has, and are experiencing flu like symptoms then we advise that stay at home and call 1111. Please do not attend the surgery.

Almost five weeks after in early March 2020, NHS disabled their online booking system due to the uncertainty around the disease. By then, they developed an online general advice (NHS, 2020). 
Source https://111.nhs.uk/covid-19.

(d) Reported Coronavirus Case (an email source)

We have been notified today a resident of $[\mathrm{xxxxx}]$ that they have tested positive for the novel coronavirus (COVID-19). The individual and roommates are currently self-quarantining inside their apartment.

The notification message then continues with safety and cleaning procedures, as well as health and well-being considerations. It then provides a detailed information about required actions, including seven precautionary measures recommended by public health officials in the New York City, the US. The guidelines are then provided and communicated with those directly and indirectly affected.

\section{BOX 5.14 "Responses and Predictions from Experts"}

Amid all disruptions, some issues never change and some governments do not reflect considerately on the situation. In the middle of this crisis-like situation, The US successfully tested its first supersonic missile, claiming that it could target any point around a globe in less than an hour. Apart from these threatening messages, North Korea kept testing its missiles into the sea at the same time. And of course, our biased media only covers the latter. This is a reminder that some issues truly stay the same or even worsen in any situation. However, the pandemic outbreak was more than just one or two military businesses. It was seen a game-changer event that could have longer impacts around the world. For instance, failures in the European Union (EU) management and control of borders, angered many who thought the restrictions and bans came later than expected. Some countries planned to print out money and some even suggested to print money and pass their financial support packages to people's doorsteps. Soon after, those who advanced in the name of human rights or becoming united, only looked after their (own) priorities and imposed their (own) country-level strategies; so much for the spirit of unity, that has a range of different benefits for different parties.

In a race to showcase economic resilience, technology, and transparency, there are always many examples of governmental resolutions and actions to combat the disease outbreak. It is a major time to showcase the capacity and capability of resources, military forces, economic supremacy, political influence, technologies, scientific advancement, etc. For instance, we could see many countries announced their success in vaccine development as early as they could. But this time, the disease had more to change that just some policies, relations, and economic situations. Under the climate conditions of calamities, we cannot only anticipate selective impacts, but should foresee those impacts 
that can make changes in different ways. In an extended article by Politico Magazine on the 19th of March 2020, COVID-19 was identified as a large scale crisis, which can reorder society in many different and dramatic ways. They also highlighted several US-based experts' predictions, which are extracted and summarised here:

\section{Under 'Community' subject:}

(1) 'The personal becomes dangerous'-by Deborah Tannen, Professor of Linguistics

This is regarded as a new order, which comes with the loss of innocence or complacency. It also highlights the paradox of distance communication and how our greater comfort and safety may just be achieved through the absence of others.

(2) 'A new kind of patriotism'-by Mark Lawrence Schrad, Associate Professor in Political Science

This is narrated as an approach to salute those services and their workforces who sacrificed their lives and times to combat the disease. This was suggested as a potential de-militarisation of patriotism, which could represent patriotic figures more than just the military forces or military veterans.

(3) 'A decline in polarisation'-By Peter T. Coleman, Professor of Psychology

This is interestingly discussed as an opportunity to reduce the escalating political and cultural polarisation. This is argued based on two reasons of "common enemy scenario" and "political shockwave scenario", which could help to enhance more constructive patterns in the contemporary cultural and political discourse. However, this only depends on the political climatic conditions of the country and how it has developed in recent years.

(4) 'A return to faith in serious experts'-By Tom Nichols, Professor of National Security Affairs

The discussions are narrated through worries on how unserious things have become in recent years and how affluence and high levels of consumer technology have changed our attitudes. The situation in return forced people to accept facts and recommendations given by the experts, in an attempt to possibly bring more seriousness to the mentality and behaviours of the society. 


\section{(5) 'Less individualism'—By Eric Klinenberg, Professor of Sociology}

This is narrated as a turning point toward authoritarianism, a chance for the reorientation of politics and possible recoveries of our primary systems and services, such as public health, healthcare system, and public services. This is recognised as an opportunity to reconsider our values and enhance what may be lacking in our economic and social orders.

(6) 'Religious worship will look different'-By Amy Sullivan, Director of strategy

The arguments are compared with the conditions and challenges of war or diaspora or precaution, and how they may impact the daily operations of religious activities. Evaluated through cultural and social differences, the discussions were focused on our common good merely to revitalise our interconnected humanity.

\section{(7) 'New forms of reform'-By Jonathan Rauch, Senior Fellow and Activist}

The pandemic event is identified as a transformational time, similar to those that are experienced by certain communities or groups of people. The impacts are predicted to be on our healthcare system, as well as how the government can become more conscious of interdependency and communities. These would then lead to potential landmark reforms.

Under 'Technology' subject:

(8) 'Regulatory barriers to online tools will fall'-By Katherine ManguWard, Editor-in-chief of Reason Magazine

This is narrated as an opportunity to fast-track online tools and virtual platforms. Examples of such transformative opportunities are seen across multiple sectors or systems, from education to simple tasks of medicare billing. These changes will provide patterns that become norms in how we practice our work routines, meetings, appointments, classes, etc. Through remote working opportunities, we expect to see innovative or simplified methods of doing the same tasks.

(9) 'A healthier digital lifestyle'—By Sherry Turkle, Professor of Social Studies

This was suggested as an approach to use our devices more thoughtfully and more creative, and to make them work better for better uses than just social media. In order to do so, we have to apply our human instincts to our devices and make progress in how digital lifestyles can become more useful and supportive. 
(10) 'A boon to virtual reality'-By Elizabeth Bradley, Scholar of Global Health

This is a chance for virtual reality (VR) to be more innovative and even provide a programme to help with matters of socialisation and mental health. Intervention $\mathrm{s}$ of such kind are expected to become more popular and applicable.

Under 'Health and Science' subject:

(11) 'The rise of telemedicine'-By Ezekiel J. Emanuel, Chair in medical ethics and health policy

The pandemic is identified as a shift in the paradigm for healthcare delivery. The ultimate impacts of such a paradigm shift would be to offer more vide call medical checks, staying home and keeping out of the transit system. This is likely to reduce the pressure on our healthcare systems and also overpopulated facilities/services.

(12) 'An opening for stronger family care'-By Ai-Jen Poo, Executive Director of the National Domestic Workers Alliance and Caring Across Generations

The pandemic event has highlighted deficiencies in our care infrastructure. With larger impacts on the health and financial conditions of families, it is important to seek additional political support for family care and overcome the challenges that most people face in the changing conditions of the outbreak. This event also highlighted the growing ageing population, and how their issues should be addressed, through a better sense of care that is shared responsibility.

(13) 'Government becomes Big Pharma'-By Steph Stirling, Vice President of advocacy and policy

This is discussed mainly from the perspective that highlights flaws in our health systems, often due to high costs, inefficient operations, and a marketbased system for medicine development and production (including vaccines). In return, this should help to make resilient government approaches and promote the public sector to take direct responsibility for the development and production of medicines.

(14) 'Science reigns again'—By Sonja Trauss, President and Founder of Yes In May Back Yard

This is narrated as an opportunity to shed light on truth and give more credit to scientific findings. This event should also become an opportunity to enlighten 
science doubters, and increase the pubic respect for expertise in specific areas of public health and epidemics.

Under 'Government' subject:

(15) 'Congress can finally go virtual'-By Ethan Zuckerman, Associate Professor of the Practice in Media Arts and Sciences

The pandemic event provides an opportunity for many governmental activities and institutions to operate virtually. The continuity of governmental operations is as important as dealing with governmental reapportionment and expansion. The use of technologies at such a level could not only virtualise the institutions but also help to expand the size of the government.

(16) 'Big government makes a comeback'-By Margaret O'Mara, Professor of History

This pandemic event provided an opportunity to enhance the visibility of the government at multiple levels. This is also a chance to highlight the role of "big government" and its effectiveness in society. This is aimed to also support the public infrastructure, health, and wellbeing of the communities, and include economic support when needed.

(17) 'Government service regains its cachet'-By Lilliana Mason, Associate Professor in Government and politics

This event is identified as a chance for the functionality of government, and a chance to prove responsive and responsible support to the society.

(18) 'A new civic federalism'-By Archon Fung, Professor of Citizenship and self-government

This means providing the opportunity for local governments to become the main centers of justice, solidarity, and problem-solving. The event also helps to harness what needs to happen at the local level to reduce inequalities and provide transformative measures for economic inclusion.

(19) 'The rules we've live by won't all apply'—By Astra Taylor, Film maker

The pandemic event is described as a rule-changing opportunity to ensure we reflect on the realities and address the needs of vulnerable groups. These are specifically related to those rules that made society more delicate and unequal.

(20) 'Revived trust in institutions'-By Michiko Kakutani, Author and critic 
This is narrated as an opportunity to regain public trust which is crucial to governance. This is required to happen through transparency, highlighting what John M. Barry mentioned in his 2004 book on 'The Great Influenza': “. . . those in authority must retain the public's trust...[and]...the way to do that is to distort nothing, to put the best face on nothing, to try to manipulate no one".

(21) 'Expect a political uprising'-By Cathy O'Neil, founder and CEO of the algorithmic auditing company

The prediction here is a new political uprising in the aftermath of the pandemic event, and perhaps a movement towards "Occupy Wall Street 2.0". This should lead to drastic changes in the political system, and those associated with our economic systems and addressing the needs of the society.

(22) 'Electronic voting goes mainstream'-By Joe Brotherton, Chairman of Democracy Live

With proven technologies, there are now more possibilities for more mobile and at-home voting. These types of voting are already practiced worldwide, but it is yet to become the new normal. In addition, such technology use could help to enhance security, transparency, and cost-effectiveness of voting procedures. By adopting more advanced technologies, we could be steps closer to making electronic voting to become permanent.

(23) 'Election day will become election month'-By Lee Drutman, Senior Fellow

The pandemic outbreak could simply change the normal election procedures. One of these potential changes would be to have early voting procedures and provide a fair, equal, and transparent experience to all communities. While there are flaws related to issues of fraud and inconsistency in the voting process, this idea could possibly become a new experience to citizens.

(24) 'Voting by mail will become the norm'-By Kevin R. Kosar, Vice President of Research Partnerships; also Dale Ho, Director of voting Rights Project

The pandemic poses a threat to people who normally vote in person. Therefore, it provides a chance to encourage and promote alternative voting systems, one of which is voting by mail. There are certain requirements for some adjustments such as issues of language barriers, disabilities, limited postal access, or late arrival of the mails. Nevertheless, voting by mail can reduce the risks and help to promote the safety of individuals and communities.

Under 'the Global Economy' subject: 


\section{(25) 'More restrains on mass consumption'-By Sonia Shah, Author}

The pandemic event is recognised as a force on society to reduce consumptions, or to accept limitations on high-level consumer culture. This is likely to change some of the increasing outsizing culture or those already-developed habits of mass consumption. This is a chance to reduce our industrial footprint.

On the contrary, "the end of mass quarantine will unleash pent-up demand for intimacy and a mini baby-boom. The hype around online education will be abandoned, as a generation of young people forced into seclusion will reshape the culture around a contrarian appreciation for communal life".

(26) 'Stronger domestic supply chains'-By Todd N. Tucker, Director of Governance Studies; also Dambisa Moyo, Economist and author

The pandemic event highlighted some of the main issues around our supply chains. It was also proven that how one country's disrupted economy could impact others. Hence, the obvious opportunity to switch to:

.... a more robust domestic supply chain would reduce dependence on an increasingly fractured global supply system. But while this would better ensure that people get the goods they need, this shift would likely also increase costs to corporations and consumers.

These measures are to be taken into future considerations for better supply chain systems, and better management of product supply and shortages.

(27) 'The inequality gap will widen'-By Theda Skocpol, Professor of Government and Sociology

There are significant issues around inequalities. The adversities would have more impact on not only the vulnerable groups, but also the less affluent groups. There are issues regarding less ability to work from home, or certain jobs that may put people in danger of coming into contact with the disease. There are also concerns about lack of home-schooling or education for children of those who cannot handle such methods due to any reason, such as lack of resources, lack of access to high-speed internet, lack of time, lack of abilities, etc. Under 'Lifestyle' subject:

(28) 'A hunger for diversion'-By Mary Frances Berry, Professor of American Social Thought, History and Africana Studies

It is anticipated that the current pandemic outbreak would probably accelerate some trends already underway, mostly related to security technologies and control measures that were practiced during the event. After the event is over, we may witness how people will find their relief and support in their communities. 


\section{(29) 'Less communal dining-but maybe more cooking'-By Paul Freedman, Professor of History}

As our eating behaviours have already changed significantly during the outbreak, it is likely we require less demand for sit-down restaurants. It is expected that in a collective way, we will be temporarily less communal than before.

\section{'A revival of parks'-By Alexandra Lange, Architecture critic}

It is anticipated that after the pandemic event, people would value their parks (or other big spaces) more than before. People may start using parks for other reasons than just for selective or seasonal activities. This may result in more public investment in places that are open, accessible, and are suitable for all seasons-i.e. parks.

\section{'A change in our understanding of change'-By Matthew Continetti,} Resident Fellow

We must anticipate some paradigm shifts and those that may change our collective notions. This will eventually force us to revise our conception of "change". This event may simply change the issues related to societal frivolity and ceaseless activities.

\section{(32) 'The tyranny of habit no more'-By Virginia Heffernan, Author}

This pandemic event was a turning point against the "fantasy of optimising a life". This is likely to lead to major changes in our regular and established behaviours, such as those that are phrased as "our favourites: driving cars, eating meat, burning electricity". This event may potentially recharge our commitment to raise new concerns about our surroundings and happenings. Perhaps this can lead to a better understanding of "living peacefully and meaningfully together is going to take much more than bed-making and canny investments. The Power of No Habits".

Although the opinions and predictions of these experts are focused on the context of the US, most of them are applicable and relevant to other contexts, too. After the recovery from this pandemic outbreak event, we anticipate having its impacts lasting for long. The aftermath of this pandemic event is likely to include changes that will be widespread, and perhaps more impactful than we can predict now.

Original source: extracted from Politico Magazine (article on 19 March 2020), online source available from: https://www.politico.com/news/magazine/2020/ 03/19/coronavirus-effect-economy-life-society-analysis-covid-135579\#sup erComments. 


\section{BOX 5.15 "Lockdown, Limitations, and Bans"}

During the outbreak, and following from diverse government responses, there was also a range of measures addressing different methods of lockdown, limitations, and bans. There were different responses, again depending on the level of risks, the situation of each region (or sub-region), and some also included geographical situations, such as the vulnerability of small island countries/areas in populated areas like Singapore, or countries that are transit points between major hubs like Italy and Iran, or countries that faced issues associated with cruise arrival to their ports or tourism. Higher risks such as high level of mobility both in China at first, and later in the US, South Korea, and Italy indicated faster progress of community transmission in the regions with higher mobility. Here are selective measures:

China's lockdown was at both city-level and provincial-level. By the time the situation was worsening in other countries, and to avoid reversing the progress internally, China imposed new restrictions for people traveling back to the country. There were new and different quarantine measures in different categories. This was first imposed by Beijing on 4 March 2020, and soon after was followed by larger and secondary cities across the countries. In this approach, the cities localised the national-level guidelines with a new categorised quarantine policy including four distinct categories of (1) high-level input countries, (2) relatively-high risk input countries, (3) middle risk input countries/regions, and (4) Other countries with low risk. In each category, the quarantine measures were different:

1. High-Risk Input Countries-People travelling back from these countries within 14 days (back-tracking from 23 February 2020) need to perform quarantine for 14 days in government appointed hotels.

2. Relatively-High Risk Input Countries-People travelling from these countries within 14 days (back-tracking from 23 February 2020) need to perform quarantine for 14 days in government appointed hotels if they done have residence here. If they have residence here, the quarantine can be in their residence. (This category was later modified to: people in this category may also now have to undergo enhanced medical observation in a government designated hotel for 14 days).

3. Middle Risk Input Countries/Regions-Same as category 2, without the later modification.

4. Other Countries: Low Risk-People traveling from these countries need to complete the information register and report health condition periodically fi they do not show health symptoms entering the city.

Note Later on, from 24 March 2020, the quarantine measures applied to all people returning to China.

The detailed guide and restriction measures were announced alongside detailed quarantine requirements for any food delivery, courier, and 
garbage/rubbish. In the guidelines, it was also recommended to include medical observation checks, including initial registration and final cancellation of the observation process. One of the main reasons behind these new measures, as explained earlier, was to avoid reversing the outbreak progress. In the earlier case of eight infected foreigners traveling from Italy to Huzhou in Zhejiang Province, East China was an example that made faster changes to the situation's guidelines. While globally, the new measures by China were not welcomed, it was received very importantly internally for a country that just suffered in the first wave of outbreak. On 11 March 2020, the 14-day quarantine rule applied to all foreigners arriving in Beijing. After the outbreak was declared a pandemic on the same day, we witnessed a new round and higher level of travel restrictions and bans. This started with the US immediately banning any travels between Mainland Europe and the US for 30 days. As the decision deemed to be political and the number of cases was escalating in the UK, similar measures were imposed on other parts of Europe after two days. Similar measures were already developing in smaller nations, but now it was widespread.

The early school bans in Iran, particularly before the start of the Persian New Year holidays, was perceived less seriously by the general public. In return, the closure announcement led to higher intra-provincial mobility. The significant impact was seen in Northern provinces from a twofold: (A) popularity for local holiday destinations, and (B) clustered layout of cities in a large corridor around coastal areas of the Caspian Sea. This led to extensive bans in many provinces, the lockdown of selective cities, and higher-level bans in highly infected districts in the capital city of Teheran. Similar patterns of mobility were experienced in other places/countries, soon after the closure of schools. In the UK, it was recorded that only one day after the school closures people were clustered in beeches, parks, and popular attractions.

With larger fears over major religious activities and events, Saudi Arabia had to cancel some of their major annual religious activities, and put more restrictions on travel bans for people exiting the country. Eventually, the Qatif region as one of the main industrial regions for oil production was under full lockdown. The restrictions went beyond just the physical lockdown (similar to those in the region), and move into the next level of travel bans: "The new travel restrictions are far-reaching, and will impact citizens, residents, and those who regularly commute to Saudi Arabia for work". Later on, all foreign entries were banned.

The heightened restrictions were not only limited to the following bans from entries from high-risk countries/regions, or bans for Saudi Arabia's own citizens and residents. By 3 March 2020, the bans also affected citizens and residents of several other countries in the region, partly the smaller Arab states in the southern region of the Persian Gulf, including the UAE, Bahrain, Kuwait, Oman, and Qatar. 
From the early days of the outbreak, there were growing strikes in Hong Kong Special Administrative Region (HK SAR) demanding immediate border closure. With an intentional fire incident in one of the treatment centers, the situation led to the closure of border crossing and extended limitations on air travel to and from Mainland China. This also coincided with the first recorded death case outside Mainland China. The early updates on flights to/from Mainland China indicated: "In light of the Government Response Plan to combat the coronavirus infection, we will be reducing the capacity of our flights to and from Mainland China by 50\% or more, from 30 January to the end of March 2020". Effective after, from 2 February 2020, local airlines stopped their operations to selective destinations.

Globally, most regional flights either reduced or suspended their operations to and from China. Amid growing fears about the disease spread, the same measures were replicated for other countries/regions. The continuous and larger scale travel bans brought major disruption to global travel.

Countries like Mongolia and Russia closed their border. And North Korea banned any mobility between the two sides. North Korea also implemented high-level measures and warned against any negligence.

Closure of border and suspension of flights by the 29th of January 2020, was soon followed by the official governmental announcements by the UK and France. As recorded by the UK's Foreign and Commonwealth Office (FCO) on 4 February 2020, they provided:

...advise against all travel to Hubei Province due to the ongoing novel coronavirus outbreak. The FCO advise against all but essential travel to the rest of mainland China (not including Hong Kong and Macao). The British Consulates-General in Wuhan and Chongqing are currently closed. If you're in China and able to leave, you should do so. The elderly and those with pre-existing medical conditions may be at heightened risk. Later on, the same measures were applied to other high-risk countries.

The US travel ban on foreign nationals who have been in China was the first international measure, suggesting for "temporarily suspending the entry into the United States of foreign nationals who pose a risk of transmitting the 2019 novel coronavirus". This was effective as early as 2 February 2020, as announced by the Health and Human Services Secretary.

Singapore was also one of the first countries, second in the row, to put travel bans in place on 3 February 2020. Their approach was taken forward from the assessment conducted by a multi-ministry task force dealing with the virus, announcing "Our approach is to...[look]... at the evidence, at the source of where the virus is, how widely it is spreading, and which are the at-risk sources". Their approach was also very reflective of the outbreak progression as the fluidity of the situation remains unpredictable. They then added: "We will not rule out more action on travel restrictions but it has to be based not just on geographical proximity or distance but based on evidence on the nature of the virus [and] how widely it is spreading". 
A similar ban was also imposed by countries like Malaysia, Brunei, etc. These were implemented firstly due to high mobility between China and Southeast Asian countries, and then later due to a similar flow of travels between the Middle East and Southeast Asia.

On other examples of high-level measures, Israel imposed 14 days of quarantine for anyone entering from abroad, a high-level ban which was partly followed by Jordan and Saudi Arabia amid the growing fear and escalating cases in the region. This was initially imposed for 14 days.

Some smaller countries had more strict restrictions, such as the Kingdom of Bhutan, who banned all foreign tourists from entering the country from the early days of the outbreak. Another example is the Maldives, which temporarily forbidden entry and exit to selective resort islands and those inhabited by locals. Also, higher restrictions were imposed from earlier stages by smaller Pacific island states, such as Kiribati, Marshall Islands, and Samoa.

As Italy entered a critical stage by 10 March 2020, also regarded as its "darkest hour", its Prime Minister confirmed: "There won't be just a red zone... There will be Italy". The impacts of this message were heard in other parts of the European continent. The UK Prime Minister then later announced on the same day, that "...containing is extremely unlikely to work on its own".

The list goes on, and each case of isolation/quarantine and bans/restrictions were different from one another. They also developed and updated regularly, depending on multiple factors associated with the outbreak progression. Decisions were made differently by different authorities, even at multiple governmental levels. For some countries, this could also vary between different cities. In most cases, the measures were continuously changing depending on the outbreak progression in a specific region. Relevant authorities and airlines continued with regular updates on their temporary or longer-term adjustments. While this book is completing, the situation continues globally. Hence, we can only capture some of those cases that represent a variety of responses and measures. This is just part of the realities during this outbreak.

Note 14 days is seen several times across many examples of travel bans and restrictions. This was mainly due to the information on the disease incubation period in an infected person's body as a carrier. However, for nearly all cases the 14 days restrictions were extended and/or intensified.

\section{BOX 5.16 "From Travel Bans to Global Disruptions"}

It did not take long for many countries/regions to escalate their measures on travel bans and entry restrictions. For some, this was from the inception, and for few, it came after ineffectiveness of the first 14 days bans and restrictions. For instance, Israel started to ban all foreign nationals' entries from abroad (with some exceptions for self-isolation for 14 days) and began digital tracking of confirmed cases. 
The same or even more restrict travel bans were imposed (before or after Israel) by many others, such as Argentina, Australia, Chile, Costa Rica, Cuba, Ecuador, El Salvador, Ethiopia, Ghana, Guatemala, India, Jordan, Kenya, Malaysia (with very limited exceptions), New Zealand, Nigeria, Peru, Russia, Saudi Arabia, Syria, the Philippines, Ukraine, and many more. Some of these travel bans were the highest measures with the highest hit on the airline industry worldwide. Some countries of Latin America (including South and Central Americas), Asia, Oceania, and Africa had their bans and restrictions in place prior to high alert situations or just at the beginning of their upsurge in infected cases. This perhaps resembles a lesson learned from the case of the European Union countries, and not to repeat their mistakes.

On 17 March 2020, the European Union closed all borders of 26 countries to all visitors for at least 30 days. Soon after, the European Central Bank (ECB) launched an emergency package worth US\$820 billion to ease the impact across the Eurozone, by buying government and company debt. One day after, the borders between Canada and the US were closed by mutual decision and only opened for trade purposes and some cases of exceptions (such as for work purposes). Some bans also appeared to be apparent reactions against one another, almost a retaliation act that worsened some of the international relations. The examples were bans between Colombia and Venezuela, China and South Korea, the EU and the US, etc. On 15 March 2020, South Africa announced a national state of disaster. Others declared a state of emergency, and some regarded it as a wartime crisis.

The impacts on countries under sanctions or in war zones were worrying and catastrophic, reminding us of the fact that the so-called international community should consider the matters more thoughtfully at the time of need. The inhumane acts could only worsen the conditions of those countries/regions that already suffer from other existing or ongoing adversities. With poorer infrastructures and widespread shortages, we could face a disastrous situation and no longer just cases of crisis or emergency.

On the day all the states of the US had confirmed cases, the oil price dropped again to its lowest in 17 years, at US\$25 a barrel. The economic impacts were already global and affected many. On 18 March 2020, China had no new domestic daily cases for the first time from the start of the outbreak. This was recorded by China's National Health Commission (NHS) who reported no domestically transmitted cases in China for the first time. This was a positive record that brought signs of hope for a country that faced the disease in a shock, with little time for preparedness and responsiveness. However, this came under the threat of the second wave of imported cases, particularly for China, Japan, Singapore, and South Korea. By then, all four countries have been successful in their robust and effective control and monitory measures. In Japan, as the situation was changing by lifting its state of emergency. Their focus was meant to be more on recovery and sustaining social and economic activities. This 
came at the time that other Asian and European governments were begging their people to stay indoors and follow the precautionary measures. A remarkable example is the announcement of Malaysia's Director-General of Health on the day the country started its semi-lockdown (18 March 2020): "We have a slim chance to break the chain of COVID-19 infections...[and]...Failure is not an option here. If not, we may face a third wave of this virus, which would be greater than a tsunami, if we maintain a 'so what' attitude".

Also recognised as an unprecedented challenge, UNESCO (2020) confirmed that education disruption affected more than half of the students around the world (by mid-March 2020). This resulted from the nationwide education closures in at least 107 countries (till 18 March 2020) and more to come (12 proposed them soon including Bhutan, India, Myanmar, Russia, UK, US, Uruguay, Vietnam, etc.). Till that date, these closures impacted 861.7 million students at various levels and it was expected that they continue with further disruptions. UNESCO also reminded us of the importance of scientific cooperation and education and knowledge sharing during this time. This also comes with recommendations to provide immediate support to those in need and with minimised education infrastructures and facilities. As the disruptions created outrageous situations around the globe, the impacts on 'health and economy' were phrased alongside each other. On many occasions, the economic impacts were perceived or even fabricated (to some extent) to be more than the health impacts. On the contrary, there are many debates on prioritising public health and allowing for the economy to recover in a longer period. Nevertheless, it soon became a question 'which one is the priority?' Health or Economy? And then, should they be regarded as important as the other? Clearly, 'health' and 'economy' are two different things, but they have significant impacts on one another. An unhealthy society would mean an unhealthy economy, and vice versa.

Started as a health emergency, the outbreak transformed into a much larger event for many countries. This came at the time when China was recovering gradually with high concerns about any reversing trends. The event turned into a case of crisis or a wartime situation for some countries. Despite the time, there was for early preparation and prevention, it was as if the world was just watching in the first few weeks. The blame game was not yet finished, but was just more severe and became a tool of retaliation between different countries. As the blames against China were increasing, there were signs of more negative reports or opinions from various places. The continuous efforts to politicise the situation were unfortunate but somehow expected. For example, on 15 March 2020, the Jerusalem Post had an article that not only attacked China's role in the containment of the disease, but also allegedly and offensively undermined China's role model figure in anything else. The wrong accusations, however, were not deflecting or reducing any of the issues faced by the outbreak. Unfortunately, this is just an example and there were many more of this kind, or 
even worse ones than had signs of racism attacks, too. The many unthoughtful examples of accusations and mental wars are normally aimed to demonise and demoralise nations, governments, and groups of people. And unfortunately, the game of blames continues as always and our absolute unity in any adversity is not yet achieved.

In the midst of all these mischievous behaviours, there were signs of humanity, too. Those countries that helped China at the beginning of the outbreak later received help and support from China. Cities that were under full lockdown, were receiving external support, even from the military forces. Communities that suffered, received support from their neighbouring communities as well as their authorities who could assist. There were many volunteers on the ground at the community-level who helped to sustain the control and monitory measures. People had to help one another, and families had to become more resilient. These happened individually and collectively, too. Sooner or later, inactions had to get replaced by more robust reactions. Those that were yet to go on the list of highly-infected countries had to reflect on the dynamism of the situation. They had to learn and avoid repeating the same mistakes as others. They had to prepare and respond effectively. Many alerting reminders were given to the developing and low-to-mid-income countries of Eastern Europe, South East Asia, Africa, Central America, and the Middle East. Meanwhile, the possibility of the disease being a bioterrorism act was still on the table.

\section{BOX 5.17 "Economic Impacts, Business, and International Trade"}

With high-level restrictions and significant impacts on travel and mobility, there were also many adverse impacts on other main sectors, of particular economic impacts, businesses, and international trade. As expressed earlier, we anticipate these impacts would last longer than anything else.

Downside risks to our outlook mainly come from a longer outbreak, more severe disruption. If the outbreak outside Hubei persists beyond the first quarter, the disruption could be more severe than we assume.-Quoted from Jian Chang, Chief China Economist for Barclays in Hong Kong.

Monday 9 March 2020 was marked as a day of major economic crisis when global stock markets crashed significantly with $£ 130$ billion losses in the FTSE 100 , and Brent crude oil was as low as US\$30 a barrel. There should be no further surprises if these sudden losses and price drops happen again.

Oil firms, and US shale oil companies too, will face serious pressures with oil now trading around \$30 for WTI (West Texas Intermediate) and \$33 for Brent. Such pressures will include funding problems, spreading through the broader economy and ramping up expectations more rate cuts, and potentially monetary easing.-Quoted from Chris Beauchamp, Chief Market Analyst at IG Group, UK, 10 March 2020 
While keeping the economy as safe as possible remains the priority of many governments, the eventual impacts of the outbreak are somewhat uncontrollable. The impacts were so significant that within the first six weeks of the outbreak, there were reports of shortages of many commodities globally, less oil demand (and a later significant drop in prices), reduced sale from smartphone to passenger cars, reduced sale of luxury bags and products, reduced tourism (and travel in general), etc. In China alone, in January and February 2020, there were significant impacts on consumer-behaviour metrics, such as $\$ 60$ billion reductions of consumer spending on food and drinks (Jan and Feb), $80 \%$ reduction in hotel occupancy (in 2nd half of Jan, and 1st half of Feb), $92 \%$ fall in retails sales of passenger cars (1st half of Feb), and 37\% drop in smartphone sales (in Jan) (McKinsey Analysis 2020). The figures are expected to continue to either fall or create instability in the market.

With the growing number of consumer-driven economies relying heavily on high production and consumption and international trade, an outbreak of such scale could cause a serious economic crisis, and even a step closer to a probable recession. Similarly, McKinsey analysis (from McKinsey \& Company1) developed three scenarios of “(1) Quick recovery, (2) Global slowdown, and (3) Global pandemic and recession". While each scenario is expected to have different outcomes both for China and the rest of the world, their assumptions were based on four key areas of "public health response", "seasonality", "fatality ratio", "change in behaviours". Of the major economic issues, supply chain challenges were highlighted as the most worrying ones:

Perhaps the biggest uncertainty for supply-chain managers and production heads is customer demand. Customers that have prebooked logistics capacity may not use it; customers may compete for prioritization in receiving a factory's output; and the unpredictability of the timing and extent of demand rebound will mean confusing signals for several weeks.-Quoted from McKinsey Analysis, 2020

${ }^{1}$ McKinsey Report on COVID-19 implications for business, extracted from original source available from: https://www.mckinsey.com/business-functions/ risk/our-insights/covid-19-implications-for-business

\section{BOX 5.18 "Policy, Regulations, and Public Health"}

During the outbreak, we should anticipate developing policies, regulations, and regular updates on public health. Here are also a selection of examples that how diverse but how important these factors can be. An example of which is the early development of "Twelve Opinions on Stabilising Labour Relations and Supporting Enterprises' Resumption of Work and Production", released by China's Ministry of Human Resources and Social Security on 7 February 2020 (Yang 2020). This indicates the importance of adaptive measures that should be taken into full consideration as early as possible. The same flow that was seen in the US and the UK, and surely in other affected countries too. 
With 117 territories having confirmed infected cases by 11 March 2020, new policies and regulations on public health were inevitable. On this day, the outbreak was declared 'pandemic'. In the US, the Centers for Disease Control and Prevention (CDC) (2020b) continuously worked on matters of 'risk assessment and management' against the disease, particularly for the provision of guidelines for actions by public health authorities of those communities that are not experiencing sustained community transmission. In the UK, similar measures were developing in the form of guidelines (Public Health Matters 2020) with early precautionary measures and warning for the future stages. By highlighting in particular the societal impacts including probable impacts on lifestyles and possible measures, the UK's Public Health England (PHE) urged the general public to "plan ahead ... [and]... consider how you or your family would manage if you had to self-isolate for a couple of weeks". This message and many similar ones are preparatory measures for what may be regulated in the early future. This was followed by what the UK Prime Minister confirmed in a news conference: "We are preparing various actions to slow the spread of this disease in order to reduce the strain it places on the NHS".

Singapore's Ministry of Health $(\mathrm{MoH})$ also provided extended guideline that was also regularly updated ( $\mathrm{MoH} 2020)$. These updates were meant to clarify any remaining public misinformation and how the country's 'Disease Outbreak Response System Condition (DORSCON)' was responding to the progress. As informative as such reports or sources could get, they are meant to provide precautionary measures, health advisory, travellers' guide, and cover any areas under overarching matters of public health.

Issued under 'Report of the WHO-China Joint Mission on Coronavirus Disease 2019 (COVID-19)' (WHO-China Joint Mission, 16-24 February (2020)), this internationally developed comprehensive document provided clarity on six areas: the virus, the outbreak, transmission dynamics, disease progression and severity, the China response, and knowledge gaps. The information is provided through an established organisational structure and response mechanism comprised of nine working groups to coordinate the response:

Each working group has a ministerial level leader. Emergency response laws and regulations for the emergency response to public health emergencies, prevention, and control of infectious diseases have been developed or updated to guide the response (ibid, p. 27).

These are just a handful of examples from countries at high risk and those that are close to high risk. The general guides can often be followed by the other countries, but they should be adapted from a reflective approach considering the conditions of the society, addressing what regulations may be missing, and what policies may be required. It is important that these get updated on a regular basis and in a reflective approach. 


\section{BOX 5.19 "Media Coverage"}

International media covers anything negative against their rivals of any kind (e.g. political, economic, trades, geographical, historical, etc.). Like many other occasions, politicising the outbreak was perceptible since the inception. As expressed earlier, this should be avoided as much as possible. The impacts from the growing international negativity could be reduced by making the national media and multi-level resources, efficient, transparent, informative, and reliable. The official records should be available and acceptable to all by various means.

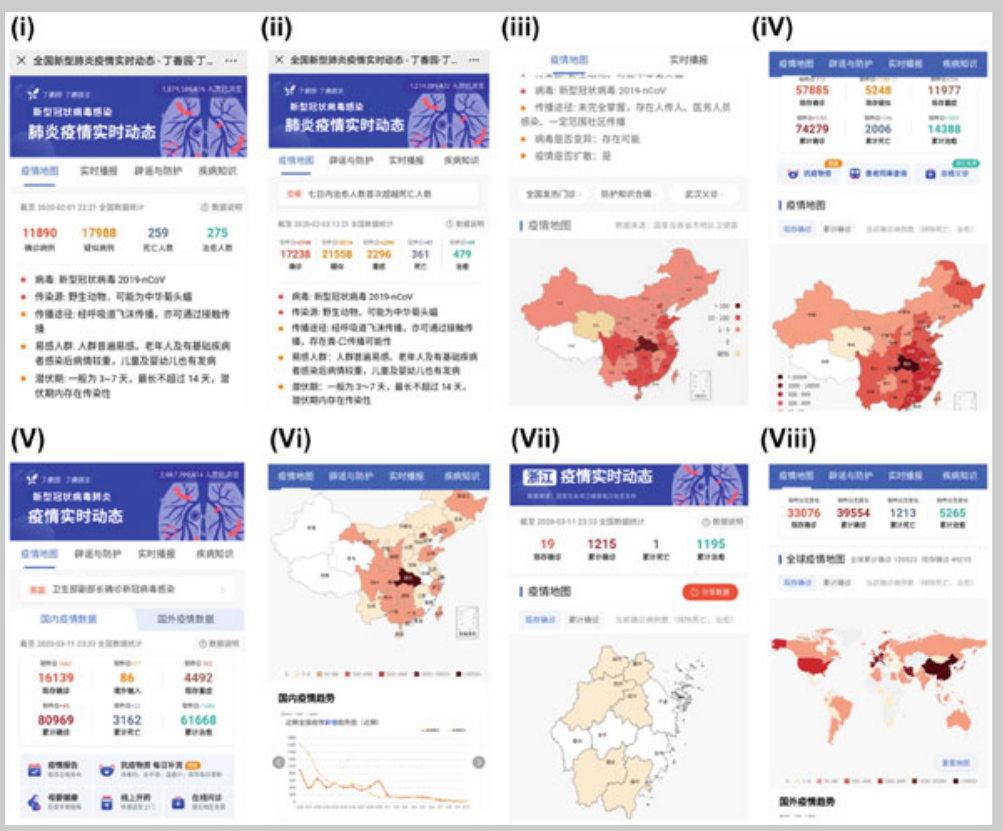

One of the best examples of this outbreak's media coverage, amid all the unofficial misinformation and international criticism, was the development of a multi-functional digital platform on social media. This official platform (as shown above in eight segments) was continuously upgraded during the outbreak. It started with very basic information and precautionary measures (i) and indicated the progress (ii). While the interactive map was utilised from the beginning (iii), more interactive tools were added at a later stage (iv). In the later stages, there more tools integrated into this platform (v), while all data were recorded with graphs and statistical reports from inception (vi). There was also available information for the smaller scale of provincial and municipalities (vii), which were later developed further to cover the global situation (viii). 
Perhaps, this is a good lesson to take on board; i.e. to make media helpful rather than harmful.

As it was described by many who faced lockdown measures for their first time, media was seen in the state of meltdown. Social media played a major part in developing manmade and manipulated scenarios, those that came with disbelief and with a lack of scientific grounds. While the so-called draconian social distancing measures believed to save lives during the pandemic event, some still phrased it as the situation of "house arrest". On the contrary, some believed in the effectiveness of the lockdown measures but also argued that the cure could be worse than the disease. Despite the many creative activities people put on social media, the ones under more pressure of facing more adversities found it unbearable and unrealistic. Nevertheless, even though the lockdown measurers were implemented late in some countries, the results then changed the situation by reducing the disastrous impacts.

The media coverage should avoid any retaliation reactions. While they may assume they could raise awareness, they could also increase the growing criticism of specific sectors. In doing so, people who are more dependent on social media may grow in disbelief and may pass their disbelief and agony to the others. This may also increase the disparities between people and their governments. An anonymous example was "The UK will likely be forced to an even worse lockdown, yet the underground tubes keep running in the capital, London is not isolated from the rest of the UK, and our borders are wide open. I am no longer taking the government responses seriously".

Some also regarded the event as a manipulating act of the government and the media who provide wrong figures, some requested more clarity, and some could not see transparency in the actual happenings. With so much of disbelief also comes narrow-minded disbelief against the actual threat of the disease, its severity, and its impact on a larger scale. Echoing some politicians, an anonymous comment was "Seasonal flu deaths far exceed COVID-19 deaths. The mass panic and deliberate power grab justified by the disease is likely to unravel with huge backlash when the public realises the size of the lie".

Despite the larger scale acceptance of science and scientific reports, some argued that the situation is manipulated by scientists and people were spoonfed. The attacks were often on virologists and epidemiologists that relate to the nature of the disease. These so-called manipulation scenarios were twosided, one that argued the government and scientists are hiding the truth and the situation is much worse, and the other assumed the situation is fine and manageable and the relevant sectors are overreacting. Both scenarios represent the group of people who could not trust the official reports and are likely to be the ones who do not comply with the official measure either.

With changes in records and methods of recording, the media could add to the uncertainties of the situation. As such, people argue about " a mockery of all graphs that appear in publications as those graphs are not and cannot be 
adapted to illustrate those changes". This came at the time, when the media was highlighting a social media material as positive news, an incident in the northern town of Wales highlighting "A herd of goats invade a village". We argue that the media should rather take a much stronger position, avoid the false spread of news, provide training, positive thoughts, and reactions, and help to raise awareness, and educate the general public.

Amid all concerns of the lockdown and multiple measures, the situation of the outbreak is always a chance for politicised discussions between countries and between different parties/groups of a country. This is specifically more visible in those nations facing the round the corner elections. The media often takes a biased position, which becomes an effective tool to manipulate society.

\section{BOX 5.20 "Micro Management of Outbreak Control and Protection"}

At the time when facial masks became part of our daily clothing attire, society experienced more fear than ever. While toilet paper shortage became a phenomenal matter, all countries already experienced disruptions of some sort. With continuous falls in the global stock market, crumbling airline industries, and drastic actions in newly-worried countries, it was clear that nearly all countries were affected by travel bans and restrictions. The pace outside China seemed much faster: the headline of every news, regular updates, upsurge in numbers, shortages, new bans almost every day, new lockdowns every few days, etc. In all these pandemonia, a simple cough was an alarming sound, and social distancing became a norm. In many places, social contacts were minimised, sudden regulations (often related to bans and restrictions) were imposed, and health systems were worryingly readjusting. For the first time, the total number of infected cases outside China overtook those in the country (as per records of WHO on 16 March 2020). In China, the push was towards full recovery, which was promised to happen by the end of March 2020. The provincial race to reach zero cases was realised as a big push for cities to accelerate treatments. Cities entering the recovery phase had to intensify their control and protection of their residents or those that were coming to the city. The extended measures were in place to take up a gradual pace of the recovery phase. Amid all these, we can refer to the importance of micro management, which is identified as the main ground of implementing the measures. 
(a)

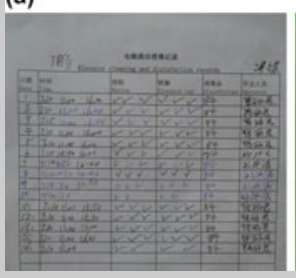

(b)

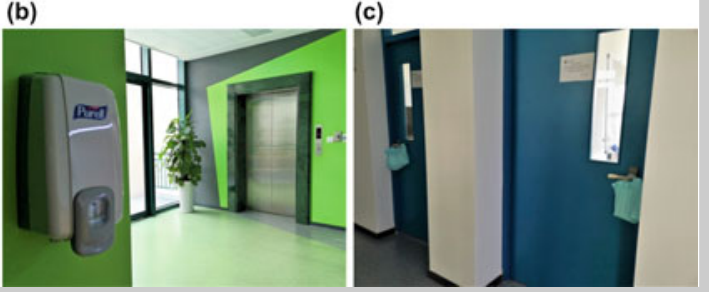

An example of this micro management is the implementation of guidelines (inclusive of control and protection) at the university campus, where we highlight some of the main measures. Apart from the earlier asset management and operation action plans (with contingency plans), there were plans for the gradual reopening of the premises and in line with the governmental announcements and planning. The facilities update that included the use of indoor sports facilities, teaching area facilities, and amenities of living areas were the highlights of gradual progress in the recovery phase. The enhanced measures also included: regular and detailed entry checks, restrictions to external nonregistered members, limited working hours of amenities, controlled sports facilities access (i.e. a maximum of seven personnel at a time), monitory of indoor environments, etc. Alongside the regular disinfection procedures of premises, more attention was given to details-e.g. for as lifts with three times disinfection procedures a day (a). Moreover, personal disinfection products were provided near any major transit points (b), with a regular check on supply. More importantly, protection measures and guidelines were provided in various forms and in various places. These included protection and prevention notes on doors (c) or in other areas. The necessary supplies (such as facial masks, disinfection sprays, and gels) were also provided to all members of staff (c), and those entered the university premises for the first time after the outbreak.

\section{BOX 5.21 "City-level Recovery under the Shadow of Global Emergency"}

With polarised decision-making processes in fighting the pandemic, we could argue one model as a more gradual 'Western Model' and the other a more controlled 'Eastern Model'. There were also signs of hybrid models, including what South Korea did with large scale lockdowns and testing. Some countries then ended up replicating the models of lockdown in their own contextualised way, which appeared to be more effective if they happened earlier. Also, in other regions, like in Eastern Europe, North Africa, Central Asia, Middle East, East Africa, there were signs of early lockdowns and early restrictions on mobility and transportation in and out of countries. This cautious reaction, while overshadowed by vast scale disease spread in specific regions, seemed to be a sensible move towards the Eastern Model. 
The widespread reductions in connectivity and mobility helped cities to have better control over the community transmission and import/export of the disease. The applicability of city borders and city boundaries proved to be a useful way to help the enhancement of city-level control measures. While cities like Ningbo were experiencing the recovery phase, risk management was highly visible across all sectors. The high level of monitory and control were intensified to avoid reversing the progression of the outbreak containment. This was an experience of city-level recovery under the shadow of a global emergency. Some more common examples of these measures were: (a) continuous health checks and temperature checks via the 'Ningbo Health Code' as the city's self-reporting health information system, (b) official records of temperature checks for people who pack and deliver food, and (c) protection guidelines provided by companies/businesses/employers to their employees/customers.
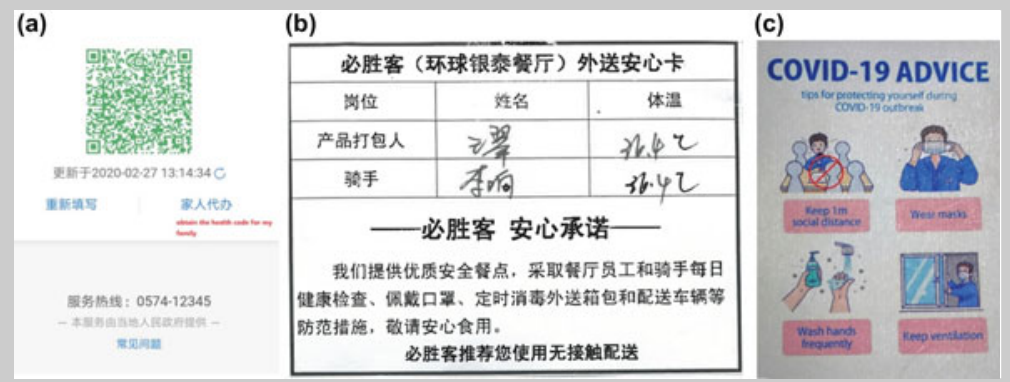

At the same people, people could not wait any longer to regain their social life and experience a life beyond their living compounds/areas. In the Chinese language, this situation is phrased as 'Wéichéng' (in Chinese 围城), which is translated as 'siege'. But in here, it actually means people inside a place would like to go outside (often due to dissatisfaction), and those who are outside would like to come inside instead. The situation in the recovery phase resembled a moment of wéichéng. With restrictions easing gradually, inner-city mobility was once again high. Soon, people found signs of hope and gradual stability.

\section{BOX 5.22 "Rapid Changes under Continuous Alert"}

Under the continuous alert situation, many changes happened so rapidly at the global level. Even though most Chinese cities were in their recovery phase (or close to recovery), they were under full alert for any escalated matters, or possible second wave of the disease outbreak. Under the shadow of global emergency and some very serious situations, China also rapidly tightened some of the regulations, restrictions, and control procedures. One of these was the 
immediate reduction of international passenger flights, announced on the 26th of March 2020. This came at the time when the number of cases was increasing rapidly in the US, Russia stopped all its flights in/out of the country (except for Russian citizens stranded outside or returning to Russia), and there was a state of alert and emergency in many regions.

Notice on Further Reducing International Passenger Flights during the Epidemic Prevention and Control Period 26/03/2020 (Notice on Further Reducing International Passenger Flights during the Epidemic Prevention and Control Period)

To All Transport Airlines: In order to resolutely contain the increasing risks of imported COVID-19 cases, and in accordance with the requirements of the State Council for joint prevention and control of the epidemic, it is decided to further reduce the number of international passenger flights. Details of the requirement are as follows:

(1) On the basis of the Information on International Flight Plans (Phase Five) released on the official website of CAAC on March 12, each Chinese airline is only allowed to maintain one route to any specific country with no more than one flight per week; each foreign airline is only allowed to maintain one route to China with no more than one weekly flight.

(2) Airlines shall, in accordance with the requirements above, apply for PreFlight plans to the Operation Supervisory Center of CAAC in advance.

(3) The Operating Permits and take-off/landing slots, etc. associated with the flights cut by airlines in accordance with requirements of this Notice will be retained.

(4) Airlines shall strictly implement the latest edition of Preventing Spread of Coronavirus Disease 2019 (COVID-19) Guideline for Airlines issued by the Office of China Civil Aviation Prevention and Control COVID-19 Leading Group, take stringent prevention and control measures on the flights to/from China and ensure passenger load factor no higher than $75 \%$.

(5) In accordance with the need for epidemic containment, CAAC may issue policy to further reduce the total number of international passenger flights. Airlines therefore are required to closely follow information released, analyse the situation and make contingency plans in advance, and handle in a proper way the issues such as extension and refund of sold air tickets, etc.

(6) Airlines may operate all-cargo flights with passenger aircraft, which will not be counted against the total number of passenger flights operated.

(7) Flight plans adjusted by airlines in accordance with paragraph 1 of this Notice shall be implemented as of March 29, 2020.

(8) This Notice shall take effect on the date of its issuance, and the expiration date will be notified separately. As of the date of taking effect of this 
Notice, the Notice MHF [2020] No. 11 issued by CAAC shall become invalid.

Civil Aviation Administration of China (Extracted directly from: http://www. caac.gov.cn/en/XWZX/202003/t20200326_201748.html?from=groupmess age \&isappinstalled $=0$ ).

Only hours after the earlier announcement on 'international passenger flight restrictions' (shown in the previous page), a much higher announcement was made by two relevant officials in China, namely the Ministry of Foreign Affairs and the National Immigration Administration. Under the growing uncertainties, global emergency, and concerns about the new waves of the outbreak, the new restriction was to temporarily ban the entry of foreign nationals to China. This was aimed to build protections against any possible blowbacks and a chance to research and maintain the full recovery at the national level; the full recovery that was showing lights of hope by the reduction of restrictions in Wuhan, the original epicenter of the outbreak. This sudden and heightened measure was seen as a reflection on other countries, and those success examples that introduced and implemented early and/or restricted travel control measures. Something that was criticised at first, but was recognised as a reflective response to the failures of the others. This can be regarded as what Fukuyama (2014) narrated as political decay in the ostensible 'democracies'. The way that ends up with weaker governance as it gets distracted by special interests to the detriment of the public good (ibid). Somehow, this can be seen as the failures of the new capitalism. It is important to note, this announcement came at the time that there were growing neglect by the US administration, while the US was already a new epicenter of the disease outbreak. A call that made it look like a retribution act at first, but it was a sensible move to keep out of the growing chaotic situations elsewhere. A call that depends on the other countries' success in flattening their curves of the outbreak progression (i.e. based on both infected cases and mortality rates). Also partly, it was also meant to avoid and reduce the growing domestic perceptions of contaminated/infected foreigners. This came after the earlier concerns of Premier Li Keqiang (CGTN News, 2020), the worries of the second wave of the outbreak, and the growing number of non-domestic cases (i.e. mainly those people travelling back to China).

This joint announcement is summarised here:

Ministry of Foreign Affairs of the People's Republic of China National Immigration Administration Announcement on the Temporary Suspension of Entry by Foreign Nationals Holding Valid Chinese Visas or Residence Permits, March 26, 2020

In view of the rapid spread of COVID-19 across the world, China has decided to temporarily suspend the entry into China by foreign nationals holding visas 
or residence permits still valid to the time of this announcement, effective from 0:00 a.m., 28 March 2020. Entry by foreign nationals with APEC Business Travel Cards will be suspended as well. Policies including port visas, 24/72/144-hour visa-free transit policy, Hainan 30-day visa-free policy, 15-day visa-free policy specified for foreign cruise-group-tour through Shanghai Port, Guangdong 144-hour visa-free policy specified for foreign tour groups from Hong Kong or Macao SAR, and Guangxi 15-day visa-free policy specified for foreign tour groups of ASEAN countries will also be temporarily suspended. Entry with diplomatic, service, courtesy or $\mathrm{C}$ visas will not be affected. Foreign nationals coming to China for necessary economic, trade, scientific or technological activities or out of emergency humanitarian needs may apply for visas at Chinese embassies or consulates. Entry by foreign nationals with visas issued after this announcement will not be affected.

The suspension is a temporary measure that China is compelled to take in light of the outbreak situation and the practices of other countries. China will stay in close touch with all sides and properly handle personnel exchanges with the rest of the world under the special circumstances. The above-mentioned measures will be calibrated in light of the evolving situation and announced accordingly.

Ministry of Foreign Affairs of the People's Republic of China and National Immigration Administration (Extracted directly from: https://www.fmprc.gov. cn/mfa_eng/wjbxw/t1761867.shtml?from=groupmessage\&isappinstalled=0).

Only a day after the earlier joint announcement on the heightened travel bans for foreigners traveling to or returning China, the ripple effects were seen in new regulations at the provincial and municipality levels. Bearing in mind that quarantine restrictions were already tightening for a while before it reached the highest level of travel bans (with some exemptions), this new measure was for the cities and provinces to focus more on their local level containment plans. After all, since the only eradication plan is based on new vaccine development, it is vital to take steps seriously and allow for no failures in the containment and recovery procedures. Here, we demonstrate an example of extended measures from the city-level foreign affairs of Shenzhen, south of China. Shenzhen is a major economic and technological hub in China, bordering Hong Kong SAR (Special Administrative Region).

The new announcement includes some of the details of the national level announcement and then includes:

- The Office of Guangdong Headquarters for Prevention and Control of COVID-19 announced that effective from 06:00 a.m., March 27, all inbound travellers (including travellers from Hong Kong SAR, Macao SAR, and Taiwan, and transit passengers) entering via ports of entry in Guangdong shall accept nucleic acid testing and undergo a 14-day collective quarantine for medical observation. 
- The accommodation and meals during the collective quarantine for medical observation shall be at their own expense. Specific persons for ensuring normal production and livelihood in Hong Kong SAR and Macao SAR, and persons such as cross-border drivers and ship crew who transport goods urgently needed in Guangdong Province, Hong Kong SAR and Macao SAR, are not subject to collective quarantine for medical observation temporarily but shall all undergo nucleic acid testing.

- Their health is strictly monitored and managed in an end-to-end manner to ensure closed-loop operation.

- For epidemic-related consultations, please call Guangdong Service Hotline 1258088 (in Chinese, English, Japanese and Korean), Shenzhen Government Service Hotline 12345 (in Chinese and English), Service Hotline of Foreign Affairs Office of Shenzhen Municipal People's Government 075588121224 (in Chinese and English), Public Hotline of Shenzhen Center for Disease Control and Prevention 88812320 (in Chinese) and Call Platform of Shenzhen Family Doctors 4401191160-2 (in Chinese).

Entry policies will be adjusted in accordance with the epidemic situation. Please follow closely. With our concerted efforts, we believe the epidemic will be over. Thank you for your understanding and support.

Foreign Affairs Office of Shenzhen Municipal

People's Government

Health Commission of Shenzhen Municipality

March 27, 2020

(Extracted directly from: The homepage of Shenzhen Foreign Affairs, China).

Under the fear of imported cases from outside China and the intensified travel bans and restrictions, there were signs of change at the city level. These were seen as examples of no-longer-gradual change, but those that were rapidly in place on 28 March 2020. For instance, "more than 30 commercial complexes in Ningbo have cancelled temperature measurement and health code display before customers enter, and the entrances and exits of shopping malls have been fully restored". While previously major supermarkets were conducting synchronous temperature measurements and health code checks, from this day, they were all cancelled. This was seen as the first stage towards gradual restoration, and bringing normal operations back to the city. With the return to normal opening hours, it was the start of the post-recovery phase under the shadow of outer-China growing cases, emergencies, and crises. This also came at the time that the original epicenter of the outbreak, the City of Wuhan, gradually started its operation. Also, Wuhan started operations in shopping malls, some public transportation systems, and inbound transport from across the country. All these occurred under the alert of a potential second wave of the outbreak. Hence, preparations were made for the gradual changes and eventual 
travel plans of people in Wuhan and other locations (i.e. cities, towns, villages) of the Hubei Province.

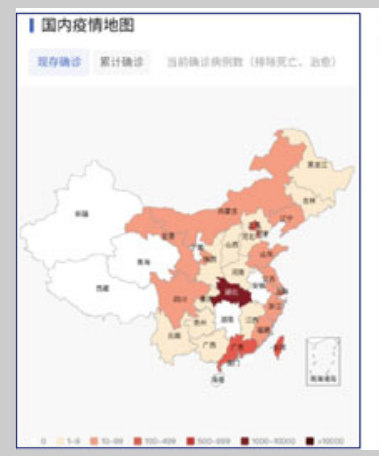

\begin{tabular}{|c|c|c|c|c|c|}
\hline Sintends & Bats: & & & satagaig & \\
\hline$m \alpha$ & novas & ithes & c & $\mathrm{en}$ & \\
\hline \multicolumn{6}{|l|}{ 신. } \\
\hline 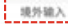 & 14 & 15 & $\therefore$ & 1. & \multirow{16}{*}{$\begin{array}{l}\text { This category was } \\
\text { added in line with the } \\
\text { growing number of } \\
\text { so-called imported } \\
\text { cases, i.e. "people } \\
\text { travelling back" to } \\
\text { China. At least } 20 \\
\text { provinces had this } \\
\text { category added by } \\
\text { the end of March } \\
2020 \text {. }\end{array}$} \\
\hline$\times 9$ & 0 & 260 & 0 & 260 & \\
\hline ตล & 0 & 61 & 1 & 60 & \\
\hline E.t & 0 & 49 & 0 & 49 & \\
\hline *a & 0 & 47 & 0 & 47 & \\
\hline พื้ & 0 & 47 & 0 & 47 & \\
\hline ats & 0 & 44 & 0 & 44 & \\
\hline mat & 。 & 38 & 1 & 37 & \\
\hline แล & 0 & 38 & 0 & 38 & \\
\hline an & 0 & 37 & 2 & 35 & \\
\hline os & 。 & 35 & 2 & 33 & \\
\hline 20 & $\circ$ & 30 & 1 & 29 & \\
\hline *⿻ & $\circ$ & 24 & 0 & 24 & \\
\hline จa & 0 & 18 & 0 & 16 & \\
\hline en & 。 & 16 & 0 & 10 & \\
\hline $\mathrm{IBN}$ & 0 & 15 & 0 & 15 & \\
\hline
\end{tabular}

At this time, at least 20 Chinese provinces were reporting a growing number of imported cases of those travellers coming back to China (both locals and foreigners). Under the fear of retaliation acts of racism and stigmatisation, the imported cases were also seen as a possible backfire and towards having another wave of the outbreak. As shown above, the allocation of a new category stating "people coming back to China" was a sign of growing imported cases, particularly for those cities and provinces that previously managed to successfully bring their inflected numbers to zero. This may also reflect negatively on the international media as well as social media, and from various perspectives.

In line with the early signs of the post-recovery phase, the need to revitalise the main urban systems of the city was essential. This requires sector-based guidelines to first restart the operations, and then help to gradually revitalise sectors, businesses, enterprises, amenities, and services. This requires time, and it is recommended to take gradual steps. One of the early examples of change was to revitalise the public transportation system, which was under pressure for a long time. With a period of the temporary closure of operations, the later limited operations, and finally with a very low number of customers, public transportation was in need to regain its face and operations.

Hence, the plan of the local government was also to support this major urban system as early as 23 March 2020 and then 28 March 2020. Here is the summary of the action plan and proposed support to revitalise this primary system:

Starting from March 23, the discount program for Ningbo metro e-tickets will last until September 30 , with up to $50 \%$ discount for passengers using Ningbo metro APP.

\section{Details:}


Within one discount period (30 days), Ningbo Rail Transit will give free etickets of different times (without mileage limitation) to passengers according to their use of e-tickets (including the ride code, the same below). Specific as follows:

- Item A: Ningbo Rail Transit will give free e-tickets for 20 trips without mileage limitation if passengers use the e-tickets for 25 or more subway rides with each ticket price no less than RMB6 within one discount period.

- Item B: Ningbo Rail Transit will give free e-tickets for 15 trips without mileage limitation if passengers use the e-tickets for 30 or more subway rides with each ticket price no less than RMB4 within one discount period.

- Item C: Ningbo Rail Transit will give free e-tickets for 10 trips without mileage limitation if passengers use the e-tickets for 35 or more subway rides with each ticket price no less than RMB3 within one discount period.

\section{Rules:}

- A 30-day discount period starts from the date the passenger first uses the e-ticket to travel.

- The start time of the next cycle is the date when the passenger uses the e-ticket again after the previous cycle.

- In the same discount period, when the passenger uses the e-ticket to take the subway, and the single ticket price meets the above multiple discount conditions, the times of use can be counted simultaneously.

- If the passenger's fare and times meets one or more conditions within the same discount period, the passenger can choose the time of collection and the number of complimentary tickets. But only one collection is allowed within the same period.

- Within the same discount period, the rides times after the passenger receives complimentary tickets can no longer be accumulated.

- After receiving complimentary tickets, passengers are free to use it within the same period.

- At the end of one period, all the cumulative times will be cleared, and the unused and uncollected complimentary tickets will become invalid.

(Extracted from: Ningbo Subway, and provided by Ningbo Focus, news article on 28 March 2020).

The more people stayed indoors, the bigger the perception that the outdoors are dangerous. The change of perceptual requires to happen at a gradual pace, as the normalisation also occurs in several steps. Under the growing fear of contaminated everything, the city has to propose innovative ideas for the use of public places, public services, public transportation, and support the local economies. A major move was to expand on the earlier changes to public transportation use, which was announced in early April 2020: 
From now on, free rail and bus travel during off-peak hours will be implemented in Ningbo, and the end date will be announced later. Passengers will be charged as usual from 7:00 to 9:00 and from 16:30 to 18:30. Free rides are available except these two periods. The starting and ending time of the free ride is subject to the boarding time of the passenger. During the free period, passengers do not need to pay for metro tickets or scan QR codes at the ticket barriers, and they do not need to pay cash or swipe cards when taking the bus. But passengers must pay for a ride during non-free hours. And passengers who enter the subway station by swiping cards should be sure to swipe cards again when exiting the station in order to avoid the delay of charging.

(Extracted directly from Ningbo Focus News, on "free Bus and Subway Rides during Specific Periods").

At the same time, public amenities and attractions were reopened with free admissions, mainly to scenic spots last up to 2 months. The support that was needed to revitalise the local economies were essential in the post-recovery phase. From the beginning of April 2020, these were proposed at the district level:

\section{For Beilun District}

From April 1 to May 31, Beilun Nine Peaks Mountain Tourist Area, Meishan Bay Beach Park and China Port Museum will offer free admission. Besides, cultural, tourism and sports gift packages will be released, including general consumption coupons with a total value of 10 million Yuan and corporate vouchers. There will also be various culinary perks. During this period, various discount coupons with a total value of 10 million Yuan will also be issued in Beilun. With the discount of up to $50 \%$ off, people can enjoy the delicacies in Beilun.

\section{For JianBei District}

In addition, Jiangbei has issued package tickets worth nearly 20 million Yuan, which covers six scenic spots in Jiangbei District, including Cicheng ancient town, Baoguo Temple, Daren Village, Lvye Daren Valley, Ali's Farm and Train Nice Theme Park. A single package is worth 475 Yuan, and there are 40,000 packages in total. Before May 31, tourists can get a package ticket worth 475 Yuan on UnionPay to visit six scenic spots for free if their consumption reaches the standard when they use Union Pay or the Apps of major banks to book accommodation or shop in the business area.

\section{For Yinzhou District}

From now to April 6, the pear garden of about $100 \mathrm{mu}$ (6.67 hectares) in Tiangong Fazenda will be open to tourists for free for the first time. Visitors can raise a pear tree by paid adoption and come to pick the pears after they are ripe. And the yield of a pear tree can reach 10 to $25 \mathrm{~kg}$.

(Extracted directly from Ningbo Focus News, on "Free Admissions to Scenic Spots Last up to 2 Months"). 


\section{BOX 5.23 "Beyond the Adversities"}

Global attention was at its peak at the time when the global economy was completely disrupted, more countries were getting into the list of countries with confirmed cases, and borders were closing every day. In most Chinese cities, people were already at the recovery stage while there were still signs of new cases coming back to the country. People resumed their daily routines with major changes in their behaviours and lifestyles. Many things seem to be settled as the new normal: temperature checks, health monitory, wearing masks, social distancing, online working, online shopping, etc. One of the common topics of conversation in the recovery phase was to compare the total weight gained during the lockdown period. The other communications were about limited exercises, new outdoor experiences, changes in daily routines, and new snack consumptions. For many, the combined effect of China's recovery stage and global emergency issues meant a prolonged recovery stage and not reaching post-recovery early.

Globally, there were many cases of recorded theft or piling up certain primary products. There were some arrests of those who stole products, who piled up products (e.g. mostly to sell them later at a higher price), who fraudulently scammed people in various ways, who made and provided fake products and necessary supplies, who violated the quarantine/lockdown measures, who rejected to self-isolate, etc. For instance, criminal scams can happen in various ways of formal and informal set-ups, from officially-looking letters and notifications to a simple knock on the door. These incidents involved tradesmen knocking on doors of the elderly, people who acted as officials, and many other cases that were targeting certain groups of people-often the vulnerable. Also, in the early days of the outbreak event, the World Health Organisation (WHO) noted many scams that were happening in their names. They then had to make an official announcement to raise the awareness of such cases and to ensure people get the right messages through the right channels. They also warned against those opportunist criminals who try to steal money or sensitive information, mainly seen through emails and online methods (UN News, 2020).

Moreover, people were yet to know how to adapt to new changes and measures, learn how to comply with precautionary measures, have collective methods to societal wellbeing, and understand the difference between lockdown, quarantine, and self-isolation. Many aspects depend on the level of trust needed between people themselves, between people and their communities, between communities and their governments, and between local governments and their upper-level governments.

All these had to happen so fast and responses had to be more humane than ever. All these happened at the time when the UN agency was continuously asking people to comply with the basic precautionary measures: 
- Frequently wash your hands with an alcohol-based hand rub or warm water and soap;

- Cover your mouth and nose with a flexed elbow or tissue when sneezing or coughing;

- Avoid close contact with anyone who has a fever or cough;

- Seek early medical help if you have a fever, cough, and difficulty breathing, and share your travel history with healthcare providers.

These actions we previously thought to be simple but then appeared not so simple after knowing the fact that many people are yet to learn the basics. All these happened at the time when vulnerable groups were even more vulnerable, and many global health organisations were warning against the inactions of governments and people. These came at the time when governments were worried about the lack of people's compliances, and people were worried about the uncertainties of the event.

Several weeks in the recovery phase, we are still asked where we are going when leaving the compound areas. Our temperature is checked before leaving, upon entry to any premises, and once we return home. Notifications are displayed everywhere reminding people about safety measures, procedures, recommendations, and requirements. Our world is changing with this invisible enemy. From 'another hoax', the disease outbreak turned into a crisis-making machine. People report "things are changing every day not only in terms of the COVID-19 situation but also the responses of different levels of government". As it has been warned by many, "things will get worse before they get better". As we expect the situation to last longer and numbers of infected cases and mortality are increasing rapidly, we expect harder measures and stricter restriction methods. Not all can manage with a strong central government, and that is only part of the problems. We also have to bear in mind that lockdown is not the same for everyone, and the economic hit will be more significant than initially calculated. It would make the vulnerable groups more vulnerable, and it will enlarge the size of our vulnerable groups.

While the UK was entering a new phase and reaching 20,000 infected cases, its government was talking about preparedness. While Iran was reaching 30,000 infected cases, cities were just moving towards the less-appreciated lockdown measures across the country. While the number of infected cases went over 100,000 in the US, they then talked about cooperation. There were many more country-level examples that represent late actions, which seem to be the aftereffect reactions to a period of initial inactions. By entering their third week of lockdown, the UK government proposed to write to all 30 million households across the country, including details about the 'national emergency' and a leaflet about official advice. This is a rather late and unnecessary burden, at a minimum cost of $£ 5.8$ million (equivalent to US\$7.2 million at the proposed time). Then we question what is the use of our digital technologies? Can we not 
innovate in any better ways at this so-called technologically-advanced age? It is important to remind those deceiving actors that their business-as-usual actions and scenarios are not fit the conditions of the outbreak. At the same time, the UK's motto was 'Stay Home, Protect the NHS, Save Lives', something that could have been done several weeks earlier and could have saved the country more effectively. To sum briefly, we confirm the measures have to be implemented at the right time. During the outbreak, governments should be more realistic and responsive. Mobilising support is not an easy task but is doable. For instance, on the 29th of March 2020, the Australian government made a significant change to its foreign investment framework and reduced it to $\$ 0$. This type of adaptive measure is important for governments to prioritise the right priorities and at the right time- not any time later, and not with any hesitation or neglect. On the contrary, we anticipate significant reduction or changes to foreign investment plans and procedures. This is at the time that many countries were admitting the success of China in the handling of the outbreak; bearing in mind that China was the original epicenter that was affected with a sudden wave of shocks and not with a long period of disbelief, neglect, and inactions.

As the international health organisations urge for more 'testing, testing, and testing', we may not have the right record of cases and mortality rates. As many cannot cope with such adversities, we see a growing number of deaths at home and non-recorded cases, those that were unattended for several days. At the time, Latin America is on the verge to become the next epicenter and African countries are closing their borders, a new chapter of this pandemic event is about to start.

For years, many unwanted wars and adversities were forced on people and their homelands leaving them in despair while leaving many of us unprepared in our safe zones. Now, the invisible enemy seems invincible and is right at our doorsteps. And for many of us, we have struggled to manage and recover.

We noted the treatment of infected cases became more difficult in compared to earlier stages of the disease outbreak. Hence, a hypothesis was developed utilising the data up to the end of March 2020.

\section{When did SARS-CoV-2 virus mutate? And did this impact treatment procedures?}

As the infected cases of the COVID-19 disease outbreak are increasing exponentially, there is evidence that the virus is already mutated. As coronaviruses often mutate, it is important to know when and where this mutation has occurred in this pandemic event. Until the end of March 2020, this pandemic outbreak has developed in three major phases: (1) the original epicenter in China and later in the region of East and Southeast Asia, (2) the second epicenters in Iran and Italy, both then affecting their regions (mostly Europe) and beyond, and (3) the rapidly-growing epicenter in the US. This is at the time that Latin America 
may potentially become the next epicenter of this pandemic event. Early signs of the virus mutation are tracked back in the early-to-mid stages of the second phase.

As the official records indicate, the severity of the virus is strengthened as early as the first week of March 2020. This is based on the accuracy of countrylevel data, but also on several factors that are very important to this pandemic progression. Started as a small outbreak then an immediate pandemic, this disease outbreak event was only become pandemic after about 50 days from its official announcement. There is a period of uncertainty at the first stages that require further investigation, which may then result in better clarity on the source and starting point of the outbreak, including more information on the first index case. Nevertheless, four factors could potentially have significant impacts on methods of recording and the development of the outbreak:

\section{- Our knowledge of the disease progressed and developed over time}

It is natural when this happens. It is unfair to argue that our knowledge of the disease should have been the same from the inception. This is unlikely to happen in any case of the outbreak, or else they may not turn into a case of an outbreak at all. As the outbreak started and based on the fact it was a novel disease, our knowledge was relatively little. It also remained like that for a long time, even at the time when the number of cases was increasing rapidly elsewhere. It took some time for us to know how the disease may transmit between people, its level of severity, and its impacts on our bodies. It took almost three months for the disease to show its first sign of transmission to other species, which could have resulted from the possible mutation of the virus.

\section{- Early measures and early responsiveness worked effectively but it was only done by selective countries/regions}

The measures in different parts of the world were not consistent. And not all of them happened at the right time. Some failed to implement early measures, and some had many inactions that caused later effects on the increase of infected cases and fatality rates. Some sacrificed their long term societal health and wellbeing with their short-term economic and political goals. Those were the ones hit the most later on. Examples of these were the hesitation to put adequate lockdown measures, prevention and control plans, travel bans, health checks, etc. For instance, it was recorded that London's Heathrow Airport had minimal health checks even days before the country's Prime Minister was hospitalised because of the disease. Countries that put early restricted measures, such as smaller countries in Oceania, were hit the least. Also, we see much better progress in countries like China, Singapore, South Korea, and Japan, where high-level measures were in place. We have to bear in mind this event 
was announced as a global health emergency only 10 days after the official announcement of the outbreak.

\section{- Forms of measurement changed during the outbreak progression}

Testing was only increased after the event was declared pandemic. Hence, many cases could have remained hidden or unrecorded. Apart from this, as our knowledge of the disease developed, our forms of measurement also developed. It is, however, important to strictly adhere to systems of measurement to the values and records of the monitory measures that are in place for the outbreak progression.

\section{- Potential (early) mutation of the disease based on multiple factors}

There are several aspects related to this. First, the information about early transmissions requires further investigation to shed light on the mutation pattern of the disease. As respiratory diseases often mutate, this has likely occurred at earlier stages. Also there are factors, such as geographical or geneticallyassociated issues that need to be studied further. For instance, there is a hypothesis that the virus became stronger or even more aggressive in colder climates.

Furthermore, it is evidenced that since early March 2020, the numbers of recovered patients are dropping significantly, particularly for those affected in the second phase and carried on to other regions. This is evidenced by the early treatment cases in countries like the UK, when the patients were able to get recovered under just 10 days. The period of treatment is now extended at 2-3 weeks, which remarks on the gradual strengthening of the virus. Apart from the longer period of treatment compared to earlier days, the resilience of the virus is also evidenced-based on the available data of fatality and recovered cases in multiple regions and at different times.

This fact is also evidenced through the apparent changes in the fatality rate. In phase 1 , the fatality rate was assumed below $2 \%$, but this increased to a much higher rate now. With the exception of China's fatality rate at $4.05 \%$ (to $31 / 03 / 2020$ ), the highly-affected countries of phase 1 have managed to maintain their low fatality rates to date; such as Singapore at $0.32 \%$, Thailand at $0.61 \%$, South Korea at $1.66 \%$, and Japan at $2.87 \%$. However, currently, we see the fatality rate increasing to a much higher rate of $6-9 \%$ with the exception of Italy, which also represents inconsistency in the fatality rate in different locations. Based on the country-level figures, we confirm the fatality rate of those affected in the second phase (until 31/03/2020) are: Iran at 6.50\%, France at $6.79 \%$, the UK at $7.19 \%$, the Netherlands at $8.25 \%$, Spain at $8.76 \%$, and Italy at $11.75 \%$. These numbers may slightly decrease later on. At the same time, the main exceptional cases are Germany (at 1.04\%) and the US (at $2.05 \%$ ), both increased by a minimum of $0.1 \%$ to $0.15 \%$ from the day before. 
They both managed to keep their country-level fatality rates close to the initial $2 \%$. These numbers may increase later on. Nevertheless, in Germany, we see a major difference in highly-affected regions, as the country's three most infected regions of Bavaria, Baden-Württemberg, and North Rhine-Westphalia all have $0 \%$ recovered cases. As the number of cases in the US increases drastically in phase 3 , we also identify a tangible change in recovered cases. Hence, we also see much lower recovered cases in highly affected states of the US, such as Florida at $0 \%$, Illinois at $0 \%$, Michigan at $0 \%$, New Jersey at $0 \%$, Washington at $0 \%$, as well as two other most affected states of California at $0.08 \%$, and New York at $0.14 \%$. These figures are likely to increase as the outbreak progresses.

Furthermore, the longer recovery period of infected cases from the second wave of the outbreak in China, and those returned to the country, indicate an extension of at least 1-2 weeks for treatment procedures. This was despite the easing pressures on the healthcare systems. Hence, for later assessments, the correlation between time, fatality rate, and recovered rate should be taken into consideration. Also, it is important that newly infected cases are monitored more carefully and treatment measures should be enhanced reflectively in the case of a mutated virus. This is required to be studied in a procedural way, one that could also assess the other aspects that may influence the treatment procedures. As the numbers of infected cases surpass 1 million, treatment becomes ever crucial.

\section{BOX 5.24 "Reflecting on the Time of Disruptions"}

It is unfortunate that we witnessed many countries playing chase-up games. Something that should be avoided in such serious health emergency situations that not only affects the city and its communities, but also the health of people, the health of the economy, health of urban systems, the health of industries, the health of governance, etc. In order to make effective progress in containment and recovery, we cannot remain with the absence of actions, and we cannot delay decision-making procedures. These decisions need to be effective and at the right time. Hence, either actions should be gradual and procedural from a reflective approach, or they should be immediate and at a high level at the early stage of outbreak progression. The examples of less-connected island countries in Oceania and their earlier high-level measures prove this point. The combination of high-level restrictions and a later response is not only not effective, but it also can be quite dangerous.

In facing the widespread adversities, indifferent attitudes should not be tolerated. When governments are seen pleading their people, we know this is not a common emergency. Also, when governments are seen relaxing their measures in the midst of the outbreak progression, we know their priorities are not right. 
And when people are seen not complying with the measures and regulations, we know what type of society has developed over the years. Unlike the common perceptions about fragile social and political systems of developing countries, we witnessed an array of failures in developed countries, and some of those assumingly-advanced and socio-politically stable countries of the global North. We saw some serious inactions of those affluent countries. Their societies would later ask, where do their taxes go if their governments cannot protect them in the time of need? Thus, the dysfunctionality of measures and regulations is a two-sided matter that involves both people and their respective governments. Some may be associated with the decline of democracies (Fukuyama 2014), some are simply based on our decaying social and political structures, some are based on our weakening institutions and institutional operationalisation, and some are truly based on our flawed methods of the global economy.

While it was assumed there are at least some sort of positive news on environmental revitalisation due to the outbreak, the US government initiated to ease their environmental regulations on businesses and productions, such as for the oil industry. This came at the time when the US just reached the top of the chart with the highest number of infected cases. Also, with the highest unemployment upsurge in recent decades, the US government had to tighten the measures, increase cooperation, and provide more support. At the same time, the US Senate passed a US\$2 trillion coronavirus bill. But there were doubts about tightening the measures and saving the economy.

The earlier environmental benefits include: general reduction in productions, general reduction in oil production and consumption, less travel and transportation, less air traffic, etc. The later studies showed signs of improvement in cleaner water around coastal areas, sudden-but temporary-drops of airborne Nitrogen Dioxide (NASA Earth Observatory 2020) and Carbon Dioxide (CarbonBrief 2020). At first, such studies analysed China, and later other affected areas and regions. Some of these environmental benefits of the outbreak were regarded as "environmental enthusiasm" by Gomes (2020), who then argued "the silver lining is that a large portion of those infected are recovering. After all the hardship and tragedy from COVID-19, we can expect some clean and pollution-free air to breathe". Apart from temporary reductions in some of our pollutions and emissions, the outbreak also reminded us about methods of reuse and recycling, more considerate consumption, less demand (only to some extent), less unnecessary travels, more efficient ways of operations, etc.

CarbonBrief (2020) summarised some of China's earlier reductions in electrical demand and industrial output, reported by 4th of March 2020, including:

- Coal consumption at power plants was down 36\%;

- Operating rates for main steel products were down by more than $15 \%$, while crude steel production was almost unchanged; 
- Coal throughput at the largest coal port fell 29\%;

- Coking plant utilization fell 23\%;

- Satellite-based NO2 levels were 37\% lower;

- Utilization of oil refining capacity was lowered by $34 \%$;

- At their peak, flight cancellations were reducing global passenger aviation volumes by $10 \%$, but the sector appears to be recovering, with global capacity down $5 \%$ on year in February as a whole.

Nevertheless, there were also adverse environmental impacts, such as imbalance in food supply chain, upsurge in production and consumption of certain products (Cheshmehzangi 2020a), as well as unhealthy disposal of medical products (Mukhopadhyay 2020). In the latter example, there are warnings regarding environmental impact and waste management failures (WHO and UNICEF 2015; WHO 2018). Hence, the deficiency of waste management systems and wrong methods of disposal would lead to adverse and unexpected environmental impacts.

Furthermore, in many countries, the so-called 'coronavirus scare' eventually turned into reality. With a non-symptomatic disease and a high level of person-to-person transmission, people had to cope with lockdown measures, quarantine, social distancing, etc. These types of disruptive times require time, financial support, responsiveness, and cooperation. Holding just about $80 \%$ of the global economy, G20 members announced they would inject US\$5 trillion into the global economy (on 27 March 2020). A decision that is likely to continue and get extended. A decision that requires regional and national attention, especially to those more vulnerable countries already facing other structural issues. In this situation, everybody is vulnerable, but there are some that appeared to be more vulnerable than the others. Eventually, from a country shutdown, the situation turned into the global shutdown.

Later on, as all countries and regions were struggling with the adversities of the outbreak, either directly or indirectly, the United Nations (UN) requested for an articulated or coordinated response to having more collective measures towards containment, treatment, and the eventual eradication of the disease.

The suggestions by the UN also includes cooperation and strengthening of the institutions. Hence, as threats are becoming more global, it was suggested to strengthen multilateral institutions and overcome the issues of dysfunctional international relations. This was narrated from the perspective that power relations are unclear, the global supply chain is under pressure, and county-level fights or attempts are not necessarily successful in the long run. It was urged that we have a choice between "chaos or united actions" against such disruptions. This reminds us of the notes on those humanitarian support that said "one world, one heart". It also reflects on the poem that was added at the beginning of this book. Finally, the UN responds to the issues of the trade-off between the global economy and fighting the disease. And in achieving this, we have to 
consider a sustainable and inclusive approach to recovery. The main message from the UN was to be responsible, be smart, and have solidarity to tackle this challenge. After all, this is not the first time we deal with such adversities, and surely, this will not be the last time either.

From governmental denial to individual disbelief, we see major disruptions caused by both. Since the inception, we were advocating the use of facial masks for enhanced prevention and control measures. Nonetheless, many countries advised against the use of such medical products, perhaps mainly because of limited stocks at first. But then this required much more thoughtful attention from the early stages, which could have reduced the scale of the spread of the disease. It was only after the publication of a scientific paper that some countries started to revise their recommendation on facial mask use. While many Asian countries already practiced this main prevention measure, some countries also made it compulsory, such as China and South Korea. At the time the number of global infected cases surpassed 1 million, some countries made the use of facial masks compulsory, such as Austria, the Czech Republic, and Slovakia. The ripple effect was also seen in parts of Germany, the US, and other countries.

It took less than three months for the globe to reach 1 million cases and 50,000 deaths. The numbers almost doubled in just a week, as the spread of disease continued rapidly in Europe and North America. By then, only a handful of countries and regions were left without any confirmed cases. With some earlier inactions, new epicenters emerged and the speed of transmission in some countries was drastic and horrific. This primarily sparkled by the act of waiting than the more effective acts of preparing and preventing. While some governments were in denial, they raised the level of disbelief in their societies. Once the situation turned into a crisis inside their boundaries, this large scale disbelief turned into a shock and then a mistrust of the government. While there were worries about more societal disruptions, people started to worry about the effectiveness of the measures. An anonymous comment was "I am giving the lockdown another 9 days, and then I am back to normal life with no isolation for me. It is obvious the lockdown is not working. You have to look at Spain and Italy. I won't be locked up like a caged animal for much longer". There were also voices of doubts and escalating mistrust: "The virus is obviously slowing down as the news is drying up and just being repeated now and that emergency hospital was supposed to be operational yesterday. But there have been no more stories on that for a few days". Some also argued against the supremacy of the governmental guidelines: "Remember, these are guidelines and not law. Not saying they should not be followed where possible, however, the police and other people who take it upon themselves to behave like they are in charge of the public, should remember that and stop trying to enforce guidelines, which are simply that". While the others, under the assumption of short-term lockdown optimism, argued that: "Under the quarantine, no-one 
should go outside even for exercise in public places. Staying at home for 14 days is not that hard". This came at the time when governments were warning about longer unimaginable lockdown measures of 3 to 6 months, and even a full year.

These were all at the time that a range of advice was given, but enforcement was still lacking. Health checks and testing were still not done as fast as they should, which indicate a lack of preparedness and wrong delays in prevention and control procedures (Cheshmehzangi 2020b). Some countries had to start reflecting on the realities more seriously, and some actions had to be passed to those who are more effective in the adaptation and implementation of the guidelines and measures, i.e. the regional and local governments (ibid). The disruptions continue as the outbreak grows more and more. At this time, many investigations are ongoing to shed light on the origin of the disease, questioning if the disease started much earlier or from other locations. At this time, the world is at a halt. People are stressed and economies are falling. With the increase of unemployment, we foresee further unwanted disruptions, some that could be crime-related. Furthermore, one small virus has done many things that we failed to do on our own and collectively as the so-called global citizens.

\section{BOX 5.25 "Normalisation Versus the New Normal(s)"}

Under the worries this outbreak may be a prolonged pandemic, it is expected for longer-term adversities and impacts. From a warlike time, there emerge new opportunities some in the form of innovations, and some development to the new normal(s) of what we may do afterward. This is evident in previous experiences and even major wars that helped to boost our technologies and techniques. In a sense, the normalisation in the post-recovery phase is not the step back to the business-as-usual situations or doings. There are expected to be tangible changes and some that will remain as the new normals.

For instance, this outbreak could potentially enhance societal resilience, or can instead worsen it through poorer relations or more vulnerabilities. The latter is highly likely based on our non-collective attitudes. Hence, we hope this does not mean an opportunity for the expansion of our growing individualism. This outbreak should be studied reflectively for us to stop overlooking our continuing social issues and political misconceptions. In other examples, there is a likelihood for the enhanced safety measures, not only those that include the safety of our supplies, but of regular operations, distributions, workplaces, and workforces. For instance, supermarkets released information on several matters that were not as important as they were before, including:

(1) 'Food for all' and especially addressing the needs of those vulnerable groups and those in need for extra help and support, 
(2) 'Safety for everyone', which is already part of the daily operations but are expected to be enhanced with further monitory measures, and

(3) 'Supporting workforces' that will include the multiplicity of safety measures, enhanced training, welfare and wellbeing, and support.

This outbreak event should give us a chance to boost some of our neglected institutions, those that are essential to our societal wellbeing, safety, and security. It should provide a chance to enhance our primary/basic social services and help to address some of the deficiencies in our institutions. Nevertheless, these all depend on how countries or cities would reflect on the afterward situations, and how they would react to nurturing some of the forgotten institutions and services. This should provide a chance to boost those unattended factors through better financial support and timely management of their integration into the enhancement of cities and communities (Cheshmehzangi 2016). This outbreak would possibly change our trade matters, and should help countries and cities/regions to look into local productions and self-sufficient approaches to enhance our supply chains. The global trade would then require to be assessed and revised, to have a better multilateralism approach and to be further developed to become all-inclusive and effective.

The most perceptible of all would be to boost our digital technologies. The possible increase in the use of smart technologies is also very likely. With the boost in our digital platforms, this outbreak opens up a unique opportunity for many digitally-advanced innovations such as: data-based and informationbased operations, enhanced monitory through data-driven methods, distance learning and online education (or e-learning), cashless operations, integrated mobile applications, e-commerce, digital product deliveries, online operations, etc. As the digital platforms were amongst those that benefitted the most from the outbreak are expected to develop opportunities for the new normals. These may appear and develop differently in different locations, depending on multiple factors of societal trust, cultural factors, social matters, and political systems.

There are also many other possible new normals, and we highlight only a few here.

Increased poverty-There is no hiding from the economic impacts, particularly on the most vulnerable groups. This event will increase poverty in those severely-hit countries. The economic crisis will last for a while before it could save some of those poorer nations or those highly-affected ones.

Cybercrime and cybersecurity-We will see an increase in both. Cybercriminals find this event as a great opportunity to innovate methods of cyberattacks and cybercrime. In return, governments and companies will be forced to spend more cybersecurity measures. 
Facial masks-The use of masks may become more common than ever. While it is wrongly advertised about the ineffectiveness of masks, it is important to note that they can be used to avoid passing the disease to others, similar to what the Japanese culture indicates. In the future, we are likely to see more use of facial masks when people get ill, or they are in busy and/or contaminated places, etc.

Security and safety services-We anticipate more power to be given to those security and safety services. This likely happens in those declining economies or those with poorer institutions. The empowerment of such services would possibly take a different turn in autonomous governments or those of totalitarian structures. Thus, such empowerment should be considered with added values or else it becomes a tool to further policing the society. It is important to put wellbeing central to such enhancement opportunities and to allow for a revitalised or strengthened institutions.

Postal and delivery operations - We anticipate seeing an adjustment in operations, from safety measures to issues of workload, and distribution methods. The postal and delivery services are likely to change, allowing for more contactless opportunities, and reduction of paper-based deliveries for letters/mail. The use of digital replacements will take over much faster.

Changes in consumption patterns -We expect to see changes at two sides of the consumption spectrum after the outbreak. Some changes would likely be temporary and some will remain for a longer period for a group of people. It is likely a larger group, affluent or not, will consume more in the after the event period. This is due to their less consumption period, which will be assumed as a time of deprivation. For those who are more reflective or become more vulnerable, then this becomes a lesson learnt that indicates a possible chance to reduce some of the habits of high consumption. This will be taken positively particularly if this can happen at a larger scale. However, in the longer term, this may not last so long.

Hoarding behaviour-Similar to the impact wars can have on people's behaviour, this outbreak could also increase the chance of hoarding behaviour. From panic-buying incidents to hoarding activities, this event would reflect negatively on some people's behaviours. The hoarding behaviours are expected to continue and this may also impact some of our consumption behaviours.

Online shopping-With the success of e-commerce and online services, we anticipate the opportunity for the enhancement of online shopping services. In countries, where online shopping services were already common, we would see the upsurge in the use of what we called the virtual amenities. In countries, were online shopping services were not as common, we would see the emergence 
of such services and later decline of physical shopping. This will be a turning point for them and will mark as an opportunity for online systems.

Hygiene improvement-Globally, we may see signs of hygiene improvement. This may support new regulations or develop in the form of sectorbased guidelines. Also, there is a likelihood that individual hygiene and the use of cleansing products will stay more popular than before. Some companies/enterprises/institutions would adopt enhanced cleaning procedures in their daily practices. People are likely to become more aware of asymptomatic incidences.

Social distancing-The longer effect of social distancing (or physical distancing) would be the reduction of unnecessary physical meetings, events, and gatherings. They would either be reduced or they would be replaced by alternative online meetings, webinars, and online forums/groups.

The emergence of high-level access management and control systems-As it is happening already, we would see more similar tools emerging for various reasons, such as security, anti-terrorism, etc.

More Caution before travelling-It is likely people would check more information about their travel plans and travel destinations. People would potentially learn from this event, knowing that outbreaks could happen anytime and anywhere. People may also be more aware that smaller outbreaks are common.

Demand for faster emergency construction - This will include faster methods for the assembly of temporary hospitals, shelters, etc., which will not only be useful for future disease outbreaks but also for war zones, natural disaster events, other crises, and emergencies, etc. We should also see more innovative design and planning strategies for transformative/flexible spaces and building typologies.

Airport health check procedures-Some measures will continue to remain in place. In some countries and regions, particularly in East Asia, temperature checks were already part of the procedural checks. This is expected to become a common practice in more countries (if not all), and hopefully more sensible than those already-practiced global security measures. Such health checks may remain in other dense transportation hubs, such as the main railway stations, ferry stations, bus stations, etc.

Regional measures and regional planning-This is a good opportunity to empower regional level strategies. National-level planning alone may not be effective and will require regional-level support. If not regional, local governments should be empowered as the main actors of the implementation process. 
Surveillance will increase - This will happen both by people and the machines. People will monitor and record any misbehaviours more than before. This will be a chance for facial recognition devices for multiple uses, starting with a more acceptable temperature detection and then into security measures.

Artificial intelligence (AI) and detection measures-This event will boost the use of $\mathrm{AI}$ in our detection and prediction methods and will become widely-used for various reasons.

The earlier mishandling of the outbreak in multiple regions caused many changes, and some of those changes would turn into our new normals. Nevertheless, normalisation would not mean 'going back to the previously normal'. There will be several major changes, and some new practices to increase global awareness and preparedness in the case of future outbreak events. We also have to note, with some caution, that in the name of security, this experience may just increase our societal surveillance through the so-call smart strategies. This can be perceived positively and negatively, depending on the actual intentions behind the use of such techniques or platforms. As it always has been, governance could become stronger by utilising the tool of societal fear. More than before, we may end up using robots, artificial intelligence, facial recognition devices, tracking devices, drones, etc.

This outbreak will open a new chapter.

\section{BOX 5.26 "Tools, Tools, and more New Tools"}

Knowing that we have a growing number of redundant positions, and many opportunists took advantage of the vulnerable situations, there were signs of more effective and supportive actions, too. Under the growing demand for digital tools and many new integrated systems that were proposed during the outbreak, we can see a positive take in how they played part in promoting education, training, awareness, medical support, charity fund, remote working solutions, real-time reporting, medical and health checks, etc. Here, we showcase some of these examples that were utilised during the outbreak. 

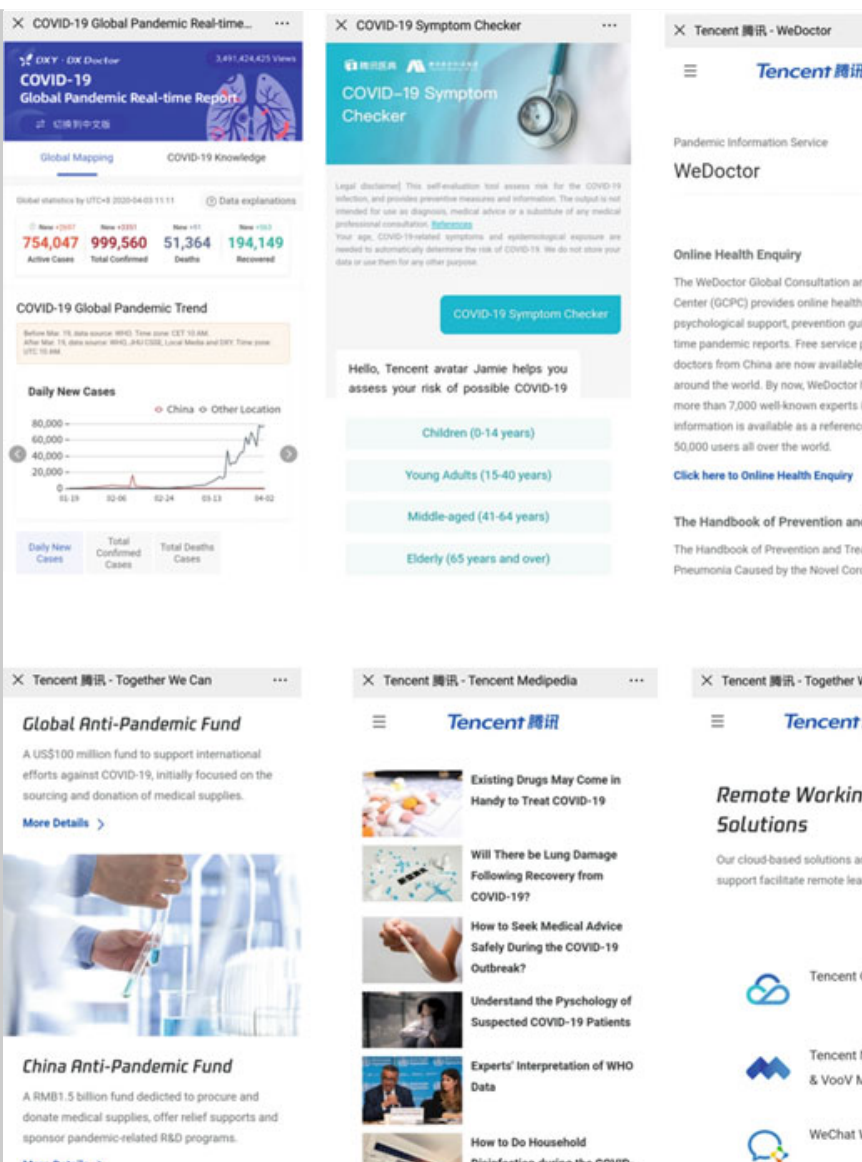

WeDoctor

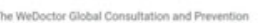

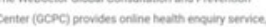

poychological wupport, peeventson qudelines and test time pandemic reports. Fiee senvice pronided by doctors from china me now walable 247 tot people cround the redid By now WeDoctor has outhered grore than 7.000 well known experts in Cina and thit chemation is maliable at a reterence to mote than 50,000 uners at over the world Click here to Online Healtes Enquiry

The Handbook of Prevention and Treatment The Handisock of Prevention and Treatmens of tove

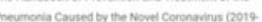
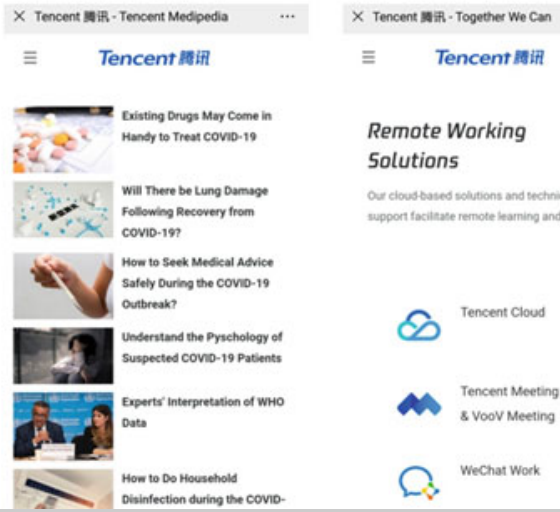

$\equiv$ Tencent m

Remote Working

Solutions

our clous bosed solutions and sectrical
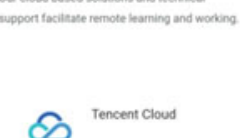
Tencent Cloud
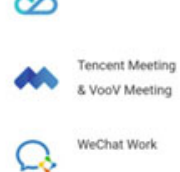

Here, we elaborate on some of these examples: Tencent Mediapedia "collaborates with medical experts to provide users with pandemic-related articles and videos that include tips on disease prevention, self-quarantining at home, and other related information". The WeDoctor, is a platform for "Global Consultation and Prevention Center (GCPC), and provides online health enquiry service, psychological support, prevention guidelines, and real-time pandemic report in China".

These are all Chinese or China-based digital platforms. We are not doubting or neglecting the fact there many similar examples developed and implemented in the countries. This is just to show some of the examples we experienced during this outbreak, as they are more, and there will be more on the way.

(Extracted from: Tencent at: http://www.tencent.com/en-us/responsibility/ combat-covid-19.html). 


\section{BOX 5.27 "Transitions vs. Transformations in Cities and the Built Environments"}

While we see there are transitional changes, we also anticipate several transformations that may affect our cities and the built environments. These are the ones that we believe may lead to new policies or regulations, new practices, and new paradigms. Such transformations are likely to differ from one context to another, and some of them may be transitory than long-term changes.

Now, as time passes, we see many studies emerging that reflect on various transformations, mostly associated with business and economic impacts and those that are affecting the policy and polity matters. Some of these are addressed based on three identified periods of "pre-COVID-19", "COVID19, and "post-COVID-19", which itself is quite interesting for us to identify the scale of this pandemic event on every sector. Some of these impacts are also seen as transitions and transformations in the built environment sectors.

In a recently published article, some of these transformations are identified as adaptive measures for public places (Cheshmehzangi 2020c), specifically aimed to help cities and city managers to face the COVID-19 impacts in public places of cities. In this brief article, two main questions are raised: (1) what measures could we apply to safeguard our public places?; and (2) to what extent, does the public place play a part in making our city and society safe for all? The two characteristics of contemporary public places, namely 'flexibility' and 'adaptability' are highlighted as methods of adaptive planning and resilience enhancement. In this study, 10 specific adaptive measures for public places are introduced and briefly discussed. These adaptive measures include:

- Limited access nodes for better management of Public Places

- Establish a one-way mobility circulation

- Checkpoint allocation for monitory and recording opportunities

- Making social spaces safe and viable

- Public places as informative nodes in the city

- Flexible public places to support essential sectors

- Restrictions on shared facilities in public places

- Closure of secondary public places

- Provision of community-level designated zones as key public places

- Temporary regulations to monitor and restrict certain activities in public places

However, these measures are the ones specifically suggested for cities and communities that are facing the outbreak. These provided guidelines, from the perspective of adaptive planning, suggest methods of spatial management and spatial arrangements (or rearrangements) that could help the city to safeguard its populated urban hubs and public realms. Some of these ideas could also develop in the way we could innovate new design and planning strategies, which could reflect on some of the deficiencies or flaws of our current planning thinking or design methods. In particular, we could address some of the 
main design principles; for instance, how adaptability could be enhanced or how public realms could be better articulated in the practice of urban design, landscape architecture, and public place design.

To summarise, there certain reflective approaches that could be utilised for future design and planning approaches. Those are the ones that could be developed further as potential design/planning innovation, new transformative strategies, and enhanced design guidelines. In doing so, we are able to provide a new range of design and planning paradigms that may help us to better contain the disease.

In at least two following short communication from the earlier work, the author has highlighted progressive thinking in adaptive planning for future development and resilience enhancement approaches. These are two brief articles currently under review. The first is a reflection on early lessons for urban resilience enhancement during the COVID-19 (Cheshmehzangi 2020d), and the second article is a brief comment on possible development changes in the construction sector, and in particular, the build environment sector due to this current pandemic outbreak (Cheshmehzangi 2020e).

In the first article (Cheshmehzangi 2020d), a set of reflective viewpoints is provided mainly from the perspective of the current happening (the first six months of the COVID-19 outbreak). The state of the art in this brief study is to highlight the role of urban resilience in practice, which provides a reflective narrative on early lessons that could help us make our cities and communities more resilient. They are identified as early lessons that successfully worked in cities and regions that are more confident in relaxing their high-level measures at a faster pace. These suggestions are narrated in a way that could be adapted for any context. These are suggested as eight reflective viewpoints as shown below:

- Consider a holistic spatial management (similar to Cheshmehzangi 2020c);

- Pay attention to details in a reflective manner;

- Early asset management and prioritisation plan;

- Regional level and local level approach for implementation;

- Early high-level measures are more effective than later restrictions;

- Include community representatives;

- Make good use of the right platforms;

- Regular safety checks, hygiene, and prevention.

In the second article (Cheshmehzangi 2020e), the narrative changes to develop several predictions that would potentially change the way we build our cities, communities, and buildings, the three main spatial levels of the built environments. In this study, the development changes are defined based on five key areas of: (1) resilience, (2) health, (3) policy, (4) practices, and (5) perspectives. These are then assessed in terms of the level of importance or potential changes in six primary areas in the civil engineering sector (i.e. construction 
engineering, construction technology, structural engineering, transport engineering, infrastructure engineering, and building/construction management), and six primary areas in the built environment sector (i.e. building engineering, architecture, urban design, urban planning, landscape architecture, and interior design). These development changes are in 10 categories as shown below:

- Decline in car-based transportation infrastructure;

- A push for information-based construction management methods;

- Increase in off-site construction and engineering;

- Increase in lightweight structural systems;

- Opportunities for new materials for performative insulation;

- Revisions in Density and Compact Design;

- Spatial planning considerations;

- Smaller and individual internal layouts;

- A push for meso-scale strategies at the neighbourhood/community level;

- New opportunities for non-centralized building systems.

To summarise briefly, we cannot neglect the potential changes as this pandemic has been a big lesson learned for all. Nevertheless, the major changes in our primary systems are yet to be seen and this may just be the beginning of a new chapter. As the pandemic comes to an end, and if everything is not.

\subsection{A Summary: Facing Disruptive Disease Outbreaks}

This chapter provides a holistic reflection on disruptions caused by the recent disease outbreak. This is a representation of many (similar) outbreak events, not necessarily as widespread as the one experienced, but from the central perspective of disruptions. This event shares many similarities to those regular outbreaks that are less impactful. With the example of the COVID-19 outbreak, we looked into a variety of aspects, from city-level local responses to global reactions. In all levels, we hope public health is not turned into a political tool and is rather supported by the enhanced urban resilience and adequate city management. As shown in Chap. 3, preparedness is essential through urban resilience, which should be comprehensive and practical by all means. Then in Chap. 4, we highlighted the role of responsiveness through allinclusive city management and the many considerations we should have to overcome the adversities of different phases of the outbreak progression. In this chapter, we summed up these aspects through a reflective viewpoint, to manage the city in need and ultimately save it, too. This sort of thinking is vital to cover all aspects, from an individual's health to the large-scale impacts on international trade. 
In this chapter, we highlighted two very important factors that could simply equip the city in the case of an outbreak event. One is 'society' and the other is 'government'. In the former, we narrated the society's experience, which in fact demonstrates the realities of the outbreak. In the latter, we covered an array of responses to show how the city could react in the case of a health emergency. Both together form a better approach to high-quality governance (see Fig. 5.77). What we have not fully covered is the other side of the coin, where society could suffer the most and the government may fail to react and respond properly and timely. Nevertheless, we note some of the main concerns addressed in both society and government-and then on what represents the role of all-inclusive governance. For instance, public disorders would still exist during the outbreak. In fact, there is a high chance that they turn into added disruptions. In such cases, the individuals who often ignore the regulations and procedures may take the city's vulnerability as an opportunity, knowing that there is little monitory on their misdemeanours and misconducts. Therefore, it is likely to see an upsurge in some of those disorders both related and unrelated to issues of the outbreak. These include-but not limited to-a range of public and social disorders, such as non-compliance with the guidelines, hoarding of primary products for resale and benefit, misuse of social services, the spread of false information/news, misguiding the public, jeopardising the society, riots, and unrests, exploitation of medical and emergency services, public fights, domestic violence, unsafe driving, unsafe littering, etc. There is also a possible increase in crime, such as theft, looting, loan sharking, arson attacks, cyber-attacks/cybercrime, physical and verbal assaults, aggressive behaviour, racism, stigmatisation behaviours, scams/fraud, false claims/accusations, prison break/unrest, and even intentional transmission of disease to others. Believe it or not, all these issues happened during this recent outbreak event; but providentially, not clustered in one location. In reality, to respond to these issues, the city needs to be fully prepared and the society needs to have the right mindset. Without any of the two, the struggle would be prevalent.

In conjunction with some of the highlights of the chapter, we referred to the significance of already emerged virtual and digital platforms, from e-commerce to education delivery, and from infected patient detection to data-based approaches that enhance control and monitory measures of the city. We did not necessarily explore associated issues related to the lack of inclusiveness of smart technologies and platforms, but we highlighted their values and support in the time of need. This was highlighted as an opportunity for innovations and smart-resilient approaches. We also highlighted some values of certain spatial and urban planning, which help to speed up some control measures. We looked into a variety of implementation factors and what they mean to various sectors and stakeholders. We also found the necessity to be resilient and less political in facing the disruptions of outbreak events. We also end this chapter with two sides of the spectrum, society and government, which in reality are complementary to one another. The combined forces would help the city in need; hence, could it be the governance of the society? Or the society that drives healthy governance? Or simply both? In sum, the government does not need to be political, all they have to do is to reflect and respond appropriately. And lastly, people do not need to be selfless, all they have to do is not be selfish in such events. Finally, 
if any of the two (i.e. society and government) becomes a burden to another, then it may just worsen the situation. The ultimate goals should be to reflect promptly on potential disruptions, and ultimately enhance the governance for the city in need.

\section{References}

Al-Nasrawi, S., El-Zaart, A., \& Adams, C. (2017). The anatomy of smartness of smart sustainable cities: An inclusive approach. proceedings for 2017 International Conference on Computer and Applications (ICCA) (pp. 348-353). Qatar: Doha.

Alterman, R. (1988). Adaptive Planning. Cognitive Science, 12, 393-421.

Ambat, A. S., Zubair, S. M., Prasad, N., Pundir, P., Rajwar, E., Patil, D. S., et al. (2019). Nipah virus: A review on epidemiological characteristics and outbreaks to inform public health decision making. Journal of Infection and Public Health, 12(5), 634-639.

Ascher, K. (2007). The words: anatomy of a city. Middlesex: Penguin Books.

Australian Government Department of Health (2020a). Government response to the COVID-19 outbreak. Retrieved March 10, 2020, from https://www.health.gov.au/news/health-alerts/novelcoronavirus-2019-ncov-health-alert/government-response-to-the-covid-19-outbreak.

Australian Government Department of Health (2020b). Australian Health Sector Emergency Response Plan for Novel Coronavirus (COVID-19). Retrieved March 10, 2020, from https://www.health.gov.au/resources/publications/australian-health-sector-emergency-res ponse-plan-for-novel-coronavirus-covid-19.

Baumol, W. J. (1967). Macroeconomics of unbalanced growth: The anatomy of urban crisis. The American Economic Review, 57(3), 415-426.

Benson, F., Musekiwa, A., Blumberg, L., \& Rispel, L. C. (2016). Is the South African notifiable diseases surveillance system effective in preventing outbreaks? Perceptions of key stakeholders, International Journal of Infectious Diseases, 45, Supplement 1, poster presentation, P. 293.

Bibri, S. E. (2019). The anatomy of the data-driven smart sustainable city: instrumentation, datafication, computerization and related applications, Journal of Big Data, 6, article number: 59.

CarbonBrief. (2020, February 19). Analysis: Coronavirus has temporarily reduced China's $\mathrm{CO}_{2}$ emissions by a quarter. Retrieved March 10, 2020, from https://www.carbonbrief.org/analysiscoronavirus-has-temporarily-reduced-chinas-co2-emissions-by-a-quarter.

Centers for Disease Control and Prevention (CDC). (2020a). Coronavirus Disease 2019 (COVID19). Retrieved March 5, 2020, from https://www.cdc.gov/coronavirus.

Centre for Disease Control and Prevention (2020b). Risk Assessment and Management, on Coronavirus Disease 2019 (COVID-19). Retrieved March 10, 2020, from https:/www.cdc.gov/corona virus/2019-ncov/php/risk-assessment.html.

CGTN News. (2020, March 9). Premier Li Keqiang sounds alert over imported COVID-19 cases amid rapid spread overseas. Retrieved March 11, 2020, from https://news.cgtn.com/news/202003-09/Li-warns-on-imported-cases-amid-rapid-spread-of-COVID-19-overseas-OIXj18mtzy/ index.html.

Cheshmehzangi, A. (2016). City enhancement beyond the notion of "Sustainable City": Introduction to integrated assessment for city enhancement (iACE) toolkit. Energy Procedia, 104, 153-158.

Cheshmehzangi, A. (2017). Sustainable development directions in China: Smart, Eco, or both? In The 2017 International Symposium on Sustainable Smart Eco-city Planning and Development, 11-13 October 2017, Cardiff, Wales.

Cheshmehzangi, A. (2018). The changing urban landscape of Chinese cities: Positive and negative impacts of urban design controls on contemporary urban housing. Sustainability, 10(8), 2839. https://doi.org/10.3390/su10082839. 
Cheshmehzangi, A. (2020a). Comprehensive Urban Resilience for the City of Ningbo. Ningbo, China. (in Chinese: 宁波市城市综合抗灾弹性框架), Report submitted to local government units in February 2020.

Cheshmehzangi, A. (2020b). Resilience Enhancement for Cities and Community during the Outbreak, at the first round of EU-China knowledge-share events on COVID-19, organised by SPI Porto, Portugal, on 3 April 2020.

Cheshmehzangi, A. (2020c). 10 Adaptive Measures for Public Places to face the COVID 19 Pandemic Outbreak. City \& Society, special issue, pp. 1-10, https://doi.org/10.1111/ciso.12282.

Cheshmehzangi, A. (2020d). Reflection on early lessons for urban resilience enhancement during the COVID-19, currently under review, 13 pages.

Cheshmehzangi, A. (2020e). 10 Possible Development Changes in Civil Engineering and the Built Environment Sectors Due to COVID-19, currently under review, 6 pages.

Cheshmehzangi, A., \& Dawodu, A. (2018). Sustainable Urban Development in the Age of Climate Change-People: the Cure or Curse. Singapore: Palgrave Macmillan.

Cohendet, P., Grandadam, D., \& Simon, L. (2010). The anatomy of the creative city. Journal of Industry and Innovation, 17(1), 91-111. Creative Jobs, Industries and Places.

Deng, W., \& Cheshmehzangi, A. (2018). Eco-development in China: Cities, Communities, and Buildings. Singapore: Palgrave Macmillan.

Desjardins, J. (2019). Infographic: The anatomy of a smart city. Retrieved March 4, 2020, from https://www.visualcapitalist.com/anatomy-smart-city/.

Foreign Affairs Office (FAO) of Ningbo Municipal People's Government. (2020, January 30). A letter to all foreign friends in ningbo. Retrieved February 2, 2020, from http://english.ningbo. gov.cn/art/2020/2/1/art_931_1041824.html.

Fukuyama, F. (2014). Political Order and Political Decay: From the Industrial Revolution to the Globalization of Democracy. London: Profile Boos.

Gallotti, R., \& Barthelemy, M. (2015). Anatomy and efficiency of urban multimodal mobility. Scientific Reports, 4 (6911).

Goldwyn, E. (2018). Anatomy of a new dollar van route: Informal transport and planning in New York City. Journal of Transport Geography, in press.

Gomes, S. (2020). Environmental Benefits of COVID-19. Retrieved March 4, 2020, from https:// www.calamitypolitics.com/2020/03/15/environmental-benefits-of-covid-19-12120/.

Hellsten, I., Jacobs, S., \& Wonneberger, A. (2019). Active and passive stakeholders in issue arenas: A communication network approach to the bird flu debate on Twitter. Public Relations Review, 45(1), 35-48.

Jauregui-Fung, F, Kenworthy, J., Almaaroufi, S., Pulido-Castro, N., Pereira, S., \& Golda-Pogratz, K. (2019). Anatomy of an informal transit city: mobility analysis of the metropolitan area of Lima, Urban Science, 3(3), article number: 67.

Kang, Y. (2019). Food safety governance in China: Change and continuity, Food Control, 106(106752).

Lamorgese, A. R., \& Petrella, A. (2016). An anatomy of Italian cities: Evidence from firm-level data (p. 362). Paper no: Bank of Italy Occasional Paper.

McKinsey Analysists (from McKinsey \& Company). (2020, March 9). COVID-19: Briefing note. Retrieved March 11, 2020, from https:/www.mckinsey.com/business-functions/risk/ourinsights/covid-19-implications-for-business.

Monge, S., García-Ortúzar, V., López Hernández, B., Lopaz Pérez, M. A., Delacour-Estrella, S., Sánchez-Seco, M. P., ..., Dengue Outbreak Investigation Team. (2020). Characterization of the first autochthonous dengue outbreak in Spain (August-September 2018). Acta Tropica, 205(105402).

Mukhopadhyay, S. (2020, March 20). COVID-19: Unmasking the environmental impact. Retrieved March 22, 2020, from https://earth.org/covid-19-unmasking-the-environmental-impact/.

NASA Earth Observatory. (2020). Airborne Nitrogen Dioxide Plummets over China, Retrieved March 9, 2020, from: https://earthobservatory.nasa.gov/images/146362/airborne-nitrogen-dio xide-plummets-over-china?utm_source=FBPAGE\&utm_medium=NASA+-+National+Aerona utics+and+Space+Administration\&utm_campaign=NASASocial\&linkId=83339382\&fbclid= IwAR0NyeT13Z9KTgBE8_p-b3IRa6j-iwdHwUSjiAUj2u5R66HDBAOtTkrORdg. 
National Health Service (NHS). (2020). About Coronavirus (COVID-19). Retrieved March 9, 2020, from https://111.nhs.uk/covid-19.

Ningbo Government Official page. (2020). The application procedure for "Ningbo Health Code". Retrieved March 1, 2020, from https://mp.weixin.qq.com/s/tMk5tfXIXyxf_uaFObSwuQ.

Ningbo Municipal Economic and Information Technology Bureau. (2020, February 13). The provincial epidemic prevention and control supervision group visits Ningbo for supervision and inspection. Retrieved March 3, 2020, from http://www.nbec.gov.cn/art/2020/2/13/art_1907_4048855. html.

Ningbo Science and Technology Bureau. (2020, January 29). Notice for preventing 2019 novel coronavirus from spreading. Retrieved February 2, 2020, from http://kjj.ningbo.gov.cn/art/2020/ 1/29/art_9940_4045698.html.

Politico Magazine. (2020, March 19). Coronavirus will change the world permanently. Friday cover article. (Materials extracted for Box 5.14). Retrieved March 20, 2020, from https://www.politico.com/news/magazine/2020/03/19/coronavirus-effect-economylife-society-analysis-covid-135579\#superComments.

Public Health Matters. (2020). Coronavirus (COVID-19)-5 things you can do to protect yourself and your community. Retrieved March 10, 2020, from https://publichealthmatters.blog.gov.uk/2020/ 03/04/coronavirus-covid-19-5-things-you-can-do-to-protect-yourself-and-your-community/.

Quirk, V. (2013). Anatomy of a Chinese city. ArchDaily article. Retrieved March 4, 2020, from https://www.archdaily.com/338302/anatomy-of-a-chinese-city.

Renner, R. (2018). Urban Being-anatomy \& Identity of the City. Salenstein, Switzerland: Niggli.

Ritchie, B. W., Dorrell, H., Miller, D., \& Miller, G. A. (2008). Crisis communication and recovery for the tourism industry. Journal of Travel \& Tourism Marketing, 15(2-3), 199-216.

Schultz, G. W. (1968). The Anatomy of Turkish Cities. United States National Research Council.

Shears, P., \& Garavan, C. (2020). The 2018/19 Ebola epidemic the democratic republic of the Congo (DRC): Epidemiology, outbreak control, and conflict. Infection Prevention in Practice, 2(1), 100038.

Stone, E. C., \& Zimansky, P. (1992). Mashkan-shapir and the Anatomy of an old Babylonian City. The Biblical Archaeologist, 55(4), 212-218.

Tillett, P. (2018). Shaping Portland: Anatomy of a healthy city, Series: Routledge Research in Planning and Urban Design. Oxon: Routledge.

The Government of Japan. (2020). Coronavirus (COVID-19) advisory information. Retrieved March 10, 2020, from https://www.japan.travel/en/coronavirus/.

The Network for Public Health Law. (2020). Emergency Legal Preparedness and Response-COVID19. Retrieved March 10, 2020, from https://www.networkforphl.org/resources/topics/emergencylegal-preparedness-and-response/covid-19/.

UNESCO. (2020). COVID-19 educational disruption and response. Retrieved March 18, 2020, from https://en.unesco.org/themes/education-emergencies/coronavirus-school-closures.

UN News. (2020, February 29). UN Health Agency warns against coronavirus COVID-19 criminal scams. Retrieved March 12, 2020, from https://www.news.un.org/en/story.2020/02/1058381.

WHO-China Joint Mission. (2020, February 16-24). Report of the WHO-China Joint Mission on Coronavirus Disease 2019 (COVID-19). Retrieved March 8, 2020, from https://www.who.int/ docs/default-source/coronaviruse/who-china-joint-mission-on-covid-19-final-report.pdf.

World Health Organization (WHO). (2018). Health-care waste.. Retrieved March 2, 2020, from https://www.who.int/news-room/fact-sheets/detail/health-care-waste.

World Health Organization (WHO). (2020, January 9). WHO statement regarding cluster of pneumonia Cases in Wuhan, China. Retrieved March 6, 2020, from https://www.who.int/china/news/ detail/09-01-2020-who-statement-regarding-cluster-of-pneumonia-cases-in-wuhan-china.

World Health Organization (WHO). (2020). Coronavirus disease (COVID-19) advice for public, including precautionary measures, education of right and wrong information. Retrieved March 8, 2020, from https://www.who.int/emergencies/diseases/novel-coronavirus-2019/advice-forpublic. 
World Health Organization (WHO) and UNICEF. (2015). Water, sanitation and hygiene in health care facilities: status in low-and middle-income countries. Geneva: World Health Organization. Yang, G. (2020, February 10). China releases twelve opinions on how companies resuming normal operations should treat their employees, breaking news material. (online document of 40 pages) Retrieved March 9, 2020, from https://www.chinalawblog.com/2020/02/breaking-news-chinareleases-twelve-opinions-on-how-companies-resuming-normal-operations-should-treat-theiremployees.html.

Zhao, S., \& Ma, C. (2020, March 7). China doing unprecedented job in battling unknown disease: WHO expert. News material. Retrieved March 7, 2020, from http://www.chinadaily.com.cn/a/ 202003/07/WS5e62dcf8a31012821727d146.html. 